\author{
UNIVERSidADE DE SÃo PAULO - USP \\ Escola de Engenharia de São Carlos \\ Departamento de Engenharia ElÉtrica e de Computação \\ Programa de Pós-GraduaÇão Em Engenharia Elétrica
}

Jeovane Vicente de Sousa

\title{
Computação em Nuvem no Contexto das Smart Grids: Uma Aplicação para Auxílio à Localização de Faltas em Sistemas de Distribuição
}





\title{
Jeovane Vicente de Sousa
}

\section{Computação em Nuvem no Contexto das Smart Grids: Uma Aplicação para Auxílio à Localização de Faltas em Sistemas de Distribuição}

\author{
Tese de doutorado apresentada ao Programa de Engenharia \\ Elétrica da Escola de Engenharia de São Carlos, da Universidade \\ de São Paulo, como parte dos requisitos para obtenção do título \\ de Doutor em Ciências.
}

Área de Concentração: Sistemas Elétricos de Potência

Orientador: Prof. Titular Denis Vinicius Coury

São Carlos

2018

Trata-se da versão corrigida da tese. A versão original se encontra disponível na EESC/USP que aloja o Programa de Pós-Graduação de Engenharia Elétrica 


\section{AUTORIZO A REPRODUĈ̃O TOTAL OU PARCIAL DESTE TRABALHO, POR QUALQUER MEIO CONVENCIONAL OU ELETRONNICO, PARA FINS DE ESTUDO E PESQUISA, DESDE QUE CITADA A FONTE.}

Ficha catalográfica elaborada pela Biblioteca Prof. Dr. Sérgio Rodrigues Fontes da EESC/USP com os dados inseridos pelo(a) autor(a).

Sousa, Jeovane Vicente de
S725c Computação em Nuvem no contexto das Smart Grids: Uma Aplicação para Auxílio à Localização de Faltas em Sistemas de Distribuição / Jeovane Vicente de Sousa; orientador Denis Vinicius Coury. São Carlos, 2018.

Tese (Doutorado) - Programa de Pós-Graduação em Engenharia Elétrica e Área de Concentração em Processamento de Sinais e Instrumentação -- Escola de Engenharia de São Carlos da Universidade de São Paulo, 2018 .

1. Sistemas de Distribuição Inteligentes. 2 . Computação em nuvem. 3. Localização de faltas. 4. Mineração de dados. 5. Smart Grids. 6. Múltipla estimação. I. Título. 


\section{FOLHA DE JULGAMENTO}

Candidato: Engenheiro JEOVANE VICENTE DE SOUSA.

Título da Tese: "Computação em nuvem no contexto das Smart Grids: uma aplicação para auxílio à localização de faltas em sistemas de distribuição".

Data da defesa: 21/09/2018.

Comissão Julgadora:

Prof. Titular Denis Vinicius Coury (Orientador)

(Escola de Engenharia de São Carlos/EESC)

Prof. Associado Eduardo Nobuhiro Asada

(Escola de Engenharia de São Carlos/EESC)

Profa. Dra. Fernanda Caseño Trindade Arioli

(Universidade Estadual de Campinas/UNICAMP)

Prof. Dr. Washington Luiz Araújo Neves

(Universidade Federal de Campina Grande/UFCG)

Prof. Dr. Miguel Moreto

(Universidade Federal de Santa Catarina/UFSC)
Resultado:

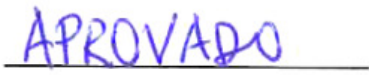

ApROVADN

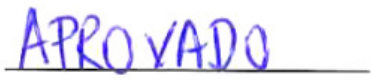

Aprovado

Coordenador do Programa de Pós-Graduação em Engenharia Elétrica: Prof. Associado Luís Fernando Costa Alberto

Presidente da Comissão de Pós-Graduação:

Prof. Associado Luís Fernando Costa Alberto 

À memória de meu pai, João Ferreira de Sousa, cujos conselhos nos momentos de incerteza garantiram a conclusão deste trabalho. À minha mãe Maria do Carmo, à minha esposa e companheira Patrícia e à minha filha Giovanna, que com amor e carinho estiveram ao meu lado me apoiando durante esta longa caminhada. 



\section{Agradecimentos}

Agradeço primeiramente a Deus, princípio e fim de todas as coisas, pelos dons necessários para o desenvolvimento deste trabalho.

À minha esposa Patrícia por estar sempre presente, compartilhando comigo todos os momentos, bons e ruins, por sua paciência, compreensão, e dedicação, que foram fundamentais para alcançarmos essa conquista.

À nossa filha Giovanna, que chegou iluminando nossas vidas e enchendo nossa família de alegria, que de maneira compassiva e paciente suportou os momentos em que não podíamos estar juntos.

Ao meu orientador prof. Denis Coury pela confiança, apoio e dedicação, por seus valorosos direcionamentos, que foram fundamentais para o desenvolvimento deste trabalho.

Ao prof. Ricardo Fernandes, da Universidade Federal de São Carlos, que esteve sempre presente durante a evolução deste trabalho, pelas recomendações e sugestões que certamente ajudaram a enriquecê-lo.

Aos meus companheiros de jornada Evandro Reche e Eduardo Gomes, que me ajudaram a desbravar o caminho das pedras compartilhando um pouco de seus conhecimentos.

Aos amigos e demais professores do Laboratório de Sistemas de Energia Elétrica (LSEE) pelas conversas no café, pelos bons momentos e alegrias compartilhadas que tornaram a caminhada mais suave, dos quais levarei sempre boas recordações.

À Escola de Engenharia de São Carlos da Universidade de São Paulo, em especial ao Departamento de Engenharia Elétrica e ao LSEE que forneceram a infraestrutura necessária para o desenvolvimento deste trabalho.

À Coordenação de Aperfeiçoamento de Pessoal de Nível Superior (CAPES) pela concessão da bolsa no âmbito do programa prodoutoral.

À Universidade Federal de Roraima pela concessão do afastamento para doutorado, em especial ao CCT e ao Departamento de Engenharia Elétrica. 

"Tudo tem seu tempo. Há um momento oportuno para tudo que acontece debaixo do céu." - Eclesiastes 3:1. 



\section{Resumo}

SOUSA, Jeovane Vicente de. Computação em Nuvem no Contexto das Smart Grids: Uma Aplicação para Auxílio à Localização de Faltas em Sistemas de Distribuição. 183 p. Tese de Doutorado - Escola de Engenharia de São Carlos, Universidade de São Paulo, São Carlos, 2018.

A computação em nuvem tem sido vislumbrada como a principal tecnologia capaz de integrar e gerenciar os diversos sistemas envolvidos em uma Smart Grid. Nesse sentido, esta pesquisa tem por objetivo desenvolver uma infraestrutura de computação em nuvem capaz de armazenar e manipular dados em sistemas de distribuição. Analisando a infraestrutura das principais aplicações que utilizam computação em nuvem nesse contexto, foi proposta uma arquitetura com serviços essenciais, que pode ser estendida, para abrigar serviços e aplicações voltadas aos sistemas de distribuição inteligentes. A partir dessa proposta, uma infraestrutura de computação em nuvem foi implementada, utilizando ferramentas open source. Essa infraestrutura permitiu o desenvolvimento de uma nova aplicação para auxílio à localização de faltas, utilizando mineração de dados sobre os dados provenientes de smart meters, que é capaz de reduzir o problema da múltipla estimação nos sistemas de distribuição radial, auxiliando na definição do ramal faltoso. Para isso, uma versão otimizada da ferramenta de mineração de dados DAMICORE (Data Mining of Code Repositories) foi implementada estendendo os serviços básicos da arquitetura proposta. A aplicação desenvolvida foi avaliada utilizando centenas de simulações de falta sujeitas ao problema da múltipla estimação, aplicadas ao longo de um alimentador de testes, sendo capaz de reduzir mais de $80 \%$ das extensões de falta susceptíveis ao problema da múltipla estimação. Os resultados 
apresentados mostraram que a arquitetura proposta e a infraestrutura de computação em nuvem desenvolvida são capazes de suportar novas aplicações para os sistemas de distribuição inteligentes contribuindo para o desenvolvimento das smart grids e para a difusão da computação em nuvem nesse contexto. Como contribuição adicional, a aplicação em nuvem desenvolvida permitirá reduzir a múltipla estimação na localização de faltas em sistemas de distribuição.

Palavras-chave: Sistemas de Distribuição Inteligentes, Computação em nuvem, Localização de faltas, Mineração de dados, Smart Grids, Múltipla estimação. 


\section{Abstract}

SOUSA, Jeovane Vicente de. Cloud Computing in the Smart Grids context: An Application to Aid Fault Location in Distribution Systems. 183 p. Ph.D. Thesis - São Carlos School of Engineering, University of São Paulo, São Carlos, 2018.

Cloud computing has been envisioned as the main technology capable to integrate and manage many systems on a Smart Grid. Thus, this research aims to develop a cloud computing infrastructure to store and manipulate smart distribution system data. By analyzing the infrastructure of the main applications using cloud computing for smart distribution systems, an extensible architecture with essential services was proposed to host smart distribution systems services and applications. Based on this proposition, a cloud computing platform was developed using open source tools. A new application to reduce multiple estimation for fault location in radial distribution systems using datamining techniques over smart meter data was implemented using this infrastructure. An optimized version of the datamining tool known as DAMICORE (Data Mining of Code Repositories) was implemented as an extension to the proposed architecture basic services. The new cloud application was tested using hundreds of fault simulations through a test feeder, being able to reduce the line extensions with multiple estimation by more than $80 \%$ in the simulated fault cases. The results show that the proposed cloud computing architecture and infrastructure enable new smart distribution systems applications, contributing to the development of smart grids and diffusion of cloud computing in this context. As an additional contribution, the cloud application developed will help to reduce the multiple estimation for fault locations in distribution systems. 
Keywords: Smart Distribution Systems, Fault Location, Cloud Computing, Data Mining, Smart Grids, Multiple estimation. 


\section{Lista de llustrações}

Figura 1 - Mapa conceitual do sistema de gerenciamento de informação. 43

Figura 2 - Estatísticas de busca para os termos Cloud Computing, Grid Computing e Distributed Computing..... 59

Figura 3 - Computação em nuvem conforme especificação do NIST . ..........................60

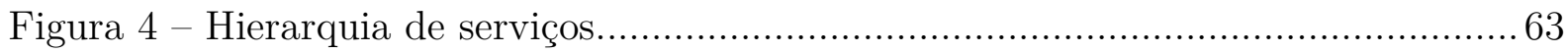

Figura 5 - Comparativo entre os recursos em nuvem em relação à infraestrutura tradicional.

Figura 6 - Comparativo entre os modelos de implantação em computação em nuvem.69

Figura 7 - Comparação entre containers e máquinas virtuais.................................... 73

Figura 8 - Interface Web de configuração do OpenNebula ........................................ 76

Figura 9 - Ambiente de execução do OpenNebula .................................................... 77

Figura 10 - Principais Frameworks para Big Data. ............................................... 82

Figura 11 - Arquitetura do sistema de computação em nuvem proposto. .................... 94

Figura 12 - Configuração do Servidor Host: Máquinas virtuais e programas utilizados. .

Figura 13 - Interface para os serviços de banco de dados. ..................................... 100

Figura 14 - Estrutura híbrida de armazenamento de dados de medidores do sMAP archiver. .

Figura 15 - Exemplo de objeto timeseries representando uma medição, juntamente com seus metadados.

Figura 16 - Exemplo de rede de distribuição com smart meters residenciais associados ao DCU e sua relação com os transformadores de distribuição.

Figura 17 - Front-End de visualização de dados do sMAP, apresentando dados de um

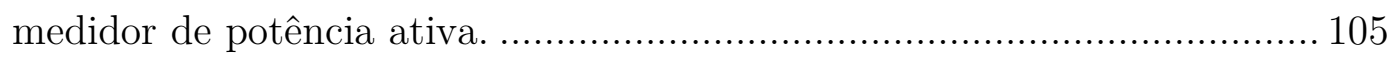

Figura 18 - Exemplo de documento JSON armazenado no mongoDB....................... 106

Figura 19 - Head-End Server: interfaces e funcionalidades ................................... 109

Figura 20 - Diagrama de execução do DAMICORE. ............................................. 111

Figura 21 - Matriz de distância e árvore filogenética obtida pelo NJ. ....................... 113

Figura 22 - Exemplo de comando para execução do dami corepyCloud................. 115

Figura 23 - Tempos de processamento dami corepyCloud. .................................. 117

Figura 24 - Definição do script de inicialização durante a criação do template da VM.

Figura 25 - Script de inicialização do DAMICORE como um serviço. ....................... 119 
Figura 26 - Exemplo de visualização de dados a partir dos resultados armazenados no mongoDB........................................................................ 120

Figura 27 - Segmentação do alimentador em Regiões de Múltipla Estimação............ 126

Figura 28 - Fluxograma para análise dos clusters................................................ 129

Figura 29 - Alimentador de teste IEEE 34 barras ............................................. 131

Figura 30 - IEEE 34 barras em escala............................................................ 133

Figura 31 - Regiões de múltipla estimação. (a) Faltas monofásicas fase A. (b) Faltas monofásicas fase B. (c) Demais tipos de falta....................................... 134

Figura 32 - Árvore filogenética com o resultado da mineração de dados para faltas do tipo ACT, no cenário 2, destacando o cluster 11 ................................ 141

Figura $33-\mathrm{R} \%$ em relação à quantidade de dados.............................................. 142

Figura 34 - Erros do método de localização de distâncias baseado em impedância.... 150

Figura 35 - Posição das faltas desconhecidas utilizadas nos estudos de caso.............. 151

Figura 36 - Árvore filogenética com os resultados da mineração de dados para o caso 1

Figura 37 - Árvore filogenética com os resultados da mineração de dados para o caso 2 154

Figura 38 - Árvore filogenética com os resultados da mineração de dados para o caso 3 


\section{Lista de Tabelas}

Tabela 1 - Rede elétrica tradicional vs. Smart Grid.

Tabela 2 - Aplicações em redes de distribuição inteligentes que funcionam como sistemas de gerenciamento de informações. 46

Tabela 3 - Hipervisores comumente utilizados em computação em nuvem .72

Tabela 4 - Recursos virtuais alocados.

Tabela 5 - Pontos de medição utilizados para cada tipo de falta e região de ME 136

Tabela 6 - Faltas simuladas por região de múltipla estimação 137

Tabela 7 - Região de múltipla estimação reduzida (R\%) para cada cenário, separada por tipo de falta e região de múltipla estimação.

Tabela 8 - Par de tensão e corrente selecionados para o cálculo da impedância aparente trifásica 



\section{Lista de Siglas}

AMI

API

ATP

$\mathrm{CC}$

CPU

CSV

DA

DAMICORE

DB

DCU

DER

DFS

DHCP

DNS

DR

EMS

EVSE

FER

FERC
Advanced Measurement Infrastructure

Application Programming Interface

Alternative Transients Program

Cloud Computing

Central Processing Unit

Comma-Separated Values

Data Analytics

Data Mining of Code Repositories

Data Base

Data Concentrator Unit

Distributed Energy Resources

Distributed File System

Dynamic Host Configuration Protocol

Domain Name System

Demand Response

Energy Management System

Electric Vehicle Supply Equipment

Fontes de Energia Renováveis

Federal Energy Regulatory Commission 


\begin{tabular}{|c|c|}
\hline $\mathbf{F N}$ & Fast Newman \\
\hline GD & Geração Distribuída \\
\hline HD & Hard Disc \\
\hline HDFS & Hadoop Distributed Filesystem \\
\hline HES & Head-End Server \\
\hline HPC & High Performance Computing \\
\hline HTML & HyperText Markup Language \\
\hline HTTP & Hypertext Transfer Protocol \\
\hline IaaS & Infrastructure as a Service \\
\hline IEDs & Intelligent Electronic Devices \\
\hline IEEE & Institute of Electrical and Electronics Engineers \\
\hline IP & Internet Protocol \\
\hline JSON & JavaScript Object Notation \\
\hline KVM & Kernel-based Virtual Machine \\
\hline LTS & Long Term Support \\
\hline LVM & Logical Volume Manager \\
\hline MARS & Multi Area Reliability Simulation \\
\hline MAS & Multi-Agent Systems \\
\hline MDMS & Measurement Data Management System \\
\hline ME & Múltipla Estimação \\
\hline MIT & Massachusetts Institute of Technology \\
\hline NAN & Neighborhood Area Network \\
\hline NCD & Normalized Compression Distance \\
\hline
\end{tabular}


NIST

NJ

NoSQL

NTP

ODM

PaaS

PM

PMU

PPM

QoS

RAM

RDBMS

REST

RL

RMS

RP

RPC

SaaS

SCADA

SE

SEP

SG

SLA
National Institute of Standards and Technology

Neighbor Joining

Not Only SQL

Network Time Protocol

Open Data Model

Platform as a Service

Ponto de Medição

Phasor Measurement Unit

Prediction by Partial Matching

Quality of services

Random Access Memory

Relational Data Base Management System

Representational State Transfer

Ramal Lateral

Root Mean Square (Valor Eficaz)

Ramal Principal

Remote Procedure Calls

Software as a Service

Supervisory Control And Data Acquisition

Subestação de Energia

Sistema Elétrico de Potência

Smart Grids

Service Level Agreements 
SM

sMAP

SO

SOA

SQL

SSH

TCP

TI

TIC

TSDB

URI

URL

UUID

V2G

vCPU

VE

VM

VPN

VPP

WAN

XML
Smart Meter

Simple Measurement and Actuation Profile

Sistema Operacional

Service-Oriented Architecture

Structured Query Language

Secure Shell

Transmission Control Protocol

Tecnologia da Informação

Tecnologia da Informação e Comunicação

Time Series Database

Uniform Resource Identifier

Uniform Resource Locator

Universal Unique IDentifier

Vehicle-To-Grid

Virtual $C P U$

Veículos Elétricos

Virtual Machine

Virtual Private Network

Virtual Power Plant

Wide Area Network

Extensible Markup Language 


\section{Sumário}

Capítulo 1 - Introdução ..........................................................27

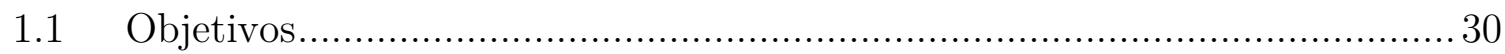

1.2 Contribuições da Pesquisa ................................................................... 31

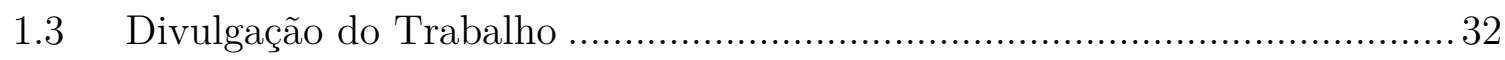

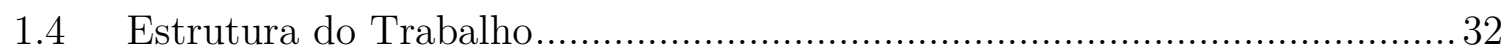

Capítulo 2 - Smart Grids..................................................................35

2.1 Fundamentos, conceitos e definições. .............................................. 35

2.2 Sistemas de distribuição inteligentes ............................................... 38

2.2.1 Infraestrutura avançada de medição ........................................ 38

2.2.2 Sistemas de automação da distribuição ..................................... 39

2.2.3 Recursos energéticos distribuídos e corte de picos ...................... 40

2.2.4 Gerenciamento da informação e ferramentas avançadas ................ 43

2.3 Aplicações em sistemas de distribuição inteligentes utilizando computação

em nuvem

2.3.1 Aplicações em gerenciamento e controle ................................. 47

2.3.2 Ferramentas avançadas ....................................................... 51

2.3.3 Data Analytics e mineração de dados....................................... 52

Capítulo 3 - Computação em nuvem: Aspectos Históricos e Conceituais ....55

3.1 Características Essenciais ............................................................ 61

3.1.1 Autosserviço sob demanda ................................................ 61 


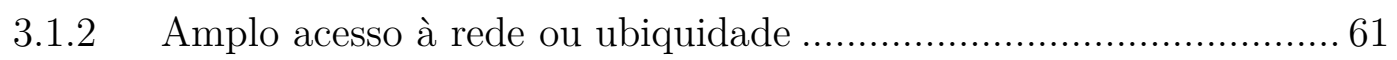

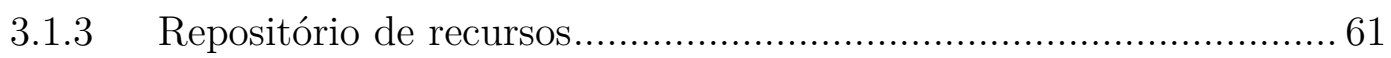

3.1.4 Elasticidade rápida .................................................................. 62

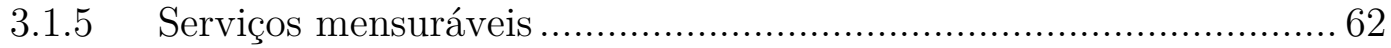

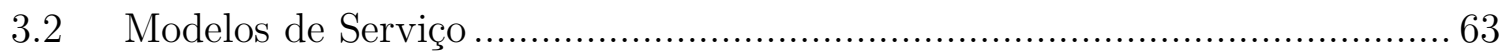

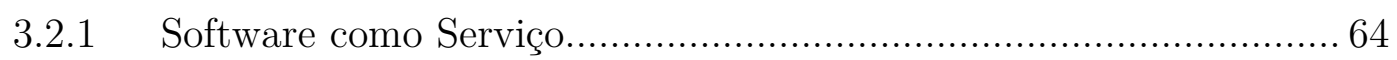

3.2.2 Plataforma como Serviço.................................................. 65

3.2.3 Infraestrutura como Serviço ........................................................ 66

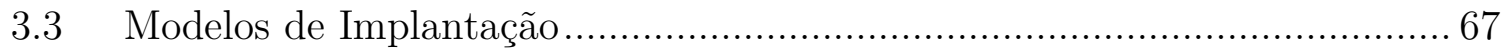

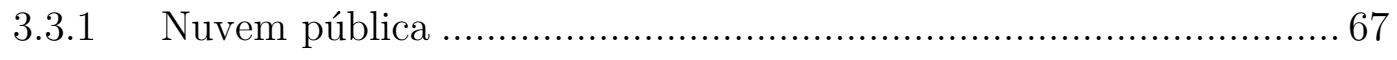

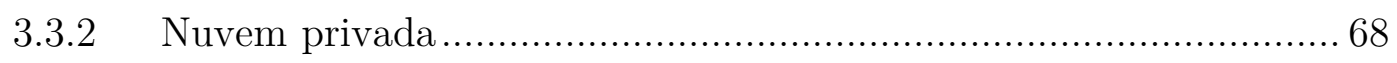

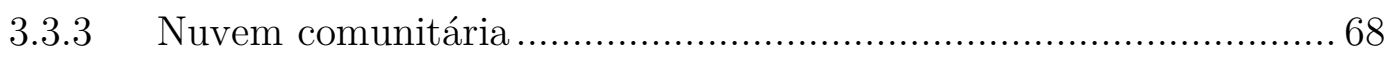

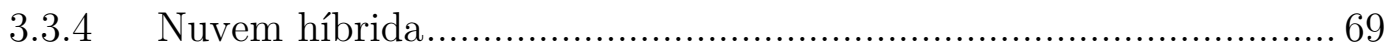

3.4 Tecnologias para computação em nuvem ............................................. 70

3.4.1 Virtualização .............................................................. 70

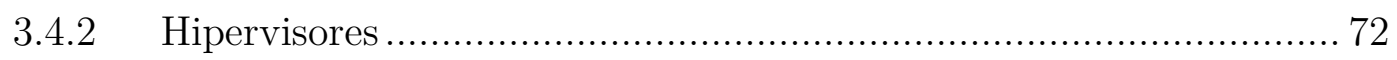

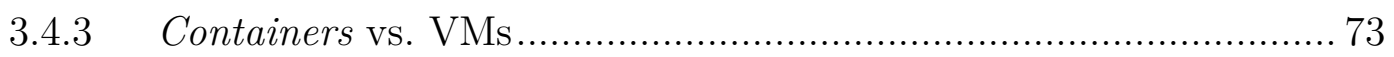

3.4.4 Gerenciadores de infraestrutura de nuvem................................. 74

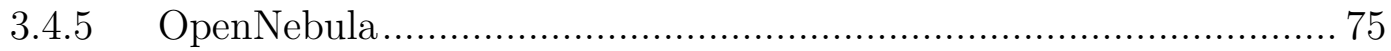

3.4.6 Armazenamento de dados e processamento em nuvem................. 77

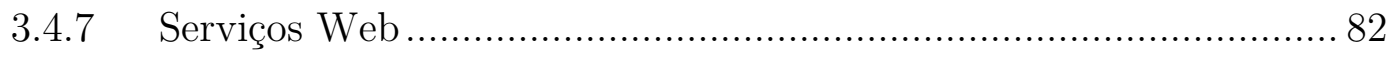

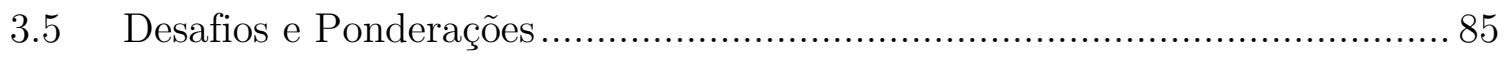

Capítulo 4 - Infraestrutura de computação em nuvem para sistemas de distribuição inteligentes ................................................... 89

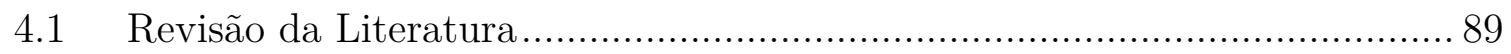

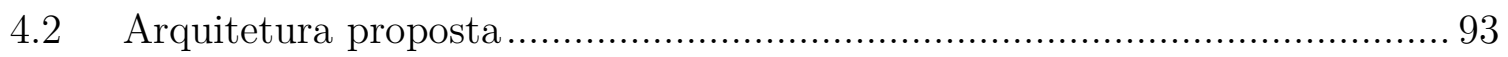


4.3 Ambiente de testes desenvolvido ......................................................... 96

4.3.1 Recursos provisionados e Configuração de Hardware...................... 97

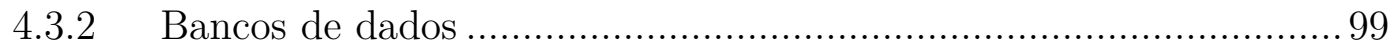

4.3.3 Head End Server - HES .............................................. 107

4.4 Serviço de mineração de dados ..................................................... 110

4.4.1 DAMICORE como ferramenta de mineração de dados................ 111

4.4.2 Implementação em Python ........................................................ 114

4.4.3 Redução no tempo de processamento considerando dados

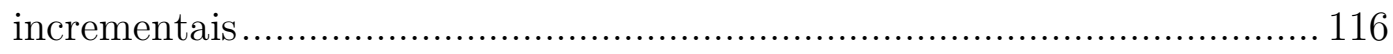

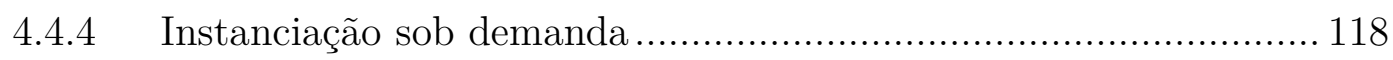

Capítulo 5 - Uma aplicação para auxílio à localização de faltas na distribuição utilizando mineração de dados .................................123

$5.1 \quad$ Aplicação proposta ................................................................... 126

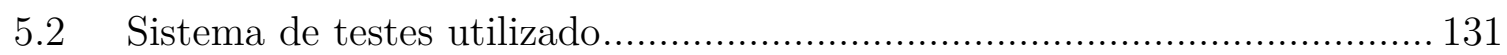

5.3 Abordagem segmentada e disposição dos pontos de medição..................... 132

5.4 Sensitividade em relação à quantidade de dados................................. 141

5.5 Método localização de faltas baseado em impedância. ............................. 148

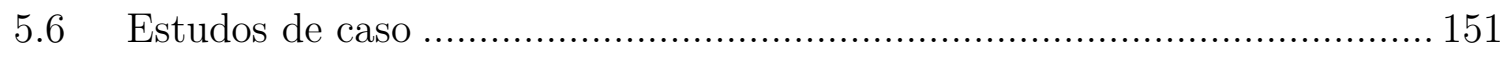

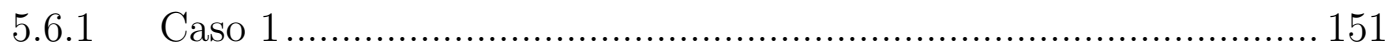

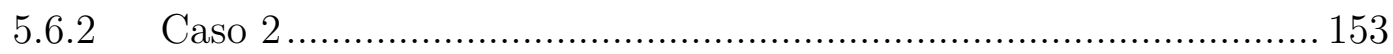

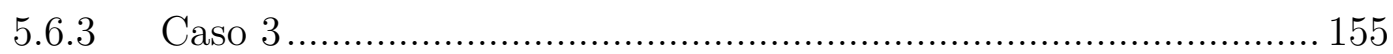

5.7 Considerações Finais Sobre o Capítulo.......................................................... 156

Capítulo 6 - Conclusões ........................................................... 157

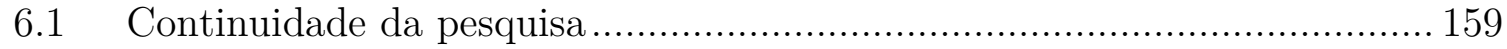

Referências Bibliográficas ........................................................161 



\section{Capítulo 1}

\section{Introdução}

O sistema elétrico de potência (SEP) é o conjunto de dispositivos e sistemas responsáveis pela geração, transmissão e distribuição da energia elétrica até o consumidor final. A necessidade de modernização do SEP como um todo, vislumbrando criar sistemas elétricos que possam superar os desafios atuais, utilizando para isso recursos de Tecnologia da Informação e Comunicação (TIC), automação e controle, levou ao conceito de Smart Grids, ou redes elétricas inteligentes. Nesse sentido, por meio de uma vasta modernização, espera-se que os sistemas elétricos se tornem mais confiáveis, seguros, econômicos, eficientes e ambientalmente corretos [1]. Além disso, os mesmos devem possibilitar ao consumidor final uma participação mais ativa no mercado de energia aumentando sua interação com o sistema, através da inserção de fontes renováveis, fazendo com que haja um novo perfil de consumo [2]. A Tabela 1 mostra um comparativo entre a rede de distribuição de energia elétrica tradicional e a Smart Grid. A rede atual encontra-se em uma fase de transição entre a rede tradicional em direção à Smart Grid.

A Smart Grid deverá suportar um modelo de geração em que coexistam geração centralizada e distribuída, onde os consumidores poderão ter sua própria fonte de geração, tornando-se simultaneamente, geradores e consumidores, possibilitando a inserção de fontes renováveis na rede de distribuição. Para alcançar esse objetivo, o novo sistema precisará de uma malha de controle e sensoriamento muito abrangente e sofisticada, totalmente integrada com uma infraestrutura de TIC. Essa infraestrutura deverá permitir o controle praticamente automático da rede, reduzindo a intervenção humana e admitindo uma participação mais efetiva do consumidor no mercado de energia, garantindo a ele consciência e controle maior sobre seu consumo [2]. Assim, nota-se que essa modernização dos sistemas elétricos (advinda do conceito de Smart Grids) trará profundas mudanças ao SEP, principalmente nos sistemas de distribuição. 
Tabela 1 - Rede elétrica tradicional vs. Smart Grid.

\begin{tabular}{ll}
\hline Rede de distribuição de energia tradicional & Smart Grid \\
\hline Medição Eletromecânica & Medição Digital \\
Comunicação unidirecional & Comunicação bidirecional em tempo real \\
Geração centralizada & Geração distribuída \\
Rede radial & Rede em malha \\
Menos dados envolvidos & Grande volume de dados envolvidos \\
Pequena quantidade de sensores & Vários sensores e monitores \\
Pouco ou nenhum monitoramento automático & Muito monitoramento automático \\
Controle e recuperação manual & Controle e recuperação automáticos \\
Poucas preocupações com segurança e privacidade & Propensa a problemas de segurança e privacidade \\
Atenção humana para interrupções do sistema & Proteção adaptativa \\
Produção e consumo simultâneos de & Utilização de sistemas de armazenamento de energia \\
energia/eletricidade & Sistema de controle pervasivo \\
Controle limitado & Resposta rápida às emergências \\
Resposta lenta às emergências & Muitas opções para os clientes \\
Menos opções para os clientes & Mado
\end{tabular}

Fonte: adaptado de [3]-[5].

Uma rede elétrica mais inteligente precisará coletar e analisar dados de diversos sensores e medidores espalhados por toda a rede, especialmente nos sistemas de distribuição devido à necessidade de monitoramento em tempo real dos consumidores.

Essa nova e imensa quantidade de dados precisa ser analisada e armazenada para fins de histórico e tomada de decisão, necessitando de uma plataforma escalável, capaz de ser implementada para operar de maneira confiável com dados da ordem de terabytes de informação diariamente [6].

Nesse cenário, a computação em nuvem, ou cloud computing, surge como uma das tecnologias capazes de atender a esses requisitos apresentando resultados promissores [5], [7]-[9]. Com a computação em nuvem é possível desenvolver novas aplicações em Smart Grid que, através da análise de dados em tempo real, monitoramento e controle, permitam a criação de sistemas mais autônomos, capazes de modificar seu comportamento (ou características), em resposta a alguma condição anómala, restaurando a sua operação normal sem a necessidade de intervenção humana [10].

Em Smart Grids, a capacidade de um sistema descobrir, diagnosticar e reagir automaticamente a faltas e interrupções iniciando ações corretivas no sentido de manter o funcionamento normal do sistema é denominada self-healing. A principal 
característica do self-healing é o autodiagnostico, que é a capacidade de diagnosticar problemas a partir de determinados sintomas para iniciar uma reação automática.

Para a implantação do self-healing em sistemas de distribuição de energia é necessário primariamente que a localização de uma falta seja identificada corretamente. A localização correta do ponto de falta em sistemas de distribuição não é uma tarefa trivial, devido a inerente complexidade do sistema, que possui condutores diferentes em diferentes seções, ramais laterais (monofásicos, bifásicos ou trifásicos), variação dinâmica de cargas, cargas espalhadas ao longo do alimentador, reguladores de tensão, capacitores, entre outros complicadores. Espera-se com o advento das Smart Grids, e o aumento da quantidade de Smart Meters e da automação do sistema, que essa detecção, localização da falta, e a possível restauração do sistema seja feita de maneira automatizada.

Tradicionalmente a detecção e localização de faltas em sistemas de distribuição são feitas de maneira manual, mapeando a região sem energia por intermédio das ligações dos consumidores, e utilizando medidas de tensão e corrente obtidas somente na subestação juntamente com parâmetros elétricos do sistema para determinar a distância [11]. Quando feita de maneira automatizada geralmente são utilizados relés de distância baseados no método de reatância/impedância aparente para a localização da falta.

Tais métodos, quando aplicados a sistemas de distribuição devido às características do sistema, apresentam diversos problemas dentre os quais o problema da múltipla estimação. A múltipla estimação acontece quando a distância da falta calculada em relação à subestação leva a uma localização que pode pertencer a diferentes ramos do sistema de distribuição.

Embora a computação em nuvem possa ser utilizada para suprir as necessidades computacionais das Smart Grids, desenvolver uma infraestrutura capaz de atender a esses requisitos não é uma tarefa trivial. A falta de padrões amplamente adotados, ausência de documentação, aliados a existência de diversas ferramentas e protocolos que podem ser utilizadas para o mesmo fim, torna a tarefa de discernir (com base em requisitos diversos por vezes conflitantes e subjetivos) dentre uma miríade de opções existentes, um desafio.

Por se tratar de uma área de desenvolvimento relativamente nova, não existe ainda um padrão de arquitetura genérico para um sistema de computação em nuvem 
que possa ser utilizado em Smart Grids. As arquiteturas propostas geralmente são desenvolvidas considerando as especificidades de cada aplicação, não existindo uma infraestrutura genérica, capaz de armazenar e processar dados de medição gerados por um sistema de distribuição inteligente, que possa ser utilizada por diferentes aplicações.

Portanto, visando contribuir para difusão da computação em nuvem aplicada aos sistemas de distribuição, esta pesquisa propõe uma arquitetura de computação em nuvem capaz de armazenar e processar dados de smart meters, com possibilidade de ser adaptada e expandida para suportar diferentes aplicações.

Com base na arquitetura proposta, como exemplo de aplicação, será desenvolvida uma ferramenta de auxílio à decisão para reduzir o problema da múltipla estimação em localizadores de falta tradicionais. Essa ferramenta utilizará mineração de dados, sobre os dados provenientes dos smart meters, para auxiliar na identificação do ramal em falta de forma independente do localizador de faltas utilizado, tornando a ferramenta extensível a qualquer outro localizador que apresente múltipla estimação.

\section{$1.1 \quad$ Objetivos}

Com o advento das Smart Grids uma nova e imensa quantidade de dados provenientes dessa nova infraestrutura estará disponível para as concessionárias. Um ambiente capaz de processar e armazenar esses dados de maneira eficiente é fundamental para o desenvolvimento de novas aplicações capazes de manipular esses dados e extrair informações úteis.

No contexto das Smart Grids, com o aumento da quantidade de dados provenientes dos sistemas de monitoramento, em especial dos Smart Meters, espera-se que seja possível aproveitar esses dados para auxiliar os métodos de localização de faltas baseados em impedância, assim como qualquer outro método que sofra com a múltipla estimação, a localizar o ponto de falta de maneira mais rápida e precisa, permitindo que a mesma possa ser prontamente corrigida, seja através do self-healing ou do envio de equipes de manutenção.

Neste sentido, este trabalho visa propor uma arquitetura em nuvem básica para receber, armazenar e processar os dados provenientes dos dispositivos de medição em um sistema de distribuição, possibilitando o desenvolvimento de novas aplicações. Complementando esse trabalho, pretende-se desenvolver uma infraestrutura de testes, 
baseada na arquitetura proposta, e sobre essa infraestrutura implementar um novo sistema de auxílio à localização de faltas que seja capaz de extrair informação dos dados dos smart meters a partir da mineração de dados, para reduzir o problema da múltipla estimação. Dessa forma, criar-se-á uma infraestrutura de nuvem para ser utilizada pelas novas aplicações em Smart Grids, dentre as quais uma aplicação em nuvem capaz de reduzir o problema da múltipla estimação na localização de faltas em rede de distribuição.

\subsection{Contribuições da Pesquisa}

As principais contribuições dessa pesquisa foram:

$\square$ Concepção de uma arquitetura de computação em nuvem, expansível, para ser integrada a uma Infraestrutura de Medição Avançada, de forma a permitir o desenvolvimento de diversas aplicações para os sistemas de distribuição inteligente;

$\square$ Desenvolvimento de uma infraestrutura de nuvem capaz de fornecer serviços essenciais para o desenvolvimento de novas aplicações, como serviços de banco de dados e de mineração de dados;

$\square$ Aprimoramento do método de mineração de dados DAMICORE para a utilização de dados incrementais e sua adaptação para ser executado sob demanda como um serviço em nuvem;

$\square$ Desenvolvimento de uma aplicação em nuvem para auxílio à localização de faltas utilizando os dados dos smart meters através da mineração de dados, capaz de reduzir a região afetada pela múltipla estimação, com os seguintes diferenciais:

- Análise automática dos resultados sem necessidade de um especialista;

- Utiliza uma nova abordagem segmentando o alimentador em regiões de múltipla estimação, tornando a aplicação menos sensível à variação na quantidade de amostras de faltas;

$\square$ Definição de uma métrica mais justa (R\%) para avaliar o desempenho da aplicação considerando a taxa de acerto na determinação do ramal faltoso e o comprimento desse ramal quando o mesmo está em uma região de múltipla estimação; 


\subsection{Divulgação do Trabalho}

As investigações realizadas sobre a mineração de dados aplicada sobre os dados dos smart meters para auxílio à localização de faltas, geraram a publicação de um artigo na XII Conferência Brasileira sobre Qualidade da Energia Elétrica, que ocorreu em agosto de 2017 em Curitiba, PR.

$\square$ RECHE, E. A.; SOUSA, J. V.; COURY, D. V.; FERnANDES, R. A. S. Auxílio à Decisão para a Localização de Faltas em Sistemas de Distribuição no Contexto das Smart Grids. XII Conferência Brasileira sobre Qualidade da Energia Elétrica (XII CBQEE), 2017.

A plataforma em nuvem desenvolvida foi utilizada para o desenvolvimento de um trabalho intitulado Data Mining-Based Method to Reduce Multiple Estimation for Fault Location in Radial Distribution Systems, que emprega a mineração de dados para a redução da múltipla estimação em sistemas de distribuição radial utilizando os dados de todos os medidores, publicado na revista IEEE PES Transactions on Smart Grids.

$\square$ RECHE, E. A.; SOUSA, J. V.; COURY, D. V.; FERnANDES, R. A. S. Data Mining-Based Method to Reduce Multiple Estimation for Fault Location in Radial Distribution Systems. IEEE PES Transactions on Smart Grids, 2018.

O levantamento bibliográfico acerca das aplicações de computação em nuvem em sistemas de distribuição inteligentes resultou em um artigo intitulado "A Survey on Cloud Computing Applications in Smart Distribution Systems", publicado na revista Electric Power Components and Systems, em 2018.

$\square$ SOUSA, J. V. de; COURY, D. V.; FERnAnDES, R. A. S. A Survey on Cloud Computing Applications in Smart Distribution Systems. Electric Power Components and Systems, 2018.

\subsection{Estrutura do Trabalho}

O Capítulo 2 traz uma revisão sobre Smart Grids, apresentando conceitos e definições. São abordados os sistemas de distribuição inteligentes apresentando suas tecnologias e características essenciais. 
O Capítulo 3 trata dos principais aspectos históricos e conceituais relacionados à computação em nuvem, fornecendo uma base teórica para o entendimento desta tecnologia, abordando também algumas das tecnologias e ferramentas que permitem a implantação de uma infraestrutura de computação em nuvem, finalizando com algumas considerações sobre sua aplicabilidade aos sistemas de distribuição inteligentes.

A descrição da arquitetura de computação em nuvem proposta pode ser encontrada no Capítulo 4, que também apresenta uma discussão sobre os trabalhos envolvendo o desenvolvimento de infraestruturas de computação em nuvem para as Smart Grids, abordando algumas tecnologias de banco de dados e processamento distribuído tipicamente utilizadas, destacando os principais trabalhos aplicados aos sistemas de distribuição inteligentes. Por fim é apresentada a implementação da infraestrutura de testes desenvolvida com base na arquitetura proposta, abordando as ferramentas utilizadas para armazenamento de dados e Data Mining.

O Capítulo 5 aborda o desenvolvimento da nova aplicação para auxílio à localização de faltas utilizando mineração de dados, apresentando seu funcionamento, testes realizados, apresentando alguns estudos de caso demonstrando sua utilização.

Finalmente, no Capítulo 6 são apresentadas as conclusões e contribuições do trabalho, bem como as etapas futuras para continuidade do mesmo. 



\section{Capítulo 2}

\section{Smart Grids}

A necessidade de modernizar o sistema elétrico de potência como um todo, agregando as mais modernas tecnologias na área de controle, instrumentação, tecnologia da informação e comunicação levou ao conceito do que é conhecido atualmente como Smart Grid (SG). Esse novo sistema deve ser capaz de acompanhar o aumento da demanda por energia elétrica e fornecer energia elétrica com qualidade, reduzir as perdas e aumentar a segurança operacional, por intermédio da monitoração, automação e controle, utilizando recursos computacionais e de comunicação avançados, de forma a garantir um sistema mais confiável, seguro, econômico, eficiente e ambientalmente correto, em que o consumidor final tenha uma participação mais ativa [1].

\subsection{Fundamentos, conceitos e definições.}

O conceito de Smart Grid é bastante abrangente e está diretamente relacionado aos interesses locais de cada nação, possuindo diferentes visões dependendo do objetivo de seu desenvolvimento, dessa maneira, não há uma definição única adotada globalmente. Nos EUA, por exemplo, o objetivo principal é abordar o envelhecimento de suas redes, melhorar a qualidade de serviço, gerar empregos, fomentar a indústria e aumentar a interação com o usuário. Na Europa, o foco principal é o de promover o uso de energias renováveis e diminuir a dependência de combustíveis fósseis para uma maior segurança energética [12].

O instituto de padronização norte americano, National Institute of Standards and Technology (NIST) [13], define a Smart Grid como um sistema que integra uma ampla variedade de serviços e tecnologias de computação e comunicação digital à 
infraestrutura do sistema de energia, permitindo fluxos bidirecionais de energia e capacidades de controle e comunicação bidirecional.

A comissão europeia no relatório da Smart Grids Task Force Expert Group 1 [14], define uma smart grid como uma rede elétrica que pode integrar eficientemente, em termos de custo, o comportamento e as ações de todos os usuários conectados a ela - geradores, consumidores e aqueles que fazem as duas coisas - para garantir um sistema de energia economicamente eficiente e sustentável, com baixas perdas e altos níveis de qualidade, garantia de fornecimento e segurança.

Uma definição mais sucinta pode ser encontrada no site do instituto de pesquisas Americano, Electric Power Research Institute (EPRI) [15], que define Smart Grid como sendo aquela que incorpora tecnologia da informação e comunicação em todos os aspectos da geração, entrega e consumo de eletricidade, a fim de minimizar o impacto ambiental, intensificar os mercados, melhorar a confiabilidade e o serviço, reduzir custos e melhorar a eficiência.

Embora o termo Smart Grid tenha várias definições, ele normalmente implica em uma rede elétrica que utiliza, de forma integrada, tecnologias de comunicação e informação, capaz de conectar inteligentemente todos os envolvidos (geradores, consumidores, mercados, prestadores de serviços, distribuidores, aparelhos etc.) [16].

Para uma rede elétrica ser considerada Smart Grid ela deve apresentar as seguintes características [17]:

1. Permitir a participação ativa por parte dos consumidores;

2. Acomodar todas as opções de geração e armazenamento;

3. Possibilitar novos produtos, serviços e mercados;

4. Fornecer qualidade de energia para a economia digital;

5. Otimizar a utilização dos ativos e operar de forma eficiente;

6. Antecipar e responder a perturbações do sistema;

7. Operar de forma resiliente contra ataques e desastres naturais.

Essas características permitirão alcançar vários benefícios, como [13]:

$\square$ Melhorar a confiabilidade e qualidade da energia;

\ Otimizar a utilização de instalações e evitar a construção de usinas backup (para picos de carga);

\Melhorar a capacidade e eficiência das redes de energia elétrica existentes;

$\square$ Melhorar a resiliência a interrupções por desastres naturais e ataques; 
$\square$ Permitir a manutenção preditiva e respostas de "auto-cura" (self-healing) para distúrbios do sistema;

- Facilitar a ampla implantação das fontes de energia renováveis;

$\square$ Acomodar fontes de energia distribuídas;

$\square$ Automatizar a manutenção e a operação;

$\square$ Reduzir as emissões de gases de efeito estufa ao permitir os veículos elétricos e novas fontes de energia;

$\square$ Reduzir o consumo de combustíveis fósseis ao reduzir a necessidade por geradores ineficientes durante os períodos de pico de utilização;

$\square$ Apresentar oportunidades para melhorar a segurança da rede elétrica;

$\square$ Permitir a transição para veículos elétricos e novas opções de armazenamento de energia;

口 Fornecer aos consumidores informações úteis e atualizadas (instantâneas) sobre seu consumo de energia;

$\square$ Aumentar a escolha do consumidor, e permitir novos produtos, serviços e mercados.

Para nortear o desenvolvimento dessa nova rede, bem como a definição de possíveis padrões para interoperabilidade e funcionalidades dos sistemas e dispositivos para as Smart Grids, o NIST elencou sete funcionalidades chaves juntamente com cibersegurança e comunicações de rede [13] como essenciais para o desenvolvimento das Smart Grids, essas funcionalidades incluem as prioridades recomendadas pelo governo Americano através da Federal Energy Regulatory Commission (FERC) [18]:

1. Resposta da demanda e eficiência energética do consumidor (Demand Response and Consumer Energy Efficiency);

2. Ampla Consciência situacional (Wide Area Situational Awareness);

3. Recursos energéticos distribuídos (Distributed Energy Resources);

4. Armazenamento de energia (Energy Storage);

5. Transporte elétrico (Electric Transportation);

6. Infraestrutura avançada de medição (Advanced Metering Infrastructure);

7. Gerenciamento da rede de distribuição (Distribution Grid Management);

8. Cibersegurança (Cybersecurity); e

9. Comunicações de rede (Network Communications). 
Essas funcionalidades aplicam-se ao sistema elétrico como um todo, mas em especial o sistema de distribuição será o mais afetado por essas mudanças [19].

O sistema de distribuição é inerentemente complexo, sendo composto por uma vasta rede de subestações, linhas de distribuição, postes, medidores, dentre outros sistemas, sendo o responsável por servir a imensa maioria dos consumidores e também pelo processo de tarifação. Para que o sistema de distribuição atual consiga atender aos requisitos de uma Smart Grid ele precisará passar por uma completa restruturação.

O desenvolvimento de um sistema de distribuição inteligente trará muitos benefícios, principalmente pela aplicação de medidores inteligentes e automação de equipamentos, permitindo controlar em tempo real o estado de toda a rede, balancear as cargas, prevenir a interrupção do fornecimento de energia detectando e isolando automaticamente as faltas, reconfigurando e restaurando o fornecimento do serviço, além de fazer o controle de tensão e do fluxo de potências. A próxima seção apresenta as principais funcionalidades de um sistema de distribuição inteligente.

\section{$2.2 \quad$ Sistemas de distribuição inteligentes}

O sistema de distribuição, atualmente, corresponde à parte menos automatizada de um SEP, não possui um nível de inteligência apreciável e, na maioria das vezes, possui apenas informações provenientes dos alimentadores nas subestações [1].

Para permitir a implantação das smart grids e tornar o sistema mais proativo, eficiente e seguro, uma série de funcionalidades e inovações estão sendo desenvolvidas. Dentre as tecnologias e/ou sistemas que permitirão o desenvolvimento de uma rede de distribuição inteligente, aquelas que mais impactarão no sistema a fim de permitir uma operação mais segura, confiável e eficiente são destacadas nas próximas subseções.

\subsubsection{Infraestrutura avançada de medição}

Uma infraestrutura avançada de medição, do inglês Advanced Metering Infrastructure (AMI), é um sistema que envolve várias tecnologias, tais como Smart Meters, sistemas de gerenciamento de energia e infraestrutura de comunicação permitindo comunicações em duas vias entre os consumidores e o sistema de energia, proporcionando o monitoramento em tempo real, ou em tempo quase-real do uso da energia [20], [21]. 
Esses sistemas incluem hardware, software, sistemas de comunicações, controladores, sistemas associados aos consumidores, software de gerenciamento de dados, entre outros sistemas, que juntos, criam uma rede bidirecional entre os medidores e os sistemas da concessionária, permitindo a coleta e a distribuição de informações aos consumidores e a outros participantes, como fornecedores de energia no varejo ou a própria concessionária [13].

Nesse contexto os Smart Meters serão capazes de conectar e desconectar remotamente os consumidores, monitorar tensão e corrente, gravar formas de onda, e suportar a precificação de energia elétrica em tempo real, gerando uma grande quantidade de dados. O sistema de gerenciamento de dados de medidores é o responsável por manipular essa enorme quantidade de dados brutos e criar informações significativas. Essas informações estarão disponíveis para atividades de operação e planejamento e podem ser utilizadas para alcançar maior confiabilidade operacional e melhor gerenciamento de ativos [22].

Adicionalmente, estes medidores permitirão a implantação de programas de Demand Response, proporcionando aos consumidores a possibilidade de reduzir suas contas de energia e as concessionárias a capacidade de operar o sistema elétrico de maneira mais robusta, reduzindo a demanda de pico. Se a demanda de pico por cliente é reduzida, os alimentadores podem ser maiores, as tensões e as bitolas de fios podem ser menores, levando a um sistema mais econômico e confiável [23].

\subsubsection{Sistemas de automação da distribuição}

O termo em inglês Distribution Automation (DA) diz respeito aos vários sistemas responsáveis pela automatização da distribuição. A implantação de sistemas de automatização da distribuição é o primeiro passo para a evolução da rede de distribuição de energia elétrica, através da adoção de um abrangente sistema de controle e monitoramento, permitindo o desenvolvimento de novas aplicações e um aumento na eficiência operacional. Distribution automation se refere a um conjunto de sistemas que permitem à concessionária monitorar, coordenar e operar os componentes da rede de distribuição remotamente e em tempo real [24]. Ela envolve a integração de sistemas de controle supervisório e aquisição de dados, sensores, dispositivos eletrônicos inteligentes e sistemas de comunicação bidirecional para aumentar a eficiência, confiabilidade e qualidade do serviço. Este sistema monitora níveis de tensão, demanda 
atual, fluxo de potência ativa e reativa, equipamentos, estado operacional, etc., e ainda controla remotamente os disjuntores, a regulação de tensão, chaves, religadores, bancos de capacitores e subestações, a fim de permitir todas as funcionalidades da Smart Grid [17].

Com estas capacidades de monitoramento e controle, o sistema pode se "autocurar" (executar automaticamente a detecção de faltas, isolamento e restauração do serviço, sem intervenção de operadores) e determinar a localização de faltas ajudando os operadores de centros de controle e as equipes de reparos durante as atividades de gerenciamento de falhas [1].

Tecnologias de automação da distribuição, juntamente com sistemas de gerenciamento da distribuição e AMIs, podem melhorar a confiabilidade e resiliência, permitindo a reconfiguração automática, a automação de sistemas de proteção, facilitando a integração de recursos energéticos distribuídos, podem ainda otimizar o desempenho do sistema reduzindo perdas técnicas e não-técnicas, utilizando informações dos consumidores, dos transformadores e modelos de carga mais exatos, proporcionando uma estimativa de carga precisa da rede de distribuição.

\subsubsection{Recursos energéticos distribuídos e corte de picos}

Recursos energéticos distribuídos (do inglês, Distributed Energy Resources DER) são pequenas fontes de energia. Eles incluem a geração distribuída (GD), a partir de tecnologias convencionais e fontes de energia renováveis, Microrredes, veículos elétricos, dispositivos de armazenamento de energia e Demand Response [3]. A integração de recursos energéticos distribuídos baseados em fontes de energia renováveis ajuda a reduzir as emissões de carbono e mitigar os problemas com a crescente demanda dos consumidores.

Outro benefício dos DER é a capacidade de atuar no corte de picos de demanda (peak-shaving) [25]. O Peak-shaving pode ser conseguido usando a energia armazenada/gerada ou pela conformação do perfil de demanda (baseado em Demand Response), através do controle de carga de aparelhos "inteligentes", e/ou por ilhamento planejado de uma Microrrede.

Como mencionado anteriormente, utilizar DER, reduzir a demanda de pico e suavizar o perfil de demanda aumenta a confiabilidade do sistema, reduzindo os custos de capital, ao retardar a construção de usinas de geração de energia para atender à 
demanda de pico, aprimora a utilização da rede fazendo melhor uso das fontes de geração variáveis e ajuda a aumentar a eficiência geral do sistema, através da redução das perdas no sistema de distribuição.

\subsubsection{Geração Distribuída e Usinas Virtuais}

Geração distribuída é a geração de pequena escala que é ligada à rede de distribuição. Quando um grande grupo de geradores distribuídos, com uma capacidade total comparável à de uma central elétrica convencional, é coletivamente controlado pelo operador do sistema, este é chamado de Virtual Power Plant (VPP), ou em tradução livre Usina Virtual [5].

A saída agregada da VPP têm características técnicas e comerciais semelhantes a uma unidade de geração centralizada e pode substituir uma central elétrica convencional, proporcionando maior eficiência e maior flexibilidade [26]. A agregação dessas fontes, no entanto, também significa que enormes quantidades de dados necessitam ser manipulados e processados.

\subsubsection{Microrrede}

Uma microrrede é um agrupamento de cargas e DER que podem fornecer energia elétrica para as áreas vizinhas. Esse agrupamento pode ser um bairro, uma cidade, ou apenas um consumidor de grande porte, como uma universidade, que age como uma entidade controlável única em relação à rede, podendo operar em modo ilhado ou conectado à rede [27].

Uma microrrede pode ser projetada para alcançar autonomia energética, mas geralmente não é independente da rede. Ela está ligada à concessionária através de uma conexão conhecida como ponto de acoplamento comum e a energia elétrica pode fluir em ambas as direções através deste acoplamento. Os participantes podem comprar e vender eletricidade da rede quando necessário para atender excedentes ou déficits na produção da microrrede [28].

Quando a microrrede está operando em modo ilhado os GDs continuam a alimentar seus clientes sem a necessidade de obter energia elétrica da concessionária. A capacidade de ilhamento, embora ainda não permitida pela legislação brasileira, oferece várias vantagens e tem o potencial de fornecer uma confiabilidade local maior do que 
aquela proporcionada pelo sistema de energia como um todo. Por exemplo, uma microrrede pode continuar a operar no caso de uma falha ou um problema de qualidade de energia elétrica na rede da distribuidora, alternando para o modo ilhado, ou a distribuidora pode desconectar a microrrede para realizar um corte de carga, enquanto essa microrrede se mantém autônoma.

Note que mesmo em um modo ilhado a microrrede ainda precisa trocar informações com a rede da concessionária para, por exemplo, saber o estado da rede e decidir se é possível se reconectar para obter energia da mesma [5].

\subsubsection{Armazenamento de Energia e Veículos Elétricos}

O armazenamento de eletricidade, incluindo em Veículos Elétricos (VEs), oferece muitos benefícios para a rede de distribuição, melhorando a eficiência e a confiabilidade local, ao reduzir a carga de pico.

Dispositivos de armazenamento de energia podem ser utilizados para capturar a energia gerada por fontes de energia renováveis variáveis (e.g., eólica e solar) e quando houver excedente de geração (e.g., geração nuclear e hidrelétrica), de forma a tornar essa energia extra, que não seria utilizada, disponível quando houver um aumento na demanda [3].

Os VEs, por sua vez, podem servir como fontes de energia independentes para a rede elétrica. Quando eles estão estacionados e ligados à rede, eles podem se comunicar com a distribuidora e fornecer parte da energia elétrica de suas baterias para a rede de distribuição, utilizando uma tecnologia conhecida como vehicle-to-grid (V2G) [29].

\subsubsection{Demand response}

Demand Response (DR), resposta da demanda em tradução livre, é uma mudança no consumo de energia elétrica (pelo lado da demanda) em resposta a mudanças na tarifa, ou a incentivos financeiros, a fim de reduzir o consumo de energia em horários de pico, ajudando a preservar a confiabilidade do sistema, ou em resposta a condições de mercado [3].

A DR permite aos consumidores participarem ativamente das operações da rede, através de mudanças comportamentais, mudanças nos processos ou equipamentos, 
através do uso de geradores próprios (despacho de GDs) ou permitindo o controle direto de aparelhos e equipamentos (controle de carga) do lado da demanda [27].

\subsubsection{Gerenciamento da informação e ferramentas avançadas}

Sistemas integrados de gerenciamento de informação são o principal diferencial das Smart Grids. Eles são o cérebro dos sistemas de distribuição inteligentes. Com eles os vários sistemas de gerenciamento, análise e otimização que tradicionalmente existem independentemente um do outro, terão as suas funcionalidades combinadas e expandidas permitindo que o sistema de distribuição opere de forma eficaz e inteligente.

O gerenciamento da informação em smart grid geralmente envolve três tarefas básicas: a coleta, o processamento e o armazenamento de informações [5], [30]-[32]. A Figura 1 mostra um mapa conceitual do sistema de gerenciamento de informação, com suas subdivisões e temas relacionados.

Figura 1 - Mapa conceitual do sistema de gerenciamento de informação.

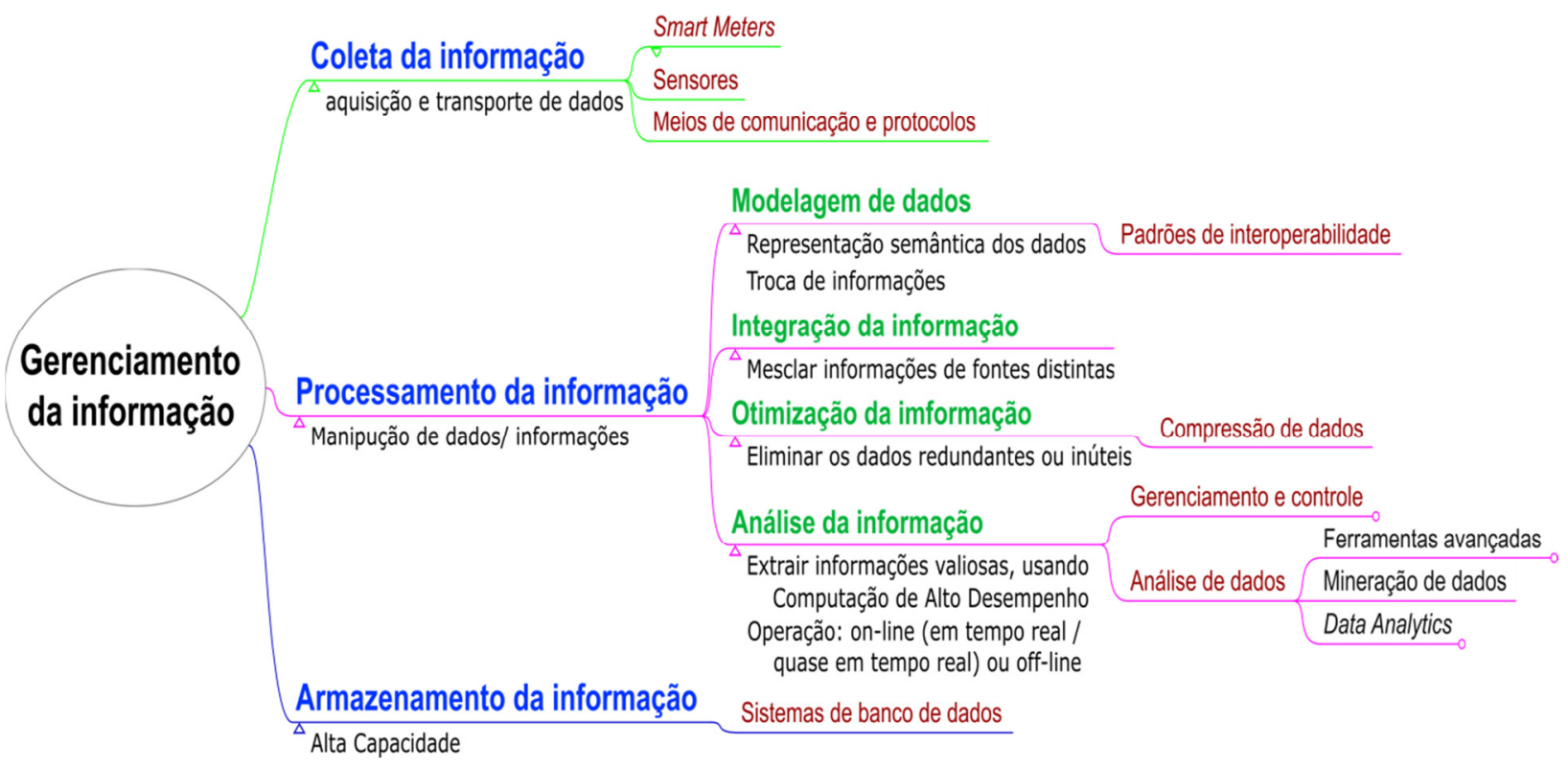

Fonte: Elaborado pelo autor.

A coleta de informações diz respeito à obtenção correta das informações dos diversos sensores, medidores inteligentes e dispositivos eletrônicos inteligentes (Intelligent Electronic Devices - IEDs), através de uma infraestrutura de comunicação eficiente (incluindo meio físico, protocolos, e segurança) [32]-[37].

Processamento da informação está relacionado com a modelagem de dados, análise, integração e otimização de informações. 
Modelagem de dados lida com representação semântica dos dados permitindo a troca de informações. Normalmente, a informação é coletada de diferentes dispositivos, que podem utilizar diferentes estruturas de dados. Esses dados precisam respeitar algumas normas de interoperabilidade para que haja integração entre dispositivos [13], [38], [39].

Integração de informações visa à fusão de informações de fontes distintas com diferentes representações conceituais, contextuais e tipográficas [5], [38]-[41].

Otimização da informação é utilizada para melhorar a eficácia da informação, a fim de reduzir a sobrecarga na comunicação e armazenar somente as informações úteis $[42]-[44]$.

A análise da informação é usada para extrair informações valiosas a partir da grande quantidade de dados gerados pelos sistemas de medição e monitoramento amplamente utilizados em SG, suportando novas funcionalidades baseadas no gerenciamento de informação em larga escala, análise de dados em tempo real e sistemas em laço fechado para o gerenciamento, monitoramento e controle da rede de distribuição inteligente [10], [45]-[52].

O armazenamento da informação está relacionado ao armazenamento de todas as informações úteis coletadas a partir de diferentes dispositivos, e transmitidas utilizando diferentes modos de transporte através de canais com e sem fio, além de outros dados processados que sejam relevantes [53]-[55]. Esses dados armazenados são utilizados para a análise, planejamento e simulação do sistema de distribuição através do uso das chamadas ferramentas avançadas.

Como mencionado anteriormente, o gerenciamento de informação em larga escala permite o desenvolvimento de novas funcionalidades. Essas novas funcionalidades juntamente com aplicações, para gerenciamento de energia, estimação de estado, análise de fluxo de energia elétrica, previsão de demanda, gerenciamento de interrupções, gerenciamento de ativos, etc. podem ser integradas, proporcionando um sistema completo de gerenciamento de distribuição com grande consciência situacional [56]-[58].

Devido à grande quantidade de dados provenientes dos subsistemas de medição, a implementação de tal sistema de gerenciamento de informações requer uma infraestrutura com alto poder de processamento e um espaço de armazenamento igualmente elevado, o que tem se mostrado um desafio [59]. 
Conforme apresentado, o desenvolvimento e a implantação de uma rede de distribuição inteligente só serão possíveis através da utilização de um sistema integrado de comunicação capaz de suportar a interconexão de diferentes tipos de sensores, atuadores e componentes de hardware, cujos dados possam ser processados em tempo hábil e armazenados para posterior utilização.

A computação em nuvem tem sido vista como uma tecnologia promissora, capaz de superar estes desafios, melhorando a integração de informações, permitindo simultaneamente interoperabilidade e extensibilidade [60]-[62]. De acordo com [63], as características enfatizadas como vantagens da computação em nuvem no domínio smart grid são o poder de processamento, capacidade de armazenamento, escalabilidade, flexibilidade, eficiência de custos, resposta em tempo real, e interconectividade.

\subsection{Aplicações em sistemas de distribuição inteligentes utilizando computação em nuvem}

A computação em nuvem tem o potencial de melhorar o nível de integração e utilização das informações na SG, agregando todos os sistemas da distribuidora em um ambiente de nuvem, simplificando o projeto do sistema de informação no domínio SG e reduzindo o custo operacional [62], [64].

A maioria dos estudos sobre computação em nuvem no domínio Smart Grid focam principalmente no uso da capacidade computacional da nuvem para o gerenciamento de informações (processamento e armazenamento de dados) [65]. Essas capacidades computacionais têm sido utilizadas em diversas áreas tradicionais, tais como, análise de sistemas de energia, análise de confiabilidade, sistemas de gerenciamento, etc., e possibilitado o desenvolvimento de novas aplicações.

A Tabela 2 condensa as principais aplicações em sistemas de distribuição inteligentes encontradas na literatura até 2016, que usam a computação em nuvem em seu desenvolvimento / implementação, que podem ser classificadas como sistema de gerenciamento de informações (mencionado anteriormente na Seção 2.2.4). 
Tabela 2 - Aplicações em redes de distribuição inteligentes que funcionam como sistemas de gerenciamento de informações.

\begin{tabular}{llr}
\hline $\begin{array}{l}\text { Aplicações em sistemas de } \\
\text { distribuição inteligentes }\end{array}$ & Assunto & Referências \\
\hline Sistemas de gerenciamento e & Gestão da demanda, Demand Response, & {$[66]-[77]$} \\
Controle & Deslocamento de carga e precificação dinâmica & {$[73],[74],[78]-[80]$} \\
& Gestão de microrrede & {$[8],[57],[81]-[86]$} \\
& Monitoramento e controle dos sistemas de energia & {$[87]-[90]$} \\
& Outros relacionados à gestão DER & {$[91]$} \\
Ferramentas Avançadas & Análise do sistema de energia & {$[92],[93]$} \\
& Otimização de custo & {$[94]-[96]$} \\
& Simulação do sistema & {$[97]$} \\
& Estimação de estado & {$[72]-[74],[98],[99]$} \\
Data Analytics/Mineração de & Previsão de demanda para balanceamento de & {$[100]$} \\
\hline
\end{tabular}

\section{Fonte: Elaborada pelo autor.}

Usando a estrutura de computação em nuvem adequada, diversas aplicações em sistemas de distribuição inteligentes podem ser desenvolvidas. Dentre aquelas encontradas na literatura a maioria está na área de sistema de gestão de energia (Energy Management System - EMS).

EMS é um conjunto de ferramentas de software de gerenciamento de energia usado para monitorar, controlar e otimizar o desempenho do sistema elétrico. Em EMSs comerciais, as funções de monitoramento e controle são também chamadas de Controle Supervisório e Aquisição de Dados, do inglês Supervisory Control and Data Acquisition (SCADA), e as aplicações de otimização são frequentemente referidas como ferramentas avançadas [101], [102].

As próximas subseções apresentam diversas aplicações e propostas de utilização da computação em nuvem em sistemas de distribuição inteligentes. Os trabalhos apresentados vislumbram a utilização da computação em nuvem para o desenvolvimento das mais diversas aplicações voltadas para as smart grids fornecendo funcionalidades como, medição em tempo real, simulação e modelagem de sistemas, demand response, e várias funções de gerenciamento, no entanto a maioria deles não apresenta detalhes da implementação da infraestrutura de nuvem utilizada, ou seus 
requisitos, focando apenas na aplicação e referindo-se à computação em nuvem numa abordagem mais conceitual / funcional.

\subsubsection{Aplicações em gerenciamento e controle}

As principais aplicações encontradas na literatura para gerenciamento de energia desenvolvidas no ambiente de nuvem são aplicações para: monitoramento e controle do sistema de energia [8], [57], [81]-[86]; gerenciamento pelo lado da demanda [66]-[77]; gerenciamento de microrredes [73], [74], [78]-[80]; entre outras aplicações de gerenciamento de DER [87]-[90].

O monitoramento e o controle do sistema de distribuição de energia são as funções mais importantes do EMS. Estas são responsáveis por coletar, visualizar e processar os dados das smart grids e executar ações de controle sobre a rede.

Nesse sentido, [86] e [83] utilizaram a computação em nuvem para armazenar e processar dados de monitoramento de condições (Condition Monitoring - CM). CM é o processo de monitorar os parâmetros e condições de operação de um equipamento (vibração, temperatura, etc.) a fim de identificar alguma mudança significativa que possa indicar uma possível falha futura na operação do mesmo. De acordo com os autores, os sistemas tradicionais de armazenamento e processamento enfrentariam grandes dificuldades para manipular a grande quantidade de dados coletadas nesse processo de monitoramento, sendo tais operações melhor desempenhadas em um sistema de nuvem.

Alcaraz e Lopez [84]; Alcaraz et al. [81] e Goose et al. [8] propuseram a utilização da computação em nuvem para o desenvolvimento de sistemas SCADA, a fim de melhorar a consciência situacional do SEP, destacando as diferentes tecnologias que poderiam ser utilizadas para esse fim, descrevendo requisitos e propondo possíveis arquiteturas.

Fazio e Puliafito [82] discutem duas possíveis estratégias para o gerenciamento de recursos de sensores na nuvem, oferecendo-os como um serviço, uma delas seguindo um modelo centrado nos dados, e outra seguindo um modelo centrado nos dispositivos. O artigo também apresenta um framework chamado Cloud4Sens, que permite a implantação desse serviço na nuvem.

Bo et al. [57] apresentaram o projeto e desenvolvimento de uma plataforma de computação em nuvem para substituir as funções de cálculo dos equipamentos 
secundários espalhados nas várias subestações da rede, com o objetivo de remover estes equipamentos das subestações, reduzindo o investimento em equipamento. Segundo os autores, a relativa falta de capacidade computacional dos dispositivos embarcados em uma subestação não é adequada à alta capacidade de transmissão de dados em rede, ao mesmo tempo, o rápido aumento de informação na operação de equipamentos em uma subestação demanda serviços de armazenamento e processamento de dados distribuídos, que são oferecidos pela computação em nuvem.

Outra aplicação é proposta por [85], que apresenta o desenvolvimento de serviços Web para processar dados de qualidade de energia gravados por medidores inteligentes ou outros dispositivos semelhantes em Smart Grids usando computação em nuvem. O objetivo desses serviços Web é implementar algoritmos de processamento de sinais em um framework distribuído para a caracterização de distúrbios (em particular afundamentos de tensão), avaliação da qualidade de energia e localização de faltas, de tal maneira que possam ser integrados a uma arquitetura de nuvem para facilitar o acesso e o gerenciamento de dados provenientes dos diferentes subsistemas envolvidos na operação e exploração de redes de energia, fornecendo uma plataforma flexível capaz de gerenciar grandes quantidades de dados.

Gerenciamento pelo lado da demanda está relacionado à modificação dos picos de carga para satisfazer a capacidade de geração, através da alteração das demandas dos consumidores em resposta a programas administrados pela distribuidora [69], [75], que incluem programas de demand response, ou outras estratégias para promover a deslocamento do pico de carga em relação ao tempo.

Simmhan et al. [72]-[74]; e Hongseok Kim et al. [71] propõem a utilização da computação em nuvem para implementar programas de demand response. Simmhan descreve o esforço para desenvolver um sistema de Demand Response dinâmico, apresentando os desafios e requisitos para o desenvolvimento do mesmo e apresenta resultados preliminares relacionados à predição de demanda. Hongseok apresenta uma visão geral da arquitetura tradicional de demand response, baseada numa arquitetura mestre/escravo, e propõe a utilização da computação em nuvem apresentando uma motivação para sua utilização no lugar da arquitetura tradicional, além de propor algoritmos de otimização que podem ser utilizados na nova arquitetura proposta. $\mathrm{O}$ autor considera um sistema de demand response em larga escala onde o número de clientes é enorme, de tal forma que até mesmo clientes residenciais que consomem uma 
pequena quantidade de energia participam no programa, e utiliza a computação em nuvem para atender aos requisitos computacionais de tal sistema.

Lohrmann e Kao [67], apresenta um conjunto de requisitos para a infraestrutura de TI das concessionárias, a fim de processar os dados provenientes dos smart meters, motivando a utilização da computação em nuvem para processar e analisar tais dados.

Sheikhi et al. [75] utiliza a computação em nuvem para viabilizar a implantação de um modelo de smart energy hub, apresentando seu modelamento, e propõem uma técnica moderna para o gerenciamento da energia em redes de eletricidade e gás natural, baseada em um sistema integrado de gerenciamento pelo lado da demanda. Apresenta ainda uma comparação entre o framework baseado em computação em nuvem com as técnicas tradicionais de processamento de dados para avaliar a eficiência da abordagem proposta. Segundo o autor, a sofisticação das SG pode levar a sistemas de gerenciamento de informação altamente complexos, e que tais sistemas podem ser caros e até mesmo estarem além da capacidade de uma concessionária, dessa forma a terceirização de algumas tarefas para a nuvem seria uma opção mais viável.

Wang et al. [66]; Mohsenian-Rad e Leon-Garcia [70]; e Xuan Li et al. [68] propuseram algumas formas de modificar o consumo de energia de cloud data centers para promover o balanço de carga com a rede de distribuição, deslocando o pico de consumo ou reduzindo o consumo dos data centers em resposta a um estimulo da concessionária, como por exemplo através da precificação dinâmica da energia.

Rajeev e Ashok [69] propuseram um programa para o deslocamento de carga dinâmico utilizando dados em tempo real em um ambiente de computação em nuvem, que permitirá uma melhora na utilização de fontes de energia intermitentes, favorecendo a integração de fontes renováveis de energia. Esse programa é baseado em sistema multiagente, o qual utilizou uma plataforma de software única para implementação de um programa de gerenciamento pelo lado da demanda no domicílio com acesso a nível de concessionária e capacidade de monitoramento. O multiagente está localizado no nó cliente e a arquitetura da nuvem é responsável por atender aos requisitos de processamento e armazenamento de dados do programa de deslocamento de carga dinâmico.

Yang et al. [76], [77] propuseram um sistema de gerenciamento de energia capaz de interagir com aparelhos elétricos convencionais, controlando a sua operação através de uma arquitetura orientada a serviços em um ambiente de computação em nuvem. $\mathrm{O}$ 
trabalho aplica tecnologias de armazenamento distribuído a fim de garantir que o sistema atenda a cargas massivas de demanda por serviços, e também realiza alguns testes de desempenho no banco de dados distribuído.

As aplicações de gerenciamento de microrredes são responsáveis por monitorar e controlar o consumo e operação de microrredes inteligentes, gerenciando as várias tarefas associadas. Algumas das aplicações utilizadas no gerenciamento de sistemas de distribuição inteligentes também podem ser aplicadas, em pequena escala, na gestão de microrredes, como as aplicações propostas por [73], [74].

Relacionado a esse assunto, Rajeev e Ashok [80], apresentaram uma arquitetura para o armazenamento de dados, alocação de recursos, gerenciamento e controle de microrredes utilizando computação em nuvem. Os autores consideraram a arquitetura sendo composta por quatro módulos: infraestrutura, monitoramento, gerenciamento de energia e serviços em nuvem, no entanto não apresentaram detalhes de funcionamento ou implementação.

Jin et al. [78], e Bertagna De Marchi et al. [79], propuseram diferentes abordagens para o uso de sistemas multiagentes, como uma arquitetura de controle distribuído para Smart Microgrids, ambas utilizando computação em nuvem. No primeiro, a arquitetura proposta considera os multiagentes como serviços em nuvem, e apresenta uma diretriz preliminar para o projeto de uma arquitetura de controle de microrredes em nuvem. O segundo considera uma arquitetura hierárquica dividindo o sistema de energia e a microrrede em três níveis de acordo com suas características, aproveitando o poder computacional dos nós clientes. A arquitetura de computação em nuvem proposta por eles visa maximizar a integração dos recursos computacionais e de armazenamento sem alterar a estrutura interna e os equipamentos existentes em um sistema de energia.

Além dessas aplicações previamente mencionadas, diversas outras aplicações de gerenciamento relacionadas aos DERs, que utilizam a computação em nuvem para o processamento e armazenamento de dados podem ser encontradas na literatura. Dentre elas, aplicações para a interface da distribuidora com equipamentos de abastecimento de veículos elétricos proposta em [90]; e para o monitoramento e controle de recursos energéticos renováveis distribuídos apresentada em [87]-[89]. 


\subsubsection{Ferramentas avançadas}

As ferramentas avançadas constituem uma função especial dentro dos EMSs, responsáveis por analisar e otimizar o sistema de distribuição. Dentro dessa perspectiva, algumas aplicações foram desenvolvidas, utilizando computação em nuvem, para análises do sistema [91]; otimização de custos [92], [93]; simulação do sistema [94]-[96]; e estimação de estados [97].

Qiuhua Huang et al. [91] desenvolveram uma plataforma baseada computação em nuvem para análise de sistemas de energia, que oferece três funções principais, são elas, análise de fluxo de carga, análise de contingência e serviços de transformação de dados de simulação de sistema de energia ODM (Open Data Model), usando o Google App Engine.

Fang et al. [93] e Devie e Kalyani [92] propuseram diferentes modelos de gestão de informação em SG baseado em computação nuvem, e apresentaram frameworks de otimização para a redução dos custos envolvidos no processamento e armazenamento de informação da SG em nuvem. O primeiro apresenta uma modelagem detalhada dos domínios envolvidos e suas respectivas contribuições para a função de otimização. O segundo, além da modelagem utilizada apresenta também uma comparação, em termos de velocidade de processamento, entre diferentes algoritmos de otimização, recomendando a técnica de otimização por enxame de partículas, por ser executada em menor tempo.

Anderson et al. [94], descreveram um sistema de simulação escalável, de código aberto chamado GridSpice, integrando Gridlab-D e MATPOWER como ferramentas de simulação. Essas ferramentas têm sido utilizadas em projetos de otimização da alocação da geração distribuída e no desenvolvimento de cronogramas de despacho ótimo para cargas flexíveis [94]. As simulações no GridSpice podem ser gerenciadas por meio de uma interface de programação ou por meio de uma biblioteca em Python, permitindo que os usuários executem simulações programaticamente e façam interface com diferentes entradas de dados, sistemas de gerenciamento de energia, sistemas de gerenciamento da distribuição e ferramentas de pós-processamento.

Leijiao et al. [95], propuseram um framework de aplicações para simulação de transitórios do sistema de energia utilizando tecnologia de computação em nuvem, apresentando sua arquitetura geral e funcionalidades. 
Maheshwari, Birman et al. [96], utilizaram a computação em nuvem para melhorar o desempenho do software Multi Area Reliability Simulation (MARS), desenvolvido pelo grupo GE Energy Consulting, através de processamento paralelo em nuvem. O software de modelagem MARS permite ao operador da distribuidora de energia elétrica avaliar a aptidão de um sistema de energia em satisfazer adequadamente os requisitos de carga do cliente [96].

Maheshwari, Lim et al. [97], descreveram um framework de monitoramento criado por eles utilizando computação em nuvem, e caracterizaram uma aplicação para estimação de estados baseada em PMU, explicando como essa aplicação proposta pode ser implementada na arquitetura da nuvem. As contribuições do artigo centraram-se na modelagem, medição e caracterização de cálculos de smart grid na nuvem, aplicados à estimação de estados.

\subsubsection{Data Analytics e mineração de dados}

Data analytics (DA) é a ciência de examinar dados brutos com a finalidade de tirar conclusões sobre essa informação; ela é focada em inferência derivando uma conclusão a partir de diferentes conjuntos de dados utilizando sistemas e softwares especializados para verificar ou refutar modelos científicos, teorias e hipóteses [103]. Mineração de dados (Data mining) é a triagem dos dados para identificar padrões desconhecidos e estabelecer relações ocultas; seu objetivo é a extração de padrões e conhecimento a partir de grandes repositórios de dados [104].

Na área de DA temos as aplicações propostas por Simmhan et al. [72]_[74], Mayilvaganan e Sabitha [98], e Martin et al. [99] que utilizaram a computação em nuvem para desenvolverem sistemas de previsão de demanda, que podem ser utilizados para manter o equilíbrio entre a demanda e o fornecimento.

Simmhan em seus artigos apresenta os desafios enfrentados para desenvolver um sistema de demand response dinâmico para a microrrede do campus da University of Southern California, apresentando um pouco das tecnologias utilizadas e resultados preliminares. Tal sistema incorpora um sistema de previsão de demanda que utiliza um modelo de aprendizagem de máquina baseado em árvore de regressão, o qual é treinado com um conjunto de dados históricos que contêm vetores de características correspondentes ao uso da energia em intervalos de 15 minutos. 
Mayilvaganan e Sabitha apresentam uma série de requisitos para o desenvolvimento de um sistema de predição de demanda e propõem uma arquitetura em nuvem para viabilizar tal sistema, no entanto, sem implementá-la ou testá-la.

Martin e seus colaboradores utilizam a infraestrutura de nuvem pública da Amazon no contexto da predição de demanda associando tecnologias de processamento de eventos em fluxo e armazenamento de dados, descrevendo os desafios relacionados à escalabilidade e elasticidade para aplicações relacionadas à predição de demanda, apresentando alguns resultados experimentais.

Utilizando ferramentas de mineração de dados em uma plataforma de computação em nuvem, Nikolopoulos et al. [100], desenvolveram uma aplicação para análise do perfil de energia, que analisa dados de consumo de energia ao longo do tempo, com o objetivo de ajudar e orientar as distribuidoras e empresas de energia a entender os padrões de consumo de seus clientes, analisar o comportamento da energia do cliente ao longo do tempo e, finalmente, criar serviços personalizados e estratégias de eficiência energética para o seu grupo-alvo [100]. O artigo propõe um algoritmo para agrupar os perfis de consumo com base em métricas de similaridades definidas, utilizando para isso uma versão modificada da técnica de "clusterização" k-médias executada como uma rede de agentes distribuídos em nuvem e em tempo real.

Como pôde ser visto existem muitas aplicações utilizando computação em nuvem que podem ser usadas em um sistema de distribuição inteligente, no entanto, o desenvolvimento de tais aplicações necessita de uma infraestrutura de nuvem adequada aos requisitos de manipulação de dados de cada aplicação. O próximo capítulo apresenta os principais conceitos e definições relacionados à tecnologia de computação em nuvem e as principais ferramentas/tecnologias utilizadas no desenvolvimento de uma infraestrutura de nuvem, concluindo com uma discussão sobre os cuidados quando da aplicação em sistemas de distribuição inteligentes. 



\section{Capítulo 3}

\section{Computação em nuvem: Aspectos Históricos e Conceituais}

Computação em nuvem, ou Cloud Computing, é um novo modelo de computação, onde os recursos computacionais são alocados de forma dinâmica e escalável sendo disponibilizados como serviços, por meio da internet [105]. A nuvem é uma metáfora para internet, que tradicionalmente era representada como uma nuvem nos diagramas de rede, a fim de abstrair a complexidade de sua infraestrutura [106]. O termo computação em nuvem começou a se popularizar após ter sido utilizado pelo diretor executivo da Google, Eric Schmidt, em uma entrevista na Search Engine Strategies Conference realizada na cidade de San Jose em agosto de 2006, para explicar a forma de prestação de serviços da sua empresa [107]. No entanto, o termo em si já havia aparecido pela primeira vez, no mundo acadêmico, em 1997 durante uma palestra intitulada "Intermediários em Computação em Nuvem: Um Novo Paradigma de Computação", apresentada na INFORMS Annual Meeting, em Dallas, pelo Professor Ramnath K. Chellappa, docente da escola de negócios Goizueta na Universidade de Emory em Atlanta [108].

Embora a computação em nuvem tenha se tornado popular apenas recentemente, a ideia de prover recursos computacionais remotamente sob demanda, data do início da década de 1960. Na época, em uma palestra, durante as comemorações dos cem anos do Instituto de Tecnologia de Massachusetts, o Prof. John McCarthy, docente da Escola de Engenharia da Universidade de Stanford, na Califórnia, sugeriu que recursos computacionais compartilhados no tempo, poderiam levar a um futuro em que o poder computacional e mesmo aplicações específicas poderiam ser comercializadas como um modelo de serviço público (em inglês, utilities), como os serviços de telefonia e eletricidade, onde cada assinante pagaria apenas pela capacidade que ele realmente utilizasse [109]. 
Com o advento da computação em nuvem há uma mudança de paradigma, onde o foco da computação não está mais no hardware ou nos recursos físicos, em uma estação de trabalho por exemplo, e sim na nuvem. Com isso, os aplicativos, arquivos e dados relacionados, ou até mesmo o sistema operacional ( $\mathrm{SO}$ ), não precisam mais estar instalados ou armazenados em um computador local. Eles ficam disponíveis na "nuvem", distribuídos em vários servidores. O usuário final não precisa se preocupar em manter a informação, e pode utilizá-la a partir de qualquer ponto de acesso, pagando somente pelos recursos e/ou pelo tempo que utilizar [110].

Dentre as principais vantagens da computação em nuvem pode-se destacar a capacidade de oferecer serviços sob demanda aos clientes, que não precisam arcar com os custos da aquisição de hardware, manutenção e operação dos mesmos, pagando apenas aquilo que utilizar e quando precisar, reduzindo assim as despesas com TI, além dos benefícios de flexibilidade e escalabilidade. Para empresas, a computação em nuvem proporciona também uma economia significativa de energia, uma vez que os custos com refrigeração e energia elétrica dos servidores não são de sua responsabilidade.

Tradicionalmente, cada empresa (clientes) deveria ter seus próprios servidores, aplicações de software e plataformas de desenvolvimento, os quais gerariam custos de manutenção e gerenciamento. Essa infraestrutura demanda altos gastos associados com a aquisição de hardware e software, além do tempo investido em atualizações e manutenção desse sistema, que na maioria das vezes não faz parte do objetivo final da empresa. Nessas empresas, os data centers são subutilizados na maior parte do tempo, pois devem ser dimensionados para a maior carga de trabalho visando atender as situações de alta demanda, que raramente acontecem.

Os benefícios da computação em nuvem estão relacionados à economia de escala que os provedores de serviços em nuvem podem alcançar. A infraestrutura de um provedor de serviços em nuvem pode ser utilizada e compartilhada por outros clientes não permanecendo ociosa durante os períodos de baixa demanda por parte de um utilizador específico, distribuindo os gastos de operação entre os diversos clientes desse provedor de serviços e aumentando a taxa de utilização dos equipamentos. Esse conceito de compartilhamento permite que os recursos computacionais sejam explorados de forma muito mais eficiente comparado com recursos computacionais próprios e dedicados. Além disso, os provedores de serviços possuem departamentos dedicados à eficiência, garantindo que a infraestrutura da nuvem trabalhe de maneira 
mais eficiente possível, acompanhando o rápido avanço da tecnologia envolvida, o que é muito difícil de conseguir sem uma equipe especializada [16].

A computação em nuvem permite também aumentar a quantidade de recursos utilizados de forma dinâmica, automaticamente ou não, sem a necessidade de interrupção dos serviços, de acordo com a necessidade de utilização e dos recursos disponíveis. Outro benefício da computação em nuvem é a possibilidade de acessar os serviços on-line, através da internet ou de outro recurso de rede, permitindo a utilização dos serviços em qualquer lugar com acesso à rede e por diversas plataformas de hardware, uma vez que o processamento dos dados deverá ser feito principalmente no servidor da nuvem, permitindo que terminais com hardware mais modestos sejam utilizados. Essa necessidade de uma conexão de rede rápida e estável com o provedor de serviços pode ser vista por alguns como um empecilho para a adoção da computação em nuvem.

A computação em nuvem traz, como uma vantagem adicional, uma maior segurança operacional, uma vez que os dados e processamento estão replicados em diversos servidores na nuvem, servidores estes que podem estar localizados fisicamente em diferentes regiões geográficas. Assim, caso haja falha em algum dos servidores envolvidos, seja por problemas técnicos ou desastres naturais, outros servidores podem assumir o papel deste que falhou diminuindo a possibilidade de perda de dados e/ou indisponibilidade do serviço.

Por ser uma tecnologia relativamente nova e não possuir ainda uma definição universal, a computação em nuvem apresenta várias definições, o que gera certa confusão e entendimento incorreto sobre o que realmente é computação em nuvem. De maneira geral, a computação em nuvem está relacionada à disponibilização de recursos computacionais, sejam eles hardware ou software.

Para Brian Chee [106], computação em nuvem pode ser definida como um modelo de processamento de informações em que as capacidades computacionais são disponibilizadas como serviços, à medida que forem necessárias, através da rede para uma variedade de dispositivos de usuários. 
Vaquero et al. [111] propuseram a definição de que nuvens são grandes repositórios de recursos virtualizados ${ }^{1}$, tais como hardware, plataformas de desenvolvimento e/ou serviços, que são facilmente acessíveis e utilizáveis, que podem ser reconfigurados dinamicamente de modo a ajustarem-se a diferentes cargas de trabalho com a intenção de otimizar sua utilização, sendo que o modelo de cobrança empregado para a exploração destes repositórios está baseado no modelo de pagamento pelo uso, no qual o provedor de infraestrutura oferece garantias ao cliente por meio de contratos de nível de serviços personalizados.

Outra definição para computação em nuvem encontrada em [112], trata a computação em nuvem como sendo um conjunto de arcabouços (frameworks) que fornecem plataforma e serviços de qualidade, em software, de forma escalável, personalizados e sob demanda, fornecendo também infraestrutura compartilhável por meio da internet, que são acessíveis e disponíveis em todos os lugares.

A partir dessas definições pode-se perceber alguns pontos chave sobre a computação em nuvem. Dessa forma, a computação em nuvem pode ser entendida como um modelo especializado de computação distribuída (conjunto de recursos computacionais disponíveis em rede), que difere dos tradicionais por ser: (1) amplamente escalável; (2) acessível em qualquer lugar por meio da internet; (3) pode ser encapsulada como uma entidade abstrata que entrega diferentes tipos de serviço aos clientes fora da nuvem; e (4) os serviços podem ser configurados dinamicamente (por virtualização ou outras abordagens similares) e entregues sob demanda.

A computação em nuvem surgiu como uma evolução e convergência de outros modelos computacionais já existentes como a computação em grade (grid computing) e a computação distribuída (distributed computing), associadas ao modelo de negócios conhecido como computação utilitária (utility computing) [113], [114]. O termo computação em nuvem é utilizado principalmente para destacar uma mudança de paradigma, onde os recursos computacionais deixam de ser proprietários e passam a ser adquiridos como serviço. A Figura 2 mostra um comparativo do aumento da popularidade do termo em Inglês "Cloud computing" em relação aos termos "Grid Computing" e "Distributed Computing" segundo as estatísticas de buscas no site do

\footnotetext{
${ }^{1}$ Em computação, virtualização se refere ao ato de criar uma versão virtual de alguma coisa, seja uma plataforma de hardware, sistema operacional, dispositivo de armazenamento, ou recursos de rede [256].
} 
Google. Por essa análise pode-se perceber o aumento nas buscas por Cloud Computing, principalmente após 2008, enquanto as buscas pelos outros termos têm diminuído ao longo do tempo.

Figura 2 - Estatísticas de busca para os termos Cloud Computing, Grid Computing e Distributed Computing.

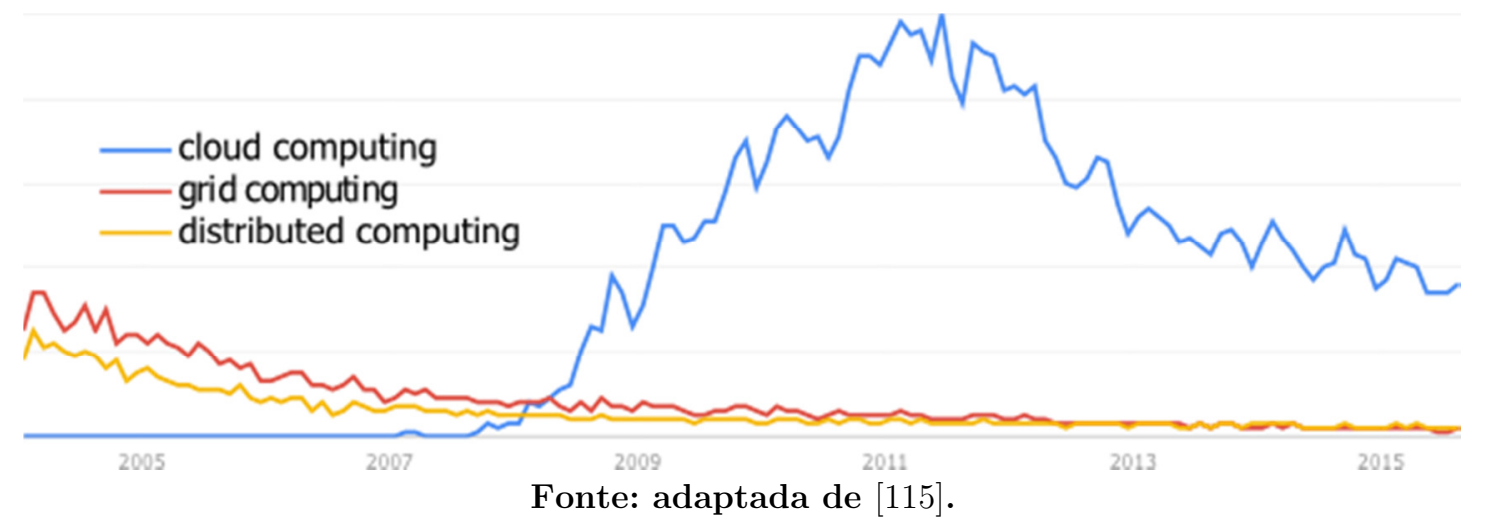

O termo computação em grade, ou computação em grelha, mencionado anteriormente, foi cunhado em meados de 1990 para descrever tecnologias que poderiam permitir aos clientes obter poder computacional sob demanda, através da utilização de recursos computacionais de diversos computadores conectados em rede. Diferentemente da computação em nuvem, ela era utilizada para resolução de um único problema, ou uma tarefa específica, com início e fim definidos, e suas aplicações necessitam estar em conformidade com as interfaces de software e protocolos padronizados para a computação em grade [105], [116]. Computação distribuída, por sua vez, é um termo genérico utilizado para designar um sistema computacional distribuído, consistindo de vários componentes de software em vários computadores, trabalhando em rede, sendo executados como um único sistema, ou seja, como um único computador [117].

Os pioneiros na utilização da computação em nuvem em larga escala foram as grandes empresas de internet como Amazon, Google entre outras, com a construção de suas próprias infraestruturas, a fim de gerenciar o grande volume de dados gerados por seus usuários.

Os principais fatores que contribuíram para o surgimento do interesse em computação em nuvem foram a: (1) a rápida redução no custo do hardware com o aumento no poder computacional e capacidade de armazenamento, e o surgimento das arquiteturas multi-core; (2) o crescimento exponencial da quantidade de dados 
publicados e arquivados na internet, e em instrumentação/simulação científica; e (3) a ampla adoção de aplicações e serviços Web e Web 2.0² [118].

Com o objetivo de acelerar a adoção da computação em nuvem pelo governo norte americano, de forma segura e eficaz, o National Institute of Standards and Technology - USA, lançou em 2010 o Programa de Computação em Nuvem, o qual tem trabalhado na definição de normas e modelos relacionados à essa tecnologia [119], [120]. Suas definições têm sido utilizadas como um modelo base para os serviços oferecidos em rede. Em [121], o NIST define a computação em nuvem como sendo um modelo para permitir acesso pela rede, de modo ubíquo, conveniente e sob demanda, a um conjunto de recursos computacionais configuráveis (tais como, redes, servidores, armazenamento, aplicações e serviços), que podem ser rapidamente provisionados e liberados com mínimo esforço de gerenciamento ou interação com o provedor de serviços.

Figura 3 - Computação em nuvem conforme especificação do NIST.

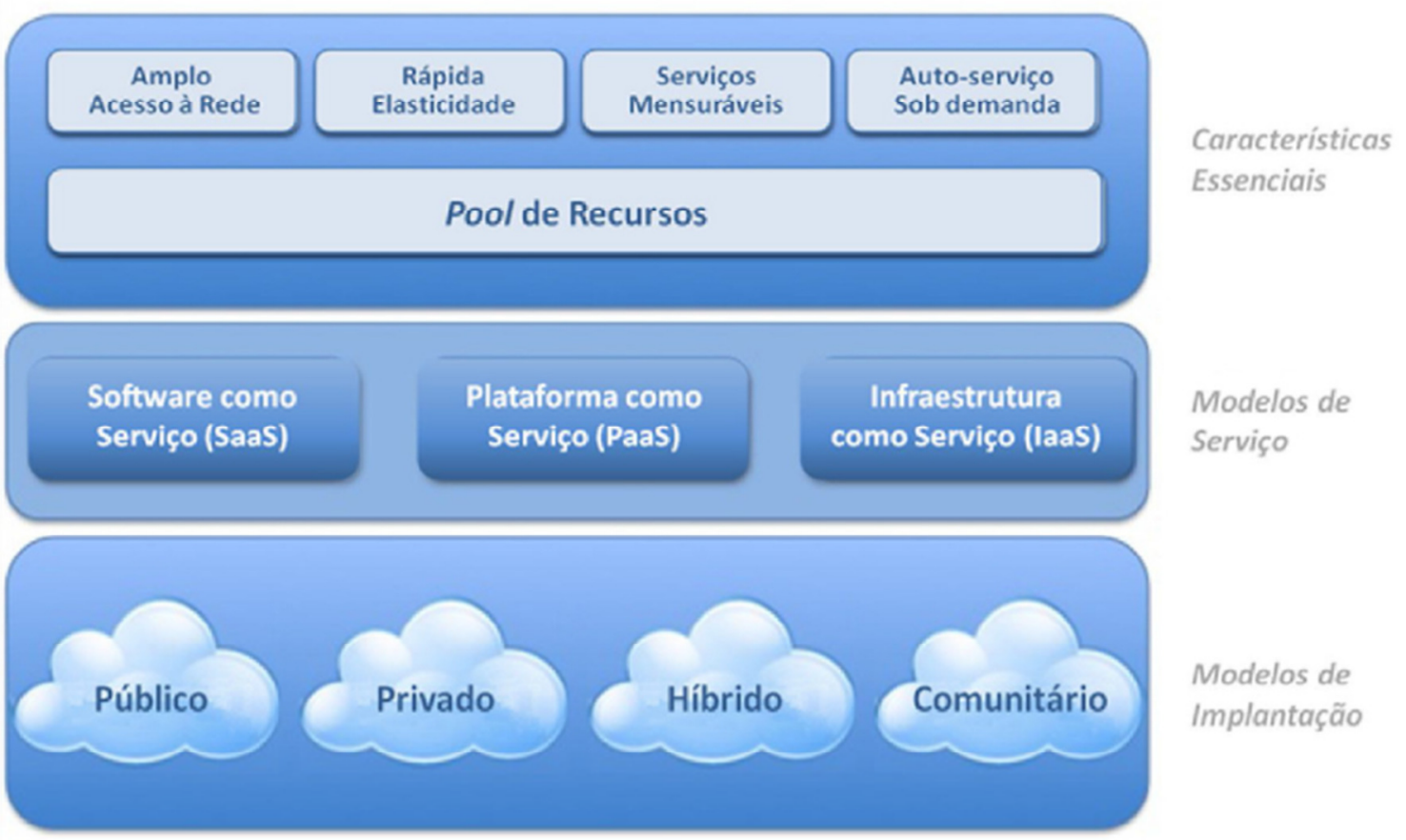

Fonte: adaptado de [122].

O modelo de computação em nuvem definido pelo NIST [123], e amplamente aceito pela comunidade em geral, é composto por cinco características essenciais, três

\footnotetext{
${ }^{2}$ Web 2.0 foi um termo criado por Tim O'Reilly, em 2004, para designar uma mudança na forma como a internet era utilizada, passando a ser vista como uma plataforma dinâmica, interativa e colaborativa, voltada para o usuário, com conteúdo colaborativo/ participativo. [257]
} 
modelos de serviço e quatro modelos de implementação, conforme apresentado no infográfico da Figura 3, os quais serão discutidos nas próximas seções.

\subsection{Características Essenciais}

As características essenciais estão diretamente relacionadas ao conceito de computação em nuvem, ou seja, definem suas funcionalidades, sendo o diferencial entre essa tecnologia e alguma outra semelhante. O fato de ter vários servidores em rede, ou em computação em grade, por si só, é insuficiente para caracterizar uma nuvem que deve cumprir estas cinco características essenciais.

\subsubsection{Autosserviço sob demanda}

Qualquer utilizador pode, unilateralmente, requerer capacidades computacionais, tais como, tempo de servidor e armazenamento na rede, dentre outras, automaticamente conforme sua necessidade e sem requerer interação humana com cada provedor de serviço. Essa característica garante que os serviços sejam adquiridos sob demanda, podendo ser solicitados ou revogados diretamente pelo utilizador.

\subsubsection{Amplo acesso à rede ou ubiquidade}

Os recursos devem estar disponíveis através da rede (internet), podendo ser acessados através de mecanismos padronizados que possibilitem o uso por plataformas clientes heterogêneas, como por exemplo, thin client, thick client, smartphones, tablets, estações de trabalho, laptops, ou outras tecnologias, independente da sua localização. Com isso, garante-se certo nível de onipresença dos serviços oferecidos, uma vez que os serviços podem ser acessados diretamente de qualquer lugar com conexão à internet, e uma independência em termos de tecnologia, permitindo acesso por qualquer dispositivo conectado à rede.

\subsubsection{Repositório de recursos}

Os recursos computacionais do provedor deverão ser agrupados em um repositório para atender múltiplos consumidores utilizando um modelo multi-locatário 
( multi-tenant $\left.^{3}\right)$, com recursos físicos e virtuais diferentes, alocados e realocados dinamicamente de acordo com a demanda do cliente. Existe uma impressão de independência de localização em que o cliente geralmente não tem controle ou conhecimento sobre a localização exata dos recursos que lhe são disponibilizados, no entanto poderá ser capaz de definir a sua localização num nível de abstração mais elevado (país, estado, ou data center). Exemplos de recursos incluem armazenamento, processamento, memória, e largura de banda.

\subsubsection{Elasticidade rápida}

Essa característica é possivelmente o principal diferencial da computação em nuvem com relação aos outros tipos de computação. É a possibilidade de prover e liberar recursos computacionais elasticamente, em alguns casos automaticamente, de forma a escalar rapidamente para cima ou para baixo a capacidade de trabalho adequando-a à demanda através da adição proporcional de recursos. Para o cliente, os recursos disponíveis geralmente parecem ilimitados e podem ser adquiridos em qualquer quantidade e a qualquer momento, ou seja, a demanda do usuário deve determinar a liberação e aquisição dos recursos e isto deve ser executado de forma rápida, transparente e sem intervenção humana.

\subsubsection{Serviços mensuráveis}

Os sistemas de gerenciamento da nuvem controlam e otimizam automaticamente a utilização de recursos por meio de medições adequadas para cada tipo de serviço (tais como, armazenamento, processamento, largura de banda e usuários ativos). A utilização dos recursos pode ser monitorada, controlada, auditada e reportada, fornecendo transparência ao provedor e ao consumidor do serviço utilizado. Essa característica pretende garantir ao utilizador total clareza sobre o que está sendo consumido e qual o custo por esse serviço, possibilitando também a alocação dos recursos computacionais de acordo com a disponibilidade financeira do utilizador.

Deste modo, o utilizador só paga aquilo que consome em cada momento, evitando assim custos desnecessários. Geralmente esse modelo de serviço é regido por

\footnotetext{
${ }^{3}$ Multi-tenancy na sua forma mais simples implica no uso dos mesmos recursos ou aplicações por múltiplos clientes, que podem pertencer à mesma organização ou organização diferentes [122].
} 
um contrato (Service Level Agreement - SLA) que especifica as características dos serviços, parâmetros de qualidade (Quality of services - QoS) e determina os valores que serão cobrados. Um SLA define os níveis de disponibilidade, funcionalidade, desempenho e outros atributos relativos aos serviços incluindo inclusive penalidades para o caso de violação das regras por qualquer uma das partes [124].

\subsection{Modelos de Serviço}

O modelo conceitual de computação em nuvem proposto pelo NIST apresenta três modelos de serviços básicos, a partir dos quais outros modelos podem ser derivados, são eles, Software como Serviço (Software as a Service - SaaS), Plataforma como Serviço (Platform as a Service - PaaS) e Infraestrutura como Serviço (Infrastructure as a Service - IaaS). Esses modelos de serviços podem ser arranjados hierarquicamente em relação ao seu nível de abstração de hardware, como apresentado na Figura 4, os quais serão discutidos a seguir. Quanto maior o nível de abstração, menos interação com o hardware é necessária/permitida ao usuário. A Figura 5 apresenta um comparativo, destacando a forma como a infraestrutura da computação em nuvem difere da tradicional em termos de responsabilidade de gerenciamento/configuração dos subsistemas envolvidos.

Figura 4 - Hierarquia de serviços.

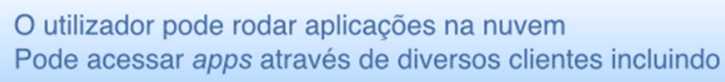

O utilizador obtém uma plataforma/solução aberta onde ele/ela pode implementar a aplicação desenvolvida em uma linguagem disponibilizada pelo provedor

Platform as a Service (PaaS)

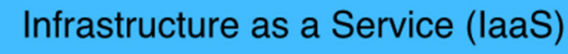
pros computacionais (rede, processamento. armazenamento, etc) sob demanda

Fonte: adaptado de [125]. 
Figura 5 - Comparativo entre os recursos em nuvem em relação à infraestrutura tradicional.

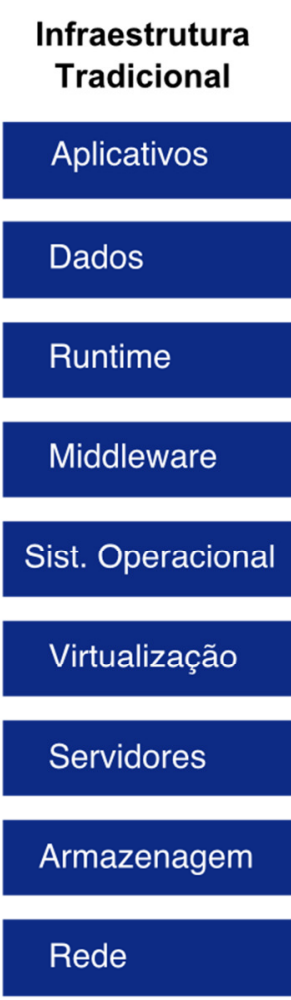

\begin{tabular}{|c|c|c|}
\hline \multicolumn{3}{|c|}{ Computação em Nuvem } \\
\hline laas & Paas & Saas \\
\hline Aplicativos & Aplicativos & Aplicativos \\
\hline Dados & Dados & Dados \\
\hline Runtime & Runtime & Runtime \\
\hline Middleware & Middleware & Middleware \\
\hline Sist. Operacional & Sist. Operacional & Sist. Operacional \\
\hline Virtualização & Virtualização & Virtualização \\
\hline Servidores & Servidores & Servidores \\
\hline Armazenagem & Armazenagem & Armazenagem \\
\hline Rede & Rede & Rede \\
\hline
\end{tabular}

Gerenciado pelo utilizador

Entregue como serviço

Fonte: adaptado de [126].

\subsubsection{Software como Serviço}

Corresponde ao nível de abstração mais alto do modelo conceitual, sendo executado sobre os outros níveis. Esse modelo de serviço provê ao cliente a capacidade de utilizar as aplicações do provedor executadas em uma infraestrutura de nuvem. A infraestrutura da nuvem é o conjunto de hardware e software que viabiliza as cinco características essenciais já apresentadas. Nesse modelo de serviço, as aplicações são acessadas por diversos dispositivos clientes, seja por uma interface thin client, como um navegador Web (e.g., webmail) ou por uma interface de programa. O cliente não gerencia, nem controla a infraestrutura básica da nuvem, como servidores, sistemas operacionais, armazenamento, ou mesmo funcionalidades de uma aplicação individual, com uma possível exceção para alguns ajustes limitados de configurações de uma aplicação específica do usuário. Todo o controle e gestão dessa infraestrutura são efetuados pelo prestador de serviço, liberando o utilizador dessas tarefas. 
Quase todas as pessoas já tiveram contato com esse tipo de serviço na forma de servidores de e-mail como o Gmail e o Yahoo; redes sociais, como o Facebook; motores de busca como o Google, ou enciclopédias on-line como a Wikipédia, pois todo serviço publicado na Internet se enquadra nessa categoria. Por esse motivo, esse modelo de serviço muitas vezes é confundido com computação em nuvem, limitando o entendimento real sobre o que é computação em nuvem. Nesse modelo, o software é oferecido como serviço, não sendo necessário ao usuário adquirir licenças de uso para instalação ou mesmo comprar computadores ou servidores para executá-lo. Nessa modalidade, normalmente paga-se uma assinatura somente pelos recursos que utilizar e/ou pelo tempo de uso.

Algumas vantagens desse modelo de serviço são: os aplicativos e softwares estão disponíveis a partir de qualquer dispositivo computacional com acesso à internet; não há necessidade de instalá-los no computador do usuário, eliminando custos e preocupações com atualizações, taxas de licença, requisitos ou limitações de hardware e suporte técnico local, pois paga-se apenas pela utilização, que irá reduzir os custos operacionais. A principal desvantagem desse modelo, assim como todos os serviços em nuvem, é a necessidade de estar conectado ao prestador de serviços, seja por meio da internet, ou outro tipo de conexão à rede, para poder acessar o serviço [110].

\subsubsection{Plataforma como Serviço}

Fornece ao consumidor uma plataforma computacional e uma pilha de soluções e frameworks como serviço. Nesse modelo de serviço, o consumidor é capaz de implementar aplicações dentro do ambiente da nuvem, sejam elas criadas por ele ou adquiridas de terceiros, através da utilização de linguagens de programação, bibliotecas, serviços e ferramentas oferecidas pelo provedor de serviço (note que essa capacidade não necessariamente exclui o uso de linguagens de programação, bibliotecas, serviços e ferramentas compatíveis de outras fontes). O consumidor não gerencia ou controla a infraestrutura básica da nuvem (redes, servidores, sistemas operacionais, ou armazenamento), porém tem controle sobre a aplicação desenvolvida e, possivelmente, a ajustes de configurações para o ambiente hospedeiro da aplicação.

Esse modelo de serviço fornece ao cliente a possibilidade de desenvolver aplicações específicas, mas impede a manipulação e/ou o controle da infraestrutura base da nuvem. Um PaaS simplifica o processo de desenvolvimento de software à medida 
que fornece ao cliente uma plataforma completa de desenvolvimento e teste de software, on-line e colaborativa, sem a necessidade de este investir em uma infraestrutura de servidores, licenças de desenvolvimento e bancos de dados, permitindo ao cliente desenvolver uma aplicação sob medida aos seus usuários finais. Os desenvolvedores escrevem suas aplicações em suas linguagens de programação preferidas, então fazem o upload de seus códigos para a nuvem onde a aplicação é executada, sendo essa nuvem tipicamente capaz de escalar para cima, ou para baixo, os recursos computacionais à medida que o número de usuários dessa aplicação varia. Alguns fornecedores desse tipo de serviço são o Tsuru e o Bitnami.

\subsubsection{Infraestrutura como Serviço}

Infraestrutura como serviço, é a camada base do modelo conceitual, a partir da qual foi possível desenvolver os outros modelos de serviço. Através deste modelo de serviço, o consumidor tem acesso a recursos computacionais fundamentais como processamento, armazenamento e rede, dentre outros, onde o consumidor é capaz de implementar e executar softwares arbitrários, que podem incluir sistemas operacionais e aplicações. O consumidor não gerencia ou controla a infraestrutura básica da nuvem, mas tem controle sobre sistemas operacionais, armazenamento e aplicativos implementados e, possivelmente, controle limitado de componentes de rede específicos (e.g., host firewalls).

A infraestrutura como serviço é o modelo que oferece ao usuário uma parcela da infraestrutura da nuvem ${ }^{4}$ como um todo, geralmente através de recursos virtualizados, que podem ser dinamicamente escalados de acordo com as necessidades das aplicações. Algumas vantagens da IaaS são: permitir às empresas focarem em seus negócios, sem preocupações com o gerenciamento e manutenção de uma infraestrutura de TI e sem os

\footnotetext{
4 A infraestrutura da nuvem é a coleção de hardware e software que possibilitam as cinco características essenciais da computação em nuvem. A infraestrutura da nuvem pode ser vista como contendo uma camada física e uma camada de abstração. A camada física consiste dos recursos de hardware que são necessários para suportar os serviços de nuvem providos, e tipicamente inclui servidor, armazenamento, e componente de rede. A camada de abstração consiste do software implementado através da camada física, que manifesta as características essenciais da nuvem, ou seja, a camada de abstração é a camada de software que possui acesso direto ao hardware, a qual permite às camadas de software superiores manipularem a infraestrutura da nuvem por meio de interfaces padronizadas. Conceitualmente a camada de abstração é situada acima da camada física.
} 
custos iniciais para a implantação dessa infraestrutura, visto que os recursos físicos são propriedades do provedor de serviços; redução das paradas por manutenção em equipamento de rede, garantindo uma maior disponibilidade de seus serviços; e utilizar equipamentos que acompanham a evolução tecnológica. Os principais provedores desse tipo de serviço são a Amazon e a Microsoft que também oferecem os outros tipos de serviços em nuvem.

\subsection{Modelos de Implantação}

Os modelos de implantação, ou implementação segundo algumas referências, dizem respeito à exclusividade dos recursos computacionais que são oferecidos para um consumidor de serviços em nuvem, podendo ser classificados como privado, público, comunitário e híbrido. Quanto mais usuários uma nuvem atender, mais baratos serão os serviços oferecidos devido à economia de escala.

\subsubsection{Nuvem pública}

A definição de pública está relacionada à possibilidade de qualquer pessoa poder utilizar sua infraestrutura, mediante o devido pagamento e/ou contrato de utilização, podendo apresentar uma estrutura multi-locatário, onde vários locatários compartilham os mesmos recursos, por vezes o mesmo servidor, distribuindo assim os custos de manutenção/ utilização entre os vários usuários, reduzindo os custos do serviço. Portanto, o conceito de nuvem pública não significa que ela ofereça serviços de maneira gratuita.

A infraestrutura da nuvem é disponibilizada para uso livre pelo público em geral. No entanto, a mesma pode pertencer, ser gerenciada e operada por uma empresa privada, instituição acadêmica ou organização governamental, ou alguma combinação delas. Ela existe nas instalações do provedor de nuvem.

Coloquialmente, o termo computação em nuvem geralmente se refere a nuvens públicas, onde as empresas adquirem os serviços necessários de um provedor especializado ao invés de possuírem e gerenciarem seus próprios data centers. Nesse caso, o hardware hospedeiro e softwares são gerenciados em algum lugar pelo provedor, o que pode levar a certas preocupações de segurança. 


\subsubsection{Nuvem privada}

Algumas grandes empresas preferem adotar outra abordagem chamada nuvem privada, na qual elas consolidam todos os seus diferentes servidores e aplicações em apenas um sistema para toda a companhia, que é mantido por "trás" do firewall da empresa e pode ser acessado através da sua intranet.

Nesse modelo de implementação, a infraestrutura da nuvem é utilizada por apenas uma organização, abrangendo múltiplos utilizadores. Por exemplo, múltiplas unidades de negócio. Ela pode pertencer, ser gerenciada e operada pela própria organização, por uma empresa terceirizada, ou por ambas, podendo existir dentro ou fora das dependências da empresa. Assim, uma empresa pode contratar um serviço de um servidor de nuvem, como a Amazon, e solicitar que determinados servidores sejam utilizados apenas por seus serviços e que toda a comunicação seja feita através de links seguros por intermédio de uma rede virtual privada (Virtual Private Network - VPN), garantindo a exclusividade de uso sobre esses recursos, que embora não pertençam à empresa nem estejam dentro de suas instalações, eles são recursos computacionais exclusivos da empresa.

A principal vantagem da nuvem privada é garantir a confidencialidade e posse dos dados mantendo total controle sobre os processos. No entanto, nesse modelo de implementação, tipicamente, a empresa deve arcar com os gastos de instalação, manutenção e operação de infraestrutura.

\subsubsection{Nuvem comunitária}

Na nuvem comunitária, a infraestrutura da nuvem é provisionada para uso exclusivo por uma comunidade específica de utilizadores, pertencentes a organizações que possuam interesses comuns (e.g., missão, requisitos de segurança, política, e obrigações legais). Ela pode pertencer, ser gerenciada, ou operada por uma ou mais organizações dessa comunidade, por uma empresa terceirizada, ou por alguma combinação delas, e pode existir dentro ou fora das instalações das empresas, como por exemplo em um datacenter alugado de terceiros.

Nesse modelo de implementação, a nuvem é compartilhada por várias organizações que não necessariamente estão ligadas administrativamente entre si, mas que compartilham interesses comuns. Tais interesses podem estar relacionados à conformidade regulatória (e.g., instituições de ensino, hospitais), ou aos requisitos de 
desempenho como velocidade de resposta (e.g., empresas de jogos on-line). Esse tipo de implementação é um meio termo entre uma nuvem privada e uma nuvem pública, tendo a vantagem da economia de escala da nuvem pública, a qual reduz os custos com essa infraestrutura e garante uma maior segurança e controle sobre os dados e processos executados nessa nuvem, semelhante a uma nuvem privada.

\subsubsection{Nuvem híbrida}

Em uma nuvem híbrida, a infraestrutura em nuvem é uma composição de duas ou mais infraestruturas de nuvem distintas (privada, comunitária ou pública) que permanecem entidades únicas, mas são ligadas entre si por tecnologia (padronizada ou proprietária) que permite a portabilidade de dados e aplicações, possibilitando, por exemplo, o cloud bursting para balanceamento de carga entre nuvens. O cloud bursting é a transferência de parte do processamento ou requisitos de armazenamento de uma nuvem privada para uma nuvem pública durante os horários de pico de consumo de recursos, com o objetivo de reduzir ou protelar os custos com investimento em ampliação da infraestrutura proprietária da nuvem privada.

A Figura 6 apresenta um diagrama comparativo entre os modelos de computação em nuvem em termos do nível de abstração de hardware, controle da infraestrutura, flexibilidade de propósito de aplicações, e custos de contratação.

Figura 6 - Comparativo entre os modelos de implantação em computação em nuvem.

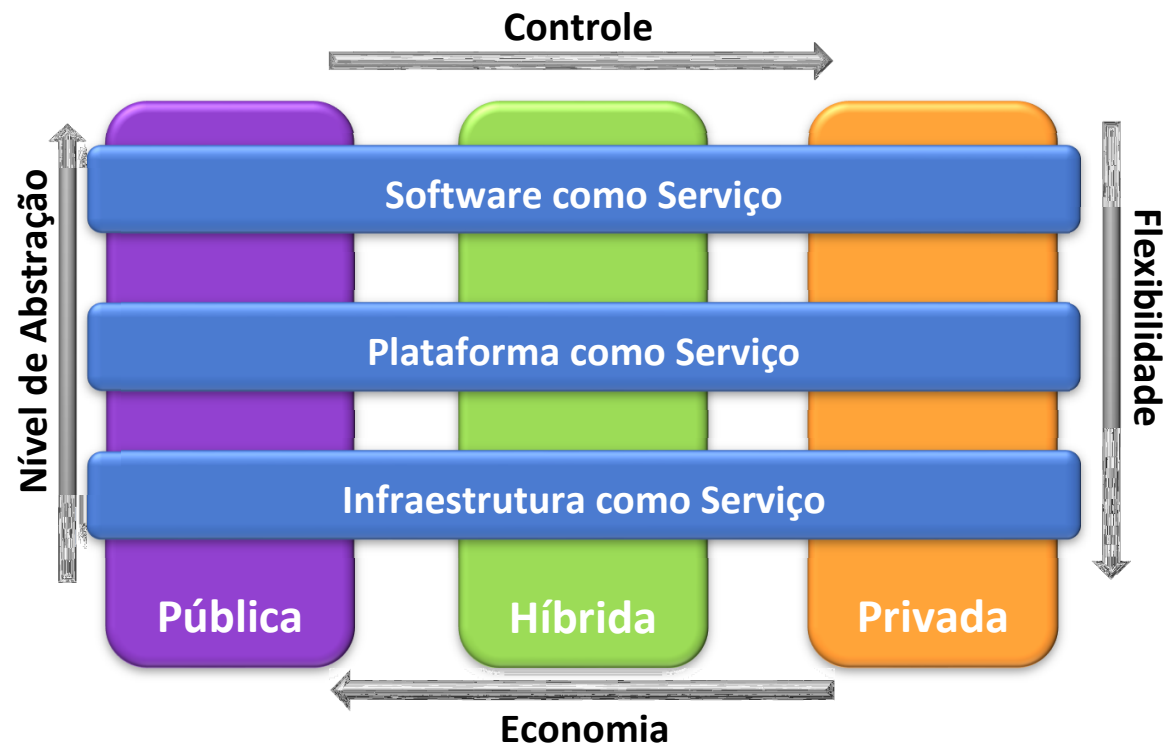

Fonte: adaptado de [127]. 
Quanto mais compartilhados forem os recursos computacionais em uma infraestrutura de nuvem, em um modelo multi-locatário, mais distribuídos serão os custos de operação/manutenção entre os seus utilizadores, diminuindo os gastos para as empresas contratantes, reduzindo em contrapartida o nível de controle sobre o hardware que essa empresa possui, o que pode levar a implicações de segurança e responsabilidade sobre os dados armazenados, portanto um contrato de prestação de serviços (SLA) bem elaborado, definindo limitações, responsabilidades e funcionalidades, é extremamente importante quando da contratação de serviços de computação em nuvem.

A computação em nuvem não é uma solução universal, ela apresenta vantagens e desvantagens e entendê-las é a chave para decidir se ela é a melhor solução para uma necessidade específica. Uma discussão mais específica sobre esse assunto é abordada na seção 3.5 .

\subsection{Tecnologias para computação em nuvem}

Existem várias tecnologias e práticas diferentes utilizadas pelos provedores de serviços em nuvem que possibilitam o desenvolvimento dos diversos tipos de serviços oferecidos. Esta seção aborda algumas dessas tecnologias e apresenta determinadas ferramentas que permitem a implantação da computação em nuvem, a interface com os serviços oferecidos, o processamento e o armazenamento de dados.

\subsubsection{Virtualização}

A computação em nuvem é fundamentada em duas características básicas, abstração e virtualização. A abstração em um contexto mais amplo é a capacidade de concentrar nos aspectos essenciais de um assunto/objeto, ignorando características menos importantes ou triviais. Em computação esse conceito diz respeito a isolar o utilizador dos detalhes de implementação que permitem a utilização de um recurso computacional, somente apresentando ao usuário como utilizar esse recurso sem a necessidade entender como ele funciona internamente.

A virtualização pode ser entendida mais amplamente como a camada de abstração entre os recursos físicos e sua representação lógica. Ela pode ser aplicada a servidores (hardware), armazenamento, aplicativos e redes, sendo assim a base da 
computação em nuvem. Através da virtualização recursos computacionais, podem ser compartilhados dividindo, por exemplo, uma máquina física em múltiplos ambientes de execução, e dessa maneira executar múltiplas tarefas simultaneamente. Além disso, a virtualização também possibilita que múltiplos sistemas discretos, como servidores, dispositivos de armazenamento e outros hardwares possam ser agrupados em um repositório de recursos, permitindo sua alocação sob demanda.

Dentre os principais tipos de virtualização de recursos físicos (servidores), podemos destacar a virtualização de hardware, que é feita por intermédio de um hipervisor e a virtualização no nível de sistema operacional, suportada por alguns sistemas operacionais, que gera os chamados containers.

A virtualização de hardware é feita através de um gerenciador de máquinas virtuais, ou hipervisor. Esse hipervisor oculta do Sistema Operacional (SO) os recursos físicos, atuando como uma camada de abstração de hardware. O hipervisor permite a criação de múltiplos SOs convidados. Cada convidado é executado em unidades de software chamadas de Máquinas Virtuais, (Virtual Machines - VM). Existem diferentes técnicas/métodos de virtualização de hardware, sendo as três mais conhecidas a virtualização total, a para-virtualização, e a virtualização assistida por hardware. Mais detalhes sobre virtualização de hardware são apresentando em [128], [129].

A virtualização no nível de sistema operacional (OS - level virtualization) ou "containerização" é outro tipo de virtualização de recursos físicos, bastante utilizada ultimamente. Ela é possível devido a característica de alguns SO's (como os sistemas Unix-like) permitirem a existência de múltiplas instancias isoladas de espaço do usuário (user-space), dessa maneira essas instâncias chamadas containers podem executar programas de usuários diferentes, em regiões de memória virtualmente isoladas uma das outras, de modo que o programa sendo executado nesses containers tenha a impressão de estar sendo executado em seu próprio hardware de maneira exclusiva.

Diferentemente da virtualização de hardware, em que o acesso ao mesmo é gerenciado pelo hipervisor, a virtualização no nível de sistema operacional, compartilha os recursos do sistema operacional nativo instalado no hardware hospedeiro. Por não precisar instanciar um novo sistema operacional sobre um hipervisor, esse método de virtualização apresenta uma inicialização muito mais rápida que a virtualização de hardware, com a vantagem de estar sendo executado com o desempenho nativo de um hardware real. 


\subsubsection{Hipervisores}

O hipervisor, ou monitor de máquina virtual, é o sistema responsável pela criação e execução das máquinas virtuais. A máquina real, ou o SO, onde o hipervisor é executado é chamado de hospedeiro (host) e cada máquina virtual criada é chamada de convidada (guest). O hipervisor é responsável por gerenciar a execução dos SO's convidados, fornecendo a eles o acesso a uma plataforma de hardware virtual, que imita um hardware real, com processador, memória, armazenamento, etc. Várias instâncias de SO's diferentes (Windows, Linux, etc.) podem compartilhar os recursos de hardware virtualizados pelos hipervisores, diferentemente da virtualização em nível de SO, que apenas compartilha os recursos SO hospedeiro.

Os hipervisores podem ser classificados em hipervisores do Tipo 1 e hipervisores do Tipo 2. Hipervisores do Tipo 1 são executados diretamente sobre o hardware hospedeiro, não havendo intermediários entre a camada física e o hipervisor. Hipervisores do Tipo 2 são executados sobre um sistema operacional hospedeiro, como um programa qualquer, geralmente utilizando o SO hospedeiro como um intermediário para acesso ao hardware. A utilização de um intermediário para acesso ao hardware costuma degradar o desempenho em relação aos hipervisores do Tipo 1. Alguns hipervisores embora sejam instalados sobre um SO hospedeiro, o que os caracterizariam como do Tipo 2, utilizam uma técnica de virtualização assistida por hardware, em que o hipervisor concede acesso direto ao hardware para o SO convidado eliminando o problema de desempenho anteriormente citado [128].

Alguns exemplos de hipervisores comumente utilizados em computação em nuvem são apresentados na Tabela 3.

Tabela 3 - Hipervisores comumente utilizados em computação em nuvem

\begin{tabular}{cccc}
\hline Hipervisor & Tipo & Desempenho do Guest & Licença \\
\hline \multirow{2}{*}{ KVM } & $\begin{array}{c}\text { Tipo } 2 \text { assistido por } \\
\text { hardware }\end{array}$ & Próximo ao nativo & Open Source \\
Xen & Tipo 1 & Nativo & Open Source \\
VMware & $\begin{array}{c}\text { Tipo } 2 \text { assistido por } \\
\text { hardware }\end{array}$ & Próximo ao nativo & Proprietária \\
\hline
\end{tabular}

Fonte: adaptado de [128]. 


\subsubsection{Containers vs. VMs}

Diferentemente das Máquinas Virtuais (Figura 7), os containers não criam uma cópia virtual do hardware do host, nem necessitam que um SO completo seja instalado neles. Eles funcionam diretamente sobre o hardware físico do host, aproveitando o kernel do SO utilizado pelo host, exigindo apenas alguns softwares de poucos bytes, bibliotecas e o básico de um SO para operarem. Vários containers podem funcionar numa mesma máquina compartilhando o kernel do SO com outros containers, cada um sendo executado de maneira isolada, dessa forma eles ocupam muito menos espaço em disco que uma VM e inicializam quase que instantaneamente.

Figura 7 - Comparação entre containers e máquinas virtuais.

\begin{tabular}{|c|c|c|}
\hline Aplic. 1 & Aplic. 2 & Aplic. 3 \\
\hline Bins/Libs & Bins/Libs & Bins/Libs \\
\hline SO Guest & SO Guest & SO Guest \\
\hline & Hipervisor \\
\hline & Sistema Operacional Host \\
\hline
\end{tabular}

Máquinas virtuais

\begin{tabular}{|c|c|c|}
\hline Aplic. 1 & Aplic. 2 & Aplic. 3 \\
\hline Bins/Libs & Bins/Libs & Bins/Libs \\
\hline & Runtime do Container \\
\hline & Sistema Operacional Host \\
\hline
\end{tabular}

\section{Containers}

Fonte: adaptado de [130]

Um container pode ser entendido como um compartimento dentro do SO host, com acesso a uma parte dos recursos computacionais do hospedeiro, limitados durante o provisionamento do container pelo seu gerenciador.

Os containers permitem a virtualização de aplicações sem a necessidade de virtualização de um sistema operacional sobre um hardware virtual, no entanto apresentam a limitação de estarem vinculados ao kernel do SO hospedeiro não possibilitando a instalação de um SO diferente como as VM's.

Containers geralmente são utilizados quando se deseja provisionar rapidamente um serviço. Cada container pode abrigar uma ou várias aplicações e até mesmo um SO, desde que esse SO compartilhe o mesmo kernel do SO host. A escolha entre um container e uma VM depende muito da aplicação, podendo ambas as soluções serem adotadas em conjunto, inclusive podendo um container ser executado dentro de uma 
VM. Os principais gerenciadores de containers são: (1) o kubernetes da Google, voltado para o provisionamento e gerenciamento de grupos de containers [131]; (2) o Docker container engine da Docker, direcionado para virtualização de aplicações [132]; (3) e o LXD mantido pela Canonical, mais interessante para virtualizar SO's Linux em containers [133].

\subsubsection{Gerenciadores de infraestrutura de nuvem}

Os gerenciadores de infraestrutura de nuvem são os responsáveis por gerenciar toda a infraestrutura virtual de maneira eficiente, fornecendo as funcionalidades básicas para criação (deploying), controle e monitoramento das VM's sobre um repositório de recursos por intermédio de comunicação com o hipervisor [128]. Esse repositório de recursos pode ser desde um único servidor até um conjunto de data centers.

Tais gerenciadores, geralmente possuem interfaces de programação (Application Programming Interface - API) que permitem o controle da infraestrutura programaticamente, além de possuírem algum tipo de interface visual (geralmente uma página Web) e interfaces de linha de comando. Os gerenciadores de infraestrutura de nuvem, open-source, mais utilizados são o OpenStack [134], e o OpenNebula [135].

O projeto OpenStack surgiu como uma iniciativa da NASA (agência espacial americana) em conjunto com a empresa Rackspace Hosting, tendo sua primeira versão lançada em outubro de 2010. Ele apresenta uma estrutura modular composta de diversos serviços/componentes, que comunicam entre si para fornecerem as funcionalidades da plataforma [136]. Cada componente é desenvolvido em um projeto diferente com equipes de desenvolvimento distintas. Dentre esses componentes o mais importante é o Nova, desenvolvido em Python, que é o gerenciador dos recursos computacionais através da comunicação com os outros componentes e com os hipervisores (KVM, Xen, VMware, Hyper-V). Além do Nova podemos destacar o Neutron responsável pelos serviços de rede, o Keystone responsável pela autenticação dos usuários, o Cinder que gerencia os dispositivos de armazenamento de blocos (como os HDs por exemplo), o Swift responsável pelo armazenamento de dados arbitrários (dados estáticos como imagens ISO por exemplo, pois são armazenados como objetos), o Glance que gerencia o repositório de imagens de disco (cópias dos programas e SO's) que serão utilizadas para a criação das máquinas virtuais, e o Horizon que fornece a interface Web para controle da infraestrutura. Justamente por possuir vários módulos 
independentes que necessitam operar em conjunto o OpenStack é visto como uma plataforma difícil de ser instalada e configurada, quando comparado com outras soluções semelhantes.

O OpenNebula teve seu início em 2005, como um projeto de pesquisa, pelos professores Ignacio Martin Llorente e Ruben Santiago Montero ambos da Universidade Complutense de Madri, na Espanha, com sua primeira versão pública lançada em 2008. Dentre os objetivos do projeto está "Desenvolver uma solução mais simples, poderosa, altamente escalável e adaptável para criar e gerenciar data centers virtualizados e nuvens empresariais" [137]. O OpenNebula é disponibilizado como um pacote único que engloba todas as funcionalidades principais para computação em nuvem, armazenamento e rede reduzindo sua complexidade de instalação. O núcleo do sistema foi desenvolvido em $\mathrm{C}++$, com algumas funcionalidades implementadas em Ruby, Java e bash script.

Uma característica importante que diferencia o OpenNebula de seus concorrentes é a capacidade de contextualização, a qual permite que parâmetros de configuração das VMs (como DNS, hostname, ou até mesmo chaves de criptografia SSH) sejam modificadas durante a etapa de inicialização (boot), permitindo a configuração automática dos serviços através de templates o que facilita a criação de serviços horizontalmente escaláveis. A contextualização facilita a inicialização de serviços permitindo que sejam instanciados e executados de maneira automática.

Além das funcionalidades básicas outras funcionalidades adicionais (Add-on), disponíveis pela comunidade, podem ser agregadas à plataforma. Atualmente o gerenciador suporta por padrão os hipervisores KVM e VMware, sendo possível adicionar outros através de $A d d$-on.

Por atender aos requisitos necessários para a implementação de uma infraestrutura de nuvem, aliado às funcionalidades e facilidades apresentadas, o OpenNebula foi utilizado como gerenciador de infraestrutura neste trabalho.

\subsubsection{OpenNebula}

O gerenciador de infraestrutura OpenNebula permite a construção de nuvens privadas, públicas e híbridas, de maneira versátil, flexível e personalizável. Ele possui uma interface Web para gerenciamento chamada SunStone (Figura 8), e outra em linha de comandos, além de uma API baseada em XML-RPC, que permite a integração com 
outros softwares e também que a infraestrutura seja controlada programaticamente. O OpenNebula foi projetado para ser integrado à diversos tipos de rede e dispositivos de armazenamento podendo ser adaptado à qualquer datacenter [138].

Figura 8 - Interface Web de configuração do OpenNebula

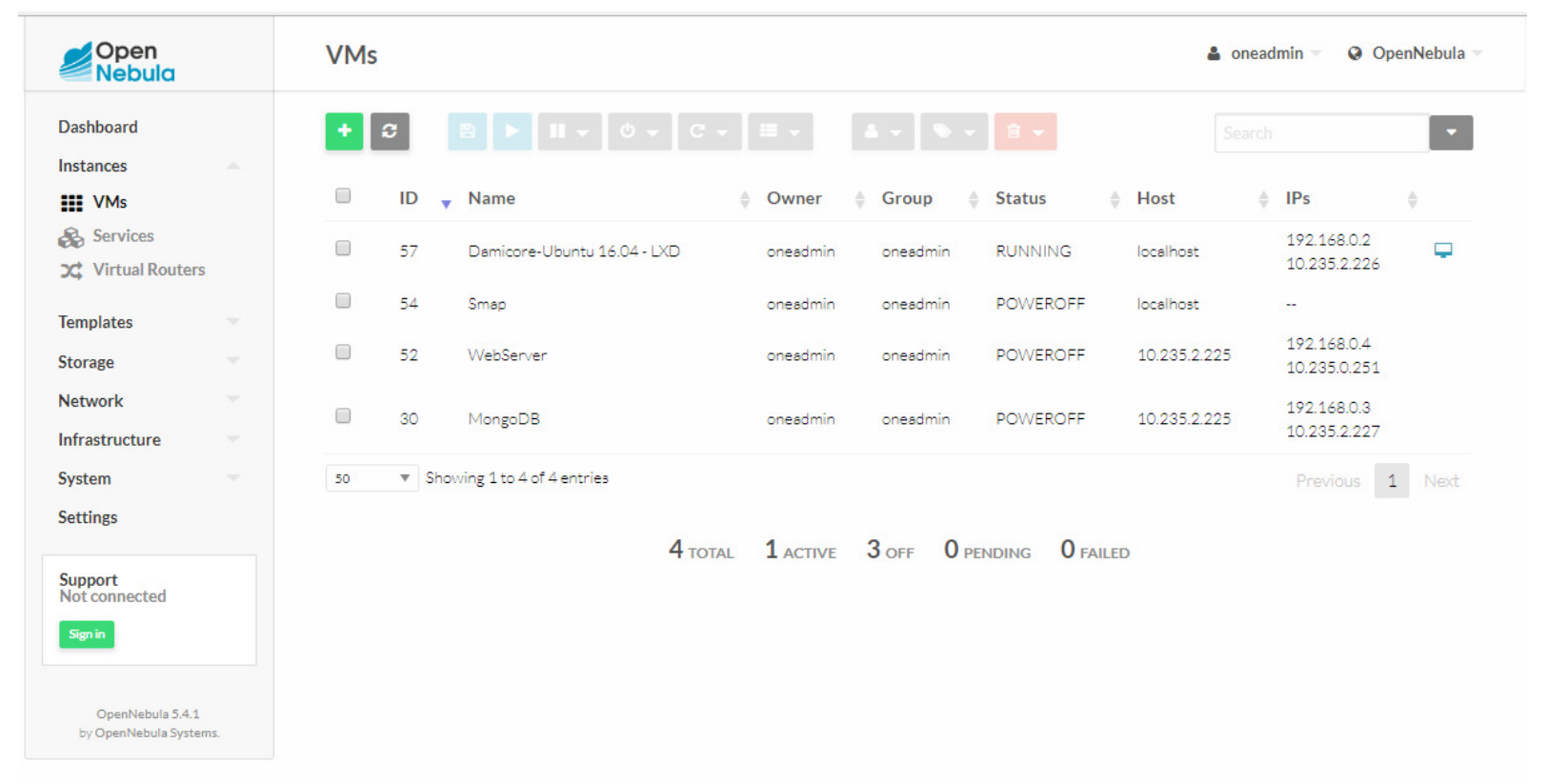

Fonte: Elaborado pelo autor.

Uma funcionalidade interessante apresentada pelo OpenNebula é a possibilidade de monitorar, controlar e criar aplicações ou serviços multicamadas compostos de máquinas virtuais interconectadas através do componente OneFlow. O OneFlow também permite a criação políticas de auto-scaling baseadas em métricas de desempenho e agendamento, além da criação de coleções de aplicações onde grupos de VM's são instanciados e gerenciados como uma entidade única.

Através do componente OneGate, o OpenNebula permite que VM's enviem e coletem informações de outras máquinas virtuais em execução, de forma que os usuários e administradores possam utilizar essas informações para coletar métricas, detectar problemas em seus aplicativos e disparar as regras de elasticidade ${ }^{5}$ do OneFlow de dentro da VM.

O OpenNebula adota uma arquitetura de funcionamento com um servidor de gerenciamento chamado de front-end, responsável por gerenciar toda a infraestrutura

\footnotetext{
${ }^{5}$ Elasticidade se refere à capacidade de ajustar os recursos computacionais consumidos sob demanda, conforme apresentado em 3.1.4.
} 
de nuvem, e um conjunto de nós (servidores) onde serão executadas as máquinas virtuais, conforme esquematizado na Figura 9. O front-end é composto pelo serviço básico de gerenciamento / agendamento de tarefas (ONED), pelos diversos drivers de virtualização, monitoramento e rede, além de um gerenciador de imagens.

Figura 9 - Ambiente de execução do OpenNebula

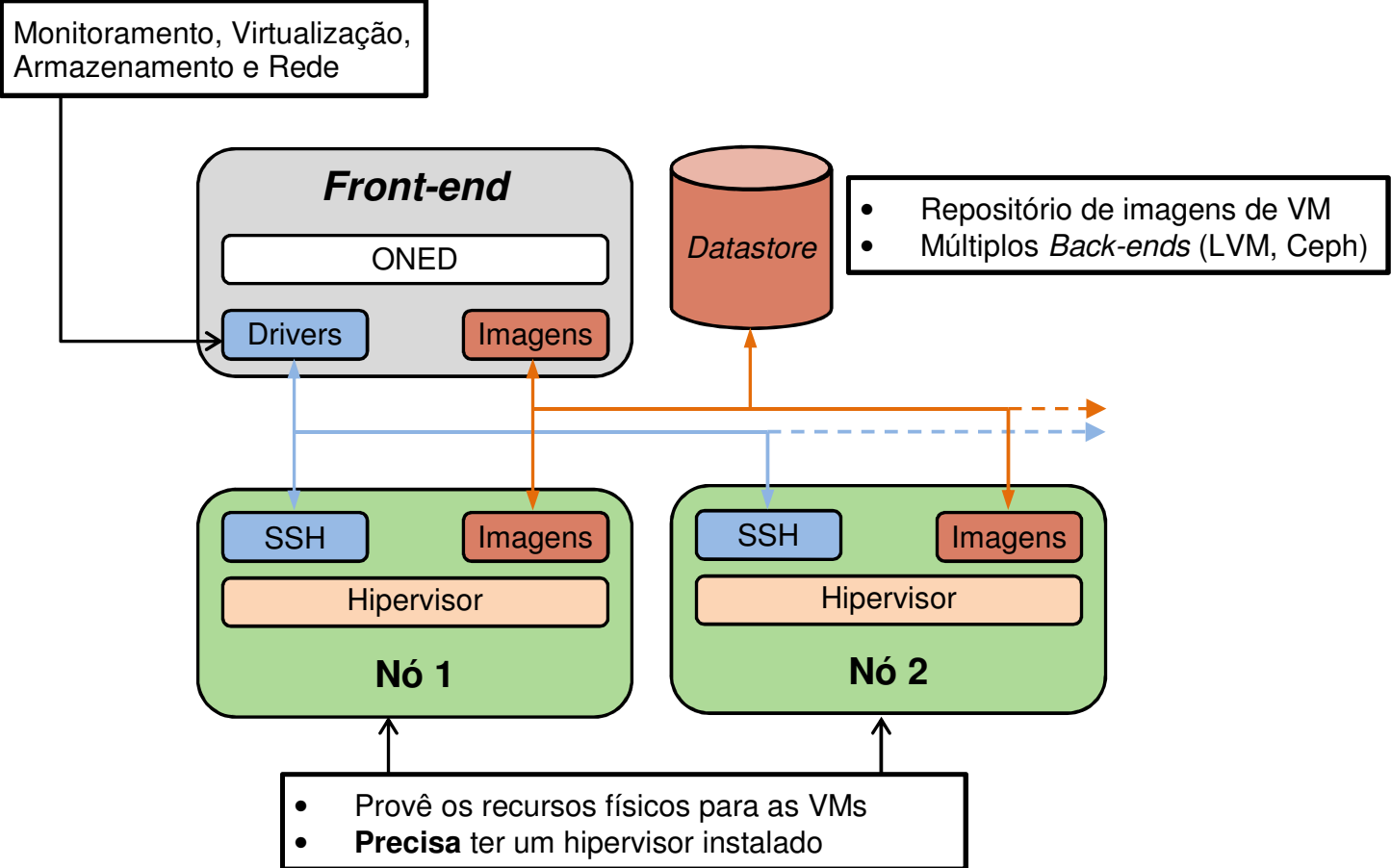

Fonte: adaptado de [139]

O OpenNebula também permite a virtualização dos serviços de rede, atribuindo os IPs previamente determinados às respectivas máquinas virtuais por contextualização, ou através da criação de um serviço especial de roteador virtual (vRouter) o qual permite a configuração automática de uma variedade de serviços de rede como servidores DHCP, servidores NTP, Firewall, servidores DNS, roteador, dentre outros.

O OpenNebula apresenta uma extensa documentação disponível em http://docs.opennebula.org/pdf/5.4/, bastante completa, além fóruns de usuários onde os usuários se auxiliam sanando dúvidas, trocando experiências, e relatando problemas e eventuais soluções.

\subsubsection{Armazenamento de dados e processamento em nuvem}

De maneira geral, uma solução de armazenamento de dados deve ser capaz de guardá-los de forma adequada e eficiente pelo tempo que for necessário sem que haja 
perda ou corrupção dos mesmos. A escolha de uma solução de armazenamento de dados deve levar em consideração as características dos dados que serão armazenados, a frequência com que serão acessados, alterados e/ou apagados, buscando operar da maneira mais eficiente possível.

Sistemas de gerenciamento de bancos de dados tradicionais baseados em SQL, chamados de banco de dados relacionais, Relational Data Base Management System (RDBMS), foram projetados inicialmente para trabalharem com dados que precisavam ser frequentemente alterados, garantindo a integridade dos dados a cada transação [140]. Eles apresentam um bom desempenho para as tarefas de busca, alteração e inserção de dados, no entanto não foram concebidos para armazenar dados que tendem a crescer indefinidamente, ou que não tenham uma forma de organização (esquema/modelo) que possa ser definida durante o projeto do banco de dados. Quando consideramos dados que crescem indefinidamente com o passar do tempo, essas soluções de armazenamento de dados tradicionais não são tão eficientes, apresentando perda de desempenho com relação ao espaço e à velocidade de armazenamento [54], [55], [141]. Como alternativa aos bancos de dados relacionais, chamados corriqueiramente de bancos de dados SQL, foi desenvolvida uma nova classe de bancos de dados chamados NoSQL, que visavam superar as limitações impostas pelos bancos de dados relacionais [142].

NoSQL (Not Only SQL) é um termo genérico usado para descrever uma classe de bancos de dados não relacionais de alto desempenho. Eles geralmente são utilizados para armazenamento de grandes volumes de dados, por serem horizontalmente escaláveis, apresentando baixa latência na execução de consultas. Esses bancos de dados possuem modelos flexíveis de armazenamento de dados, pois normalmente não apresentam um esquema rígido como os bancos de dados relacionais. Os bancos de dados dessa classe utilizam diversos modelos de dados para armazenamento da informação, incluindo grafos, documentos, chave-valor, colunas, objetos, etc. [143]$[145]$.

Bancos de dados orientados a documentos, por exemplo, são bancos de dados projetados para manipular dados semiestruturados. Diferentemente dos bancos relacionais que armazenam as informações em tabelas separadas com esquemas rígidos, definidas pelo programador, em que determinada informação pode estar espalhada por várias tabelas, num banco de dados orientado a documentos, toda a informação (de um 
mesmo registro) está armazenada em uma única instância (arquivo) no banco de dados. Cada documento é autossuficiente e contém todos os dados que possa precisar sem a necessidade de fazer junções de dados de várias tabelas, e cada arquivo (documento) pode ser diferente um do outro, reduzindo o espaço de armazenamento e o tempo para consulta em relação a um banco de dados relacional.

Um banco de dados de séries temporais (Time series database - TSDB) é um software especializado em manipular séries temporais (valores que são coletados sequencialmente em relação ao tempo, como os dados provenientes de medições), nele os dados armazenados são indexados com relação ao tempo, diferente dos bancos de dados relacionais onde os índices podem ser diferentes tipos de dados desde que esses dados não se repitam na coluna de referência.

É preciso deixar claro que tais bancos de dados não têm como objetivo substituir os bancos de dados relacionais, mas oferecer uma alternativa mais adequada para determinadas situações, podendo inclusive ser utilizado de forma complementar implementando alguma solução híbrida [146].

Existem inúmeros bancos de dados NoSQL, com diferentes estratégias de armazenamento, sejam elas, orientadas a documento (mongoDB, CouchDB, etc.), destinadas ao armazenamento de séries temporais (OpenTSDB, etc.), orientadas a par chave-valor (Riak, Redis, etc.), orientadas por colunas (Cassandra, Hbase, etc.) [142]. Esses bancos de dados geralmente apresentam características de desempenho melhores em relação aos bancos de dados relacionais quando considerada a especificidade dos dados/ aplicações, por exemplo:

$\square$ Sistemas em que a velocidade de acesso aos dados é crítica, que exigem leituras e escritas rápidas, podem utilizar um banco de dados em memória;

$\square$ Dados que não tem uma formatação rígida, geralmente de diferentes fontes de dados, são melhores atendidos por bancos de dados orientados a documentos ou objetos;

$\square$ Dados com aquisição periódica, como os dados de medição e monitoramento, se adaptam melhor a bancos de dados de séries temporais;

$\square$ Dados potencialmente massivos, da ordem de petabytes de informação, que serão utilizados para data analytics, como em ferramentas de predição, 
podem ser armazenados em bancos de dados orientados a colunas com tecnologia bigtable ${ }^{6}$ para serem processados posteriormente por MapReduce.

Mais detalhes sobre bancos de dados NoSQL com alguns comparativos e sugestões de uso podem ser encontrados em [54], [146]-[149].

Ao desenvolver um sistema de banco dados em nuvem, uma consideração importante para a escolha da estratégia de armazenamento está relacionada à localização física dos dados: se o dado será armazenado de forma centralizada (em um único servidor) ou distribuída (em diversos servidores espalhados pela rede). Essa escolha irá depender da quantidade de dados que se pretende armazenar e do nível de redundância desejado. O armazenamento distribuído apresenta certas vantagens em relação ao armazenamento centralizado, como a ausência de um ponto de falha único (geralmente os dados são replicados em diversos servidores), porém podem apresentar inconsistências locais (em relação aos demais nós) e geralmente são mais lentos durante a atualização dos dados [150].

Para armazenar esses dados de maneira distribuída é preciso utilizar algum tipo de sistema de arquivos distribuído, Distributed File System (DFS). Alguns bancos de dados distribuídos já possuem um DFS embutido e outros utilizam softwares de terceiros. Ferramentas como o GlusterFS7 ou o $\mathrm{Ceph}^{8}$, que provêm um sistema de armazenamento distribuído de forma transparente para as aplicações, podem ser utilizadas para prover armazenamento distribuído para bancos de dados que não tenham sido desenvolvidos nativamente com essa funcionalidade.

Com relação ao processamento dos dados, diversos fatores devem ser considerados, tais como: em quanto tempo o dado precisa ser analisado; se esse dado após analisado será armazenado ou descartado; se o dado a ser analisado é proveniente de um fluxo de dados ou está armazenado em um banco de dados; etc. Essas considerações definirão o melhor tipo de processamento a ser adotado, sendo que algumas dessas estratégias estão intimamente relacionadas ao modelo de armazenamento utilizado.

\footnotetext{
${ }^{6}$ https://cloud.google.com/bigtable/

${ }^{7}$ https://www.gluster.org/

${ }^{8}$ https://ceph.com/
} 
Quando se trata de dados massivos (Big Data), com tamanhos variando de terabytes a zetabytes, provenientes de diversas fontes, estruturados de maneiras distintas (ou desorganizados), podem ser utilizados modos de processamento diferentes dependendo se a análise será feita por partes (em lotes) ou em tempo real (de maneira contínua, como um fluxo) [50],[151]. O processamento em lote trata o volume e a variedade dos dados enquanto o processamento em tempo real geralmente analisa os dados à medida em que são recebidos, processando fluxos contínuos e ilimitados de dados. Esse tipo de processamento é chamado stream processing (processamento em fluxo, em tradução livre).

O processamento em lote mais comumente utilizado é o baseado em MapReduce, que se beneficia do processamento paralelo para processar grandes quantidades de dados através de clusters de computadores. O MapReduce cujo nome é derivado das duas principais funções utilizadas em seu algoritmo (Map e Reduce) é um modelo de programação introduzido pela Google em 2004, no entanto diversas implementações open-source foram desenvolvidas sendo a mais famosa delas disponível no Apache Hadoop [152], [153].

O Apache Hadoop é um conjunto de ferramentas open-source para computação distribuída, mantido pela Apache Software Foundation ${ }^{9}$. O núcleo do sistema é composto por um sistema de arquivos distribuídos chamado Hadoop Distributed Filesystem (HDFS) e pelo ambiente de execução paralela do MapReduce. Dentro desse framework existem outros subprojetos, como por exemplo o HBase, que é um banco de dados distribuído NoSQL capaz de lidar com enormes conjuntos de dados com bilhões de linhas e milhões de colunas executado sobre o HDFS.

Além do Hodoop existem outros frameworks para processamento paralelo em lote de dados massivos, como por exemplo, o Apache Spark, que clama ser até 100 vezes mais rápido que o Hadoop/MapReduce quando executado em memória e 10 vezes mais rápido executando em disco [154], [155], e o Apache Flink que é um framework de processamento em fluxo que também pode ser usado para processamento em lote [156].

Ferramentas de processamento em lote geralmente não são indicadas para aplicações com requisitos de tempo real muito restritos, por exemplo, quando os dados são recebidos de maneira contínua e precisam ser processados rapidamente [53]. Para

\footnotetext{
${ }^{9}$ https://www.apache.org/
} 
esses casos uma solução mais adequada seria a utilização de um stream processing, que pode ser aplicada a fluxos de dados de alta velocidade.

Existem diversas ferramentas para processamento em fluxo, dentre elas o Apache Storm e o Apache Samza que são sistemas de computação distribuídos, para processamento em tempo real, gratuitos e de código aberto [157], [158]; e o Spark Streaming, que é um componente do framework Spark para processar micro lotes de arquivo em tempo real [159]. A Figura 10 apresenta uma classificação para as principais tecnologias de processamento de dados em Big Data com relação à velocidade e ao volume de dados. Mais informações sobre processamento em fluxo com alguns comparativos e sugestões de uso podem ser encontradas em [151], [160]-[163].

Figura 10 - Principais Frameworks para Big Data.

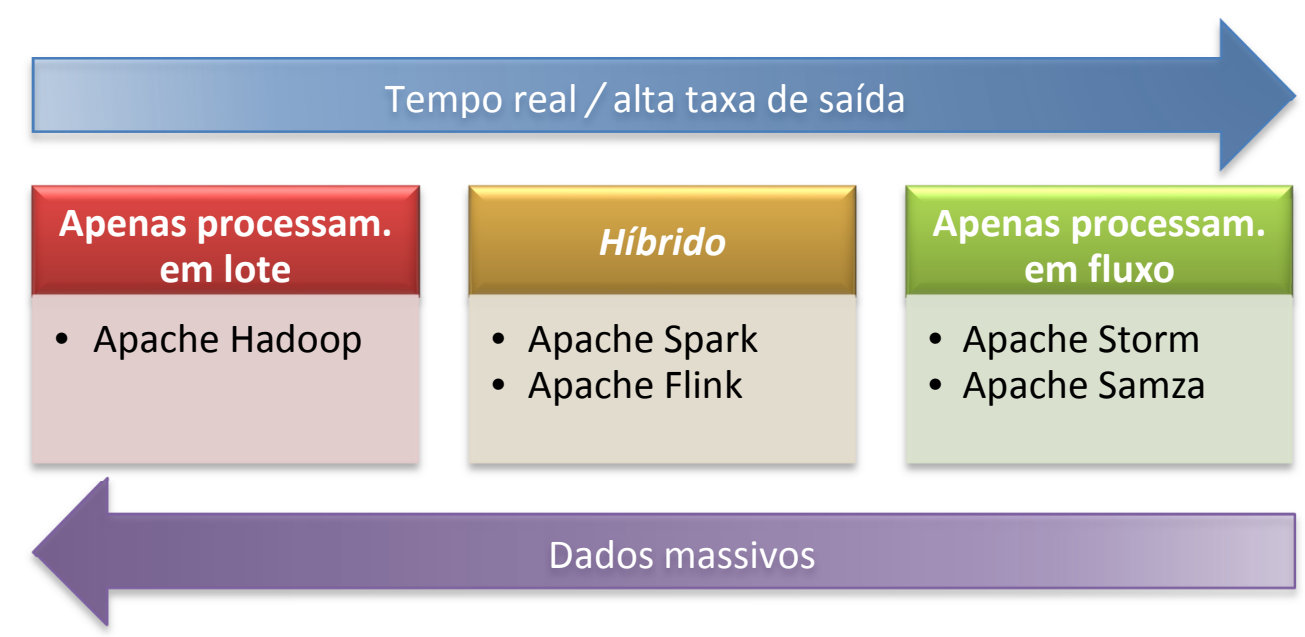

Fonte: Elaborada pelo autor.

\subsubsection{Serviços Web}

Serviços Web são o ponto chave para a integração das diferentes plataformas e sistemas em um ambiente de CC, possibilitando a comunicação entre diferentes aplicações desenvolvidas utilizando tecnologias distintas, as quais podem estar sendo executadas em diferentes locais. Por meio dos serviços Web é possível enviar e receber dados das aplicações, utilizando uma linguagem padrão comum como intermediária.

O World Wide Web Consortium (W3C) define web services como um sistema de software projetado para apoiar a interação máquina-máquina interoperável sobre uma rede [164]. De maneira geral um web service é um software executado remotamente, em um sistema que hospeda os serviços, solicitados sob demanda quando invocado a partir 
de um web browser por meio de um URI, ou via um código cliente através de um conjunto de regras pré-definidas (APIs).

Os serviços Web são identificados por um identificador universal de recursos, (Universal Resource Identifier - URI). Esse URI é um conjunto de caracteres que identifica unicamente um recurso, permitindo a interação com o mesmo através de uma rede, utilizando protocolos específicos.

Em um serviço Web as mensagens trocadas entre as aplicações são transformadas em um formato intermediário que pode ser serializado e transmitido através da web utilizando tecnologias como o HTTP para o transporte dos dados. Os principais formatos utilizados são o JSON e o XML.

JSON é um acrônimo para JavaScript Object Notation e é um formato leve para troca de dados estruturados através da rede, muitas vezes utilizado como uma alternativa ao XML por ser mais compacto e exigir menos processamento para interpretação dos objetos encapsulados. Embora baseado e um subconjunto do JavaScript ele é considerado um formato independente de linguagem, possuindo bibliotecas para geração e interpretação dos dados disponíveis para várias linguagens de programação [165].

A Extensible Markup Language (XML) é uma linguagem de marcação, semelhante ao HTML, que define um conjunto de regras para codificação de um documento, capaz de descrever diversos tipos de dados, de maneira simples e legível tanto para humanos quanto para computadores. Por ser baseado em texto, assim com o JSON, a XML também é independente da plataforma utilizada. Ela organiza os documentos de forma hierárquica permitindo a criação ilimitada de tags, permitindo também a criação de arquivos para validação da estrutura desses documentos.

Existem diversas tecnologias que possibilitam a troca dessas mensagens entre as aplicações, as principais utilizadas para o desenvolvimento de interfaces web são o SOAP, XML-RPC e o REST,

O XML-RPC é uma especificação e um conjunto de implementações que permitem que softwares rodando em diferentes sistemas operacionais, em ambientes diferentes façam chamadas de procedimentos pela internet, utilizando HTTP como transporte e XML como codificação [166]. Ele foi projetado para ser tão simples quanto possível, permitindo que estruturas de dados complexas sejam transmitidas, processadas e retornadas. 
O SOAP, originalmente um acrônimo para Simple Object Access Protocol que foi descartado na versão 1.2 do SOAP, é um protocolo baseado em XML que consiste em três partes: um envelope que define uma estrutura para descrever o que está em uma mensagem e como processá-la, um conjunto de regras de codificação para expressar instâncias de tipos de dados definidos pela aplicação e uma convenção para representar chamadas de procedimento remoto e respostas [167].

De uma perspectiva de alto nível o XML-RPC e o SOAP são protocolos muito similares. Ambos utilizam XML para o encapsulamento de chamadas de procedimentos remotos, Remote Procedure Calls (RPC), baseadas no método request-response. No entanto o XML-RPC tem uma arquitetura mais simples, podendo ser descrito como um subconjunto das funcionalidades do SOAP. Por exemplo, em termos de protocolo de transporte o XML-RPC só pode fazer requisições utilizando uma conexão HTTP/ HTTPS, o SOAP por sua vez, embora comumente use HTTP/ HTTPS, é independente do protocolo utilizado, podendo ser executado sobre vários outros protocolos. Em termos de segurança o XML-RPC utiliza apenas a autenticação de acesso básica do protocolo HTTP, enquanto o SOAP permite uma gama maior de implementações de segurança.

O REST (Representational State Transfer), ou paradigma da Transferência de Estado Representativo, fornece uma alternativa ao RPC, e é construído em torno da ideia de "recursos". O REST é um estilo de arquitetura que define um conjunto de restrições e propriedades baseado em HTTP, descrito por Roy Fielding em [168], permitindo aos agentes (softwares) envolvidos fornecerem uma semântica de interface uniforme utilizando a tecnologia já existente nos protocolos da web, ao invés de criar interfaces arbitrárias ou específicas da aplicação.

Um recurso web é basicamente um recurso que pode ser acessado e manipulado através da web. Esse recurso pode ser a representação de algum objeto, uma função, uma página web, etc. Eles são unicamente identificados por seus URIs. Quando uma requisição é feita a um URI de um recurso web, o mesmo retornará uma resposta textual representando o estado de um recurso. Essa resposta pode ser a confirmação de alguma alteração solicitada, o conteúdo do recurso acessado, etc., utilizando para isso algum formato padrão de representação, como XML, HTML, JSON, dentre outros.

Uma aplicação web REST apresenta uma abordagem de projeto diferente de uma aplicação baseada em RPC, como o SOAP e o XML-RPC. Enquanto o RPC 
enfatiza a diversidade de operações do protocolo (funções), em REST a ênfase está na diversidade de recursos (nomes).

Serviços Web que obedecem ao estilo arquitetural REST, ou serviços Web RESTful, fornecem interoperabilidade entre sistemas de computadores na Internet utilizando um conjunto uniforme e predefinido de operações sem estado (stateless ${ }^{10}$ ) para a manipulação de recursos web.

No REST, geralmente o HTTP é utilizado como interface para acesso aos recursos, utilizando, por exemplo, as requisições GET, POST, PUT, DELETE para a manipulação dos mesmos. Neste caso, cada verbo HTTP é mapeado para uma operação específica sobre o recurso, por exemplo, o método GET poderia ser utilizado para retornar o conteúdo de um objeto, o método DELETE para excluí-lo, o POST e o PUT para modificar ou criar um objeto, etc.

\subsection{Desafios e Ponderações}

Embora a computação em nuvem apresente diversas vantagens em relação à computação tradicional, algumas precauções devem ser tomadas com relação à tecnologia. A principal preocupação que se deve ter é com relação à conexão com a rede, uma vez que todos os serviços são oferecidos remotamente, é necessária uma conexão estável, sempre disponível para ser acessada, conectando serviços e clientes.

Outra questão diz respeito ao atraso de comunicação inerente aos sistemas em rede, e a garantia de entrega de dados, que podem ser fatores cruciais em aplicações críticas, que possuem requisitos de tempo real muito restrito, uma vez que a comunicação geralmente é feita pela Internet, onde a troca de dados em tempo real com alta probabilidade de entrega não é facilmente alcançada.

Ao transportar dados através de redes públicas como a Internet, há algumas preocupações sobre segurança e privacidade que não podem ser negligenciadas, a fim de garantir a integridade dos dados e a privacidade das informações, e devem ser abordadas ao utilizar a computação em nuvem para o desenvolvimento de aplicações em sistemas de distribuição inteligentes. Nesse caso, a utilização de mecanismos de segurança como autenticação, gerenciamento da confiança (trust management),

${ }^{10}$ Não depende do estado das interações/requisições anteriores. 
criptografia e deteç̧ão de invasão (intrusion detection) podem prevenir ataques, aprimorando a segurança dos dados. Este tema é bastante discutido em [5], [6], [16], [60], [169]-[171].

Um dos fatores que afetam o nível de segurança e privacidade é o modelo de implantação de nuvem utilizado. Dependendo da situação, há um compromisso entre segurança e compatibilidade versus complexidade e custo, relacionado a nuvens privadas e nuvens públicas $[15,79]$. As nuvens públicas apresentam algumas vantagens em relação às nuvens privadas como, menor custo operacional, não exigem um investimento inicial, possui alta escalabilidade, facilidade de acesso, com risco de negócio e despesas de manutenção reduzidos, no entanto são mais propensas à ataques cibernéticos, uma vez que o hardware físico, que é geralmente compartilhado, está sob responsabilidade de outra empresa que não a concessionária, podendo estar espalhado em diversas localidades [63]. Por outro lado, esse espalhamento dos dados ao longo de diferentes localidades ao redor do mundo tende a melhorar a capacidade de recuperação de desastres desses dados, uma vez que, no caso de alguma catástrofe natural destruir os dados localizados em uma região específica, esses dados ainda estariam disponíveis em outra localidade.

Para se resguardar de possíveis eventualidades, é improvável que uma concessionária de energia elétrica terceirize todas as funções de gerenciamento de informações para uma nuvem pública. Nesse caso, pode ser mais interessante adotar um modelo híbrido para aproveitar a economia de escala oferecida pelas nuvens públicas, ao mesmo tempo preservando a segurança dos dados críticos presentes nas nuvens privadas.

Ao terceirizar a computação e o armazenamento para um provedor de serviços externo, é interessante que o contrato de serviços (SLA), entre a concessionária e o provedor, leve em consideração fatores de risco como segurança, desempenho e confiabilidade [171]. De uma maneira geral, os SLAs não abrangem aspectos, como confidencialidade e integridade dos dados, os quais requerem certa atenção.

Para avaliar os riscos relacionados a desempenho e a confiabilidade algumas questões podem ser levantadas [16]:

$\square$ Se o desempenho dos serviços em nuvem oscilar, como isso afetará a empresa? 
$\square$ Como a latência e a variação na latência afetariam as experiências dos clientes?

$\square$ Quanta latência é aceitável?

$\square$ E se o sistema ficar inativo por algumas horas?

$\square$ Se o sistema cair, dados importantes serão perdidos?

Essas perguntas podem ajudar a planejar o que terceirizar e quando terceirizar. Em alguns casos, a concessionária pode preferir usar uma nuvem pública somente quando a demanda por recursos computacionais for alta, transferindo parte do processamento para servidores externos em momentos de pico, fazendo cloud bursting. Outras considerações relativas à computação em nuvem foram abordadas pelo Smart Grid Interoperability Panel (SGIP) em [173], que podem ajudar a criar um SLA mais efetivo para aplicações em Smart Grids.

Utilizando uma infraestrutura de computação em nuvem apropriada diversas aplicações em sistemas de distribuição inteligente podem ser desenvolvidas, em diversas áreas como gerenciamento pelo lado da demanda, resposta à demanda, monitoramento e controle do sistema de energia, análise do sistema de energia, simulação do sistema e estimação de estado, previsão de demanda e análise do perfil de consumo, entre outros.

O próximo capítulo apresentará uma proposta de arquitetura de computação em nuvem básica e expansível, para ser utilizada pelas aplicações voltadas para os sistemas de distribuição inteligentes. 



\section{Capítulo 4}

\section{Infraestrutura de computação em nuvem para sistemas de distribuição inteligentes}

Com o intuito de possibilitar o desenvolvimento de novas aplicações para sistemas de distribuição inteligente foi desenvolvida uma infraestrutura de computação em nuvem capaz de armazenar e processar dados de smart meters. A partir de uma extensa revisão bibliográfica, foram destacadas as principais tecnologias utilizadas, tendências e limitações. Essa revisão permitiu definir alguns requisitos básicos para propor uma arquitetura genérica modular com serviços essenciais, que pode ser estendida para abrigar novos serviços dependendo dos requisitos da aplicação.

Essa arquitetura básica permitirá o desenvolvimento de aplicações voltadas para gerenciamento pelo lado da demanda, resposta da demanda, monitoramento de ativos, dentre outras, além de possibilitar o desenvolvimento de novas aplicações, como por exemplo, análise do perfil de consumo, ou até mesmo ferramentas para auxiliar na localização de faltas, conforme será apresentado no Capítulo 5.

\subsection{Revisão da Literatura}

Na Seção 2.3 foram descritas algumas aplicações para sistemas de distribuição inteligentes utilizando computação em nuvem, tais trabalhos, no entanto, não especificavam a arquitetura de CC utilizada, ou focavam apenas na aplicação sem considerarem a infraestrutura. Nesta seção serão apresentados os principais trabalhos no sentido de desenvolver uma infraestrutura capaz de suportar tais aplicações.

De maneira geral a computação em nuvem tem sido aplicada em smart grid para alavancar o desenvolvimento das tecnologias voltadas para gerenciamento da informação e ferramentas avançadas, apresentadas na Seção 2.2.4. Conforme descrito naquela seção, o gerenciamento da informação em smart grid geralmente envolve três 
tarefas básicas: a coleta, o processamento e o armazenamento de informações ou dados. Nesse contexto, a computação em nuvem é utilizada principalmente para prover os recursos computacionais necessários para o processamento e armazenamento de dados.

Dentre os dados produzidos por um sistema de distribuição inteligente estão presentes dados de smart meters, sinais de equipamentos que estão sendo monitorados, dados geográficos e meteorológicos, dados de cadastro de clientes e equipamentos, sinais de monitoramento e controle, oscilografias, etc. A taxa com que esses dados são amostrados/coletados depende do tipo de sinal envolvido e do objetivo de sua aquisição, podendo variar de 15 ordens de grandeza em sua escala de tempo de microssegundos ou milissegundos até dias ou anos, de acordo com o evento que se deseja registrar [55], [174]. Tal granularidade de dados requer diferentes tecnologias e estratégias de armazenamento e processamento. Esses dados podem ser processados/tratados assim que recebidos antes mesmo de serem armazenados, ou podem ser armazenados para serem processados posteriormente conforme os requisitos da aplicação.

Desenvolver uma infraestrutura de computação em nuvem capaz de fornecer capacidade computacional de grande escala em tempo hábil para suprir as necessidades de armazenamento, e processamento de dados, requeridas pelas smart grids não é uma tarefa trivial, tendo sido objeto de estudo de várias pesquisas [6], [49], [51], [55], [60], [61], [74], [76], [77], [83], [86], [141], [162], [175]-[192], sendo as principais apresentadas a seguir.

Os trabalhos de Birman et al. [192] e Rusitschka et al. [60] analisaram as características das smart grids, identificando os requisitos necessários para o gerenciamento de informação, onde o primeiro avalia as limitações da computação em nuvem e apresenta até onde ela pode ser utilizada para alcançar esses requisitos, e o segundo fornece uma visão conceitual sobre a computação em nuvem como uma plataforma para gerenciamento de dados em smart grid, no entanto, sem apresentar soluções ou propor modelos de implementação. Mikkola et al. [178], por outro lado, analisam os requisitos para um sistema de monitoramento de energia em tempo real para toda a rede elétrica, identificando os requisitos mais importantes e descrevendo brevemente um sistema capaz de atendê-los, enfatizando que a computação em nuvem também pode ser utilizada para implementar tal sistema. 
Areias [191], em sua dissertação de mestrado, sugere a utilização de uma arquitetura baseada em computação em nuvem para o controle e gerenciamento da rede elétrica inteligente, e apresenta uma análise de risco e viabilidade de migração para uma arquitetura em nuvem, destacando os requisitos que a arquitetura em nuvem deve cumprir para suportar um sistema de gerenciamento e controle para as smart grids.

Baek et al. [61], [175] propõem conceitualmente um framework seguro para gerenciamento de informação massiva em smart grids utilizando computação em nuvem, baseado em três níveis hierárquicos de responsabilidade, supostamente capaz de fornecer diferentes tipos de serviços para o gerenciamento de informação e análise de dados. Além desse framework, eles apresentam também uma solução de segurança de dados por criptografia, para o framework proposto. Como prova de conceito eles implementaram um protótipo do sistema em uma plataforma para gerenciamento de infraestrutura de nuvens chamada Eucalyptus [193], onde foi testada a solução de segurança apresentada.

O trabalho de Benhaddou, Abid e Achahbar [176] propõe o uso de um modelo de computação em nuvem privada para fornecer computação de alto desempenho, como serviço para processamento de dados em SG, esboçando uma arquitetura apropriada. Sua infraestrutura de teste foi desenvolvida usando Hadoop, como plataforma de computação distribuída para armazenamento de dados, e o modelo de programação MapReduce para processamento distribuído, ambos sendo executados sobre a plataforma de gerenciamento de infraestrutura de nuvem OpenStack. A infraestrutura foi testada utilizando benchmarks conhecidos apresentando bom desempenho em termos de tempo de processamento para uma quantidade moderada de dados, degradando o mesmo à medida que os dados aumentaram devido a limitações do hardware utilizado.

Bai, Ma e Zhu [83] propõem uma solução para o monitoramento das condições da SG, também baseado em Hadoop/MapReduce, utilizando um banco de dados distribuído orientado a colunas chamado HBase, o qual é adequado para aplicações de leitura/escrita de acesso aleatório a grandes conjuntos de dados. Tal solução consiste de um gerenciador de tarefas responsável por agendar a execução de algoritmos a serem desenvolvidos por terceiros. No entanto, em seu trabalho, os autores alertam que sua técnica somente deve ser aplicada para processos que tenham requisitos de tempo real relativamente baixos, não devendo ser utilizada em projetos que tenham requisitos de 
tempo real para interação homem-computador, devido ao tempo gasto pelo Hadoop para designar as tarefas durante as consultas ao banco de dados, o qual deve ser considerado.

Prasad e Avinash [141], [186] propõem uma abordagem híbrida que permite o acesso coletivo a uma combinação de diferentes bancos de dados, relacionais e não relacionais, um conceito denominado de persistência poliglota, aproveitando as vantagens de cada um e permitindo o desenvolvimento de novas aplicações capazes de armazenar e processar múltiplos tipos de dados de uma maneira customizada melhorando o desempenho.

$\mathrm{Na}$ mesma linha de raciocínio, o trabalho de $\mathrm{Xu}$ et al. [185] propõe um método em que os dados da AMI são divididos em dados de medição e dados de gerenciamento de acordo com suas respectivas características, os quais são armazenados em bancos de dados diferentes. Um banco de dados baseado em Hadoop/ HBase para os dados de medição e um banco de dados relacional para os dados de gerenciamento, aproveitando dessa maneira a capacidade de computação distribuída do Hadoop juntamente com a capacidade de modificação frequente e associações complexas de dados de um banco de dados relacional.

Fazio et al. [184] também utilizam uma arquitetura híbrida, porém usando dois bancos de dados NoSQL diferentes, um orientado a Documentos e outro orientado a Objetos, para o armazenamento de dados de monitoramento, de maneira a otimizar o armazenamento, a consulta e o acesso aos dados.

A partir desses trabalhos foram levantados alguns requisitos gerais e tendências para tecnologias de armazenamento e processamento de dados.

A maioria das propostas de infraestruturas destinadas a processamento paralelo de dados massivos (em [51], [76], [77], [83], [86], [162], [176], [180], [182], [189]) utilizaram algum framework baseado em Apache Hadoop e o modelo de programação MapReduce para implementar as funcionalidades de armazenamento distribuído / processamento paralelo. Porém, o tempo gasto pelo Hadoop para designar as tarefas durante as consultas ao banco de dados pode ser um limitador o qual deve ser levado em consideração, não sendo recomendada sua utilização em projetos que tenham requisitos de tempo real relativamente baixos como os que exigem interação homemcomputador, conforme ressaltado em [83]. 
Outros autores [141], [184]-[188] propuseram soluções alternativas interessantes, as quais abordam uma arquitetura híbrida de armazenamento, diferente da utilizada pelo Hadoop, composta por diferentes bancos de dados (NoSQL e/ou SQL) para o armazenamento de dados de diferentes tipos. Essa arquitetura tende a ser mais eficiente em alguns casos, pois considera as características dos dados a serem armazenados.

Em termos de processamento de dados, o Hadoop/MapReduce é melhor utilizado quando os dados são altamente paralelizáveis, ou seja, quando podem ser divididos para serem processados independentemente uns dos outros. Para outras situações pode ser necessária uma análise detalhada para saber se sua utilização é apropriada. Por exemplo, quando os dados precisam sem processados rapidamente e de maneira contínua, uma solução melhor seria utilizar algum tipo de processamento em fluxo, onde o dado é analisado assim que entra no sistema, ou alguma solução híbrida dependendo da aplicação.

Embora computação em nuvem seja vista como uma solução para os desafios de armazenamento/processamento enfrentados pelas Smart Grids de uma forma geral, nem todas as aplicações nessa área requerem um alto poder de processamento ou manipulam grandes quantidades de dados. No entanto, elas ainda podem ser desenvolvidas em nuvem aproveitando as características e benefícios que a computação em nuvem oferece.

Com base nas informações obtidas desses trabalhos foi proposta uma arquitetura de computação em nuvem para ser utilizada pelos sistemas de distribuição inteligentes.

\subsection{Arquitetura proposta}

A arquitetura proposta foi concebida para ser integrada a uma AMI podendo ser utilizada para implementar as funções do sistema de gerenciamento de dados de medidores dessa infraestrutura. Uma AMI, conforme apresentado na Seção 2.2.1, é composta por vários sistemas dentre os quais o sistema de gerenciamento de dados de medidores (meter data management system - MDMS) é o responsável por manipular os dados brutos gerados pelos medidores e criar informações significativas. Nesse sentido foi proposta uma arquitetura modular, apresentada na Figura 11, capaz de armazenar e processar tais dados e que pudesse ser utilizada por diferentes aplicações. 
Figura 11 - Arquitetura do sistema de computação em nuvem proposto.

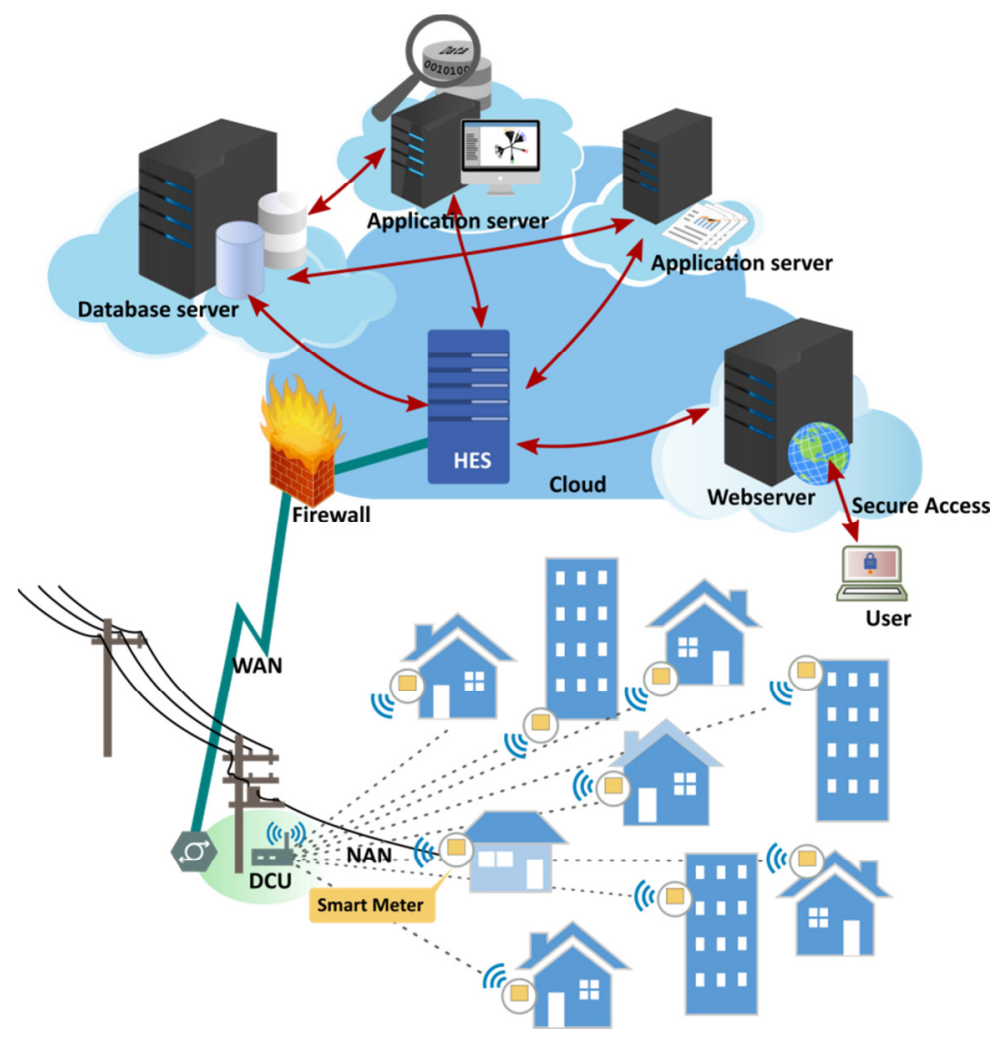

Fonte: Elaborado pelo autor.

Por ser parte integrante de uma AMI, a arquitetura proposta faz uso de tecnologias já existentes em uma AMI, como os Smart Meters e as unidades de concentração de dados, Data Concentrator Unit (DCU), que ao invés de transmitirem seus dados para um MDMS físico na concessionária, transmitem esses dados para a infraestrutura de nuvem. Na nuvem, tais dados poderão ser utilizados por diferentes aplicações.

Os Smart Meters, ou medidores inteligentes, são equipamentos eletrônicos dotados de comunicação bidirecional e certa capacidade de armazenamento e processamento, cuja função principal é registrar o consumo de energia elétrica em intervalos predefinidos e enviar essas informações à distribuidora para fins de monitoramento e tarifação, sendo um componente crucial em uma AMI. Em comparação com os medidores convencionais, os smart meters suportam comunicação bidirecional de dados, apresentando a capacidade de conectar e desconectar remotamente os consumidores, monitorar tensão e corrente, gravar formas de onda, frequência e ângulo de fase, e permitem a precificação dinâmica de energia. Os smart meters podem ser projetados ainda para monitorar a qualidade de energia, detectar alguma adulteração física e notificar perda/restauração de energia, etc. [21], [194]. 
A DCU conhecida como concentrador de dados, coletor de dados (data collector), ou gateway serve como um nó de comunicação entre a nuvem e os medidores. Sua função principal é coletar os dados dos medidores em sua área de atuação através de alguma tecnologia de comunicação para neighborhood area networking (NAN), e armazenar esses dados para posterior envio à nuvem. Além disso, o concentrador de dados também é responsável por gerenciar os medidores detectando-os automaticamente, coordenar a entrega bidirecional de dados e monitorar as condições dos medidores [26].

Por não fazer parte do escopo dessa pesquisa, a infraestrutura/tecnologia de comunicação capaz de transmitir esses dados foi assumida como ideal, sendo desconsiderado qualquer atraso, limitação ou falha que possa interferir na transferência dos mesmos. Uma revisão sobre as características de tráfego de determinadas aplicações em smart grid, destacando alguns dos principais desafios e direcionamentos para pesquisas, é apresentada em [195]. Essa infraestrutura pode ser composta de várias redes com diferentes tipos de protocolos e meios de comunicação (com ou sem fio) [33],[36]. A Rede de longa distância, Wide Area Network (WAN), algumas vezes chamada de backhaul network, é responsável por conectar o DCU à nuvem. O link WAN tipicamente é baseado em protocolo de internet, (Internet protocol - IP), utilizando dessa forma tecnologias padrão para garantir segurança e alta velocidade para as comunicações. Toda a comunicação smart meters / DCUs com o ambiente de nuvem deverá adotar dispositivos de segurança como autenticação e criptografia, visando garantir a segurança e a privacidade dos dados.

O Sistema da nuvem é composto por um firewall de entrada, que controla o trafego de dados monitorando a entrada/saída de pacotes e bloqueando os que não atendem a determinadas regras de segurança; por um servidor de entrada, Head-end server (HES); por servidores de banco de dados; servidores Web; e pelas aplicações que podem implementar outros serviços.

O HES é a porta de entrada para o sistema da nuvem. Ele tem as funções básicas receber/enviar, redirecionar e distribuir os dados dos DCUs / smart meters para serem processados ou armazenados, de forma semelhante a um Gateway. Na ausência de um sistema de gerenciamento específico, o HES também pode ser desenvolvido para gerenciar a infraestrutura, de forma a tomar decisões com base nas suas entradas; iniciar processos/serviço; solicitar o envio de dados pelos DCUs / smart 
meters e controlar suas operações, podendo também assumir outras funções de gerenciamento.

Os servidores de banco de dados são responsáveis por armazenar as medições dos equipamentos de medição para fins de histórico e processamento, e os dados já processados pelas aplicações, além de outros dados arbitrários como os dados dos clientes, informações sobre configurações dos medidores, etc. Para essa finalidade propõe-se a adoção de uma abordagem híbrida a qual permita a utilização de bancos de dados distintos, que apresentem melhor adequação aos diferentes tipos de dados.

Outros serviços ${ }^{11}$ poderão ser oferecidos e agregados a essa arquitetura básica à medida que forem necessários. As aplicações ${ }^{12}$ desenvolvidas poderão fazer uso dos serviços básicos disponíveis e/ou oferecer seus próprios serviços.

Para reduzir o consumo de recursos da infraestrutura de nuvem, é interessante que as aplicações e serviços não essenciais, que não estiverem sendo utilizados sejam desalocados da infraestrutura.

O acesso às aplicações pelos usuários (concessionária de energia, ou outros envolvidos) é disponibilizado por meio do servidor Web (que pode estar integrado à aplicação ou centralizado dedicado às aplicações), o qual deve utilizar tecnologias que garantam acesso seguro, como criptografia e autenticação de usuários.

\subsection{Ambiente de testes desenvolvido}

Um ambiente de testes, baseado na proposta apresentada, foi implementado utilizando uma nuvem privada do tipo IaaS de forma a permitir o desenvolvimento de novas aplicações. Para isso foi utilizado o hipervisor open source KVM e o gerenciador de containers LXD, juntamente com o gerenciador de infraestrutura OpenNebula versão 5.4.1, rodando sobre o sistema operacional Ubuntu 16.04.3 LTS, sendo esses softwares responsáveis pelo gerenciamento, controle e compartilhamento da

\footnotetext{
${ }^{11}$ Serviço é um processo (software) dedicado a realizar tarefas especificas para outro serviço ou aplicação, geralmente não apresentam nenhuma interface de usuário, e são acessados por meio de APIs ou via linha de comando.

${ }^{12}$ Aplicativo ou aplicação é um software que desempenha uma gama de operações com o objetivo ajudar o seu usuário a realizar alguma atividade, em geral ligada a processamento de dados, podendo fazer uso de algum serviço, e inclusive expor algumas de suas operações como serviço. Geralmente são executados por demanda do usuário e possuem interface gráfica.
} 
infraestrutura física, alocando os recursos virtualizados para cada serviço. Como serviços básicos foram disponibilizados servidores de banco de dados e um servidor Web, que poderão ser utilizados pelas aplicações e/ou para a implementação de serviços mais especializados. Os bancos de dados utilizados foram: o mongoDB, que é um banco de dados NoSQL orientado à documentos o qual é utilizado para armazenar dados diversos; e um banco de dados híbrido chamado sMAP destinado ao armazenamento de dados de medidores e séries temporais.

Utilizando essa infraestrutura, foi desenvolvida uma aplicação em Python, capaz de auxiliar no processo de localização de faltas, que será detalhada no Capítulo 5. Para isso ela aplica mineração de dados sobre os dados armazenados, visando a extração de informações a partir da correlação entre eles, utilizando o DAMICORE (DAta MIning of COde REpositories) como ferramenta de mineração de dados.

O DAMICORE foi implementado para ser executado como um serviço, sendo utilizado para minerar dados previamente armazenados conforme requisitado pelo usuário ou por outros serviços. O resultado dessa mineração será salvo no servidor de banco de dados mongoDB podendo ser utilizado por outras aplicações/serviços. Detalhes da implementação do DAMICORE serão apresentados na Sessão 4.4.

\subsubsection{Recursos provisionados e Configuração de Hardware}

Para a criação do ambiente de computação em nuvem foi utilizado um servidor HP ProLiant ML350p geração 8, com 6 CPUs físicas de núcleo duplo capazes de prover 12 CPUs virtuais (vCPU), 2TB de HD e 32GB de memória RAM. Nesse servidor Host foi instalado o SO Ubuntu 16.04.3 LTS, o hipervisor KVM com virtualização assistida por hardware, e o gerenciador de virtualização LXD, responsável pela criação de containers Linux.

O gerenciador de infraestrutura utilizado foi o OpenNebula apresentado na Seção 3.4.5. O OpenNebula foi configurado para utilizar o hipervisor KVM, permitindo a virtualização de diferentes VMs com diversos SO's. Também foi instalado o add-on $\mathrm{LXDoNe}^{13}$, o qual permite ao OpenNebula gerenciar containers LXD. Os containers

\footnotetext{
${ }^{13}$ Mais detalhes em: https://opennebula.org/lxdone-lightweight-virtualization-for-opennebula/
} 
serão utilizados para a criação de aplicações/serviços executados em Linux que necessitem de uma inicialização rápida, permitindo sua instanciação sob demanda.

$\mathrm{Na}$ infraestrutura implementada foi adotada uma configuração single-server na qual os serviços de front-end do OpenNebula são instalados no mesmo servidor Host que abrigará as VMs, conforme representado na Figura 12. O OpenNebula é responsável também pela virtualização dos serviços de rede, atribuindo os IPs previamente definidos às respectivas máquinas virtuais por contextualização.

Figura 12 - Configuração do Servidor Host: Máquinas virtuais e programas utilizados.

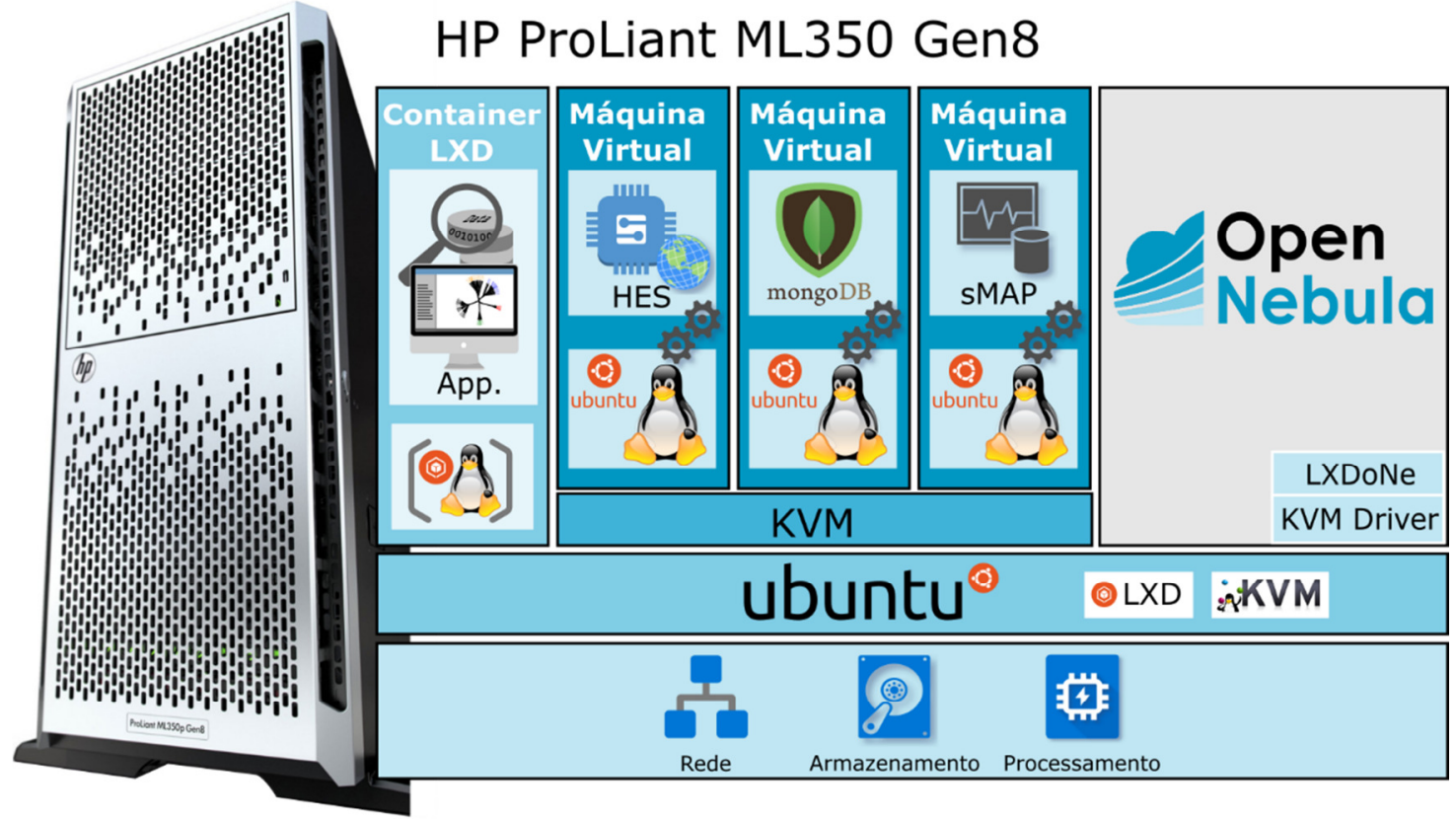

Fonte: Elaborado pelo autor.

O serviço de Firewall foi implementado através de filtros de pacotes (Ip Tables) diretamente no servidor Host, por meio de regras de acesso e encaminhamento de portas, para permitir a comunicação entre a rede externa e interna somente aos conjuntos de IPs e portas previamente configurados.

A princípio foram alocados recursos fixos para três VMs Linux que serão responsáveis por prover os serviços básicos, que serão utilizados constantemente pelas aplicações, sendo eles os servidores de banco de dados sMAP e mongoDB, e o servidor de entrada HES. Além desses, um container Linux será utilizado para a aplicação exemplo, com capacidade de alocação dinâmica. A Tabela 4 mostra um resumo dos recursos alocados para as principais máquinas virtuais Linux criadas na infraestrutura de computação em nuvem desenvolvida. Nela podemos ver a quantidade de processadores virtuais, o espaço em disco, a quantidade de memória RAM destinada a 
cada máquina virtual e o tipo de instanciação e virtualização. Essa alocação e organização dos recursos computacionais podem ser modificadas de acordo com os requisitos dos serviços ou para atender a novas aplicações. Devido à limitação de recursos de Hardware, algumas máquinas virtuais foram destinadas para mais de um serviço.

Tabela 4 - Recursos virtuais alocados.

\begin{tabular}{l|lllll}
\hline Serviço & Processador & $\boldsymbol{R A M}$ & HD & S. $\boldsymbol{O}$. & Instanciação \\
\hline Banco de dados mongoDB & $2 \mathrm{vCPU}$ & $2 \mathrm{~GB}$ & $500 \mathrm{~GB}$ & Ubuntu 14.04 & Estática / KVM \\
Banco de dados sMAP & $1 \mathrm{vCPU}$ & $2 \mathrm{~GB}$ & $500 \mathrm{~GB}$ & Ubuntu 14.04 & Estática / KVM \\
Servidor Web / HES & $1 \mathrm{vCPU}$ & $2 \mathrm{~GB}$ & $50 \mathrm{~GB}$ & Ubuntu 16.04 & Estática / KVM \\
Aplicação Exemplo & $8 \mathrm{vCPU}$ & $2 \mathrm{~GB}$ & $10 \mathrm{~GB}$ & Ubuntu 16.04 & Dinâmica/ LXD \\
\hline
\end{tabular}

Fonte: Elaborado pelo autor

Na tabela, uma instanciação estática/KVM informa que a máquina virtual estará sempre alocada/ativa para atender aos serviços e sua virtualização é feita pelo KVM, já uma instanciação dinâmica/LXD refere-se a um container Linux que só é inicializado quando da utilização do serviço/aplicação e seu mecanismo de virtualização é através do gerenciador LXD.

Nas próximas subseções serão apresentadas de maneira geral as ferramentas utilizadas para a implementação do ambiente de testes, o seu funcionamento, alguns detalhes específicos de sua arquitetura e a maneira como foram integradas, omitindo os detalhes de instalação, gerenciamento e configuração básicos dos sistemas utilizados, os quais podem ser obtidos em suas respectivas documentações, que estão disponíveis gratuitamente na Internet.

\subsubsection{Bancos de dados}

O serviço de banco de dados é responsável por armazenar os dados e informações que serão utilizadas pelas aplicações. Esses dados geralmente são provenientes de diversas fontes, e possuem diferentes características e formatos (e.g., dados de medição de consumo e dados de cadastro de equipamentos). Quando considerados em conjunto todos os medidores de uma distribuidora, a quantidade de dados gerada por eles se torna muito grande. Por exemplo, se uma distribuidora tiver um milhão de residências com um medidor que colete apenas dados de consumo a cada 15 minutos, ao final de um dia ela teria 96 milhões de registros que precisariam ser armazenados, sem considerar as outras informações que podem ser fornecidas por esses medidores, 
portanto, um banco de dados capaz de armazenar essa grande quantidade de dados é fundamental. Conforme discutido em 4.1, a utilização de bancos de dados que se adequem melhor a diferentes tipos e quantidades de dados tende a deixar o sistema mais eficiente. Nesse sentido, o presente trabalho utilizará uma abordagem híbrida baseada em bancos de dados relacionais e não relacionais visando uma melhor adequação aos dados que serão armazenados.

Os dados recebidos dos smart meters serão armazenados em um banco de dados especialista em armazenar dados de medidores. Outras informações não relacionadas diretamente à medição, informações internas à nuvem, ou cujos dados não possuam um esquema bem definido, ou que possam se alterar com o tempo, como por exemplo, o resultado de algum processamento de dados, serão armazenadas em um banco de dados orientado a documentos que possa ser acessado diretamente pelas aplicações.

Para armazenar os dados de medição foi disponibilizado o banco de dados sMAP Archiver $^{14}$, e para o armazenamento de outros dados o mongoDB ${ }^{15}$. Cada solução de armazenamento foi instalada em sua respectiva VM, com os recursos apresentados na Tabela 4, seguindo as configurações de instalação padrão para um funcionamento standalone, sem redundância ou distribuição de dados.

Cada servidor provê acesso aos serviços através de conexões TCP/IP, sendo cada um deles configurado com um endereço IP e uma porta para o respectivo serviço. As aplicações utilizam essas informações para acessar os diferentes serviços através de suas APIs, conforme ilustrado na Figura 13.

Figura 13 - Interface para os serviços de banco de dados.

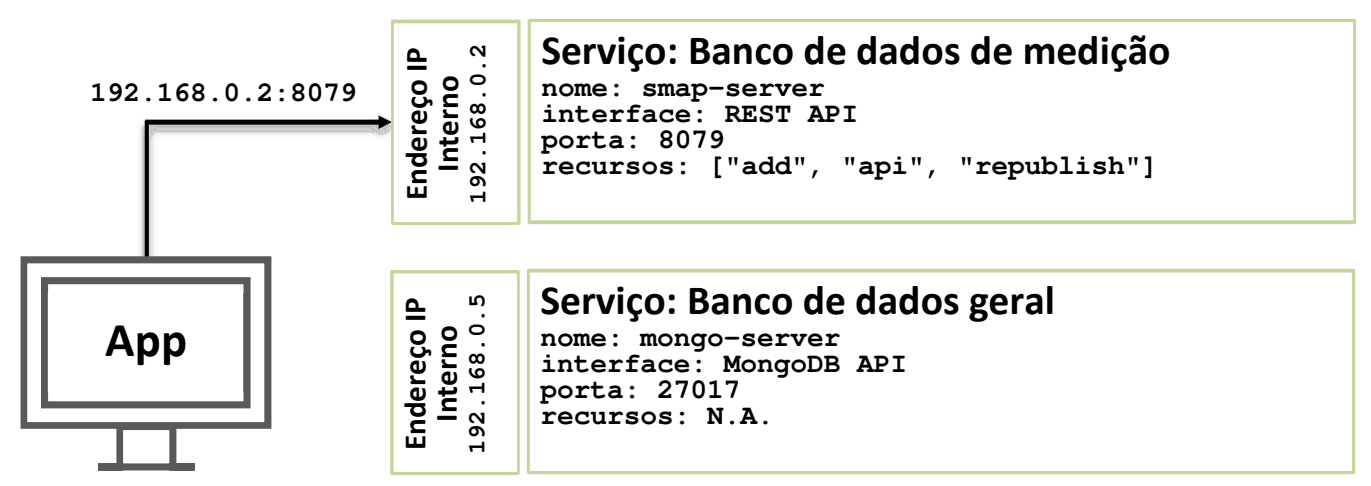

Fonte: Elaborado pelo autor.

\footnotetext{
${ }^{14}$ http://people.eecs.berkeley.edu/ stevedh/smap2/index.html

${ }^{15}$ https://www.mongodb.com/mongodb-architecture
} 
Tais aplicações devem ser desenvolvidas considerando as funcionalidades e particularidades de dada serviço de armazenamento, ficando a cargo do desenvolvedor a definição da modelagem de dados que será utilizada. A seguir são apresentadas algumas características e funcionalidades de cada sistema.

O sMAP Archiver é um gerenciador de armazenamento de streaming capaz de armazenar e acessar de maneira eficiente dados históricos e de tempo real baseado em séries temporais [196], [197]. Ele faz parte de um conjunto de ferramentas, composto por vários componentes que podem ser utilizados para coletar, transmitir, armazenar e visualizar dados de séries temporais, desenvolvido por Stephen Dawson-Haggerty [198], em sua tese de doutorado na Universidade de Berkeley, como parte de um sistema de automação de edifícios chamado BOSS (Building Operating System Services) [199]. Ele utiliza uma abordagem híbrida de armazenamento de dados, esquematizada na Figura 14, baseada no banco de dados relacional PostgreSQL [200], onde são armazenados os metadados dos medidores, e no banco de dados de séries temporais ReadingDB [201], que armazena os valores das medições.

Figura 14 - Estrutura híbrida de armazenamento de dados de medidores do sMAP archiver.

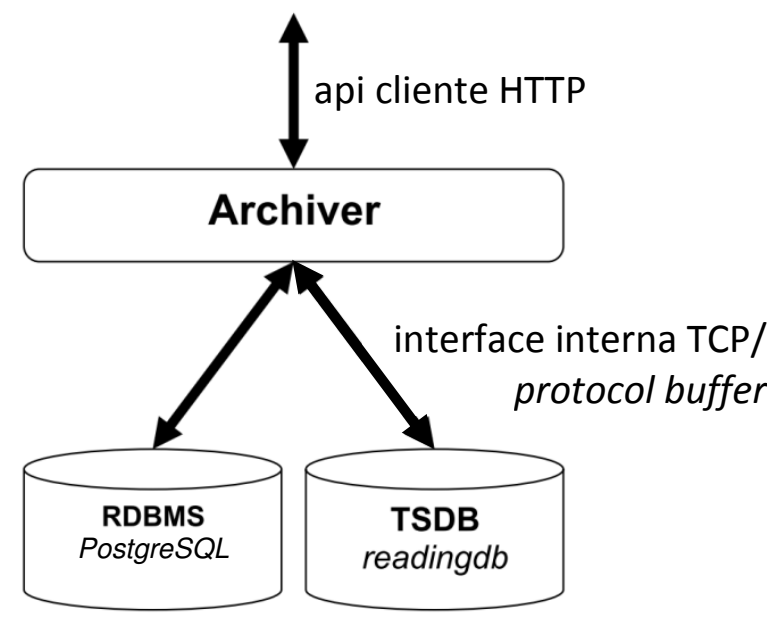

Fonte: Adaptado de [198].

Ele possui uma interface Web REST e uma linguagem de consulta (Query Language) para inserção e consulta dos dados, o que simplifica a utilização do mesmo. O sMAP foi escolhido por atender aos requisitos de armazenamento para teste da plataforma, sem a pretensão de ser a única ou a melhor solução de armazenamento para dados de medidores. Existem outras soluções de armazenamento de séries temporais especialmente desenvolvidas para dados de medições, como o 
openHistorian2 [202] e o Berkeley Tree Database [203], [204], que também poderiam ser utilizadas.

Além de ser uma ferramenta para armazenamento de dados o sMAP também define um perfil de organização para os dados dos medidores, o qual originou seu nome Simple Measurement and Actuation Profile. O princípio de organização de dado no sMAP é baseado em séries temporais representadas pelos objetos timeseries, onde cada objeto está associado a um canal de um instrumento de medição, sendo que cada instrumento pode possuir vários canais representando medições distintas.

Uma série temporal é uma sequência de leituras de um único canal de um instrumento de medição e seu respectivo metadado, sendo unicamente identificada por um UUID. Essas séries temporais podem ser agrupadas, pelo implementador do sistema, em coleções, representando uma organização lógica, a qual é refletida na hierarquia de recursos exposta pelo servidor HTTP do sMAP [196]. As coleções fornecem um mecanismo para aplicar metadados comuns a um conjunto de séries temporais ou a outro conjunto de coleções.

Os metadados são informações sobre o dado que está sendo coletado, como taxa de amostragem, unidade de medida, entre outros, as quais são estruturadas como um conjunto de pares chave-valor dentro do objeto sMAP. Eles são obtidos programaticamente a partir das informações fornecidas pelo sistema de medição, ou inseridas pelo implementador, sendo raramente alterados. Uma característica importante do sMAP é que o próprio sistema se encarrega de separar dados de medição dos metadados, de maneira automática, livrando o utilizador dessa preocupação.

Um objeto timeserie exemplo em formato JSON, para um medidor de potência ativa, contendo os metadados relacionados à série temporal coletada, é ilustrado na Figura 15. Quando recuperados utilizando a interface HTTP do sMAP, cada um desses objetos timeseries é representado usando uma estrutura JSON seguindo uma especificação. Essa especificação define cinco campos principais [198]:

$\square$ Description: um texto descrevendo o canal

$\square$ Properties: informações sobre o canal necessário para armazenar ou exibir os dados. Isso é composto pelo tipo de dados, unidades de engenharia e fuso horário.

$\square$ Metadata: informações adicionais sobre o canal que não são necessárias para arquivar ou exibir corretamente as leituras. O conjunto completo de 
metadados para uma série temporal também inclui todos os metadados das Coleções das quais faz parte.

$\square$ Readings: um vetor no formato (tempo, valor) composto pelas últimas leituras do instrumento. Os tempos devem ser em milissegundos UTC.

$\square$ uuid: um identificador único global para cada séries temporal.

Para facilitar a troca de informações o sMAP define os tipos de metadados Instrument e Location, e para adicionar outras informações o campo Extra.

Figura 15 - Exemplo de objeto timeseries representando uma medição, juntamente com seus metadados.

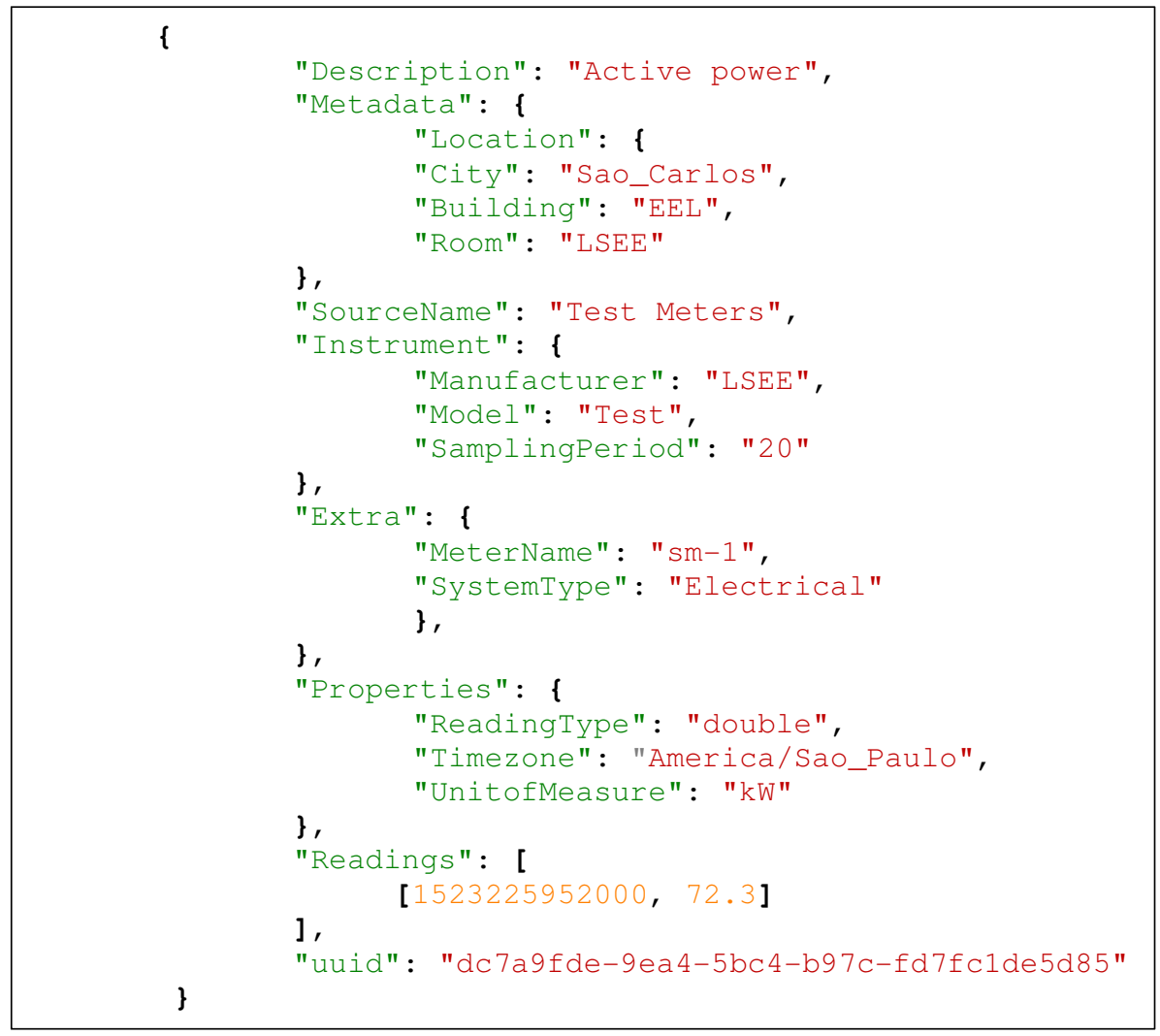

Fonte: Elaborado pelo autor.

Utilizando a interface REST disponibilizada pelo sMAP é possível ter acesso aos dados por intermédio de requisições HTTP a endereços URLs padronizados em relação à um endereço raiz /api. O endereço padrão mais utilizado é o /api/data o qual provê acesso a todas as séries temporais. A partir dele as séries temporais são organizadas dentro de coleções, de forma hierárquica, com as séries temporais sendo os últimos elementos da hierarquia. Essa organização é definida pela forma como os dados 
são inseridos no banco de dados, devendo o implementador adotar uma organização lógica de coleções e séries temporais.

Considerando uma rede de distribuição fictícia, apresentada na Figura 16, onde cada residência está associada a um SM, e conectada à rede da distribuidora por intermédio de um transformador de distribuição que pode ser compartilhado por várias residências, sendo que os SMs das residências conectadas a um mesmo transformador estão logicamente associados a um mesmo DCU e cada DCU pode estar recebendo dados dos SMs de residências conectadas à transformadores diferentes dentro de sua NAN, então uma possível organização hierárquica para esses dados seria /api /data $/\langle\mathrm{DCU}>/\langle\mathrm{TRF}>/\langle\mathrm{SM}\rangle /\langle\mathrm{Canal}>/<$ objeto $\rangle$. Essa organização permite que cada DCU tenha uma coleção de transformadores que por sua vez possuem uma coleção de SM. Cada SM pode possuir um ou mais canais, que representam diferentes medições, como potência ativa, potência reativa, fator de potência, etc., onde cada medição está associada a um objeto timeseries.

Figura 16 - Exemplo de rede de distribuição com smart meters residenciais associados ao DCU e sua relação com os transformadores de distribuição.

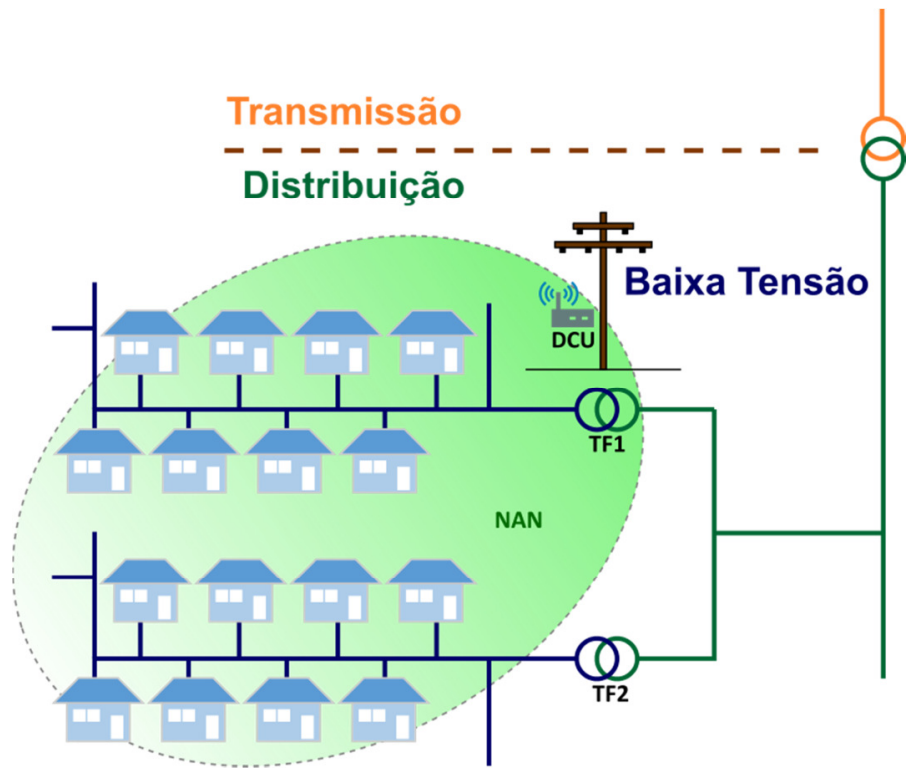

Fonte: Elaborado pelo autor.

A utilização do sMAP em uma aplicação pode ser feita utilizando suas APIs para as linguagens Python, $\mathrm{R}$ e Java, ou através da sua interface REST. Para acessar os dados do banco de dados utilizando a interface REST, basta fazer uma requisição HTTP utilizando o verbo GET sobre o endereço que se deseja as informações. 
No sMAP os dados podem ser adicionados utilizando um Driver específico responsável por buscar os dados no medidor, ou diretamente pelo medidor através de uma requisição HTTP utilizando o método POST direcionado para o endereço /add/[key]. Para isso é utilizada uma API key, previamente cadastrada no sMAP Archiver, que permite a inserção de dados no sistema a partir da interface REST. Nesse caso é enviado, juntamente com a requisição POST, um objeto timeseries, onde apenas os campos uuid e Readings são necessários. O envio dos campos de metadados deve preferivelmente ser feito apenas ocasionalmente (e.g., na inicialização) para reduzir a quantidade de dados enviados, embora seja permitido seu envio durante cada inserção dos dados.

O sMAP também possui um front-end Web para visualização e organização dos dados chamado powerdb2. A Figura 17 mostra um sinal com 10.000 pontos armazenados no sMAP seguindo a organização hierárquica descrita anteriormente visualizada no powerdb2.

Figura 17 - Front-End de visualização de dados do sMAP, apresentando dados de um medidor de potência ativa.

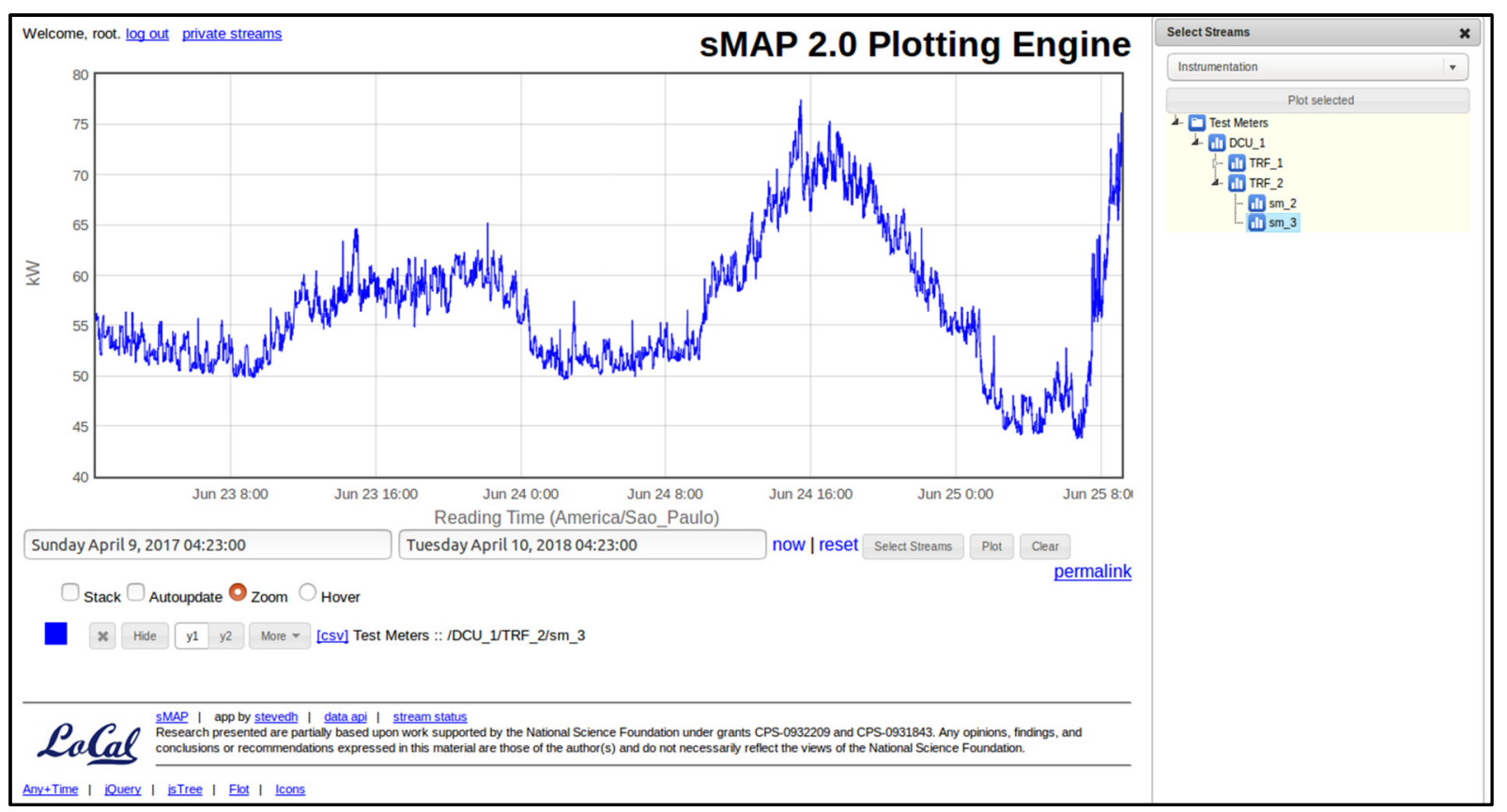

Fonte: Elaborado pelo autor.

Para o armazenamento de dados não diretamente relacionados às medições, como dados de cadastros, dados já processados pelas aplicações, ou direcionados a aplicações específicas, será utilizado o banco de dados orientado a documentos mongoDB. 
O mongoDB ${ }^{16}$ é um banco de dados orientado a documentos, distribuído de alta performance, open-source, escrito em C++ [205]. Seus dados são baseados em documentos JSON, que se assemelham a objetos. O mongoDB fornece mecanismos para que esses dados sejam replicados e/ou distribuídos melhorando a sua disponibilidade e o balanceamento de carga, e também permite a implementação de serviços de processamento em lote como o MapReduce.

A interface de comunicação com o mongoDB é feita através de APIs que utilizam um protocolo simples de requisição-resposta baseado em sockets TCP/IP para a transferência de dados, essa API possui bibliotecas de comunicação (Drivers) disponíveis para várias linguagens como C, C\#, Java, Python, dentre outras, permitindo sua integração às aplicações de maneira nativa.

A utilização do mongoDB é recomendada quando os dados puderem ser armazenados em um único documento, mesmo que para isso exista uma pequena replicação de dados, evitando a utilização de "junções" com outros documentos. Diferentemente de um RDBMS toda operação de "junção" é executada em nível de aplicação, ficando a cargo do desenvolvedor sua implementação.

A Figura 18 mostra um exemplo de documento JSON armazenado pelo mongoDB. Esse documento é composto basicamente por pares chave-valor separados por vírgula, o qual possui obrigatoriamente um campo_id hexadecimal de 12 bytes, que pode ser gerado automaticamente ou inserido pelo usuário, que serve para identificar unicamente o documento, semelhante a uma chave primária de um RDBMS.

\section{Figura 18 - Exemplo de documento JSON armazenado no mongoDB}

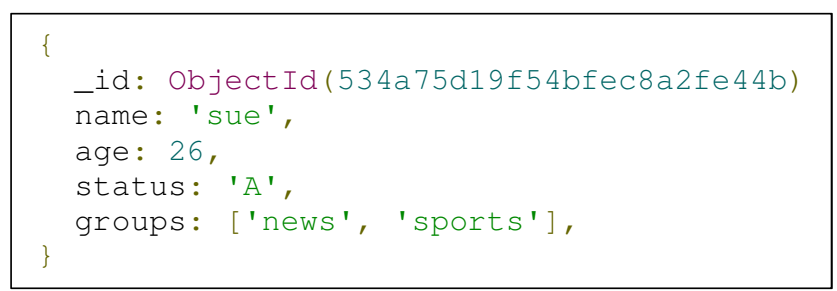

Fonte: Adaptado de [206].

Esse campo _id é utilizado para indexação e consulta de documentos. Outros campos com valores únicos podem ser utilizados para indexação de documentos melhorando o desempenho durante as consultas. O mongoDB trabalha com os conceitos

\footnotetext{
${ }^{16}$ https://www.mongodb.com
} 
de Coleção e Documento. Coleção é um agrupamento de documentos semelhante a uma tabela em um RDBMS, já um documento seria o equivalente a um registro, uma linha de uma tabela em um RDBMS, onde cada campo do documento JSON equivaleria a uma coluna dessa tabela.

O tamanho dos documentos que podem ser armazenados no mongoDB são limitados pelo tamanho máximo dos documentos (Binary jSON) $\mathrm{BSON}^{17}$, os quais são limitados em $16 \mathrm{MB}$, no entanto o mongoDB permite o armazenamento de arquivos grandes como imagens, filmes, e documentos que extrapolam o tamanho máximo de $16 \mathrm{MB}$, utilizando a especificação GridFS, a qual divide os arquivos em partes e os armazena como documentos separados.

A consulta no mongoDB é expressa com uma sintaxe semelhante a utilizada pelos documentos JSON. Um driver envia essa consulta como um objeto BSON para o mongoDB que processa e devolve um objeto BSON com a resposta. O sistema permite consulta em todos os documentos, incluindo objetos JSON embutidos nos documentos e matrizes.

O mongoDB na versão gratuita não disponibiliza uma interface Web para manipulação dos dados, para que isso seja possível é necessária a instalação de complementos externos que viabilizem essa funcionalidade. Para a implementação de uma interface REST com o mongoDB, caso seja necessária, podem ser utilizados: o Eve, que é um framework open source baseado em Python, que permite a implementação de serviços Web RESTfull altamente personalizável, utilizando o Flask ${ }^{18}$ como servidor Web [207]; o RESTHeart feito em Java sobre o servidor HTTP Undertow $^{19}$ [208]; ou DreamFactory [209], dentre outros.

\subsubsection{Head End Server - HES}

Em um ambiente comum de AMI o DCU solicita aos smart meters seus dados de medição e os armazena em um buffer local até que os dados de todos os smart meters tenham sido coletados. Após receber todos esses dados o DCU os envia para o

\footnotetext{
${ }^{17}$ http://bsonspec.org/

${ }^{18}$ http://flask.pocoo.org/

${ }^{19}$ http://undertow.io/
} 
servidor de entradas, Head-End Server, o qual recebe e redireciona esses dados para o serviço de armazenamento.

Nessa estrutura, o servidor de entrada atua como interface entre os dispositivos de medição (DCUs / smart meters) e os serviços em nuvem, devendo o HES ser capaz de trocar informações adequadamente com esses dispositivos. Essa troca de informação é regida por um conjunto de regras (protocolo) que devem ser suportados pelos sistemas envolvidos.

Embora existam diversos protocolos que podem ser utilizados para essa troca de informação, como o ANSI C12.22/IEEE 1703 [210], o IEC 62056 [211], o IEEE 2030.5 [212] e o OSGP [213], dentre outros, nenhum protocolo foi amplamente adotado como padrão. Nesse sentido, a implementação do HES em um ambiente real deverá levar em consideração o protocolo adotado pelos medidores em uso. Para este ambiente de testes foi utilizado o protocolo HTTP sobre TCP/IP. Mais informações sobre protocolos de comunicação podem ser encontradas em [32], [33], [38], [214].

A função básica do HES é servir como um gateway de entrada para as aplicações em nuvem, devendo atuar como tradutor de protocolo entre os ambientes externo e interno, quando forem utilizados protocolos diferentes nesses ambientes, a fim de interconectar os dispositivos envolvidos. Como neste sistema de testes foi utilizado o protocolo HTTP para ambos os ambientes o HES nada mais é que um proxy reverso que redireciona as requisições feitas a um determinado URI para o seu respectivo serviço, de maneira transparente para o dispositivo cliente. Dessa maneira, o dispositivo cliente faz a requisição para o HES como se ele fosse o servidor Web; o proxy reverso converte essa requisição para a URL do servidor interno, adequando alguns campos no cabeçalho HTTP para referenciarem corretamente o servidor Web interno, e encaminha a requisição para esse servidor. Após o processamento pelo servidor interno, este retorna a resposta para o HES que faz o processo reverso de adequação da mensagem e a encaminha para o dispositivo cliente.

De maneira geral, os dados manipulados pelo HES podem ser divididos em duas grandes classes: dados de medições e dados de controle. Dados de medição contêm as medições propriamente ditas e seus metadados, os quais precisam ser armazenados para fins de histórico e posterior processamento. Dados de controle são aqueles utilizados para gerenciar, monitorar e controlar os medidores. 
Para simular as funções de um Head-End Server foi desenvolvido em python ${ }^{20}$ um servidor HTTP simples, para fins de teste de conceito, utilizando o framework flask $^{21}$, o qual é capaz de receber os dados dos dispositivos, redirecionar esses dados para os serviços requisitados e tomar decisões com base nas suas entradas. A Figura 19 apresenta esquematicamente o HES e suas principais interfaces e funcionalidades.

Figura 19 - Head-End Server: interfaces e funcionalidades

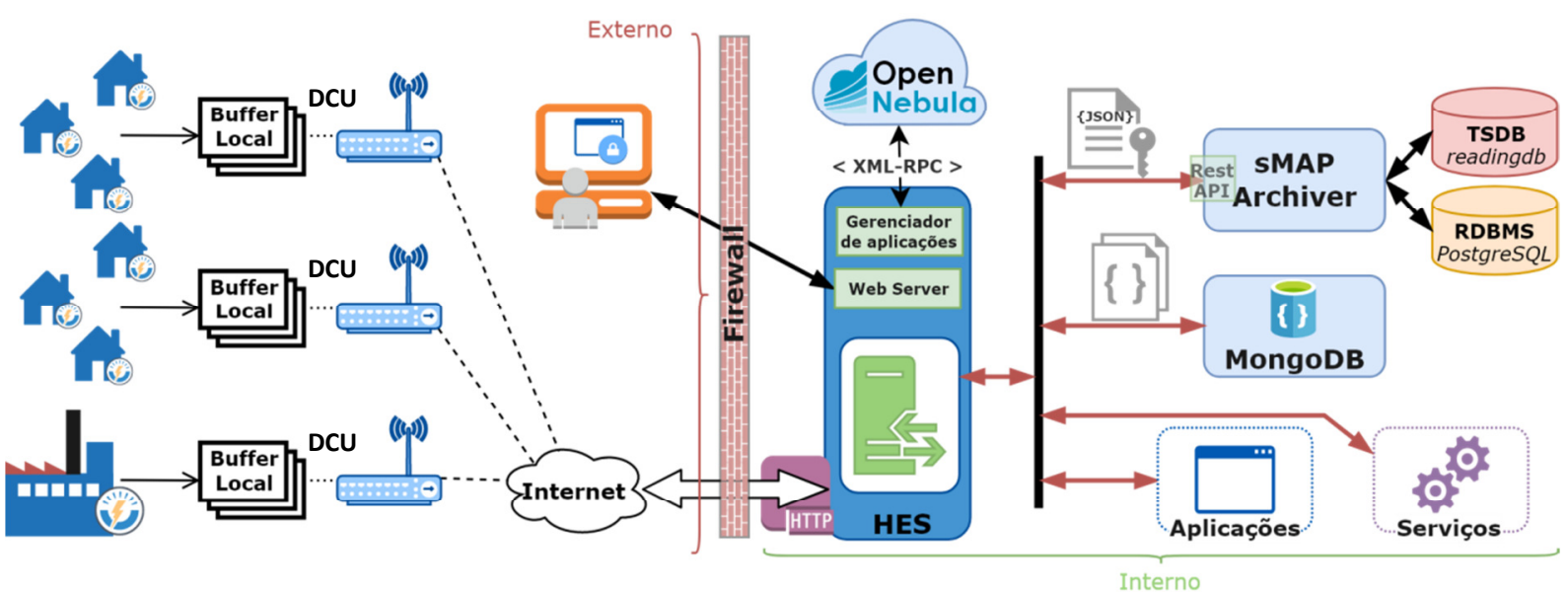

Fonte: Elaborada pelo autor

Ele é capaz de receber requisições HTTP endereçadas a URIs específicas e tomar ações com base nesses URIs. Por exemplo, quando os medidores enviam seus dados de medição, encapsulados como documentos JSON através de uma requisição POST, para o URI externo do HES em http://10.235.0.51:5000/hes/smap/[api_key], estes dados são encaminhados ao servidor de banco de dados de medição (sMAP) em http://192.168.0.2:8079/api/add/[api_key] de maneira transparente, o qual é responsável por receber, autenticar e armazenar esses dados. De maneira semelhante, de acordo com os URIs requisitados, o HES pode ser utilizado para tomar decisões ou executar outras ações, como por exemplo, iniciar processos/serviço, verificar o status de algum serviço, enviar ou manipular dados de controle, etc.

O HES, da maneira como foi implementado, também permite a criação de uma interface Web para as aplicações que serão instanciadas sob demanda, livrando tais aplicações da necessidade de manter em suas VMs um serviço Web operante o tempo todo para atender as requisições externas, as quais utilizariam para isso o servidor

\footnotetext{
${ }^{20}$ https://www.python.org/

${ }^{21}$ http://flask.pocoo.org/
} 
WEB do HES permitindo a desalocação de seus recursos virtuais quando não estiverem em uso. Nesse sentido o HES atua como um gerenciador de aplicações, comunicando-se com o gerenciador de infraestrutura OpenNebula, através de sua API baseada em XML-RPC, solicitando a instanciação de determinado serviço/aplicação e monitorando seu funcionamento, desde que essa aplicação tenha sido previamente configurada no OpenNebula através de templates e contextualização.

Por ser uma plataforma de teste utilizada em um ambiente com acesso restrito, não foram implementados métodos de autenticação e/ou criptografia para as comunicações, porém tais recursos de segurança são fundamentais para sua utilização em um ambiente real. Ainda não existe uma tecnologia padrão utilizada para esse fim, no entanto, por se tratar de uma área de pesquisa em constante desenvolvimento é esperado que novas soluções de segurança surjam com esse propósito. Dentre as alternativas existentes, soluções baseadas em TLS ${ }^{22}$ utilizando certificados digitais, como os utilizados em conexões seguras na internet, ou implementações mais direcionadas para smart grids como as propostas em [61], [215], [216] poderiam ser utilizadas em um cenário real.

\subsection{Serviço de mineração de dados}

Para atender a aplicação teste desenvolvida para auxílio à localização de faltas, que está detalhada no Capítulo 5, foi implementado um serviço de mineração de dados baseado na técnica DAMICORE.

O DAMICORE é uma técnica de mineração de dados que busca encontrar relações entre dados através de uma métrica de compressão de dados chamada NCD (distância por compressão normalizada, do inglês Normalized Compression Distance), a qual determina semelhança entre as variáveis com base nos tamanhos de seus dados compactados e descompactados agrupando-os por similaridade.

A NCD é uma métrica universal e robusta que tem sido aplicada com sucesso em áreas como a genética, literatura, música e astronomia [217]. A principal vantagem dessa métrica é que ela não exige um conhecimento específico do domínio de aplicação, podendo ser aplicada a diversos tipos de dados.

\footnotetext{
${ }^{22}$ https://en.wikipedia.org/wiki/Transport_Layer_Security
} 
Nesta seção é apresentada a implementação dessa técnica para funcionar como um serviço instanciado dinamicamente no ambiente de nuvem, sua integração com os outros serviços, alguns aprimoramentos e testes.

\subsubsection{DAMICORE como ferramenta de mineração de dados}

O DAMICORE, acrônimo para DAta MIning of COde REpositories, é um método de mineração de dados que integra um conjunto de técnicas conhecidas de diversas áreas do conhecimento, de forma a extrair informações relevantes, identificando padrões similares e agrupando-os em clusters [218]. Ele possui três etapas principais, conforme apresentado na Figura 20. A primeira delas consiste em detectar a similaridade entre os dados através da NCD, a qual gera uma matriz de distâncias, que considera a semelhança entre os arquivos de entrada com base no tamanho da sua compressão individual e dois a dois.

Figura 20 - Diagrama de execução do DAMICORE.

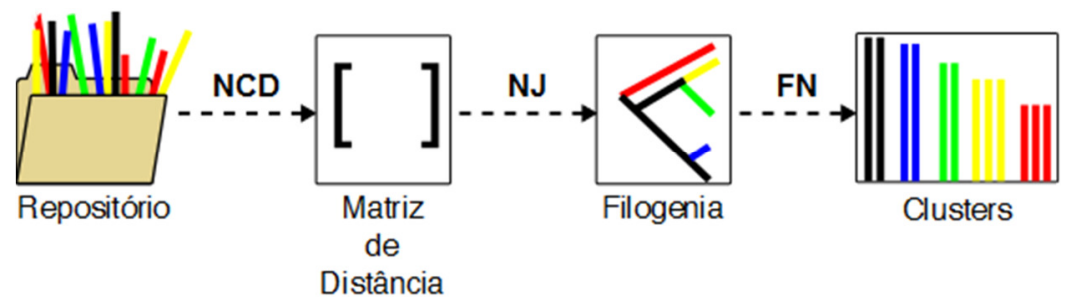

Fonte: Elaborado pelo autor.

A compressão reduz o espaço ocupado por um arquivo removendo a redundância nos dados, de forma que quanto mais semelhantes são seus dados, maior é sua compressão e consequentemente menor é o tamanho do arquivo final comprimido. Essa característica permite agrupar os arquivos de entrada de acordo com as características dominantes que eles compartilham. Pelo fato da compressão não exigir nenhum conhecimento prévio sobre os dados nos arquivos, ela fornece generalidade ao método, podendo ser utilizado em diversas áreas do conhecimento.

O valor da distância entre dois arquivos de dados quaisquer $X$ e $Y$, pertencentes ao conjunto de arquivos de entrada, é obtido pela Equação (1):

$$
D_{N C D}(X, Y)=\frac{C(X Y)-\min \{C(X), C(Y)\}}{\max \{C(X), C(Y)\}},
$$

em que $C(X)$ e $C(Y)$ são os tamanhos de $X$ e $Y$ comprimidos individualmente, respectivamente, e $C(X Y)$ é o tamanho comprimido de $X$ e $Y$ concatenados em um 
único arquivo. O valor de $D_{N C D}$ é um número positivo pertencente ao intervalo $[0 ; 1+\varepsilon]$ representando o quão diferente são os dois arquivos, onde $\varepsilon$ no limitante superior é devido às imperfeições do compressor usado. Para a maioria dos algoritmos de compressão padrão $\varepsilon<0,1[217]$.

A matriz de distâncias, calculada pela NCD, é uma matriz quadrada em que cada elemento é o resultado da aplicação da Equação (1) a um par de arquivos do conjunto de entrada. Considerando as propriedades de um compressor Normal, em que $C(X Y)=C(Y X)$ e $C(X X)=C(X)$ então essa matriz de distâncias pode ser reduzida para uma matriz triangular, cujos elementos da diagonal principal são nulos, reduzindo a quantidade de elementos a serem calculados.

A escolha do compressor e dos parâmetros utilizados para a compressão interfere diretamente na distância calculada pela NCD, devido a variações na taxa de compressão, portanto o compressor utilizado deve ser escolhido em função da quantidade e do tipo de dados envolvidos, levando em consideração a efetividade do compressor para comprimir esses dados [219], [220]. Diferentes algoritmos de compactação padrão têm sido utilizados para o cálculo da NCD, como gzip, bzip2, os baseados na técnica de predição por correspondência parcial, do inglês prediction by partial matching (PPM), dentre outros [221].

A partir da Matriz Distância calculada, a segunda etapa é agrupar esses dados através da construção de uma árvore filogenética, que representa hierarquicamente o relacionamento provável entre os indivíduos, utilizando o método de agrupamento Neighbor Joining (NJ). Nessa árvore, cada nó folha representa um arquivo de dados e a distância entre um nó folha e outro, considerando-se os pesos de cada ramo (aresta), corresponde ao valor da NCD para os arquivos envolvidos.

Um exemplo de árvore e sua respectiva matriz de distância é apresentado na Figura 21, onde os nós folhas são representados pelas letras maiúsculas, os vértices internos em letras minúsculas e os comprimentos dos ramos ao lado de cada ramo. 
Figura 21 - Matriz de distância e árvore filogenética obtida pelo NJ.

\begin{tabular}{|c|c|c|c|c|c|}
\hline & A & B & C & D & E \\
\hline A & 0 & 5 & 10 & 10 & 9 \\
\hline B & 5 & 0 & 9 & 9 & 8 \\
\hline C & 10 & 9 & 0 & 8 & 7 \\
\hline D & 10 & 9 & 8 & 0 & 3 \\
\hline E & 9 & 8 & 7 & 3 & 0 \\
\hline
\end{tabular}

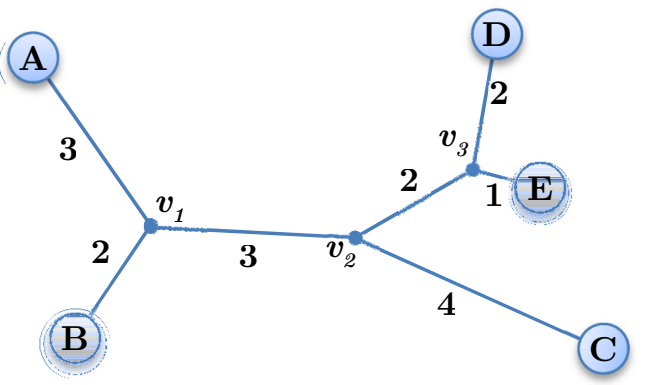

Fonte: Elaborada pelo autor.

O NJ, idealmente, tenta encontrar uma árvore que possua a menor soma de distância entre os nós vizinhos dentre todas as topologias de árvores possíveis para o conjunto de dados de entrada, de forma a minimizar o comprimento total dos ramos, portanto quanto mais próximos os nós, mais similares tendem a ser os dados. No entanto, o NJ não garante que a árvore encontrada será a de menor soma das distâncias, mas de maneira geral obtém uma boa aproximação dessa árvore, com um custo computacional relativamente baixo [222], [223].

A última etapa do DAMICORE consiste em determinar o agrupamento final ("clusterização") dos dados a partir da árvore filogenética. Dessa árvore é obtida uma matriz de adjacências (i.e., uma matriz que representa todas as conexões entre ramos e nós da árvore), que serve como parâmetro de entrada para o algoritmo Fast Newman (FN). O FN é uma técnica utilizada para detectar comunidades ou agrupamentos de objetos (nós) em redes complexas, sendo capaz de identificar no grafo da árvore os grupos similares [224]-[226]. Cada grupo encontrado corresponde a um cluster. Um exemplo de agrupamento que poderia ser obtido da árvore da Figura 21, seria: grupo 1 - nós $\mathrm{A}, \mathrm{B}$ e $v_{1}$; grupo 2 - nós $\mathrm{D}, \mathrm{E}$ e $v_{3}$; e grupo 3 - nós $\mathrm{C}$ e $v_{2}$. Desconsiderando os nós internos (vértices), teríamos como resultado final três clusters. Um cluster agrupando os arquivos $\mathrm{A}$ e $\mathrm{B}$, outro agrupando $\mathrm{D}$ e $\mathrm{E}$, e o arquivo $\mathrm{C}$ agrupado sozinho em um cluster unitário.

Por ser uma técnica de análise de dados genérica o DAMICORE também pode ser utilizado como uma ferramenta de análise exploratória ${ }^{23}$ de dados através da árvore filogenética gerada pelo NJ, a qual fornece uma boa noção da organização do conjunto de dados, de forma que um analista capacitado poderia limpar e extrair características

${ }^{23}$ https://www.itl.nist.gov/div898/handbook/eda/section1/eda11.htm 
relevantes desse conjunto, e iterativamente reaplicar o método refinando os resultados e ressaltando as semelhanças e agrupamentos a cada iteração.

\subsubsection{Implementação em Python}

A implementação do DAMICORE como um serviço, foi feita utilizando a linguagem Python. Para isso tomou-se por base a implementação desenvolvida por Cesar em [227] chamada de damicorepy ${ }^{24}$, modificando sua estrutura para utilizar o banco de dados mongoDB como um repositório de dados, donde os dados serão lidos e os resultados do processamento armazenados.

O damicorepy foi desenvolvido em Python 2.7 para ser executado em linha de comandos. Ele recebe como parâmetros mínimos de entrada, o caminho para um diretório contendo o conjunto de arquivos sobre os quais serão executadas as etapas do DAMICORE, e um caminho para um diretório de saída onde será gravado o resultado do processamento. Além disso, ele possui uma série de parâmetros de configuração que podem ser utilizados para alterar o tipo do compressor e sua respectiva configuração, o formato dos dados de saída, a forma de processamento da compressão (serial ou paralela), dentre outros. Os compressores suportados são o gzip, o bzip2, o zlib, o bz2, e o ppmd. Dentre estes o ppmd, o qual faz parte da classe de compressores PPM, é o que apresenta a melhor compressão para dados em formato de texto, sendo esse também o compressor utilizado por padrão.

Como dados de saída são gerados três arquivos de texto: um arquivo, com valores separados por vírgula tipo CSV, com os dados da NCD; um arquivo contendo a representação da árvore filogenética em formato $\mathrm{Newick}^{25}$, e um arquivo em formato CSV contendo a relação dos arquivos de entrada associados seus respectivos clusters, com cada cluster numerado em ordem crescente a partir de zero até a quantidade total de clusters encontrada.

A compressão (individual e dois a dois) dos dados de entrada pode ser executada de maneira serial ou em paralelo. Quando executada em paralelo, as compressões são distribuídas uniformemente para cada núcleo de processamento existente no computador. Cada núcleo executa um processo diferente que comprime e registra o

\footnotetext{
${ }^{24}$ Versão original com algumas correções disponível em https://gitlab.com/jeovanevs/damicorepy

${ }^{25}$ http://evolution.genetics.washington.edu/phylip/newicktree.html
} 
tamanho final dessa compressão em um arquivo intermediário cujos dados são utilizados para o cálculo da NCD e posterior geração da matriz de distâncias. Com essa matriz de distância é gerada a árvore filogenética através do NJ. Dessa árvore são determinados os agrupamentos (clusters) através do $\mathrm{FN}$, utilizando a biblioteca igraph ${ }^{26}$. Essa biblioteca possibilita a detecção de comunidades sobre árvores/grafos, utilizando uma versão altamente eficiente do algoritmo do FN.

Utilizando a biblioteca pymongo ${ }^{27}$ foi implementada uma modificação no damicorepy de maneira a possibilitar a utilização do mongoDB. Essa versão modificada, chamada de damicorepycloud, recebe quatro parâmetros de entrada: uma string de conexão com o mongoDB, que contém as informações para a conexão e o banco de dados que será acessado; o nome da coleção de documentos que contém os dados previamente processados (dados antigos); o nome da coleção com os dados ainda não processados (dados novos); e o nome da coleção onde deverão ser salvos os resultados dos processamentos. Além disso, ela também permite a utilização dos mesmos parâmetros de configuração/utilização oferecidos pelo damicorepy. A Figura 22 apresenta um exemplo do comando para execução do damicorepycloud.

Figura 22 - Exemplo de comando para execução do damicorepycloud.

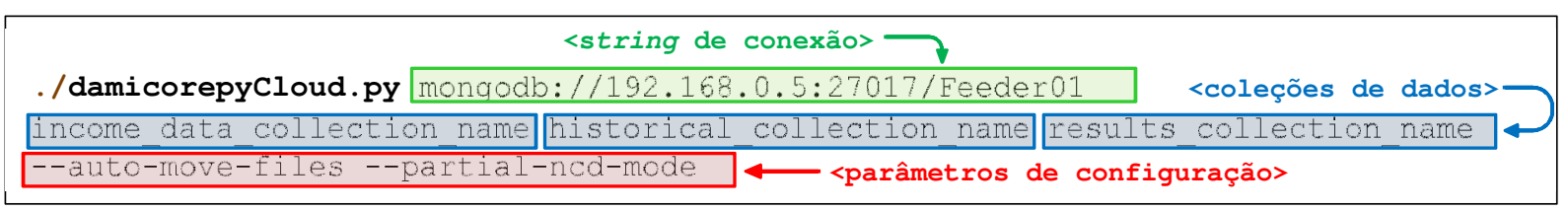

Fonte: Elaborada pelo autor.

Ao ser executado, o damicorepycloud se conecta ao banco de dados mongoDB e busca os documentos das coleções dados novos e dados antigos, transforma esses documentos em arquivos de texto e salva esses arquivos em um diretório temporário. A partir daí ela se integra à implementação damicorepy executando os passos de processamento do DAMICORE, descritos anteriormente, exceto pela última parte que seria o salvamento em disco. Após o término processamento dessas etapas, o resultado da mineração contendo a matriz de distâncias, a árvore filogenética em formato Newick, e os clusters são transformados em um documento JSON e

\footnotetext{
${ }^{26}$ http://igraph.org/python/

${ }^{27}$ https://api.mongodb.com/python/current/
} 
armazenados no mongoDB na coleção de resultados. O damicorepyCloud também implementa uma última etapa de manipulação de dados, onde os documentos da coleção dados novos são movidos para a coleção dados antigos, quando o parâmetro auto-move-files está ativado. Essa separação entre dados novos e antigos garante uma maior disponibilidade de dados, reduzindo o acesso de leitura/escrita em ambas as coleções, o que minimiza intertravamentos nas operações de leitura e escrita por múltiplos clientes [228]. Além disso, essa divisão permite que apenas a coleção com dados novos precise ser acessada ao alimentar o mongoDB com dados incrementais para serem minerados.

\subsubsection{Redução no tempo de processamento considerando dados incrementais}

O damicorepy foi implementado para ser executado sobre um diretório contento o conjunto de arquivos de entrada, por isso, para o cálculo da NCD, ele comprime todos os arquivos de entrada e suas combinações dois a dois. Essa etapa de compressão é computacionalmente muito exigente demandando muito tempo de processamento, mesmo com a possibilidade de ser executada em paralelo. Esse tempo tende a aumentar exponencialmente em relação à quantidade de arquivos. Para um repositório com $N$ arquivos de entrada, seriam necessárias $\frac{N^{2}+N}{2}$ compressões para gerar uma matriz de distâncias triangular, conforme descrita em 4.4.1. Caso um novo arquivo seja adicionado aos dados de entrada, todo o processo de compressão precisaria ser refeito.

Pensando nisso, visando reduzir o tempo de processamento para as aplicações que trabalham com um repositório de dados incremental, foi desenvolvida uma nova opção no damicorepycloud chamada partial-ncd-mode, que reutiliza os resultados das compressões anteriormente realizadas, reduzindo a quantidade de compressões para $N+1$ (sendo $N$ relativo às compressões do arquivo novo concatenado com cada arquivo antigo e mais uma referente à compressão do arquivo novo individualmente), o que diminui consideravelmente o tempo de processamento. Essa forma de determinação da matriz de distâncias, reaproveitando os cálculos e compressões anteriores, foi chamada de NCD parcial, uma vez que a NCD é calculada apenas para os dados novos. 
A Figura 23 mostra os tempos de processamento do damicorepyCloud utilizando a NCD parcial, representado pela curva vermelha com legenda DAMICORE, e a NCD completa, representado pela curva azul com legenda DAMICORE (FULL). Nesse gráfico, também estão representados os tempos de acesso ao banco de dados mongoDB para busca e movimentação dos dados utilizados e salvamento dos resultados. O tempo total de processamento da aplicação para os cálculos utilizando a NCD parcial e a NCD completa é apresentado nas curvas azul clara e verde clara respectivamente, juntamente com suas respectivas curvas de regressão e seus polinômios interpoladores.

Esses testes foram obtidos partir de um conjunto de arquivos de dados contendo inicialmente 54 arquivos de 414 bytes cada, utilizando o compressor ppmd, com compressão paralela em 8 núcleos de processamento. A cada iteração foi aumentado 24 arquivos a esse conjunto inicial até o valor final de 510 arquivos. A partir da figura podemos perceber que os tempos de execução tendem a crescer segundo uma exponencial de ordem dois para ambos os casos, no entanto a inclinação da curva obtida a partir da NCD parcial é mais branda, possuindo uma inclinação muito menor.

Figura 23 - Tempos de processamento damicorepycloud.

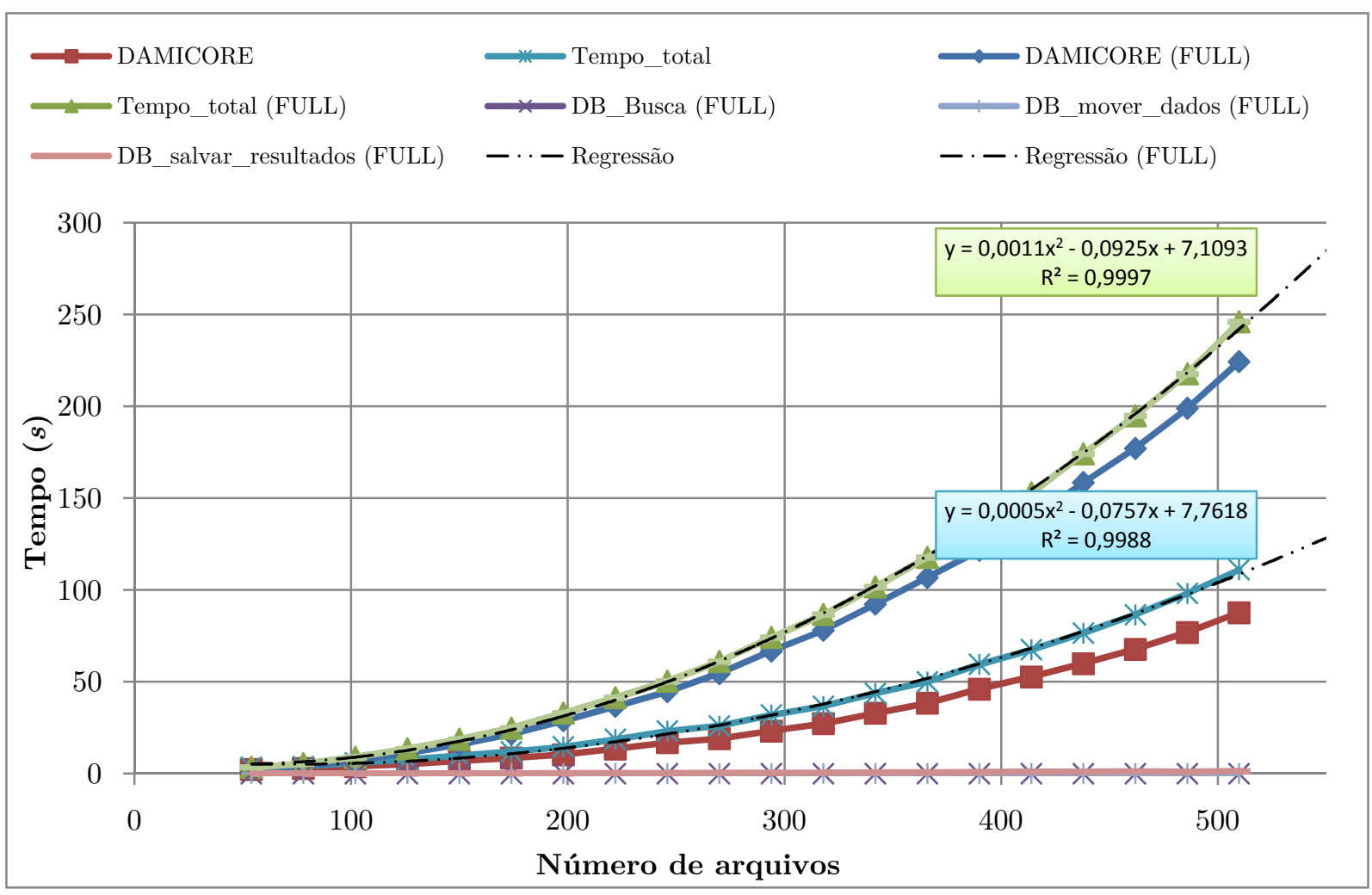

Fonte: Elaborada pelo autor 
Embora esse tempo de processamento seja dependente de vários fatores como o tipo de compressor, o tamanho e o tipo dos arquivos de dados, a capacidade de processamento, etc., aquela curva tende a manter o perfil exponencial independentemente desses fatores. Os tempos de busca, movimentação e salvamento remoto dos dados no mongoDB é irrelevante em relação ao tempo total de processamento.

Fazendo a regressão polinomial das curvas de tempos de execução total obtemos a função exponencial que melhor se aproxima dessas curvas. Utilizando essa função de regressão e extrapolando o resultado para uma coleção com 1.000 (mil) arquivos de entrada obtemos um tempo de processamento de aproximadamente 999 segundos para a versão utilizando o cálculo da NCD completa, e um tempo aproximado de 468 segundos utilizando a NCD parcial, perfazendo uma redução de $47 \%$ no tempo total de processamento. Esse percentual de redução tende a aumentar a medida que o número de dados aumenta, visto que as curvas tendem a se distanciar uma da outra, com a curva da NCD completa divergindo da curva da NCD parcial.

\subsubsection{Instanciação sob demanda}

Para permitir a instanciação do serviço de mineração de dados sob demanda, foi utilizado um container Linux, conforme as configurações da Tabela 4 (aplicação exemplo). Esse container foi preparado para executar o damicorepycloud automaticamente, logo após a inicialização do SO, por meio de um script de inicialização definido durante a criação do template da VM, como destacado na Figura 24. Esse script, que é apresentado na Figura 25, busca uma variável de ambiente chamada DAMI_PAR, atualizada dinamicamente por contextualização através do OpenNebula durante a instanciação do container. Essa variável contém os parâmetros de entrada e execução do dami corepyCloud, conforme apresentado em 4.4.2.

O damicorepycloud é então executado utilizando os parâmetros dessa variável. A variável define a string de conexão com o mongoDB o qual atua como uma espécie de interface para entrada e saída de dados, permitindo a integração do sistema com outros serviços/aplicações. Após a execução do script, o container é finalizado encerrando a execução do serviço. 
Figura 24 - Definição do script de inicialização durante a criação do template da VM.

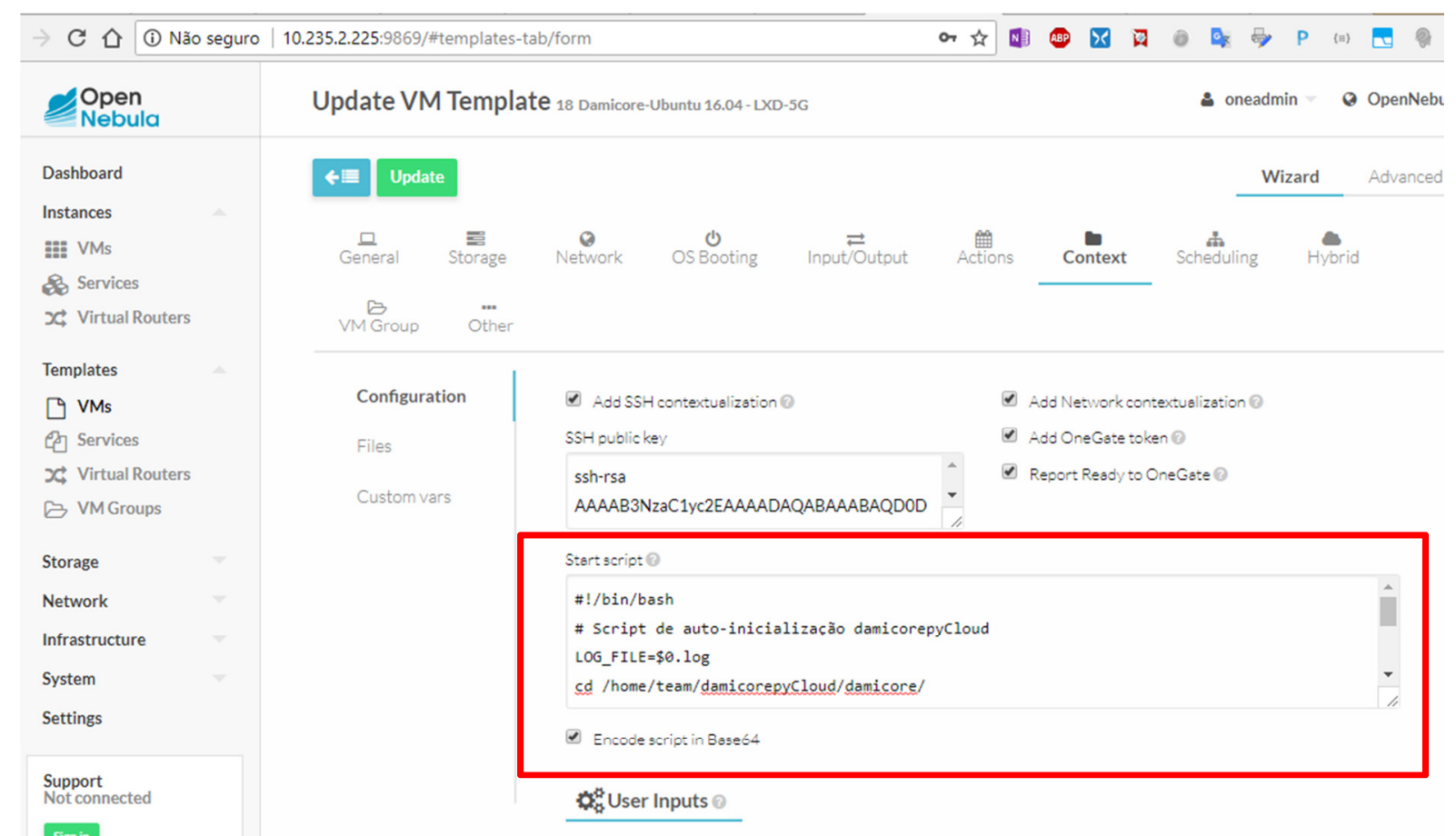

Fonte: Elaborada pelo autor.

Figura 25 - Script de inicialização do DAMICORE como um serviço.

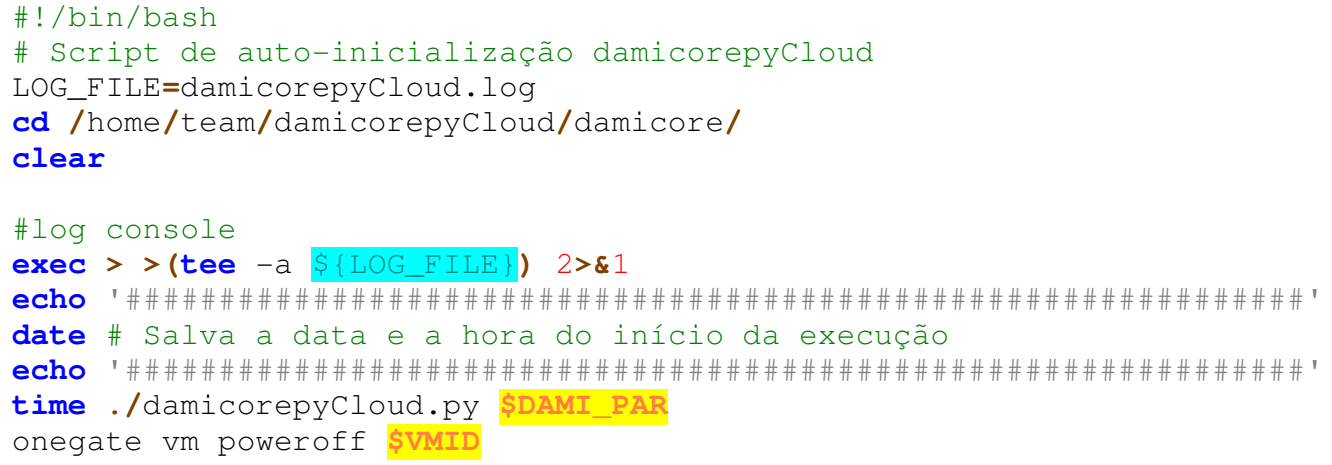

Fonte: Elaborada pelo autor.

A instanciação do container deve ser inicializada externamente pelo gerenciador de aplicações do HES (Seção 4.3.3). É ele que se comunica com o front-end do OpenNebula, através da interface XML-RPC, informa o valor da variável DAMI_PAR e solicita a instanciação do serviço. Após a execução do serviço os dados ficam disponíveis no banco de dados mongoDB para serem utilizados pelas aplicações.

A Figura 26 mostra a interface gráfica de uma aplicação exemplo que busca esses resultados e apresenta ao usuário através de uma página web. Nela podemos ver a árvore filogenética colorida conforme o resultado da "clusterização"; ao lado esquerdo está um painel com este resultado em forma de texto, nele o valor antes da vírgula é o 
nome do arquivo de entrada e após ela está o número do seu respectivo cluster. O mesmo pode ser observado na figura, porém no lugar da vírgula estão dois hifens (--).

Figura 26 - Exemplo de visualização de dados a partir dos resultados armazenados no mongoDB.

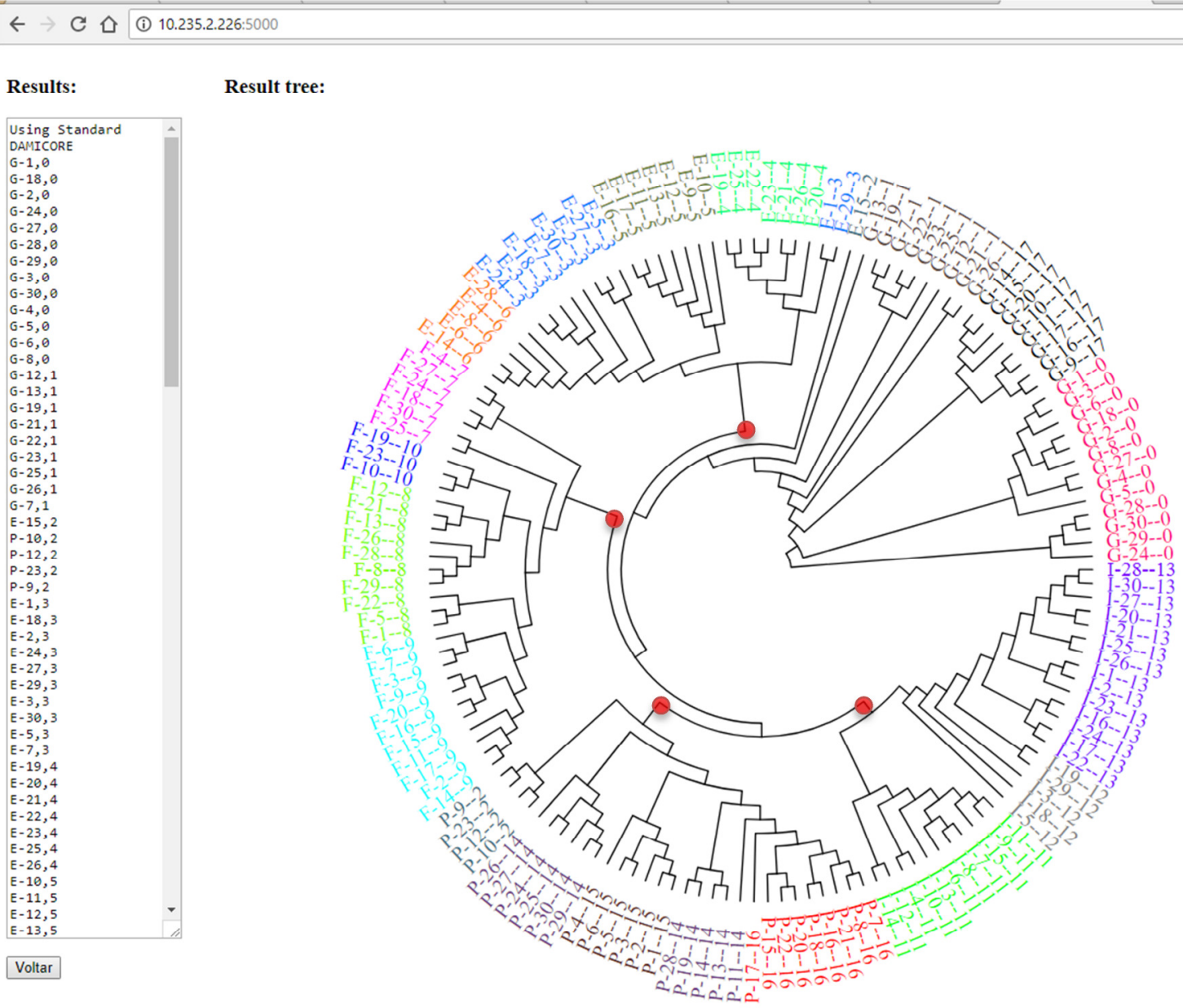

Fonte: Elaborada pelo autor.

Nessa demonstração o DAMICORE foi executado sobre um banco de dados com arquivos de texto escritos em diferentes idiomas, a saber, Inglês (E), Francês (F), Português (P), Italiano (I) e Alemão (G). Como podemos ver na Figura 26, dentre os fatores preponderantes nos agrupamentos estão a similaridade entre arquivos de um mesmo idioma, visto que em nenhum cluster houve mistura de arquivos com idiomas diferentes. Até mesmo idiomas latinos com estrutura semelhante, como Português, Espanhol e Italiano, foram corretamente separados. Na figura também é possível notar que o arquivo E-15 foi agrupado no cluster 2, porém na hierarquia da árvore ele está isolado dos outros arquivos do mesmo cluster. Ao analisar o conteúdo desse arquivo percebemos que o mesmo estava vazio, possivelmente devido a alguma falha na geração 
dos dados, portanto não apresentando similaridade com nenhum outro arquivo. Isso ajuda a demonstrar a potencialidade do método em ressaltar situações que poderiam passar despercebidas à primeira vista.

Seguindo os agrupamentos da árvore filogenética, podemos perceber também uma separação entre os idiomas de origem latina e os idiomas com origens nórdicas. Os pontos em vermelho na figura, foram adicionados por inspeção visual e representam pontos de separação entre os diferentes idiomas. Com isso podemos perceber a utilidade do DAMICORE como ferramenta de análise exploratória de dados. 



\section{Capítulo 5}

\section{Uma aplicação para auxílio à localização de faltas na distribuição utilizando mineração de dados}

Um dos principais problemas enfrentados pelas distribuidoras de energia está associado às interrupções no fornecimento de energia devido a faltas transitórias ou permanentes. Essas faltas são causadas por uma diversidade de eventos, podendo ser decorrentes de condições climáticas, de falhas de equipamentos, de contatos com árvores, de acidentes, dentre outros. Esses eventos são relativamente comuns e passíveis de acontecer, porém comprometem a qualidade com que a energia elétrica é fornecida, podendo ocasionar desde um leve desconforto, para alguns consumidores residenciais, até a interrupção ou falha de processos inteiros, para consumidores industriais e comerciais, gerando prejuízos financeiros consideráveis [229]. Além disso, caso essas interrupções ultrapassem certos limites pré-estabelecidos, as concessionárias são obrigadas a compensar os consumidores afetados, e podem ser penalizadas através multas. Portanto, é muito importante para as distribuidoras restabelecer o fornecimento de energia aos consumidores, no menor tempo possível, minimizando os prejuízos financeiros ocasionados pelo desligamento do sistema.

Detectar e localizar corretamente uma falta nos sistemas de distribuição é uma tarefa relativamente complexa. Essa complexidade se deve atualmente ao baixo índice de instrumentação da distribuição, a sistemas heterogêneos (seções de condutores com diferentes bitolas e comprimento no mesmo sistema, redes aéreas e/ou subterrâneas), ao desbalanceamento da rede (não transposição das linhas, presença de circuitos monofásicos, bifásicos e/ou trifásicos), ao dinamismo dos níveis de cargas, falta de informação sobre a rede (recondutoramento de trechos da rede ou troca de equipamentos sem atualização dos bancos de dados das distribuidoras), aliados ao 
desconhecimento da impedância equivalente do sistema a montante da subestação [230], [231].

Devido a essa inerente complexidade dos sistemas de distribuição boa parte dos métodos/sistemas tradicionais utilizados para a localização das faltas apresentam um erro na estimação da distância até falta, exigindo que a equipe de manutenção despachada para reparar a falta tenha que percorrer parte do alimentador fazendo inspeções visuais no percurso das linhas à procura do ponto defeituoso, o qual pode ser de difícil identificação. Além desse erro, localizadores que determinam apenas à distância da falta em relação à subestação sofrem com o problema da múltipla estimação.

A múltipla estimação (ME) acontece quando a distância da falta calculada em relação à subestação leva a uma localização que pode pertencer a diferentes ramos do sistema de distribuição. Quando a distância à falta é estimada em uma região sujeita a múltipla estimação esse trabalho das equipes de manutenção é redobrado podendo exigir a procura em diversos ramos. Todo esse processo de detecção e localização tende a ser demorado e ineficiente, e o tempo de inspeção requerido pode ser muito dispendioso, por isso o desenvolvimento de estratégias para agilizar o restabelecimento do fornecimento de energia são essenciais [232].

Tradicionalmente a detecção e localização de faltas em sistemas de distribuição radiais são feitas de maneira não automatizada, mapeando a região sem energia por intermédio das ligações dos consumidores, e utilizando medidas de tensão e corrente obtidas somente na subestação juntamente com parâmetros elétricos do sistema para determinar a distância [11]. Quando feitas de maneira automatizada geralmente são utilizados relés de distância baseados no método de reatância/impedância aparente para a localização da falta. Ambos os métodos apresentam o problema da múltipla estimação.

Tentando superar esse problema, diferentes métodos de localização de faltas têm sido propostos recentemente [233]-[242]. Em sua grande maioria, esses métodos foram elaborados visando substituir os métodos já existentes, apresentando uma implementação mais complexa, ou exigindo dados de difícil obtenção. Isso tem contribuído para que essas soluções não sejam amplamente adotadas na prática pelas distribuidoras, que têm optado por soluções alternativas baseadas em medições remotas ao longo do alimentador [243]-[246]. No entanto, tais medições são baseadas em 
equipamentos caros, como monitores de qualidade de energia, ou exigem a inserção de algum sinal de alta frequência na rede elétrica.

Uma solução mais econômica, proposta em [247], utiliza dados provenientes dos smart meters ao longo do alimentador para melhorar a performance do método de localização de faltas baseado em impedância, reduzindo a múltipla estimação, por intermédio da identificação de zonas de baixa tensão. Esse método, embora não elimine totalmente o problema da múltipla estimação, apresenta um bom resultado, sendo mais barato e flexível, utilizando apenas as informações disponíveis a partir do método baseado em impedância (como a impedância de sequência positiva do sistema e a distância estimada) e dos smart meters (valores de tensão rms).

Uma solução alternativa, elaborada pelo grupo de pesquisa do SEL/EESC/USP, proposta em [248], cujos resultados preliminares foram apresentados em [249], utiliza mineração de dados aplicada sobre dados pré-processados dos smart meters para auxiliar na identificação do ramal em falta, reduzindo a múltipla estimação. Embora esse método não elimine totalmente o problema da múltipla estimação, apresenta uma boa taxa de identificação do ramo faltoso.

Tal método utiliza dados de pré-falta e pós-falta dos smart meters conectados ao sistema para gerar um arquivo com as informações da falta, que é correlacionado com perfis conhecidos a fim de identificar aqueles com características semelhantes. Para isso é necessário certa quantidade de perfis previamente conhecidos, os quais podem ser criados por simulação, ou obtidos de sinais reais. Perfis de faltas semelhantes indicam faltas com características semelhantes, dentre essas características está a região de ocorrência da falta, que quando comparada com faltas de localização conhecida ajuda a determinar se a mesma ocorreu em um ramal lateral ou no ramal principal. Graças à utilização de sinais de pré e pós-falta sobrepostos, esse método não é afetado por variação no carregamento do sistema, e funciona de maneira independente do método de localização de faltas utilizado, porém necessita da análise de um especialista para a avaliação dos resultados.

Embora apresentando bons resultados, uma análise mais detalhada revela que esse método, que utiliza os dados de todas as faltas ocorridas ao longo do alimentador, não apresenta uma relação direta entre a quantidade de dados de faltas (perfis de falta) e a qualidade da sua resposta como se poderia pensar a priori, apresentando uma variação nesses resultados (melhorando ou piorando), não relacionada à quantidade de 
dados de faltas analisada. A complexidade inerente do sistema de distribuição faz com que outras características se tornem mais preponderantes do que a região de ocorrência da falta, influenciando no agrupamento, prejudicando a identificação do ramal faltoso.

Nesse contexto, este capítulo apresenta o desenvolvimento de uma ferramenta de auxílio à decisão que, utilizando a infraestrutura de nuvem já apresentada (Capítulo 4), é capaz de reduzir o problema da múltipla estimação em localizadores de falta. Essa aplicação em nuvem é uma evolução dos trabalhos previamente desenvolvidos, em [248] e [249], tornando o sistema menos sensível à variação na quantidade dos dados, dentre outras melhorias, como a análise automática de resultados e a utilização de dados apenas da região de múltipla estimação em que a falta foi localizada.

Essa ferramenta utiliza a técnica de data mining DAMICORE, sobre dados préprocessados pelos smart meters, para auxiliar na identificação do ramal em falta, porém segmentando o alimentador em regiões de múltipla estimação. Essa segmentação permitirá processar apenas os dados das faltas ocorridas dentro dessa região destacando os relacionamentos entre os dados com relação a essa região específica, conforme apresentado na Figura 27, melhorando assim os agrupamentos. Mais detalhes da aplicação serão apresentados no decorrer do capítulo.

Figura 27 - Segmentação do alimentador em Regiões de Múltipla Estimação

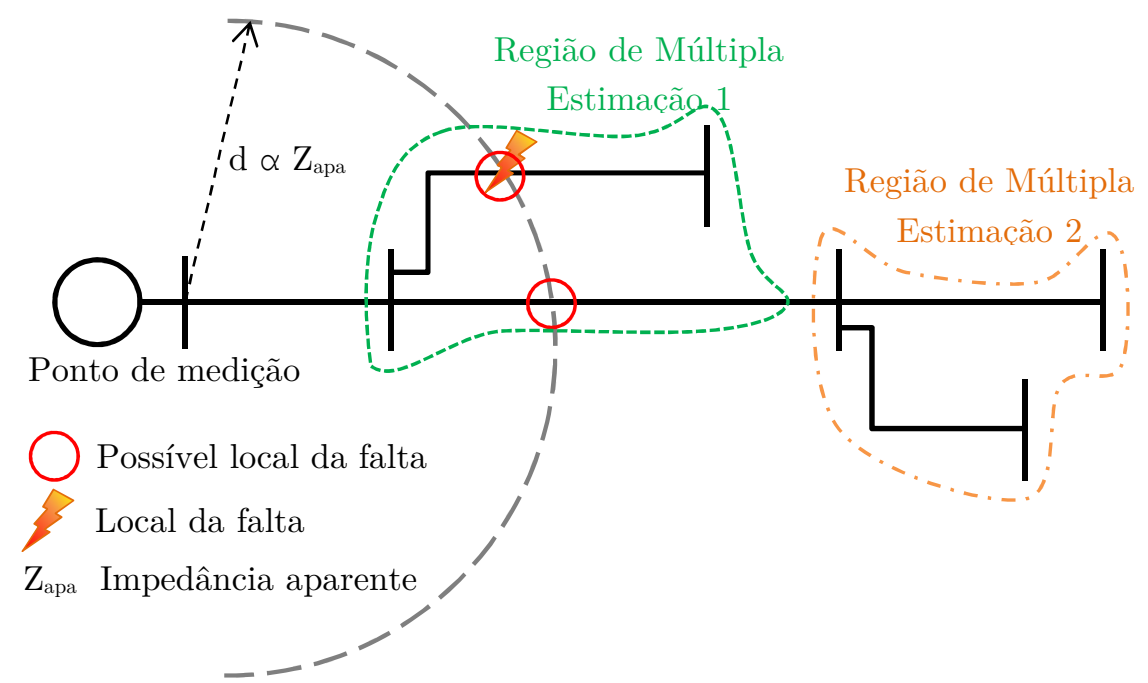

Fonte: Elaborado pelo autor.

\subsection{Aplicação proposta}

A aplicação proposta foi desenvolvida considerando que os smart meters estejam sincronizados em relação ao tempo com os demais sistemas envolvidos, que tenham 
comunicação bidirecional e capacidade de extrair, dos sinais de pré e pós-falta, as características que serão utilizadas para gerar o perfil da falta ${ }^{28}$ a ser minerado, sendo elas: (a) a variação do ângulo de fase entre sinais de tensão de pré e pós-falta, $\Delta \theta=\theta_{\text {pós }}-\theta_{\text {pré; }}$ e $(b)$ o valor RMS dos componentes superpostos ${ }^{29}$ de um ciclo da tensão, $S=\operatorname{rms}\left(U_{\text {pós }}-U_{\text {pré }}\right)$. Essas características devem ser extraídas para cada fase em relação ao instante de detecção da falta.

Os smart meters também devem ter a capacidade de armazenar os sinais de pré e pós-falta até que sejam processados, e possuir algum tipo de alimentação independente da rede de distribuição que possibilite o envio dos dados extraídos, mesmo durante a ausência de alimentação externa.

Num primeiro momento, o sistema de detecção/classificação e localização faltas da distribuidora deve atuar identificando, classificando e estimando a distância até a falta. Equipamentos de proteção comerciais como relés de proteção [250], [251] e registradores de falta [252] podem ser utilizados para essa finalidade. As informações geradas por esse equipamento precisam ser repassadas ao sistema de nuvem. Para isso é necessário utilizar algum dispositivo capaz de fazer a interface de comunicação entre a aplicação em nuvem e o equipamento de proteção.

A partir da detecção/classificação e localização de uma falta pelo sistema da distribuidora, uma mensagem notificação de falta deve ser gerada e transmitida ao sistema em nuvem iniciando assim a aplicação. Essa notificação é uma requisição HTTP/POST, direcionada a um URI específico no HES (Figura 19) responsável por receber e tratar essas notificações. A mensagem no corpo dessa requisição é um documento JSON contendo pelo menos o instante de detecção da falta, o tipo de falta, a distância estimada, o grau de exatidão dessa estimação (caso se pretenda considerar o erro do localizador).

Com a distância estimada pelo sistema de localização de faltas, a aplicação em nuvem, utilizando os dados topológicos do sistema de distribuição (esses dados podem

\footnotetext{
${ }^{28} \mathrm{O}$ perfil de falta é um arquivo contendo os dados da falta enviados por cada DCU, composto pelos ângulos de falta e os valores RMS das componentes superpostas, consolidados de seus Smart Meters, para cada fase os quais são agrupados e normalizados por DCU e por fase.

${ }^{29} \mathrm{O}$ cálculo dos componentes superpostos é feito subtraindo o sinal de pré-falta (antes do instante de incidência da falta) do sinal de pós-falta correspondente (após o instante de incidência da falta, antes da falta ser eliminada), para cada amostra do sinal.
} 
estar armazenados em um banco de dados, ou podem ser enviados juntamente com a notificação da falta) e considerando a exatidão da estimação caso tenha sido informada, determina se a falta está em uma região sujeita aos efeitos da múltipla estimação para o tipo da falta em questão. Em caso positivo, a aplicação em nuvem solicita simultaneamente a todos os DCUs próximos dessas regiões as características do sinal de falta consolidados de seus smart meters, as quais serão utilizadas para produzir o perfil da falta.

Os DCUs repassam a solicitação, recebida da aplicação em nuvem, aos smart meters informando o instante em que a falta foi detectada. Os smart meters utilizam essa informação para extrair as características do sinal de tensão e retornam o resultado do processamento ao DCU. Os DCUs consolidam esses dados calculando a média, para cada fase, das características extraídas para todos os seus smart meters que estejam conectados a um mesmo transformador de distribuição e armazena esse resultado em seu buffer local. Quando os dados de todos os seus smart meters tiverem sido consolidados o DCU os envia à aplicação em nuvem.

Após receber os dados de todos os DCUs, a aplicação em nuvem cria um perfil da falta para a região de múltipla estimação determinada e armazena-o como um documento na coleção de dados novos (income_data) do banco de dados mongoDB, de acordo com a classificação do tipo de falta: monofásica (A-t, B-t, C-t), bifásica (A-B, B-C, C-A), trifásica (A-B-C), bifásica com envolvimento de terra (A-B-t, B-C-t, C-A-t) e trifásica com envolvimento de terra (A-B-C-t), separando dessa forma os perfis de faltas em coleções de dados distintas para cada um dos 11 tipos de falta, e para cada região de múltipla estimação.

Depois de salvar os dados, a aplicação em nuvem inicia o serviço de mineração de dados conforme descrito na Seção 4.4. O resultado dessa mineração é armazenado no banco de dados mongoDB, na coleção de resultados (results_collection), ficando disponível para consulta, visualização e análise.

Após a eliminação da falta pelas equipes de solo, a localização real da falta deve ser inserida no seu respectivo perfil de falta, atualizando a coleção de dados antigos (historical_collection) no MongoDB, de modo que essa falta possa contribuir para a análise de novas faltas que possa ocorrer, juntamente com os dados previamente armazenados. 
A etapa de análise consiste em avaliar o cluster no qual a falta foi agrupada a fim de determinar, a partir das faltas conhecidas, se o cluster agrupa, predominantemente, faltas no ramal lateral ou no ramal principal, o que fornece um indicativo sobre a qual ramal a falta desconhecida pertence. Essa análise depende do conhecimento do especialista, que tomando por base a topologia do sistema, suas características e as características das demais faltas agrupadas no cluster, consegue avaliar a qualidade do agrupamento e extrair informações sobre a falta.

Visando automatizar esse processo, foi desenvolvida uma ferramenta de análise automática, a qual não existia nos trabalhos anteriores, cujo fluxograma de funcionamento é apresentado na Figura 28.

Figura 28 - Fluxograma para análise dos clusters

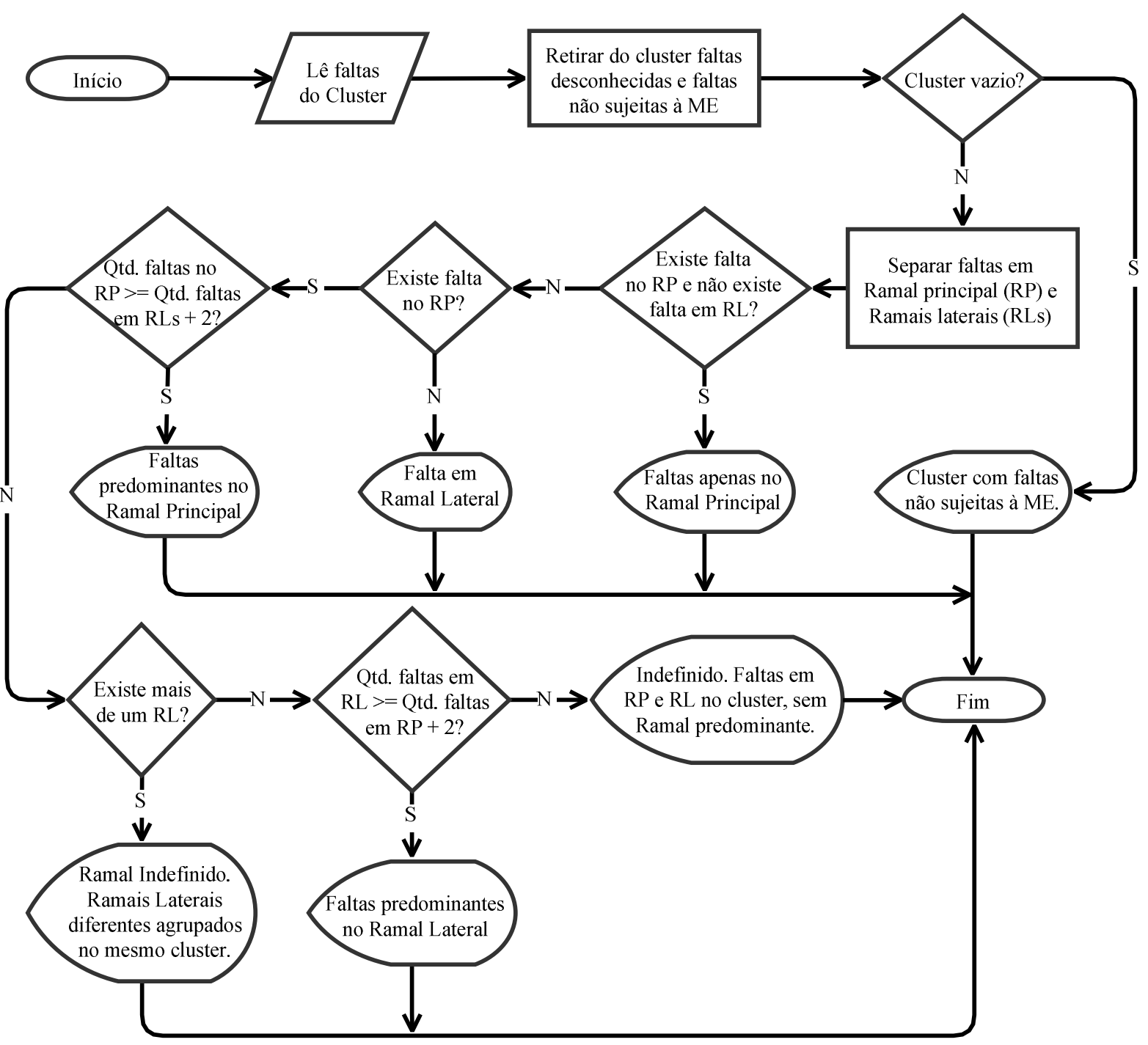

Fonte: Elaborada pelo autor. 
A ferramenta de análise utiliza as informações topológicas do sistema e o resultado da mineração de dados, para avaliar a qualidade do agrupamento e determinar o ramal mais provável onde tenha ocorrido a falta.

De forma resumida, uma vez que a falta já tenha sido identificada e classificada pelo sistema da concessionária, os passos para a localização da falta utilizando a aplicação proposta, considerando que já existam dados de faltas conhecidas armazenados no banco de dados da aplicação, são:

Passo 1: Aplicar um método de localização;

Passo 2: Iniciar a aplicação em nuvem através do envio de uma mensagem de notificação de falta;

Passo 3: Determinar se a falta está em uma região de múltipla estimação. Em caso positivo continuar para o passo 4. Caso contrário, informar que falta não está em uma região de múltipla estimação e finalizar a aplicação (passo 10);

Passo 4: Solicitar aos DCUs selecionados, para a região de múltipla estimação definida, as características do sinal de falta;

Passo 5: Criar um perfil de falta com os dados dos DCUs e armazenar no MongoDB;

Passo 6: Iniciar o serviço de mineração de dados (DAMICORE);

Passo 7: Salvar o resultado do DAMICORE no MongoDB e finalizar o serviço de mineração de dados;

Passo 8: Executar a ferramenta de análise automática do resultado (fluxograma da Figura 28) e apresentar a resposta encontrada;

Passo 9: Atualizar os dados da falta no MongoDB com a localização real da falta, determinada pelas equipes de manutenção, de modo que essa falta possa contribuir para a análise de novas faltas que venham a ocorrer (opcional);

Passo 10: Finalizar a aplicação.

Para avaliar essa aplicação foram feitas uma série de simulações. Essas simulações tomaram por base o sistema de testes do IEEE de 34 barras [253], [254], o qual foi modelado utilizando o software ATPDraw. A simulação foi realizada no 
software ATP, utilizando o software MatLab para automatizar o processo de geração, captura e processamento das amostras de faltas. Essas faltas foram utilizadas para alimentar o banco de dados em nuvem para o teste da aplicação. As etapas de teste e avaliação serão apresentadas as próximas seções.

\subsection{Sistema de testes utilizado}

O sistema utilizado para simular as situações de faltas foi o alimentador de testes do IEEE de 34 barras, cujo diagrama é apresentado na Figura 29.

Figura 29 - Alimentador de teste IEEE 34 barras

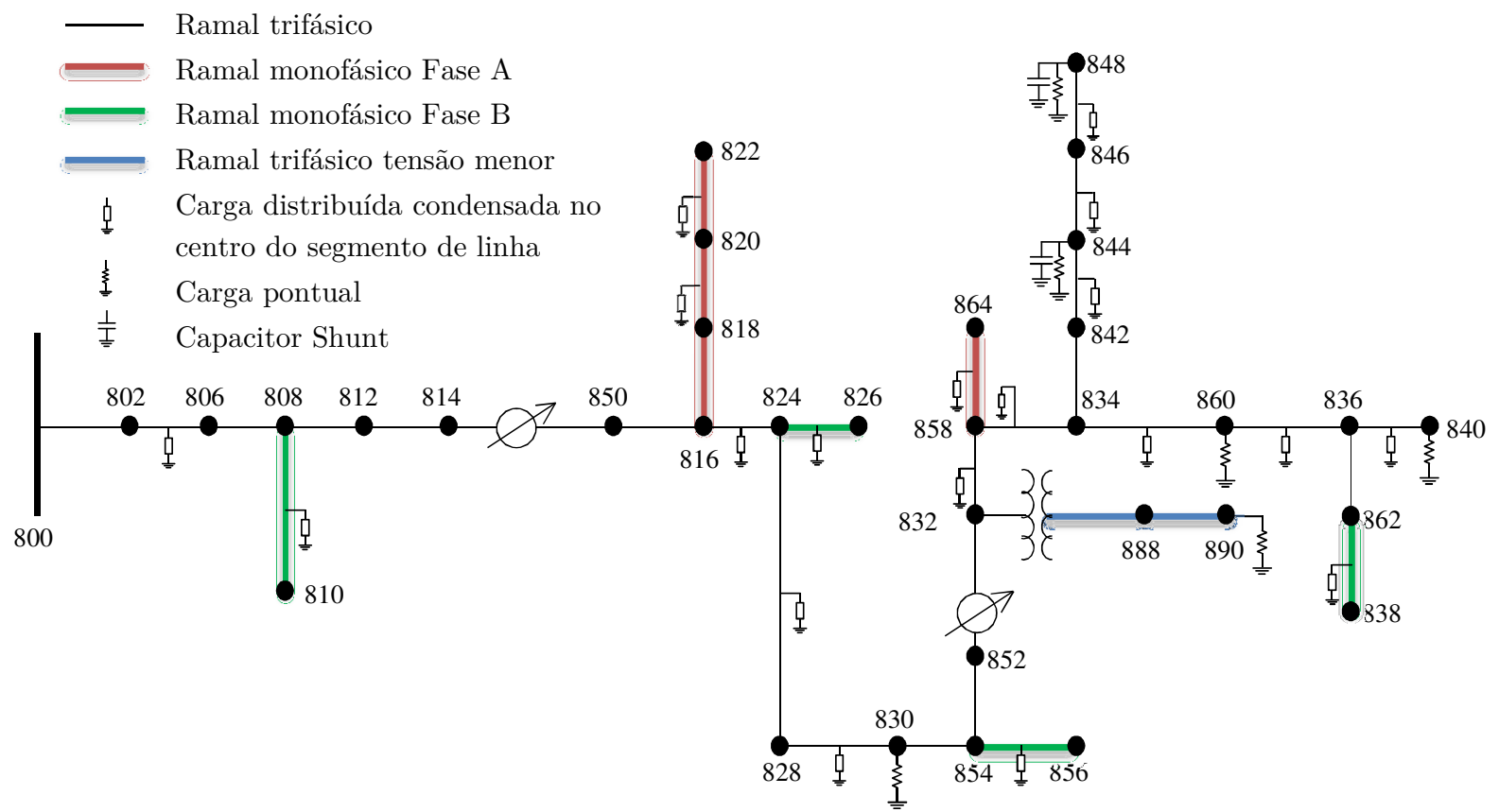

Fonte: adaptado de [253]

Esse sistema é parte de um alimentador real existente no Arizona quando da divulgação do sistema de testes em 1991. A tensão (de linha) nominal do alimentador, conforme descrito em [253], é de 24,9 kV e suas características são:

1. Muito longo $(\sim 94 \mathrm{~km})$ e levemente carregado;

2. Possui dois reguladores de tensão para manter um bom perfil de tensão;

3. Em um pequeno trecho do alimentador um transformador reduz a tensão para $4,16 \mathrm{kV}$; 
4. Carregamento desequilibrado com cargas "pontuais" e cargas "distribuídas", sendo as cargas distribuídas consideradas conectadas no centro do segmento de linha;

5. Bancos de capacitores;

6. Ramais laterais monofásicos.

Todas as cargas foram simuladas com impedância constante. Não foram aplicadas faltas no trecho trifásico de menor tensão em azul.

A Figura 29 embora seja interessante para representar os nós (barras) do alimentador, a disposição de suas cargas e segmentos de linha, ela não reflete a extensão real do alimentador, nem a região susceptível ao efeito da múltipla estimação. Nesse sentido, é apresentado na Figura 30 o alimentador em escala. Por ela podemos visualizar a extensão dos ramais laterais, mantida as mesmas cores da legenda da Figura 29. Pode-se perceber que o alimentador possui um grande ramal monofásico fase A e outros ramais laterais menores, tanto fase $\mathrm{A}$, quanto fase $\mathrm{B}$ e nenhum fase $\mathrm{C}$, sendo o final do alimentador a região mais densamente carregada, com muitas cargas em uma extensão relativamente pequena.

Esse sistema foi segmentado em regiões distintas de múltipla estimação de acordo com o tipo de falta, permitindo a coletar somente os dados dos smart meter próximos à região de múltipla estimação e limitando a análise apenas às faltas de determinada região. Essa abordagem segmentada será apresentada na próxima seção.

\subsection{Abordagem segmentada e disposição dos pontos de medição}

Neste trabalho, o alimentador de testes foi dividido em regiões de múltipla estimação, considerando como ramal principal os segmentos trifásicos que ligam a barra 800 até a 840 e como ramal lateral os trechos que derivam do ramal principal. Essas regiões contemplam o ramal lateral e o comprimento desse ramal lateral projetado sobre o ramal principal, conforme apresentado na Figura 31. 


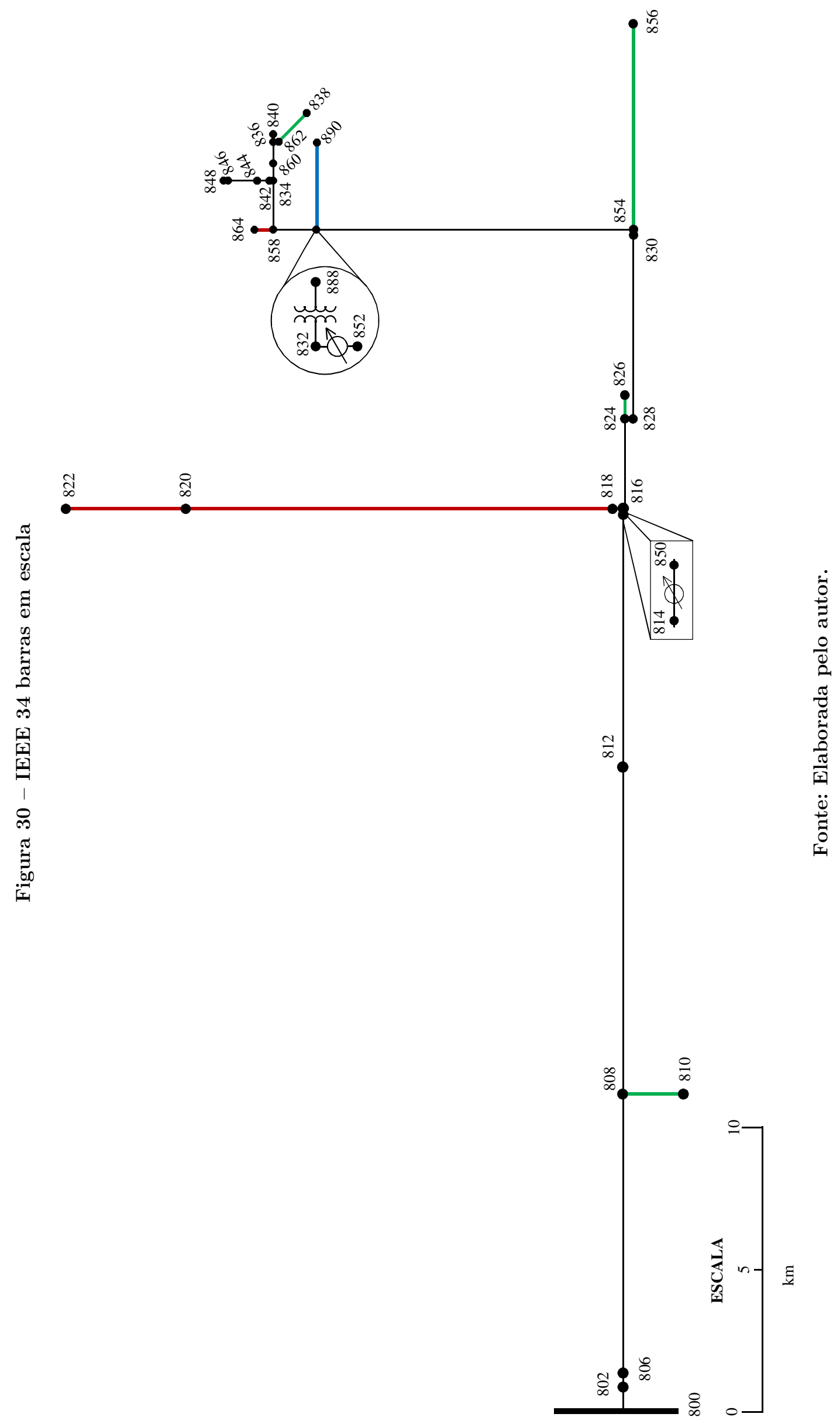


Figura 31 - Regiões de múltipla estimação. (a) Faltas monofásicas fase A. (b) Faltas monofásicas fase B. (c) Demais tipos de falta.

\#. Ponto de medição (DCU)

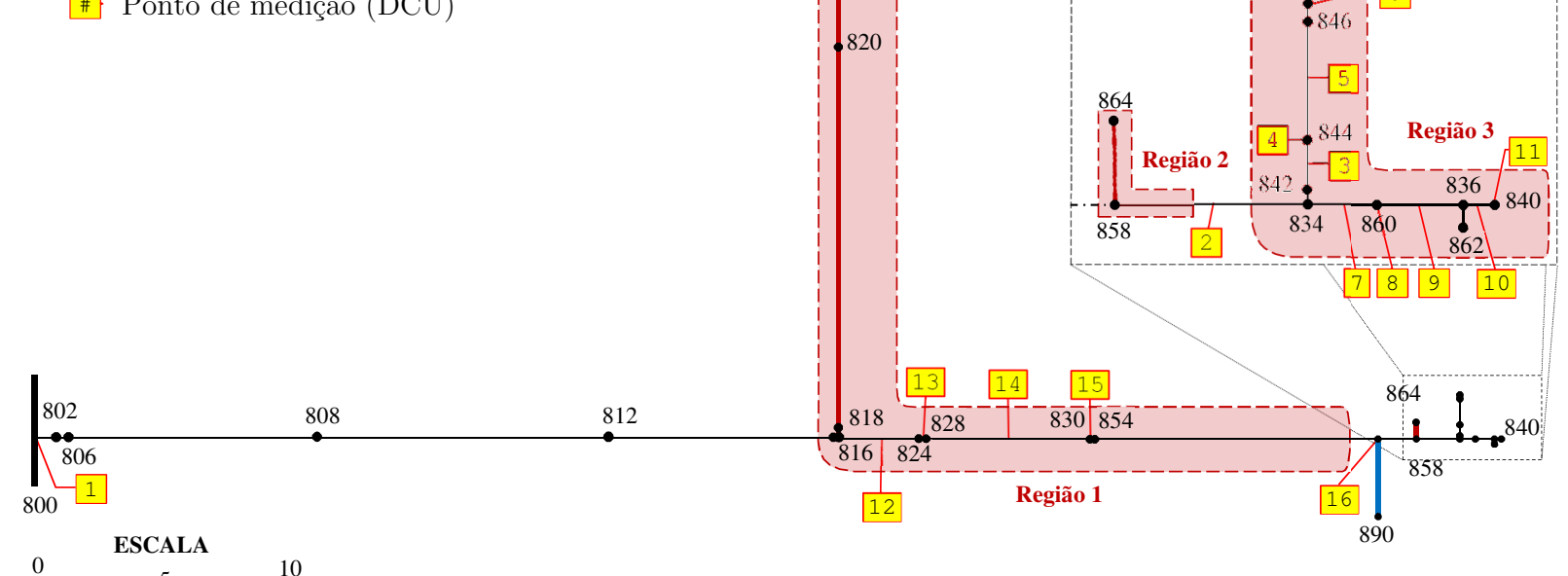

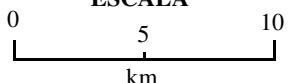

\# Ponto de medição (DCU)

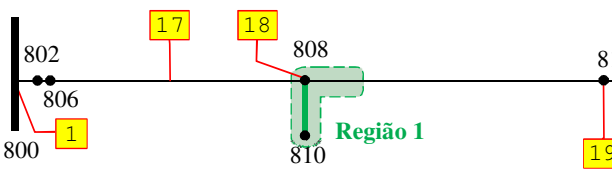

ESCALA

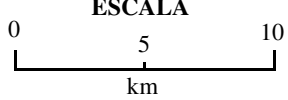

\#. Ponto de medição (DCU)

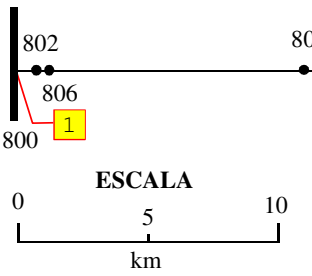

(b)

(a)
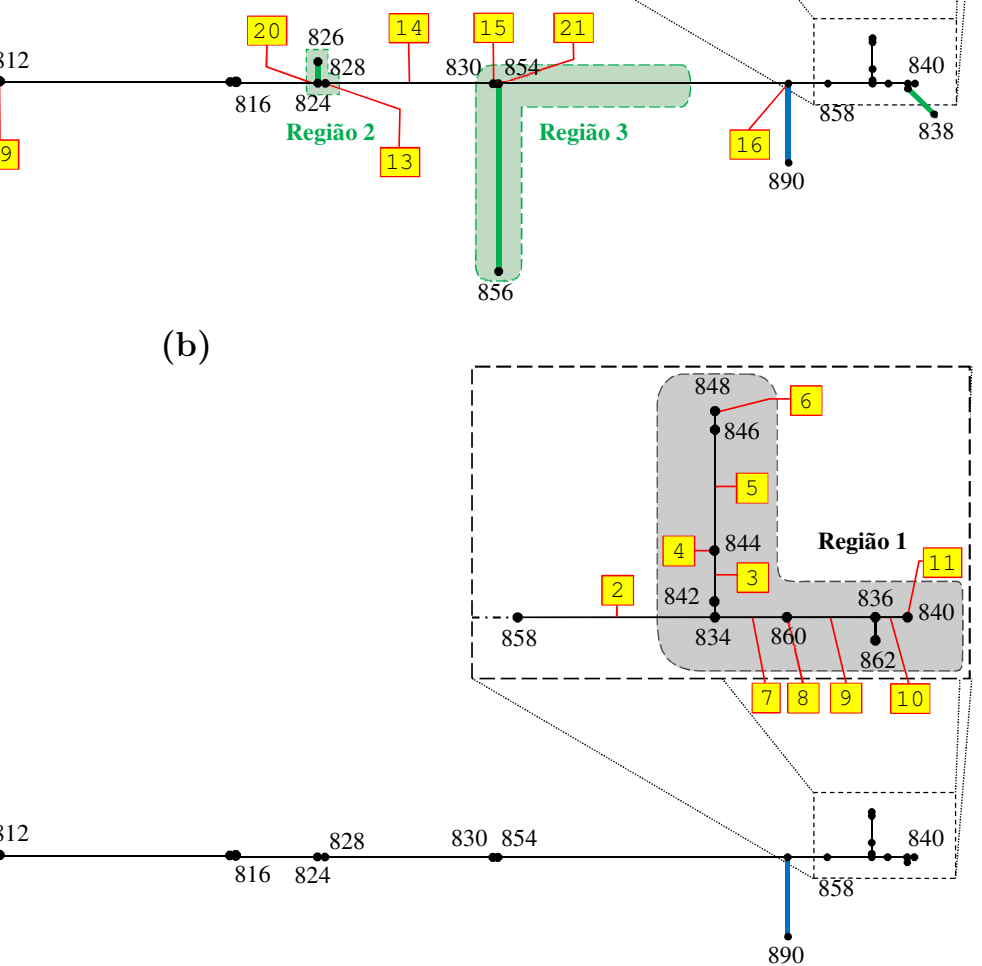

(c)

Fonte: Elaborada pelo autor. 
As faltas cuja localização, considerando o tipo de falta e o erro do localizador, forem identificadas dentro dessas regiões sujeitas a múltipla estimação serão analisadas pela aplicação conforme descrito anteriormente. Para faltas monofásicas envolvendo a fase A o alimentador foi dividido em três regiões conforme apresentado na Figura 31(a). Faltas monofásicas na fase B são possíveis em quatro regiões, conforme Figura 31(b), já os demais tipos de faltas (monofásicas em C, bifásicas e trifásicas envolvendo ou não o terra) somente serão possíveis na região trifásica da porção final do alimentador, conforme destacado na Figura 31(c).

Para avaliar a metodologia proposta foram realizados testes em diferentes cenários considerando a contribuição das medições de tensão e corrente na subestação e a influência da quantidade de pontos de medição na determinação do ramal faltoso.

Nesses testes o localizador de faltas foi considerado ideal, não apresentando erro de estimação de distância, e os dados da falta, gerados pelos smart meters, foram considerados já consolidados nos seus respectivos DCUs. Cada DCU representa um ponto de medição $(\mathrm{PM})$, e retorna uma matriz contendo as características da falta, descritas na Seção 5.1, separadas por fase. Os pontos de medição foram alocados no ramal principal, sobre um barramento (nó) do sistema, ou sobre uma carga, conforme os marcadores amarelos na Figura 31.

Para os testes foram criados cinco cenários:

$\square$ O cenário 1 considera apenas as medições da subestação para a extração das características da falta. São utilizados os sinais de tensão e corrente por fase para gerar o perfil da falta. Neste cenário apenas o ponto de medição 1 é utilizado;

$\square$ O cenário 2 considera as medições nas cargas trifásicas no ramal principal dentro da região de múltipla estimação, e quando essas não existirem considera-se as medições em cargas trifásica e/ou nós mais próximos dessa região;

$\square$ O cenário 3 considera apenas um ponto de medição para cada Ramal Lateral (RL) da região de múltipla estimação. Esse PM é o ponto no ramal principal mais distante da ramificação para cada RL na região analisada;

$\square$ Os cenários 4 e 5 consideram os dois cenários anteriores agregando as características obtidas das medições na subestação. 
A quantidade de pontos de medição utilizados para os cenários 2 e 3 é apresentada na Tabela 5. Os pontos de medição para os cenários 5 e 6 são os mesmos dos cenários 2 e 3 respectivamente acrescidos do PM 1 da subestação de energia (SE).

Tabela 5 - Pontos de medição utilizados para cada tipo de falta e região de ME

\begin{tabular}{cccccc}
\hline \multirow{2}{*}{ Tipo de falta } & Região de & \multicolumn{3}{c}{ Cenário 2 } & \multicolumn{2}{c}{ Cenário 3 } \\
\cline { 3 - 6 } & ME & Qtd. & Número do PM & Qtd. & Número do PM \\
\hline \multirow{2}{*}{ Monofásicas } & $\mathbf{1}$ & 5 & $12,13,14,15,16$ & 1 & 16 \\
fase A & $\mathbf{2}$ & 1 & 2 & 1 & 2 \\
& $\mathbf{3}$ & 10 & $3,4,5,6,7,8,9,10,11$ & 2 & 6,10 \\
\hline \multirow{2}{*}{ Monofásicas } & $\mathbf{1}$ & 3 & $17,18,19$ & 1 & 19 \\
fase B & $\mathbf{2}$ & 3 & $20,13,14$ & 1 & 16 \\
& $\mathbf{3}$ & 3 & $15,21,16$ & 2 & 6,10 \\
\hline Outros tipos & $\mathbf{4}$ & 10 & $3,4,5,6,7,8,9,10,11$ & 2 & 6,10 \\
\hline
\end{tabular}

Fonte: Elaborado pelo autor.

Os seguintes critérios foram adotados para a simulação das faltas:

$\square$ Faltas igualmente espaçadas entre cada trecho de linha da região de múltipla estimação;

$\square$ Para trechos cujo comprimento seja inferior à distância entre faltas definida para a região de múltipla estimação, adota-se apenas uma falta no meio do trecho.

$\square$ Para cada posição de falta foram simuladas 5 faltas com valor de resistência de falta à terra aletoriamente definido ${ }^{30}$ no intervalo de $1,0 \mathrm{a}$ 50,0 ohms utilizando uma distribuição uniforme.

$\square$ Para faltas entre fases, foi utilizada uma resistência fixa de 0,5 ohms entre as fases envolvidas;

A fim de avaliar os resultados de uma maneira mais generalista, independente da resistência de falta utilizada nas simulações, o valor das mesmas foi definido de maneira aleatória, tornando o sistema mais abrangente, podendo ser aplicado para qualquer valor de resistência de falta dentro do escopo definido.

\footnotetext{
${ }^{30}$ A resistência de falta foi definida utilizando a função rand do MATLAB através do comando $r=a$ $+(b-a) * r a n d$, onde a e b são respectivamente os limites inferiores e superiores da variável r. A função rand gera um número pseudoaleatório entre 0 e 1 que pode ser utilizado como um valor verdadeiramente aleatório e independente [258].
} 
Dessa maneira, foram simulados diversos casos de faltas com localizações conhecidas, linearmente espaçadas dentro de cada região de múltipla estimação, como apresentado na Tabela 6.

Tabela 6 - Faltas simuladas por região de múltipla estimação

\begin{tabular}{ccccc}
\hline \multirow{2}{*}{ Tipo de falta } & $\begin{array}{c}\text { Região de } \\
\text { ME }\end{array}$ & $\begin{array}{c}\text { Qtd. de } \\
\text { faltas }\end{array}$ & $\begin{array}{c}\text { Posições } \\
\text { diferentes }\end{array}$ & $\begin{array}{c}\text { Espaçamento } \\
(\mathbf{m})\end{array}$ \\
\hline \multirow{2}{*}{ Monofásicas fase A } & $\mathbf{1}$ & 435 & 87 & 500 \\
\cline { 2 - 5 } & $\mathbf{2}$ & 340 & 68 & 20 \\
\cline { 2 - 5 } & $\mathbf{3}$ & 450 & 90 & 50 \\
\cline { 2 - 5 } Monofásicas fase B & $\mathbf{1}$ & 580 & 116 & 50 \\
\cline { 2 - 5 } & $\mathbf{2}$ & 600 & 120 & 50 \\
\cline { 2 - 5 } & $\mathbf{3}$ & 510 & 102 & 500 \\
\hline Outros tipos com terra & $\mathbf{4}$ & 450 & 90 & 50 \\
\hline Outros tipos sem terra & $\mathbf{1}$ & 450 & 450 & 10 \\
\hline
\end{tabular}

Fonte: Elaborada pelo autor.

A partir dessas simulações, para cada falta, foi gerado um perfil de falta e armazenado no banco de dados, para cada cenário de teste. A Tabela 7 apresenta o resultado desses testes, considerando a redução percentual na região de múltipla estimação. Essa redução foi calculada como:

$$
R_{\%}=\frac{\sum D F_{R}(n)}{\sum D F_{\text {sme }}(n)} \times 100,
$$

onde $n$ varia de 1 até a quantidade total de faltas simuladas, $D F_{s m e}$ é a distância da falta sujeita a múltipla estimação, cujo somatório equivale à distância de todas faltas em múltipla estimação, $D F_{R}$ é a distância da falta sujeita a múltipla estimação cujo ramal foi corretamente identificado pela análise automática apresentada na Figura 28, reduzindo assim a distância sujeita a múltipla estimação quando a falta for corretamente identificada. R\% avalia o quanto a ferramenta foi capaz de reduzir a extensão sujeita a múltipla estimação dentro do universo de faltas com múltipla estimação simuladas. Na prática, esse valor está relacionado com a distância total que a equipe de manutenção deixaria de percorrer para encontrar o ponto de falta, com a utilização da ferramenta, caso todas as faltas simuladas fossem reais [248]. R\% também pode ser interpretado como uma média ponderada dos acertos e erros utilizando a distância da falta como ponderação, atribuindo o valor 1 para os acertos e 0 para os erros, multiplicada por 100, e é uma medida que representa quão boa foi a capacidade da aplicação para reduzir o a região de múltipla estimação. 
Tabela 7 - Região de múltipla estimação reduzida ( $\mathrm{R \%})$ para cada cenário, separada por tipo de falta e região de múltipla estimação.

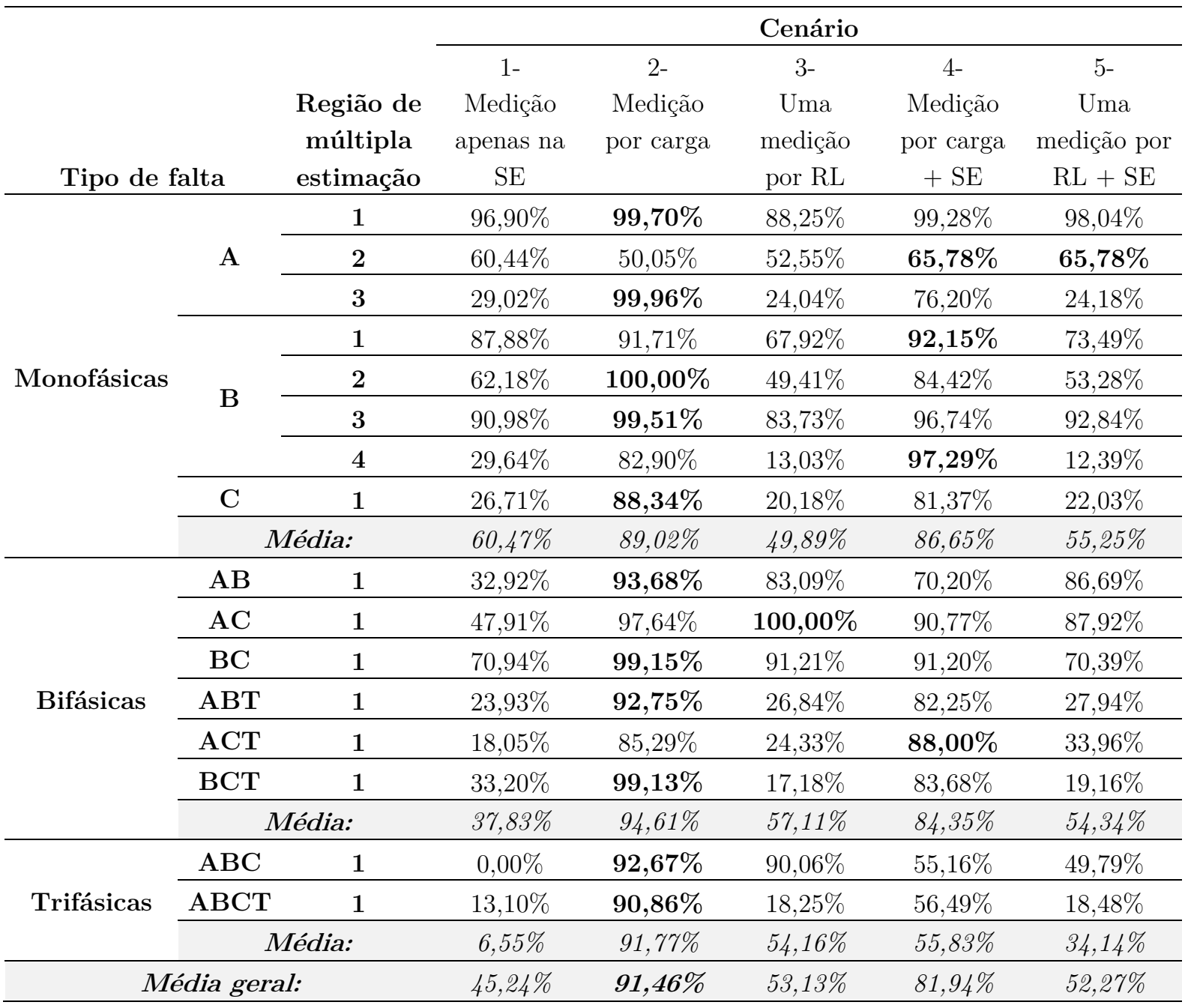

Fonte: Elaborada pelo autor.

Na Tabela 7 os maiores percentuais de redução, obtidos para cada tipo de falta em uma mesma região foram destacados em negrito. A partir dessa tabela podemos perceber que o cenário 2, que utiliza um ponto de medição por carga na região de múltipla estimação, apresentou os melhores resultados, de uma maneira geral, para todos os casos simulados, obtendo a melhor média geral na redução da extensão de múltipla estimação. Comparando esses resultados com as informações da Tabela 5, percebemos que esse cenário é o que apresenta mais pontos de medição por região de múltipla estimação. Nesse mesmo sentido, a região 2 das faltas monofásicas em A foi a que apresentou menor redução em todos os cenários, sendo também a região que possui a menor quantidade de pontos de medição, indicando a influência da quantidade de pontos de medição no resultado obtido. 
O cenário 1, com medições apenas na subestação, foi o que apresentou piores resultados de uma maneira geral, sendo ineficiente principalmente para faltas ocorridas no final do alimentador como era de se esperar (na região 3 da fase A, região 4 da fase B e região 1 para os outros tipos de falta), pois quanto mais distante a falta em relação ao ponto de medição na SE menor a variação nos perfis de falta, fazendo com que sua "clusterização" não seja tão eficiente.

O cenário 3, que considera apenas um ponto de medição por ramal lateral, apresentou bons resultados apenas em algumas situações, sendo muito instável, possivelmente devido à baixa quantidade de pontos de medição utilizados.

O cenário 5 que utiliza os mesmos pontos de medição do cenário 3, incluindo as medições da subestação não apresentou melhoras significativas em relação ao cenário 3. No cenário 4, que utiliza os mesmos pontos de medição do cenário 2 juntamente com as medições da subestação, apresentou uma leve piora na maioria dos resultados principalmente para as faltas trifásicas.

A inclusão das medições feitas na subestação trouxe pouca contribuição para os cenários analisados, principalmente para faltas localizadas na porção final do alimentador, pois a subestação está distante das regiões onde ocorreram as faltas. Como essas medições trazem pouca informação sobre o ramal faltoso a qualidade dos dados de entrada diminui influenciando negativamente o perfil de falta gerado, atrapalhando na "clusterização". No entanto, para as faltas monofásicas na fase A, que estão mais próximas da SE, as medidas da SE ajudaram a melhorar o resultado obtido, sugerindo que as medidas da subestação podem ser utilizadas para melhorar os resultados, caso a SE esteja localizada próxima à região de ME analisada.

Outra observação interessante é que houve uma piora nos resultados das faltas bifásicas e trifásicas ambas com envolvimento do terra em relação às faltas sem envolvimento do terra. Essa piora se deve à menor diversidade nos perfis de falta para faltas com envolvimento de terra.

Em ambos os casos (com envolvimento do terra e sem envolvimento do terra), conforme apresentado anteriormente, foram simuladas 450 faltas, no entanto para os casos sem envolvimento de terra foram geradas 450 faltas em 450 posições de faltas diferentes, uma vez que não existe resistência de falta para o terra; já para os casos com envolvimento de terra foram geradas 5 faltas para cada posição de falta, em um total de 90 posições de falta. Essas 5 faltas geradas em uma mesma posição de falta, 
apresentam características muito semelhantes, exceto pela resistência de falta à terra, essa semelhança faz com que tais faltas estejam muito próximas na árvore filogenética, como era de se esperar.

Essa menor diversidade nos dados e a grande semelhança entre as faltas aplicadas num mesmo ponto de medição, em especial para as faltas trifásicas, fazem com que a última etapa do DAMICORE, algoritmo FN, agrupe os dados de dois ou mais ramos em um único cluster, prejudicando o resultado obtido pela análise da Figura 28. Para exemplificar o que foi descrito, a Figura 32 apresenta o resultado da mineração de dados, em forma de árvore filogenética, para o cenário 2 faltas tipo ACT destacando o cluster 11, nesse cenário $\mathrm{R} \%$ para as faltas tipo $\mathrm{AC}$ foi de $97,64 \%$ enquanto as faltas ACT tiveram um resultado pior de 85,29\%.

$\mathrm{Na}$ Figura 32, a árvore filogenética foi separada por cluster, sendo cada cor relativa a um cluster diferente, o número do cluster é apresentado após os dois hifens (--) no final do nome do perfil de falta. Os perfis de faltas foram nomeados da seguinte maneira SSEE_DDDD_RR_0X em relação ao trecho onde a falta foi aplicada, onde SS representa os dois últimos algarismos da barra inicial, EE representa os dois últimos algarismos da barra final, DDDD é a distância percentual em relação à barra inicial do trecho multiplicada por cem, RR é a impedância da falta e X é um fator diferenciador caso exista mais de uma falta com as mesmas características. Nela observa-se que no cluster 11 há uma mistura entre faltas que ocorreram no RL e no RP, porém os ramos da árvore mostram agrupamentos bem definidos das faltas aplicadas na mesma posição, o que indica que embora o NJ tenha organizado a árvore filogenética corretamente, o FN não foi capaz de separar os agrupamentos em cluster menores devido a pouca diversidade nos dados. Essa diversidade pode ser conseguida aumentando os pontos de aplicação de falta para os casos com envolvimento do terra. Resultados semelhantes foram observados para as faltas trifásicas, porém com uma maior frequência, visto que as faltas trifásicas são equilibradas sofrendo menor influência da resistência para o terra quando comparadas à faltas bifásicas com o terra.

Com base nas informações apresentadas a configuração mais indicada para o alimentador de testes escolhido é a utilizada no cenário 2, com mais pontos de medição distribuídos sobre o alimentador principal na região de múltipla estimação, sendo essa configuração adotada no decorrer deste trabalho. 
Figura 32 - Árvore filogenética com o resultado da mineração de dados para faltas do tipo ACT, no cenário 2, destacando o cluster 11

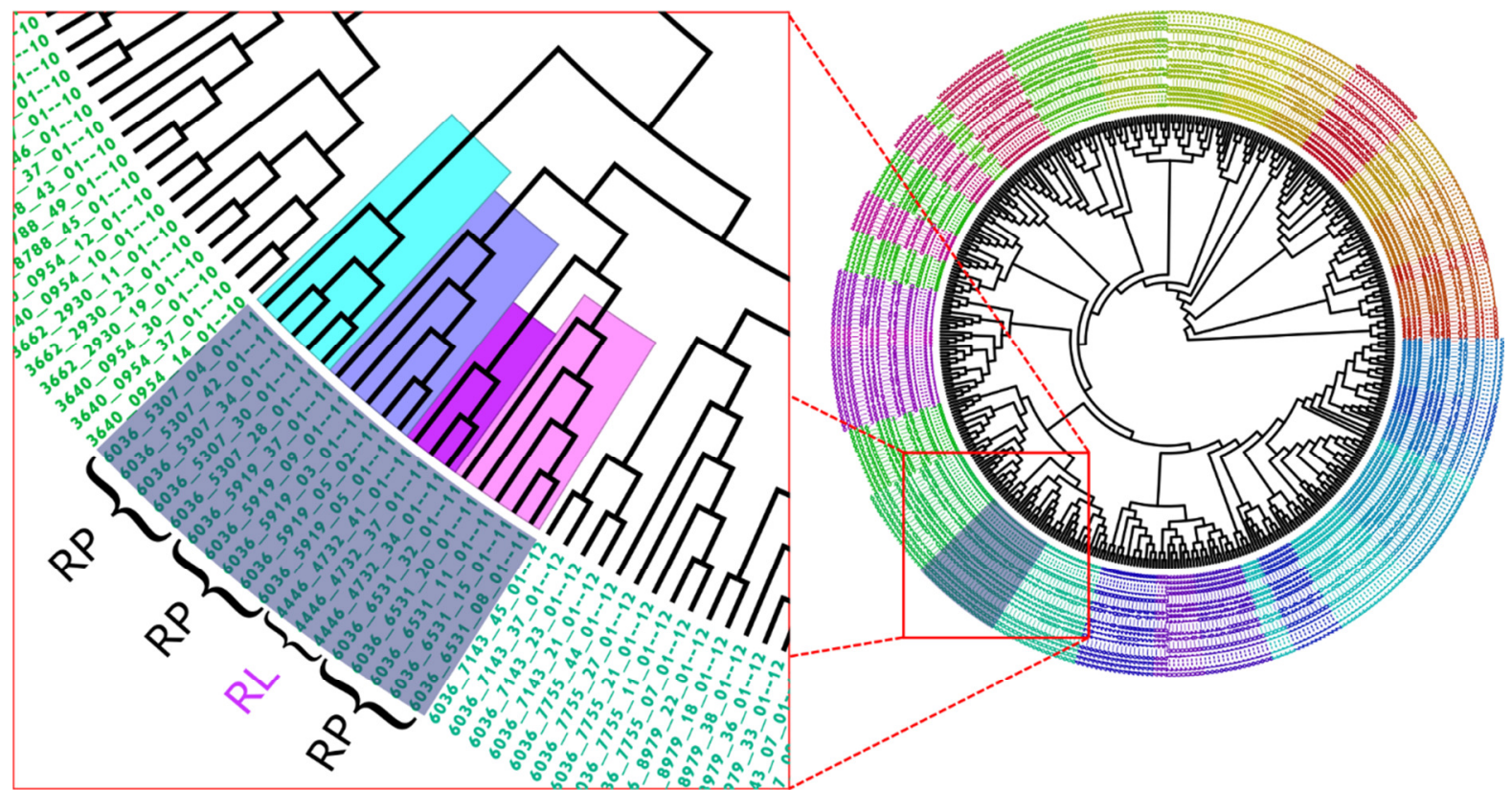

Fonte: Elaborada pelo autor.

\subsection{Sensitividade em relação à quantidade de dados}

Para avaliar a sensitividade dos resultados obtidos pelo cenário 2 em relação à quantidade de perfis de falta utilizados para a mineração de dados, foram realizadas simulações aumentando progressivamente a quantidade de dados utilizados a fim de analisar o comportamento das respostas obtidas.

O ensaio foi realizado da seguinte maneira:

\ Para cada tipo de falta e respectivas regiões de múltipla estimação foram selecionadas aleatoriamente, dos dados de faltas gerados para o cenário 2, pelo menos 50 amostras de dados para comporem um conjunto inicial de dados. Essas amostras foram mineradas e analisadas segundo a metodologia previamente explicada, anotando-se o $\mathrm{R} \%$ obtido.

$\square$ A esse conjunto inicial foram adicionadas pelo menos 15 outras amostras aleatórias de forma que ao final do processo fossem realizados 20 ensaios consecutivos contemplando todos os dados previamente simulados para o cenário 2. Esse novo conjunto de dados foi minerado e analisado anotando-se o R\% de cada etapa. 
口 Ao final do processo foi calculada a média acumulada a cada iteração.

Os resultados obtidos por esse ensaio para os 11 tipos de faltas em suas respectivas regiões de múltipla estimação são apresentados nos gráficos da Figura 33. A partir desses gráficos podemos perceber que à medida que a quantidade de dados aumenta, de modo geral a partir de 100 amostras, a resposta tende a sofrer menos variação.

Figura $33-\mathbf{R} \%$ em relação à quantidade de dados

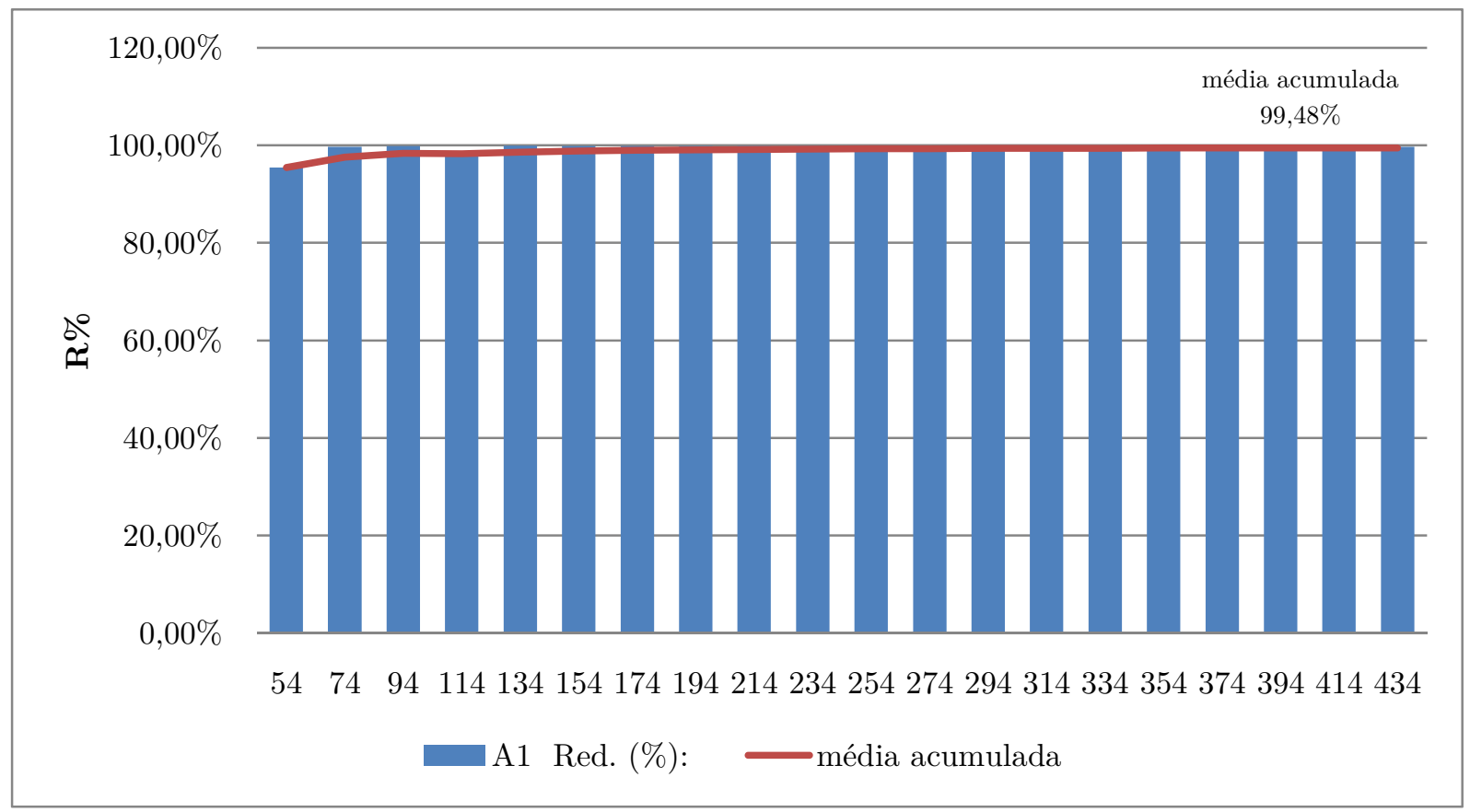

(a) Faltas monofásicas em A na região 1

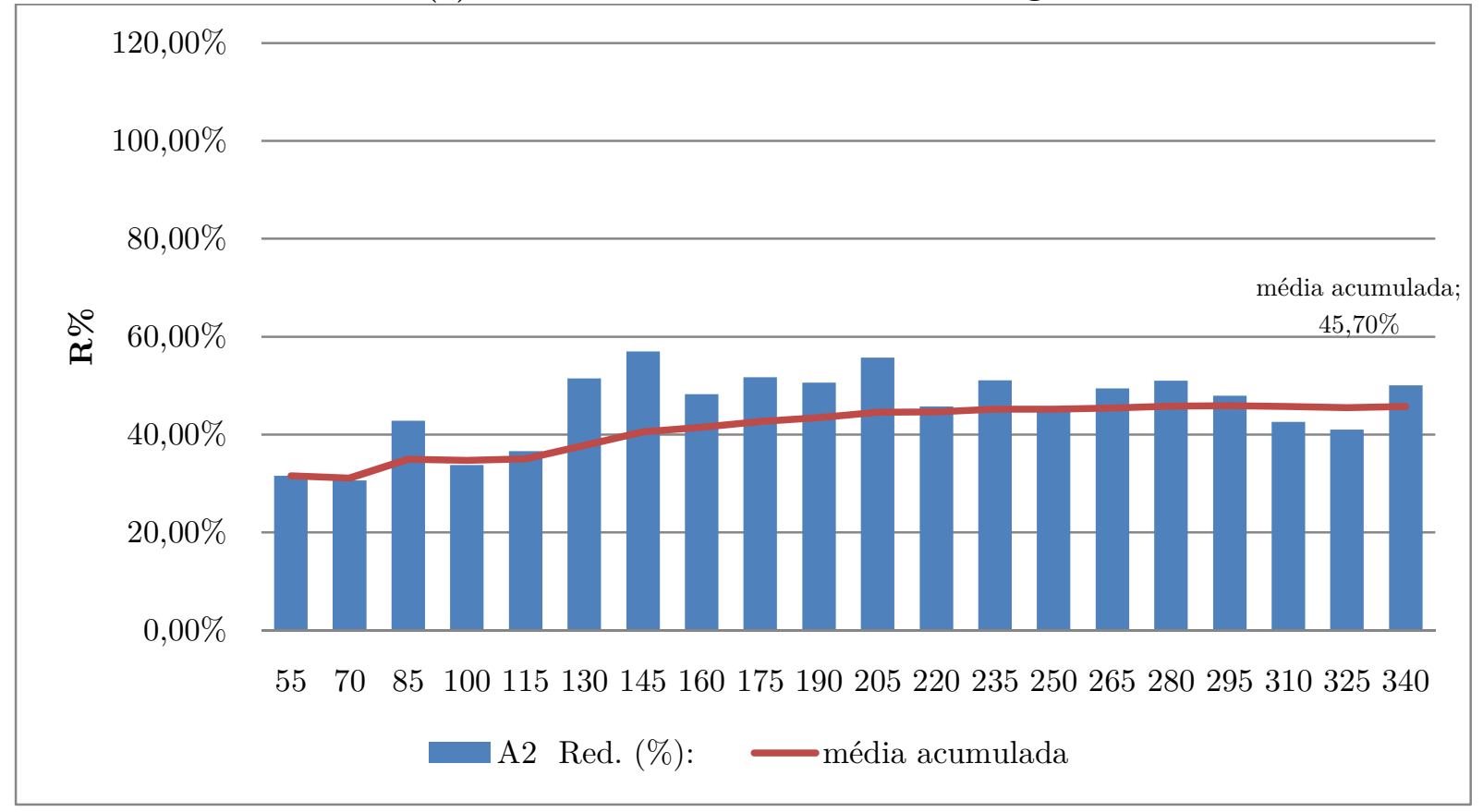

(b) Faltas monofásicas em $\mathrm{A}$ na região 2 


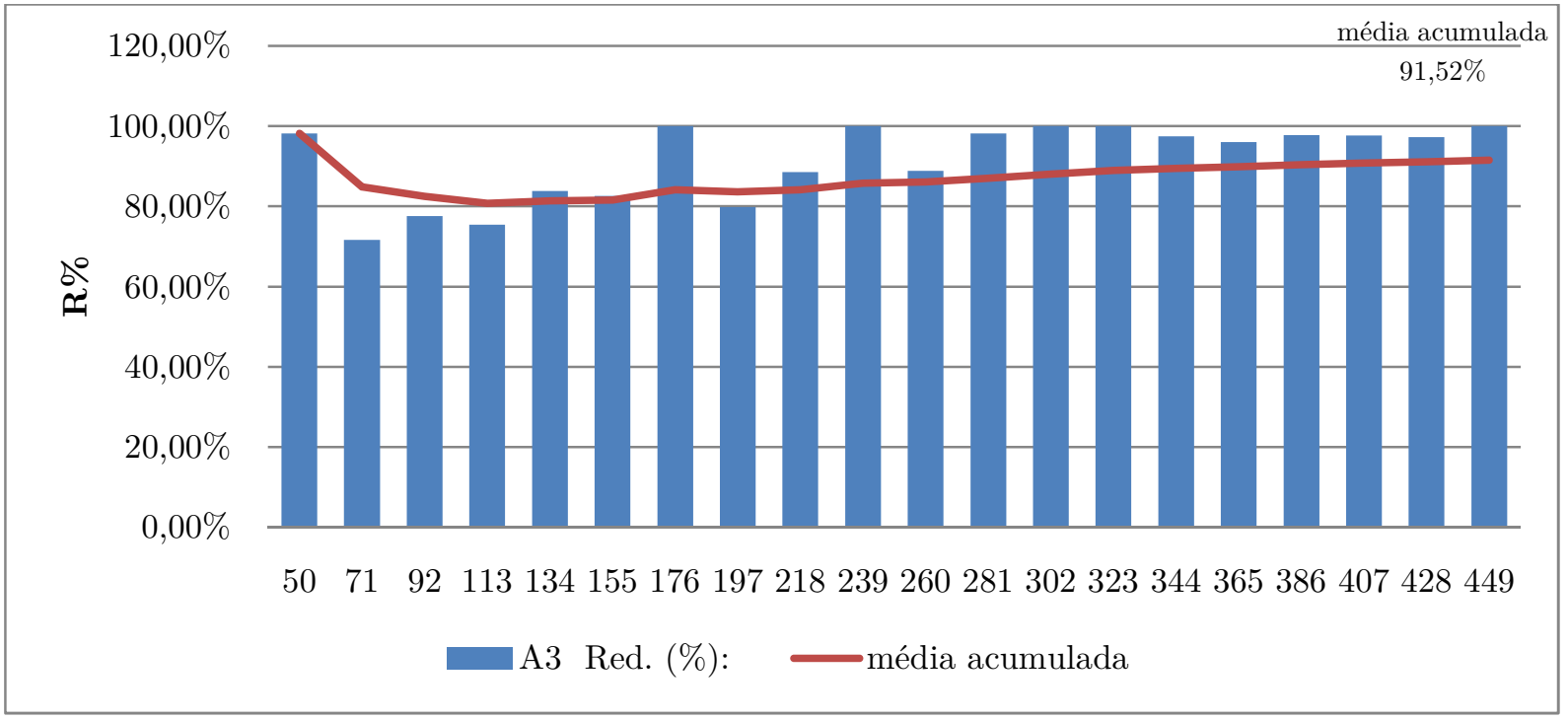

(c) Faltas monofásicas em $\mathrm{A}$ na região 3

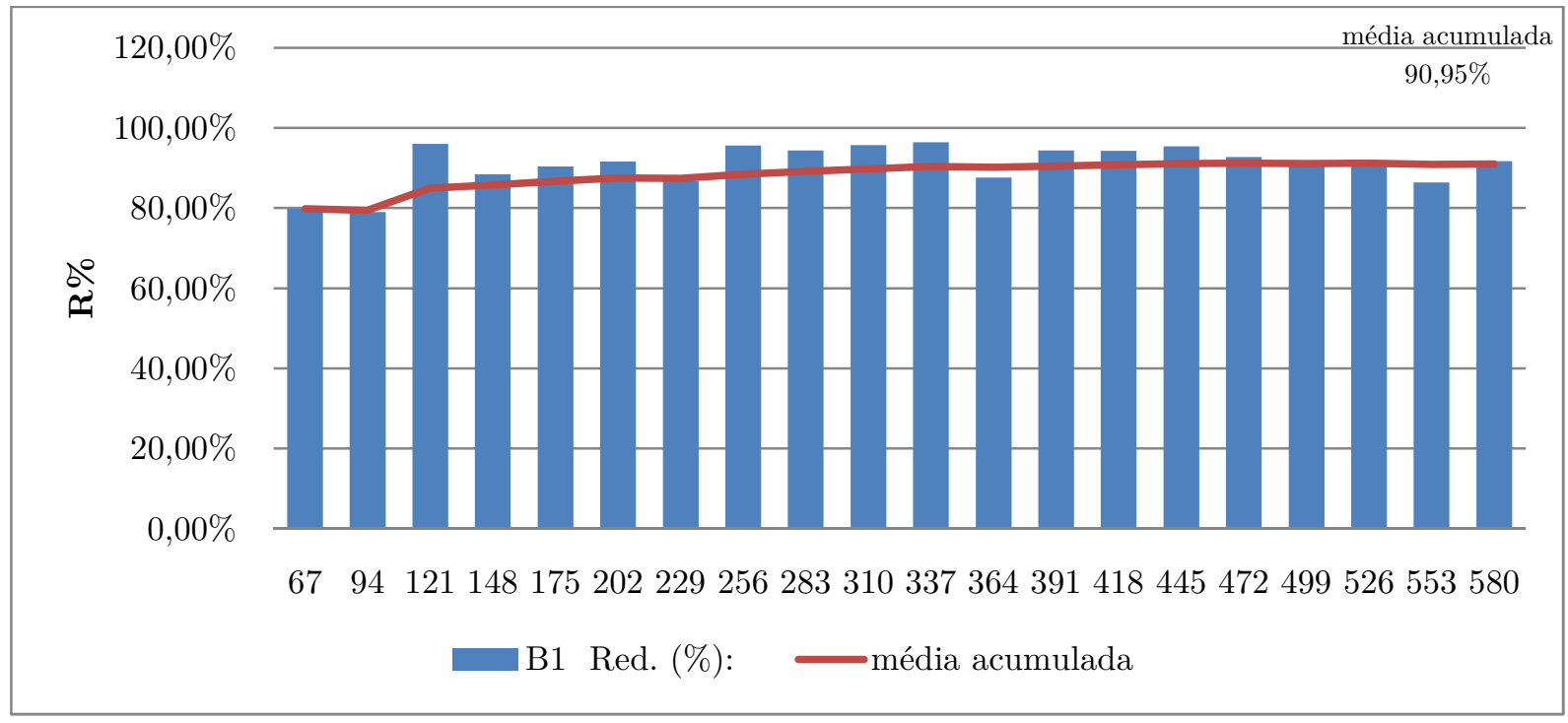

(d) Faltas monofásicas em $\mathrm{B}$ na região 1

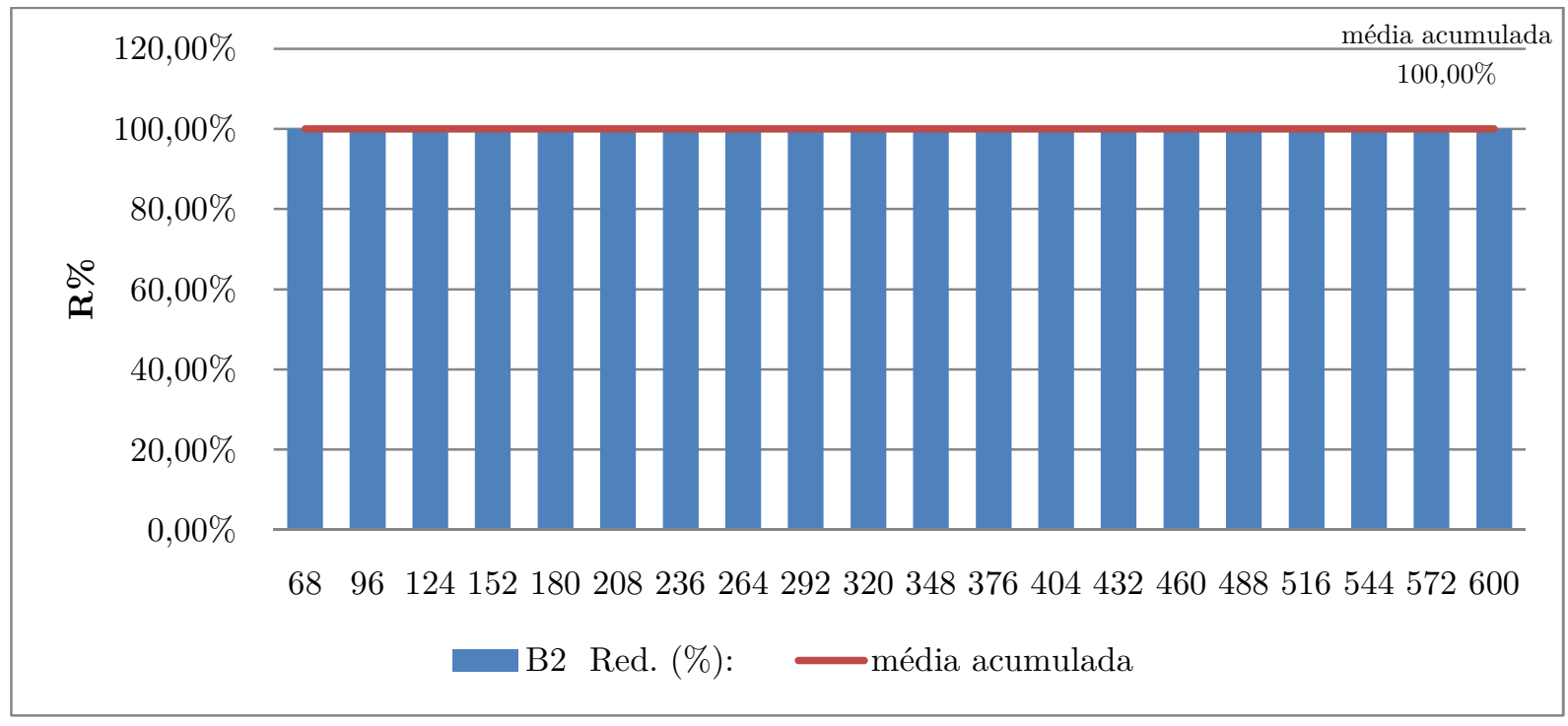

(e) Faltas monofásicas em $\mathrm{B}$ na região 2 


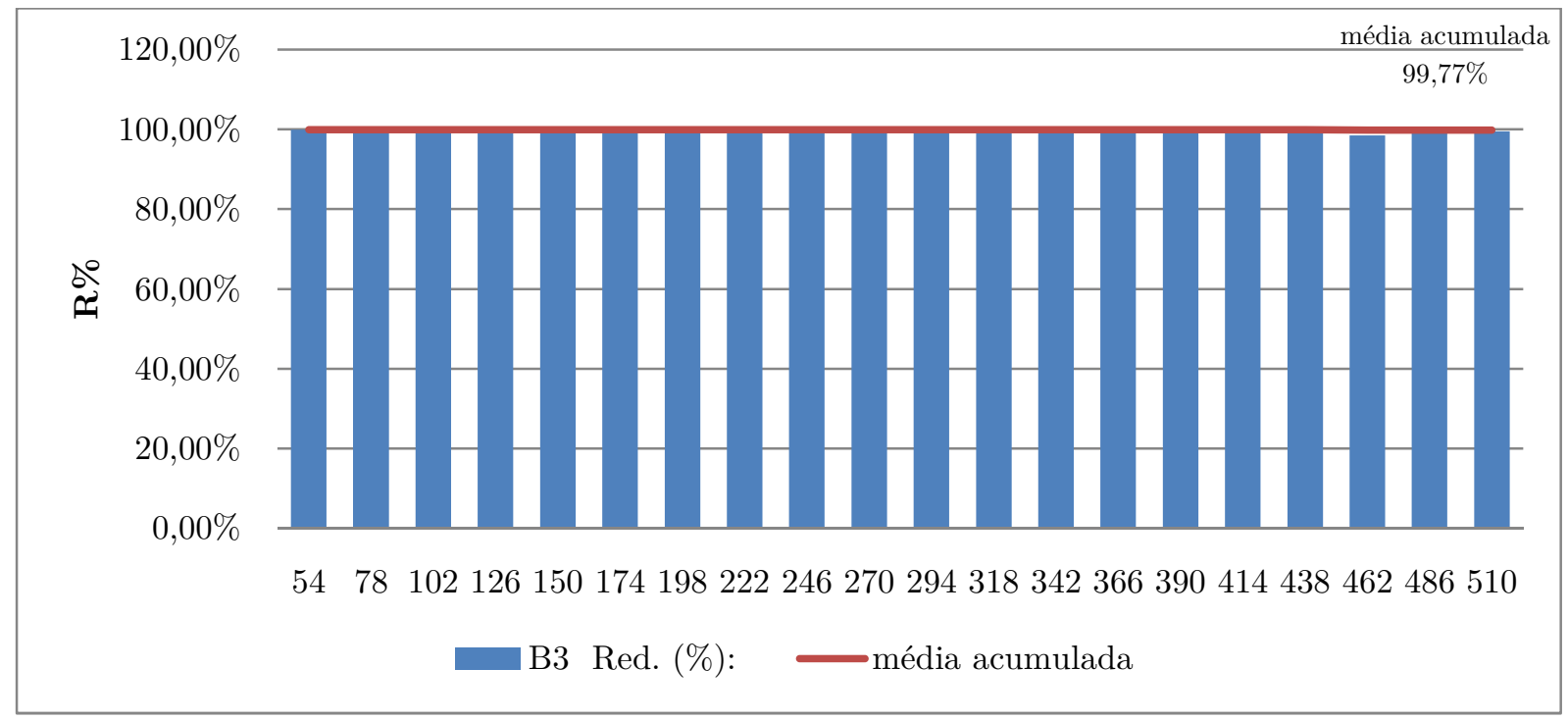

(f) Faltas monofásicas em $\mathrm{B}$ na região 3

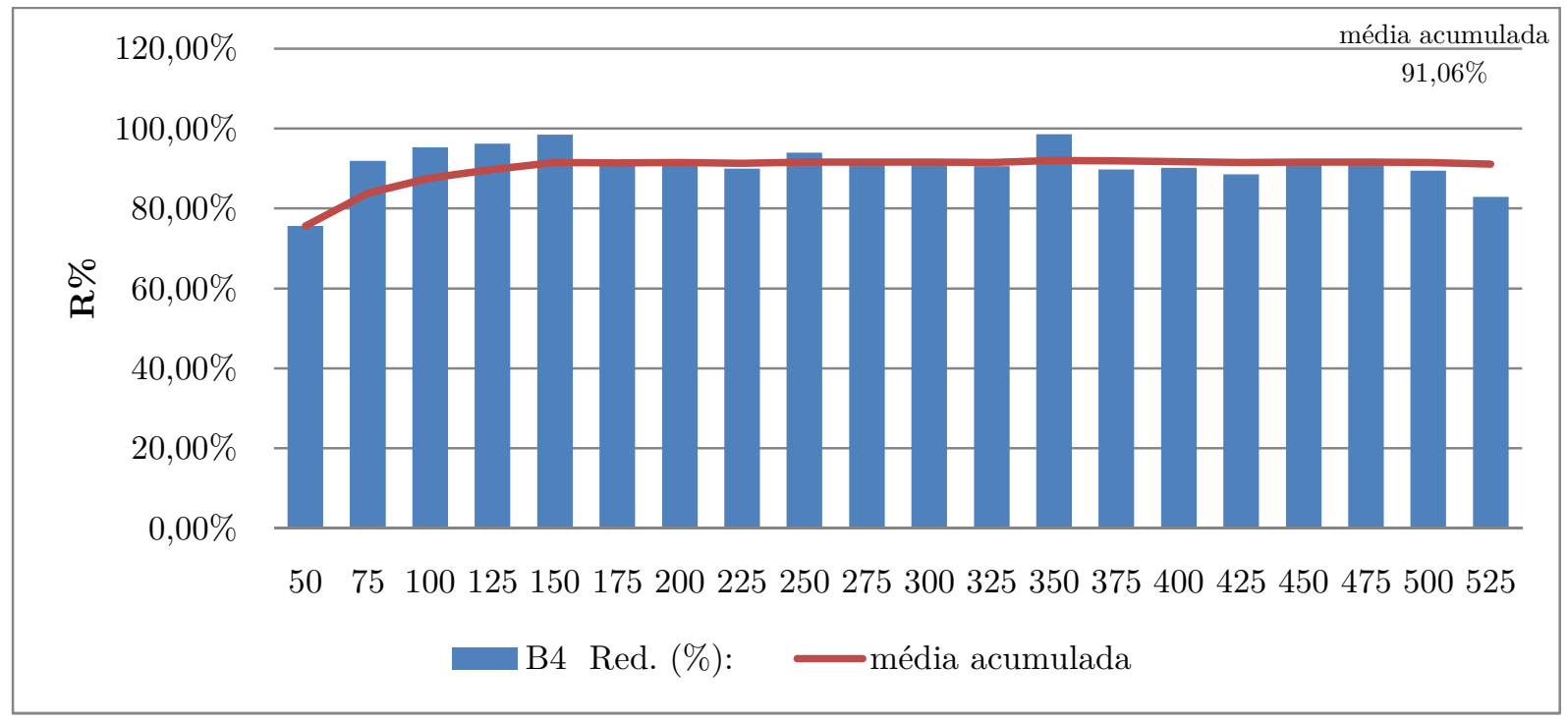

(g) Faltas monofásicas em $\mathrm{B}$ na região 4

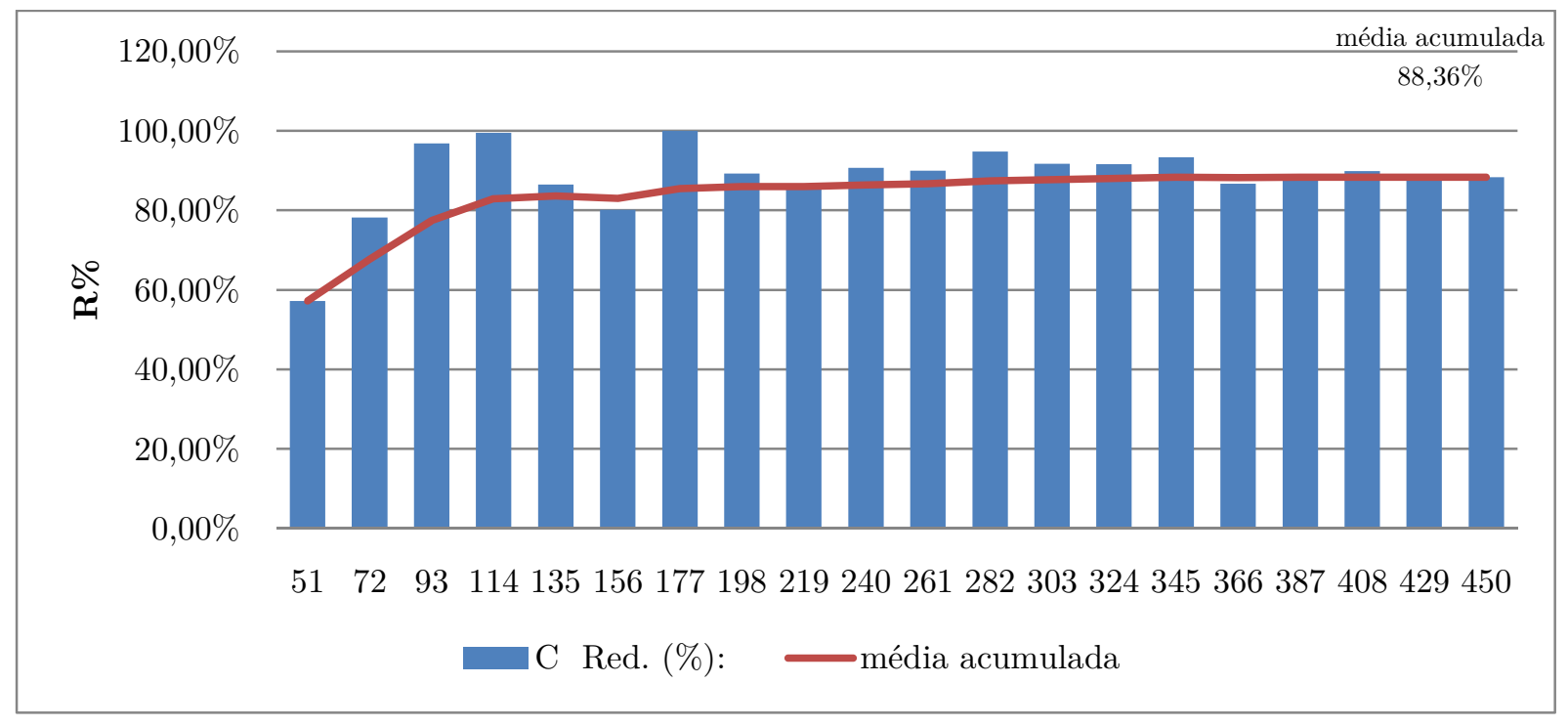

(h) Faltas monofásicas em $\mathrm{C}$ na região 1 


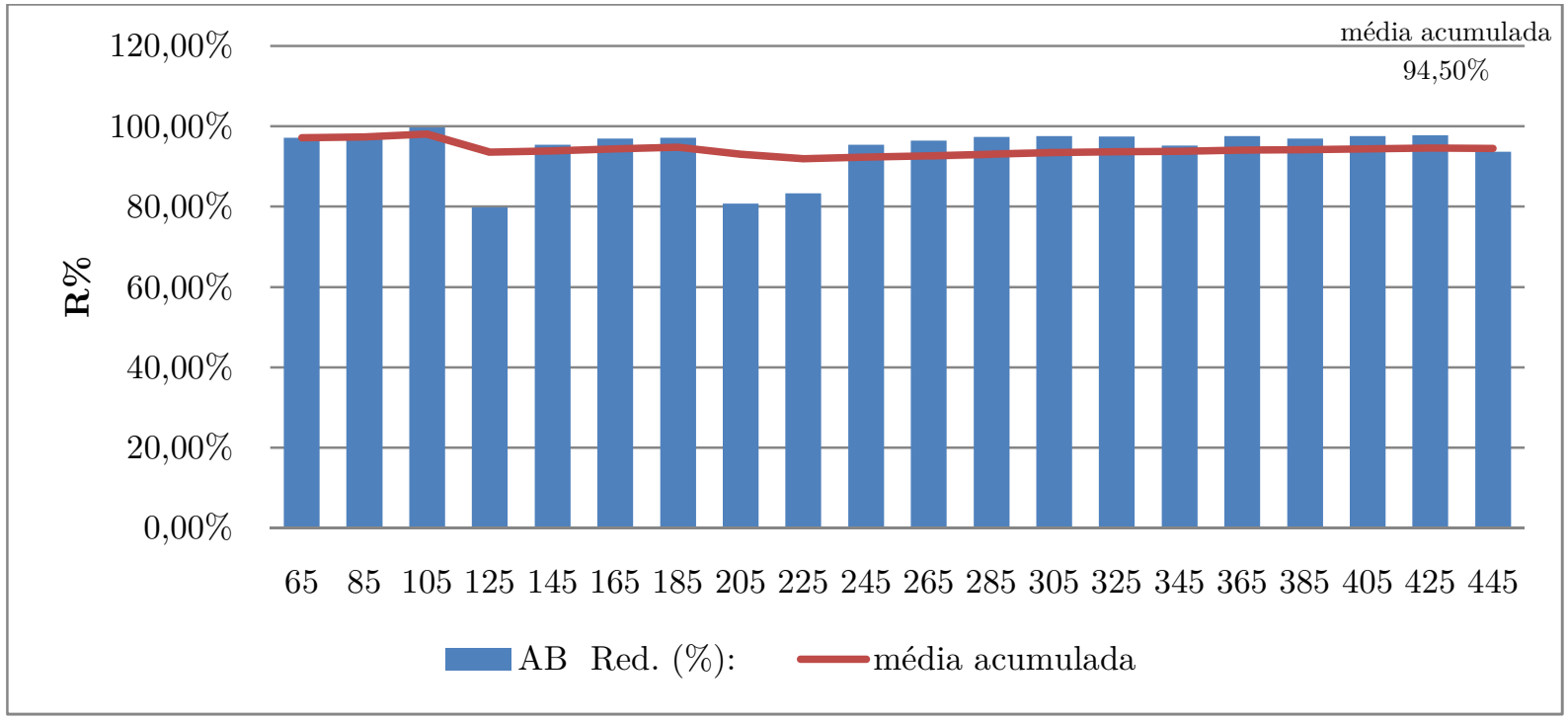

(i) Faltas bifásicas A-B na região 1

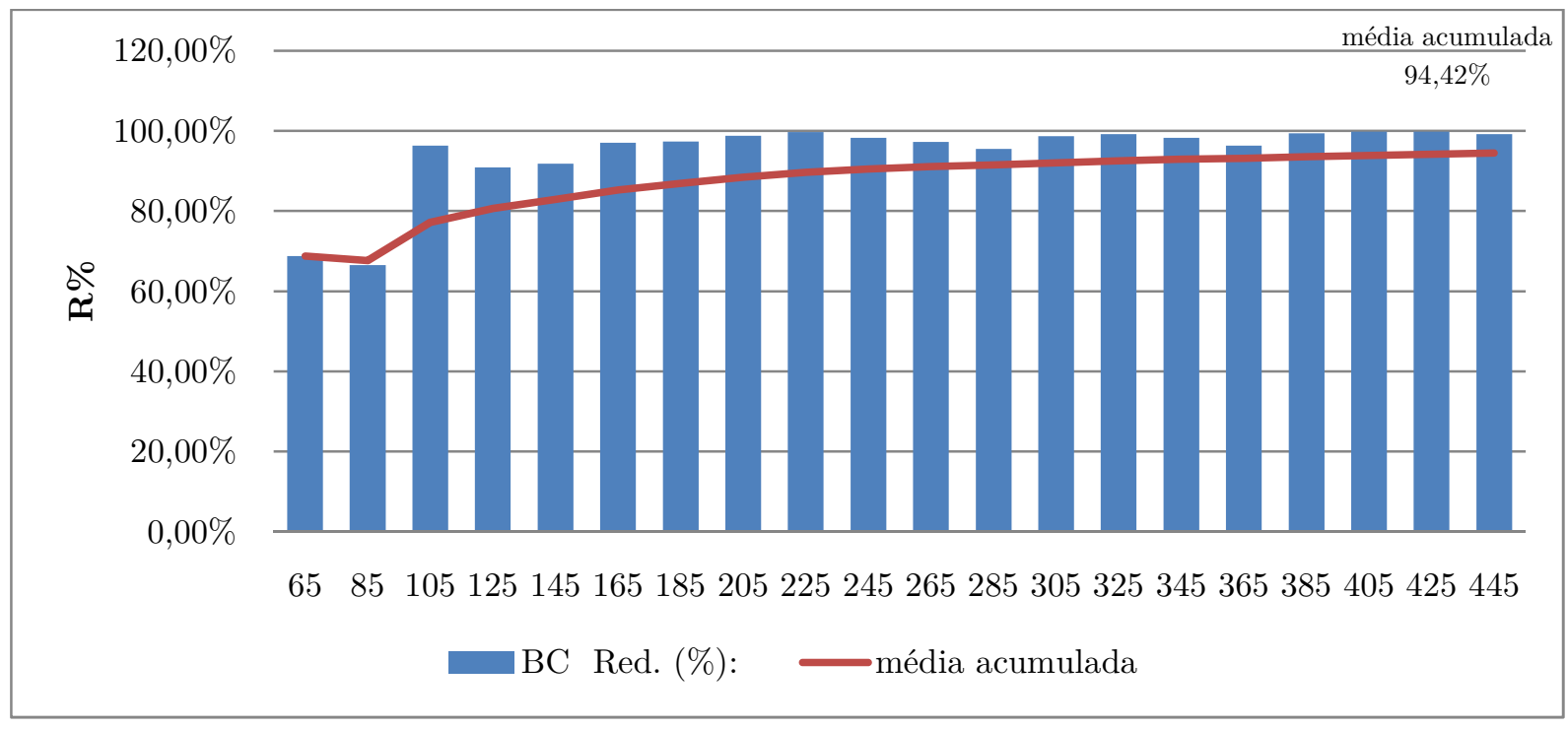

(j) Faltas bifásicas B-C na região 1

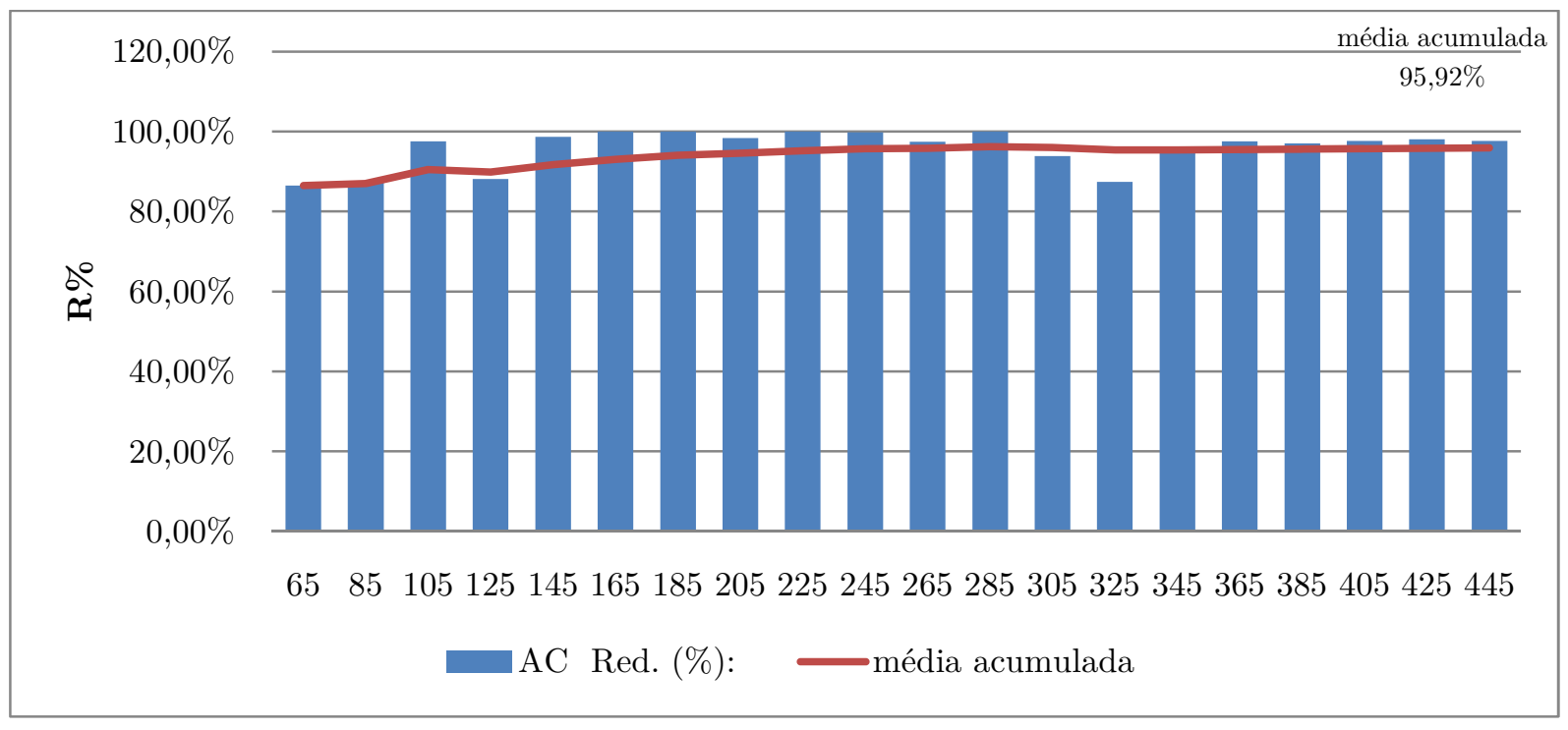

(k) Faltas bifásicas C-A na região 1 


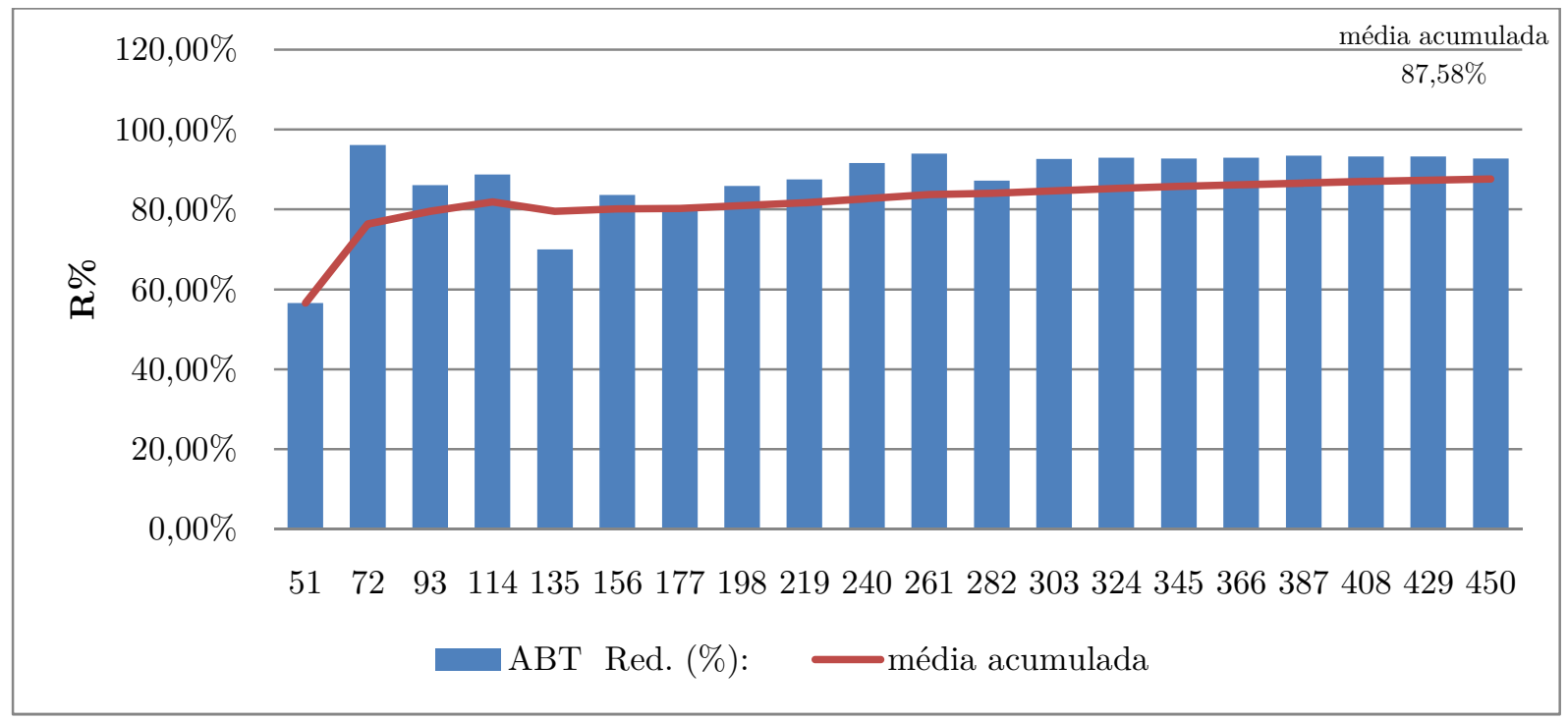

(1) Faltas bifásicas com envolvimento de terra A-B-t na região 1

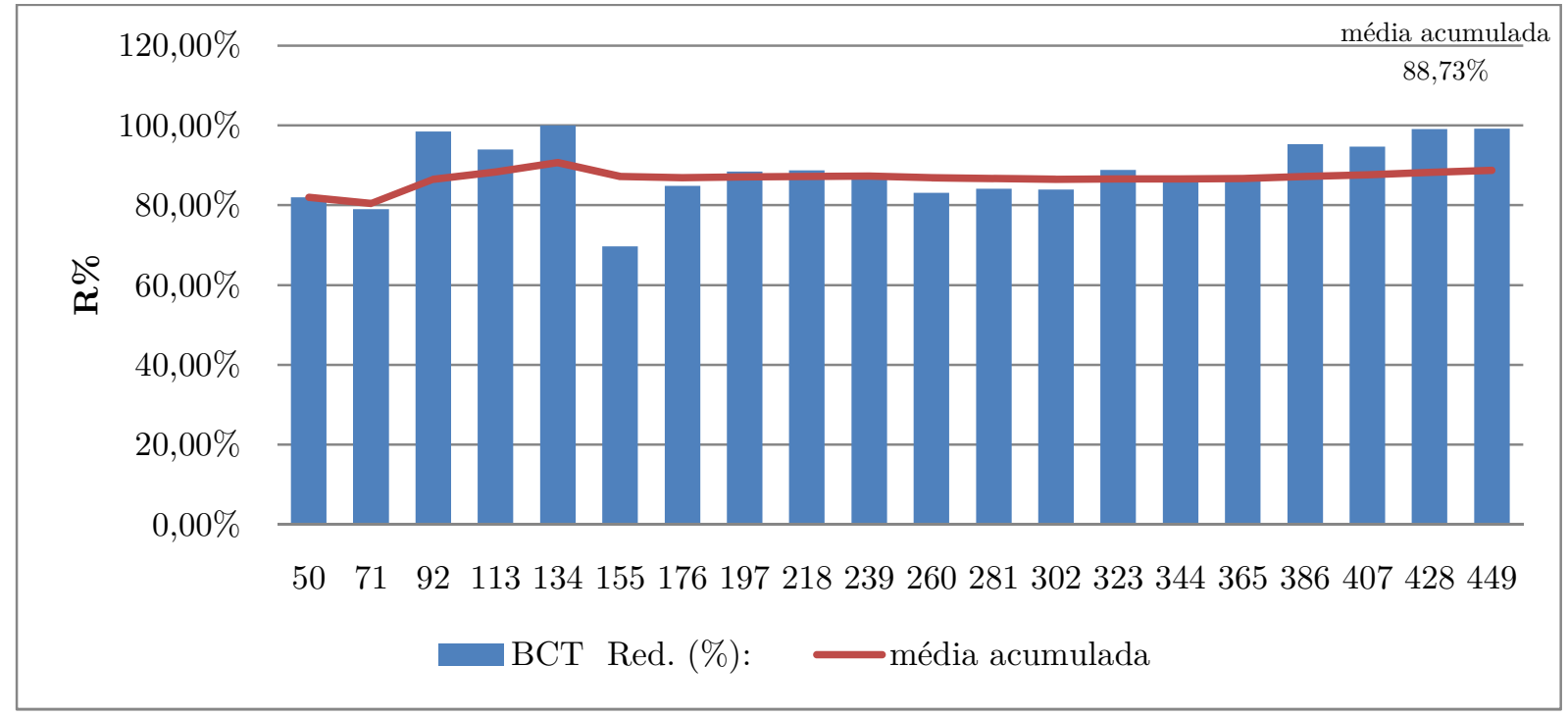

(m) Faltas bifásicas com envolvimento de terra B-C-t na região 1

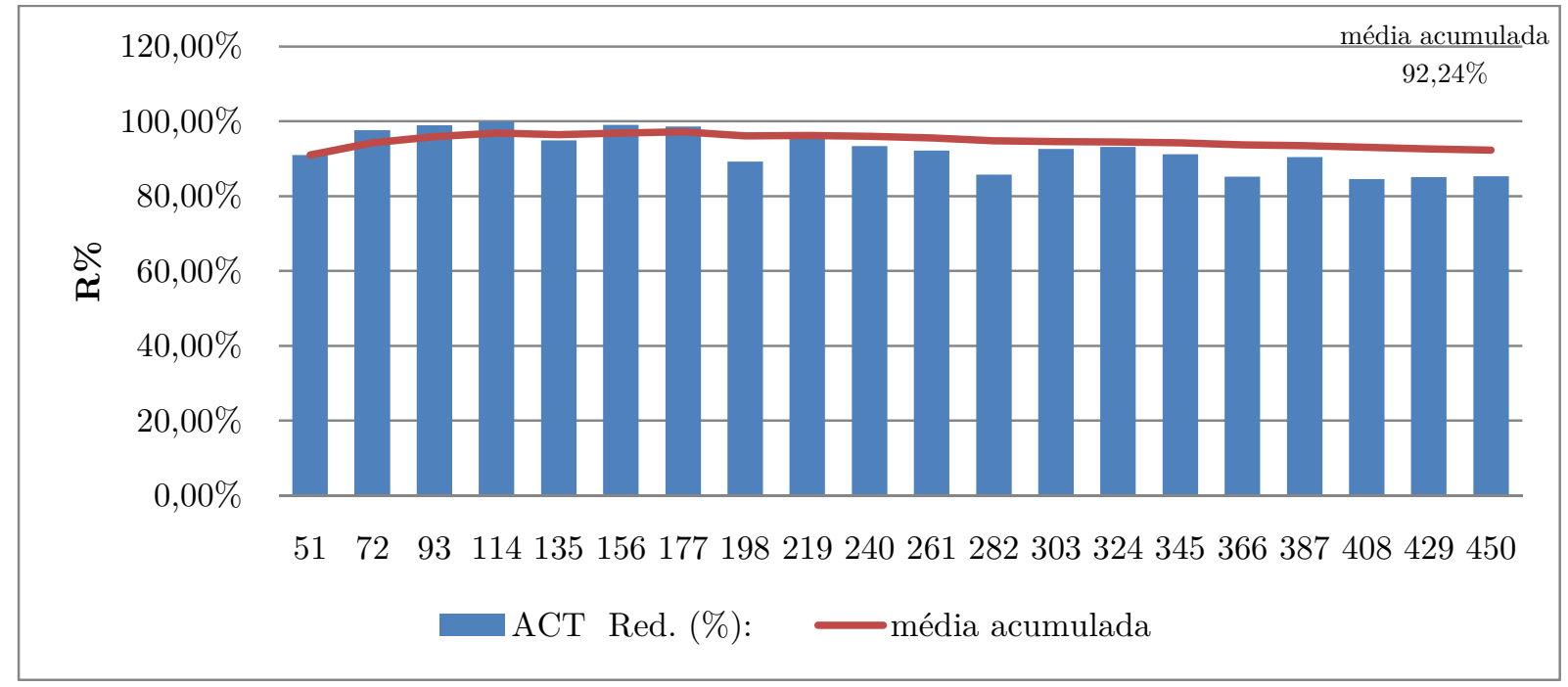

(n) Faltas bifásicas com envolvimento de terra C-A-t na região 1 


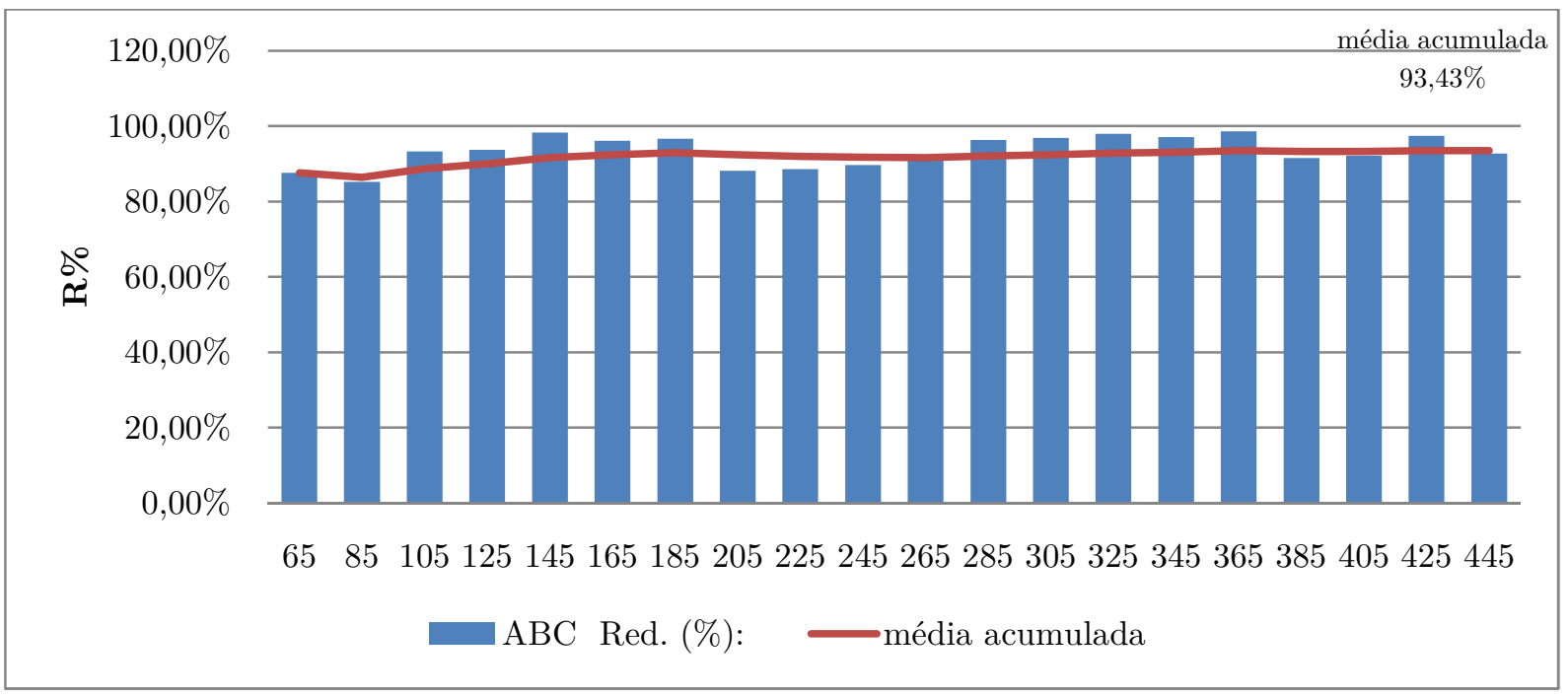

(o) Faltas trifásicas A-B-C na região 1

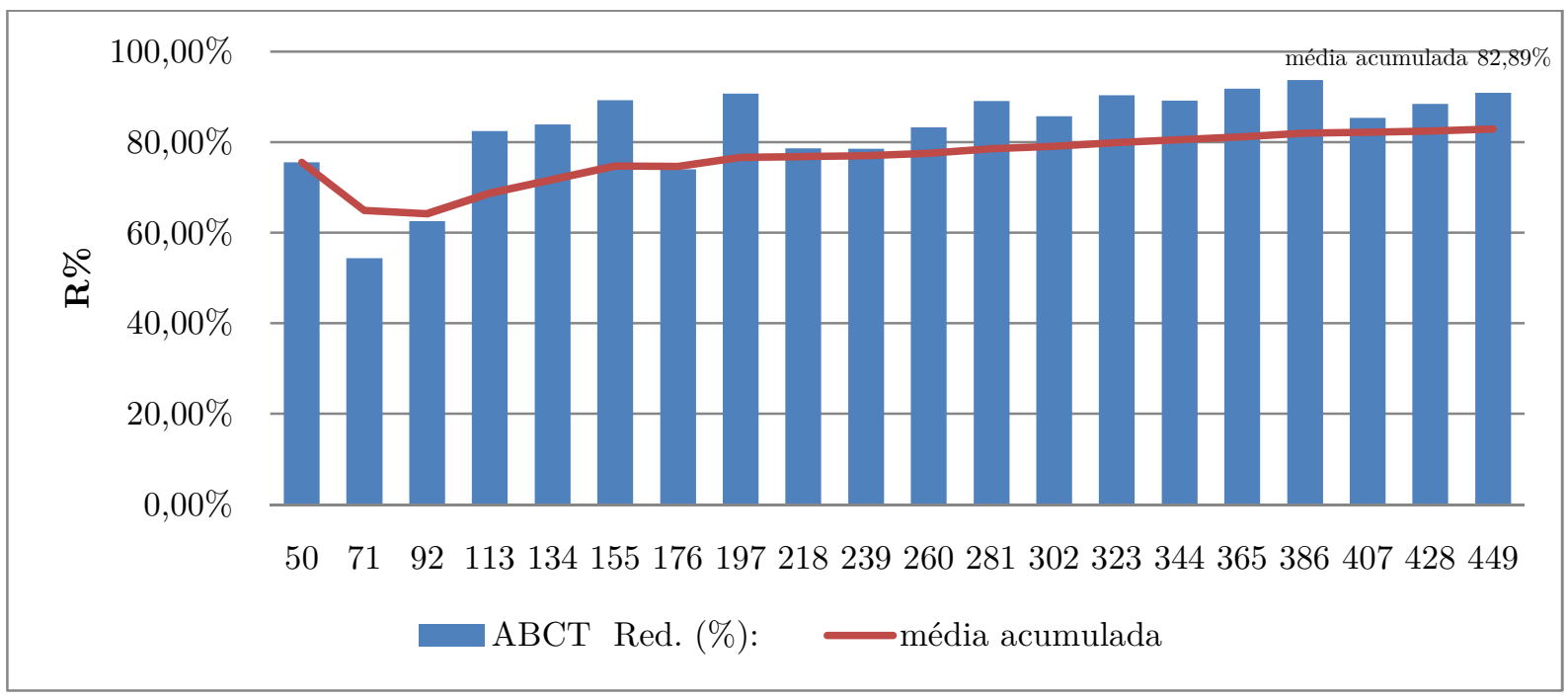

(p) Faltas trifásicas com envolvimento de terra A-B-C-t na região 1

Fonte: Elaborada pelo Autor.

Um destaque especial deve ser dado para a região 2 das faltas monofásicas na fase A, a qual apresenta uma situação em que o sistema não contribuiu de maneira decisiva parar a identificação do ramal faltoso. Conforme apresentado na Figura 33(b) a região de múltipla estimação 2 para faltas monofásicas na fase A apresenta um baixo $^{31}$ índice de redução dos comprimentos em múltipla estimação, menor que $50 \%$ na média em relação aos outros casos, mesmo aumentando a quantidade de amostras devido ao baixo número de pontos de medição utilizados. Ao analisarmos os

\footnotetext{
${ }^{31}$ De maneira geral, quando $\mathrm{R} \%$ fica abaixo de $50 \%$ indica que a mineração de dados não considerou predominante a diferença entre os dados do RP e do RL, agrupando a partir de outras característica.
} 
agrupamentos feitos pela mineração de dados nessa região percebemos que ele agrupa os dados por resistência de falta, sendo esta uma característica mais dominante, no pequeno trecho analisado na região 2 , do que o ramal ao qual a falta pertence. Como a resistência de falta foi escolhida de maneira aleatória durante a geração dos dados précarregados, o resultado dessa "clusterização" não contribui significativamente para a identificação do ramal faltoso. Nesse caso recomenda-se aumentar o número de pontos de medição ou utilizar outros métodos.

Para avaliar o comportamento do sistema em relação a um estimador de distância não ideal foi implementado um método de localização de faltas baseado em impedância, o qual foi utilizado para estimar a distância da falta de maneira similar a um sistema real. Esse método de localização é apresentado na próxima seção.

Embora tenha sido utilizado um método baseado em impedância, é preciso deixar claro que a aplicação em nuvem desenvolvida é independente do método de localização utilizado, ficando a critério da concessionária qual método será utilizado.

\subsection{Método localização de faltas baseado em impedância.}

O método de localização de faltas utilizado foi baseado no método proposto por Girgis et al. [255], o qual utiliza basicamente as impedâncias de sequência e impedância serie do sistema, em conjunto com as medições de tensão e corrente da subestação, para estimar a localização da falta propondo algumas correções no valor estimado quando considerando a falta em ramais laterais, podendo também considerar a influência de cargas estáticas ao longo do alimentador.

A presente implementação considerou apenas a etapa principal do método de Girgis, corrigindo os valores estimados considerando as alterações na impedância de sequência do sistema.

Já conhecendo o tipo de falta, as tensões e correntes de pré-falta e de falta, a distância da falta é estimada pelas seguintes equações.

$$
Z_{\text {app }}=\frac{V_{\text {select }}}{I_{\text {select }}}
$$

onde $V_{\text {select }}$ e $I_{\text {select }}$ são os valores de tensão e corrente selecionados da Tabela 8 para cada tipo de falta. 


$$
\begin{gathered}
D=\frac{R_{a p p} M-X_{a p p} L}{R_{1} M-X_{1} L}, \\
L=\frac{I_{d} I_{s 1}-I_{q} I_{s 2}}{I_{s m}^{2}}, \\
M=\frac{-I_{d} I_{s 2}+I_{q} I_{s 1}}{I_{s m}^{2}}, \\
I_{s m}^{2}=I_{s 1}^{2}+I_{s 2}^{2},
\end{gathered}
$$

onde $D$ é a distância estimada até a falta, $I_{d}, I_{q}$ e $I_{s 1}, I_{s 2}$ são componente das correntes complexas $I_{\text {comp }}$ e $I_{\text {select, }}$ respectivamente, sendo

$$
\begin{gathered}
I_{\text {select }}=I_{s 1}+j I_{s 2}, \\
I_{\text {comp }}=I_{d}+j I_{q} \mathrm{e} \\
k=\frac{Z_{0}-Z_{1}}{Z_{1}} .
\end{gathered}
$$

Tabela 8 - Par de tensão e corrente selecionados para o cálculo da impedância aparente trifásica

\begin{tabular}{c|ccc}
\hline Tipo de Falta & $\boldsymbol{V}_{\text {select }}$ & $\boldsymbol{I}_{\text {select }}$ & $\boldsymbol{I}_{\text {comp }}$ \\
\hline MONO A & $V_{a}$ & $I_{a}+k I_{0}$ & $3 I_{0}$ \\
MONO B & $V_{b}$ & $I_{b}+k I_{0}$ & $3 I_{0}$ \\
MONO C & $V_{c}$ & $I_{c}+k I_{0}$ & $3 I_{0}$ \\
BI (AB) ou (ABt) & $V_{a^{-}} V_{b}$ & $I_{a}-I_{b}$ & $\Delta I_{a^{-}} \Delta I_{b}$ \\
BI (BC) ou (BCt) & $V_{b^{-}} V_{c}$ & $I_{b}-I_{c}$ & $\Delta I_{b^{-}} \Delta I_{c}$ \\
BI (CA) ou (CAt) & $V_{c^{-}} V_{a}$ & $I_{c}-I_{a}$ & $\Delta I_{c^{-}} \Delta I_{a}$ \\
TRIFÁSICAS & \multicolumn{3}{|c}{ Igual as Bifásicas } \\
\hline
\end{tabular}

Fonte: Adaptado de [255]

Caso haja mudança nos valores das impedâncias de sequência ao longo do alimentador e a distância estimada esteja à jusante desse ponto no sistema, as tensões de fase durante a falta $(\mathrm{Va}, \mathrm{Vb}, \mathrm{Vc})$ são ajustadas considerando as quedas de tensão no alimentador até o ponto onde houve a mudança de configuração, utilizando as impedâncias e correntes de fase do sistema. Esses novos valores de tensão são utilizados nas equações anteriores para determinar o restante da distância do ponto de alteração até o ponto da falta. Se houver mais alterações de impedância pelo caminho até a falta, o processo se repete até alcançar o ponto de falta.

O erro produzido por esse método foi avaliado simulando-se faltas monofásicas, bifásicas e trifásicas com cinco resistências de falta diferentes variando linearmente entre 1 e 50 ohms ao longo do alimentador, para cada região de múltipla estimação, perfazendo um total de 6951 faltas. A grande amplitude de variação na resistência de 
falta implica em uma grande variação na precisão do estimador. Para os casos simulados, os piores erros foram obtidos para as faltas com impedância mais alta, próximas a 50 ohms, localizadas no final do alimentador, chegando ao valor máximo de 16,6\% para uma falta monofásica na fase A com impedância de 50 ohms a oito metros do nó 848. No entanto, na grande maioria das faltas aplicadas o erro ficou abaixo de 12\%. O erro foi calculado a partir da equação (11), onde $D$ é a distância estimada até a falta, $d$ é a distância real da falta e $l$ é o comprimento total do alimentador.

$$
\text { Erro }=\left|\frac{D-d}{l}\right| \times 100 \%
$$

Em todos os casos simulados em que houve erro de estimação, o erro foi sempre de subestimação da distância da falta, ou seja, a distância estimada foi menor que a distância real da falta. A Figura 34 mostra a distribuição de erros desse localizador para cada tipo de falta e região de múltipla estimação. Por ela podemos perceber que apenas faltas monofásicas apresentaram erro maior que $12 \%$ de subestimação de distância. Esses erros serão utilizados para as análises e simulações de estudos de casos.

Figura 34 - Erros do método de localização de distâncias baseado em impedância.

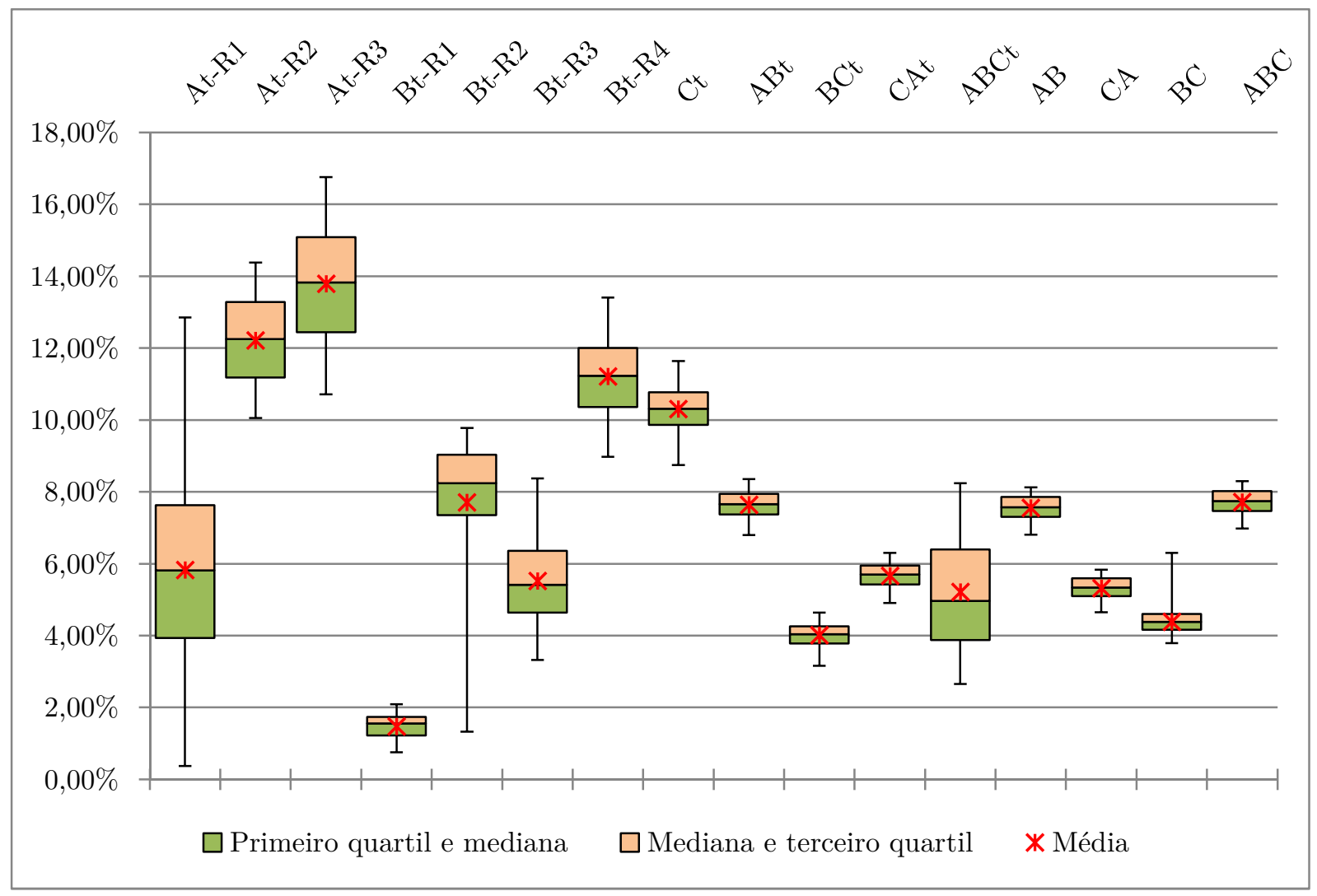

Fonte: Elaborada pelo autor. 


\subsection{Estudos de caso}

Nesta seção serão apresentados três estudos de caso apresentando o comportamento da aplicação como um todo. Para isso foi utilizado um computador para realizar as funções dos DCUs enviando para a aplicação em nuvem as características das faltas nos pontos de medição assim que solicitado. Foram aplicadas três faltas de tipos diferentes em diferentes localizações, cada uma com resistência de falta aleatoriamente definida.

\subsubsection{Caso 1}

Nesse caso uma falta trifásica a terra, com impedância de falta ${ }^{32}$ de 27 ohms, foi aplicada no ramal principal entre as barras 858 e 834 após o ponto de medição 2, a uma distância real de $55.469 \mathrm{~m}$ da subestação conforme apresentado na Figura 35, a aproximadamente $71 \%$ do comprimento do trecho em questão.

Figura 35 - Posição das faltas desconhecidas utilizadas nos estudos de caso

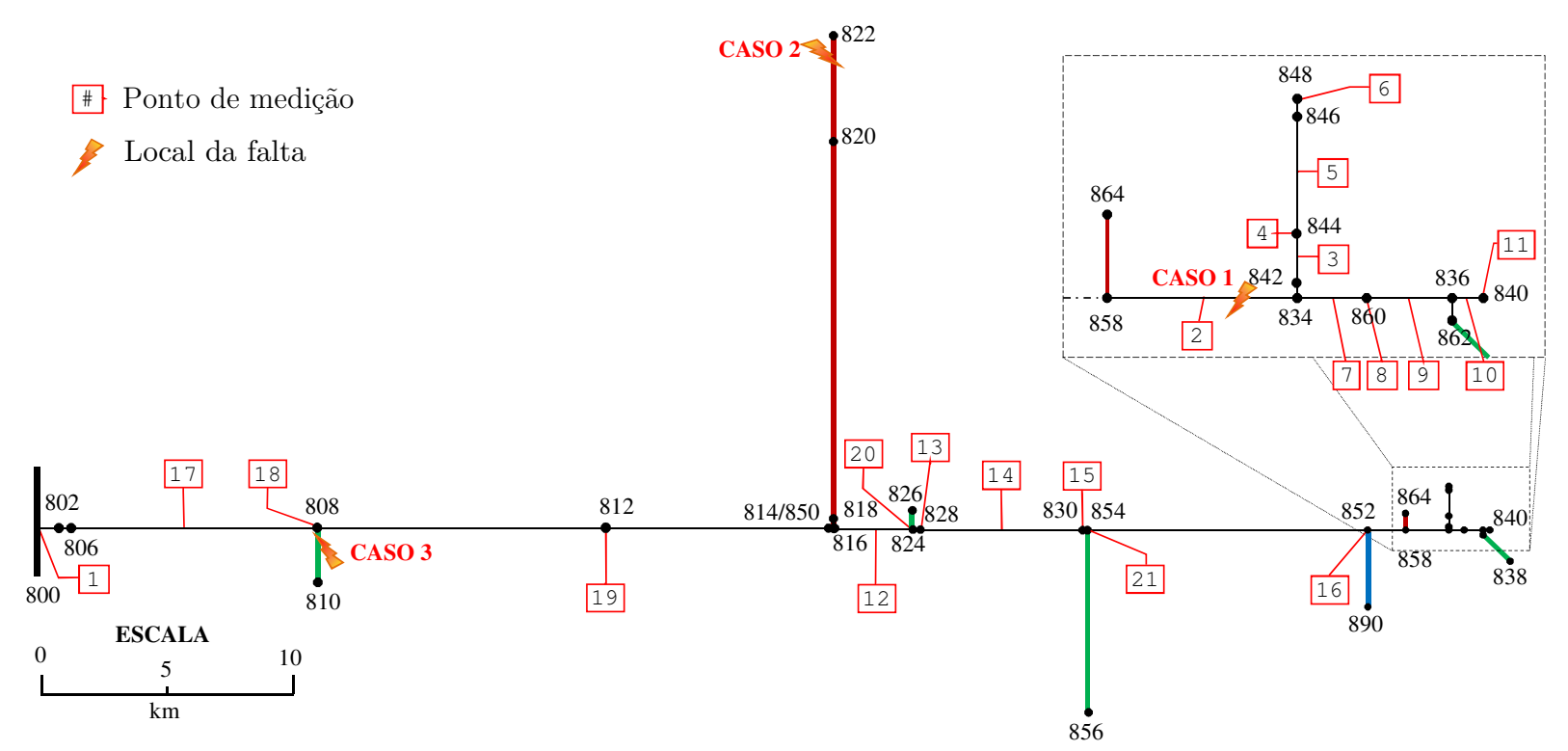

Fonte: Elaborada pelo autor.

Com os sinais de tensão e corrente medidos na subestação, ponto de medição 1 , o localizador de faltas estimou a distância em $53.004 \mathrm{~m}$ da subestação. Esse valor foi repassado manualmente à aplicação em nuvem, juntamente com o erro do estimador

\footnotetext{
${ }^{32}$ Por se tratar de um ambiente de simulação a impedância de falta simulada é conhecida, mas essa informação não é necessária em um ambiente real.
} 
adotado como $7 \%$ para o trecho em questão, em relação ao comprimento total do alimentador, através de uma requisição HTTP/POST direcionada ao URI externo do HES em http://10.235.0.51:5000/hes/falta, com o seguinte objeto JSON no corpo da mensagem, \{"f_type":"ABCt", "timestamp":1523225952000, "f_dist": 53004, "d_error":7\}. O campo "f_type" especifica o tipo da falta, o "timestamp" está relacionado à estampa de tempo de detecção da falta, "f_dist" é a distância da falta estimada em metros, e "d_error" é o erro percentual adotado para o estimador.

Ao receber essa requisição a aplicação em nuvem, devido ao erro adotado para o estimador, reconhece a falta como pertencente a uma região sujeita a múltipla estimação, embora fisicamente esteja localizada antes da região afetada, e solicita os dados aos PM selecionados para a respectiva região. O computador responsável por atuar como os DCUs envia os dados à aplicação em nuvem, que após receber todos os dados inicia o processamento dos dados conforme descrito em 5.1. A aplicação em nuvem desenvolvida gera um perfil de falta a partir dos dados novos e minera juntamente com os dados pré-carregados de faltas cuja localização é conhecida, armazenados no banco de dados MongoDB. O banco de dados foi pré-inicializado com 112 amostras de faltas.

O resultado da mineração é apresentado na Figura 36, nela podemos observar que a falta desconhecida, chamada de NEW_UNKNOW, foi agrupada no cluster 3. Pela análise apresentada na Figura 28 obtemos que o cluster, excluindo a falta desconhecida, apresenta apenas faltas no ramal principal, portanto a falta desconhecida deve ser considerada como sendo no ramal principal, como de fato é. Uma equipe de manutenção seguindo essa recomendação encontraria a falta sem a necessidade de percorrer o ramal lateral à procura da mesma, reduzindo assim a distância percorrida.

Fazendo uso do potencial analítico da árvore filogenética, um especialista poderia perceber que a falta desconhecida foi agrupada em um cluster contendo faltas com características semelhantes majoritariamente localizadas no ramo 854-834, em uma região e torno de $75 \%$ do comprimento desse trecho, o que poderia sugerir que essa falta desconhecida está próxima a essa região. 
Figura 36 - Árvore filogenética com os resultados da mineração de dados para o caso 1

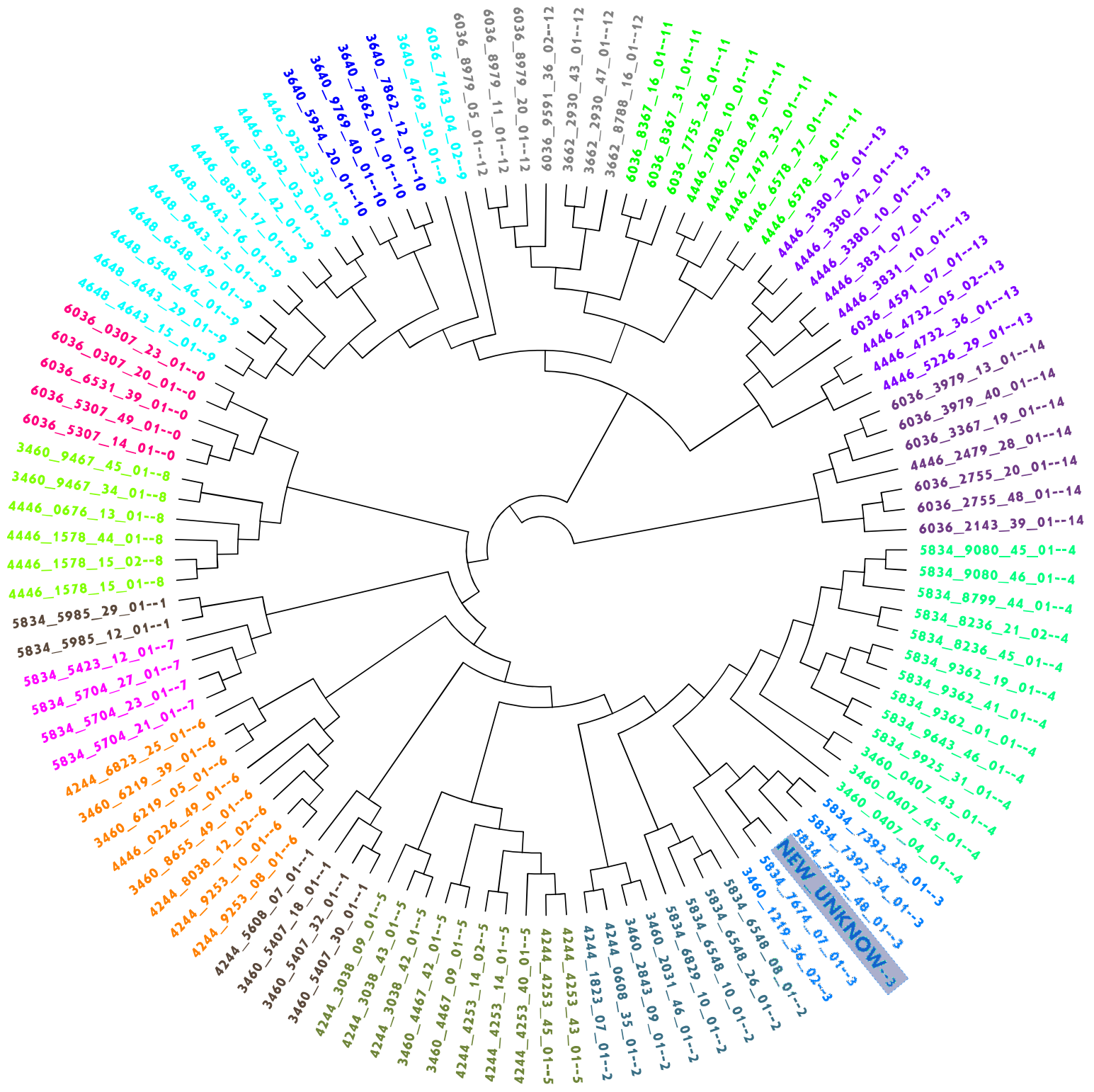

Fonte: Elaborada pelo autor.

\subsubsection{Caso 2}

Nesse caso foi aplicada uma falta monofásica na fase A na região 1, entre as barras 820-822 no ramal lateral, a 50.268 metros da subestação, em 80\% do trecho de linha em questão com uma resistência de falta de 38 ohms. De maneira semelhante ao caso anterior, o banco de dados foi inicializado com 113 amostras de faltas conhecidas previamente simuladas. O localizador de faltas estimou a distância da falta em $44190 \mathrm{~m}$ da subestação. A aplicação em nuvem foi iniciada considerando um erro de $12 \%$ para as faltas localizadas nessa região, minerando e armazenando o resultado no banco de dados. Os resultados dessa mineração são apresentados na Figura 37. Analisando o 
cluster percebe-se que o mesmo contém apenas faltas no ramal lateral, portanto a falta deve ser procurada no ramal lateral, reduzindo a múltipla estimação, uma vez que a falta realmente está no ramal lateral.

Observando a árvore filogenética não é possível identificar algum relacionamento direto com as outras faltas conhecidas, porém o cluster como um todo possui mais faltas no trecho 820-822 o que pode ser um indicativo de onde a falta ocorreu.

Figura 37 - Árvore filogenética com os resultados da mineração de dados para o caso 2

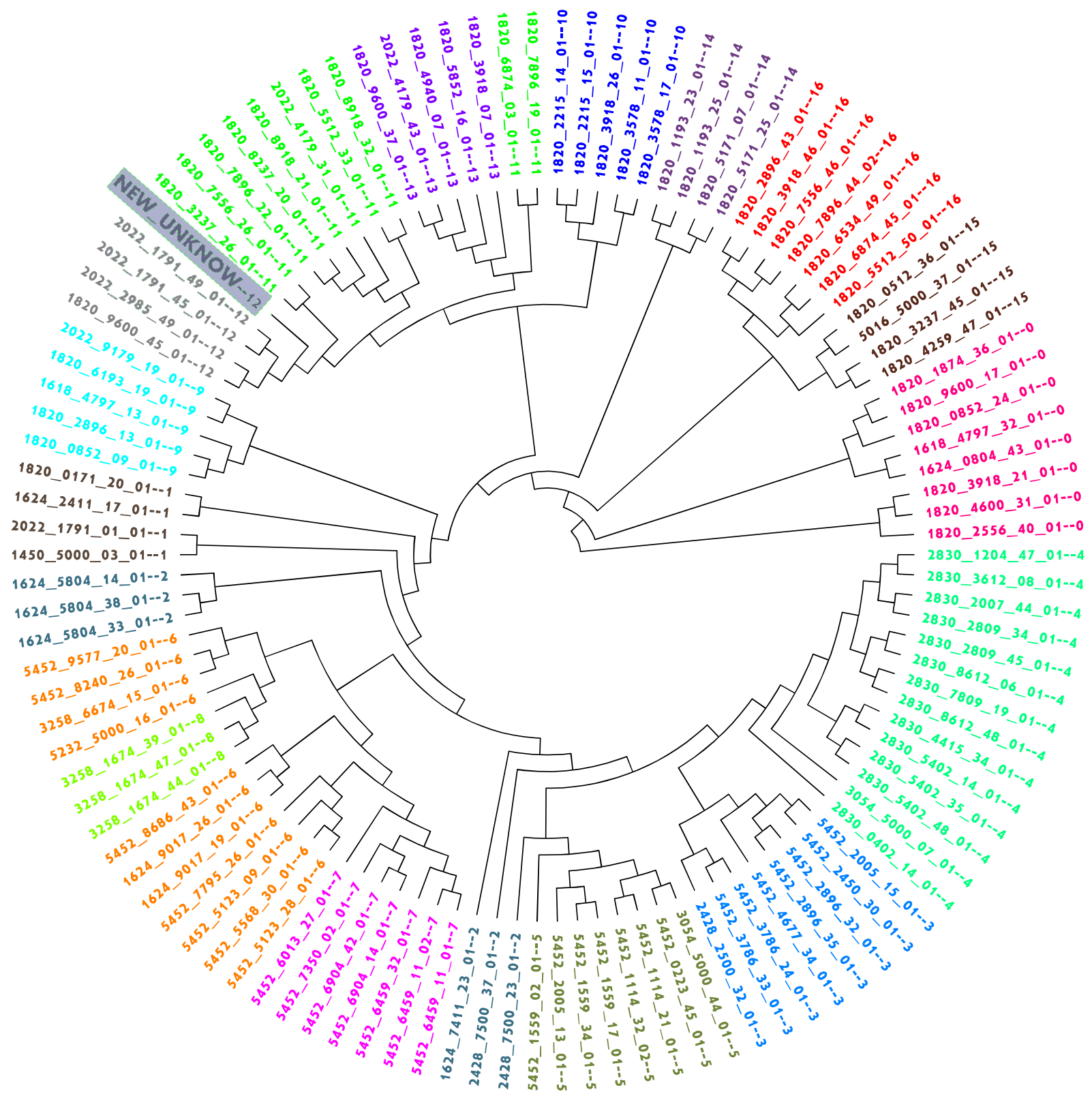

Fonte: Elaborada pelo autor. 


\subsubsection{Caso 3}

No caso 3 foi escolhida uma falta que foi incorretamente classificada pela aplicação. Essa falta, cujo código é o 0812_0022_37_01, foi aplicada na região 1 para as faltas monofásicas na fase $\mathrm{C}$ entre as barras 808-812, com impedância de falta de 37 ohms, a $0,2 \%$ do comprimento do trecho, ou seja, a $251 \mathrm{~m}$ da barra 808, e com uma distância de $11.162 \mathrm{~m}$ da subestação. O localizador de faltas estimou a distância da falta em $10.284 \mathrm{~m}$. O erro do localizador foi adotado como $-2 \%$ para essa região. O banco de dados de falta foi pré-inicializado com 120 faltas conhecidas. Para essas faltas o R\% obtido foi de 96\%. A árvore filogenética com o resultado dos agrupamentos é apresentada na Figura 38.

Figura 38 - Árvore filogenética com os resultados da mineração de dados para o caso 3

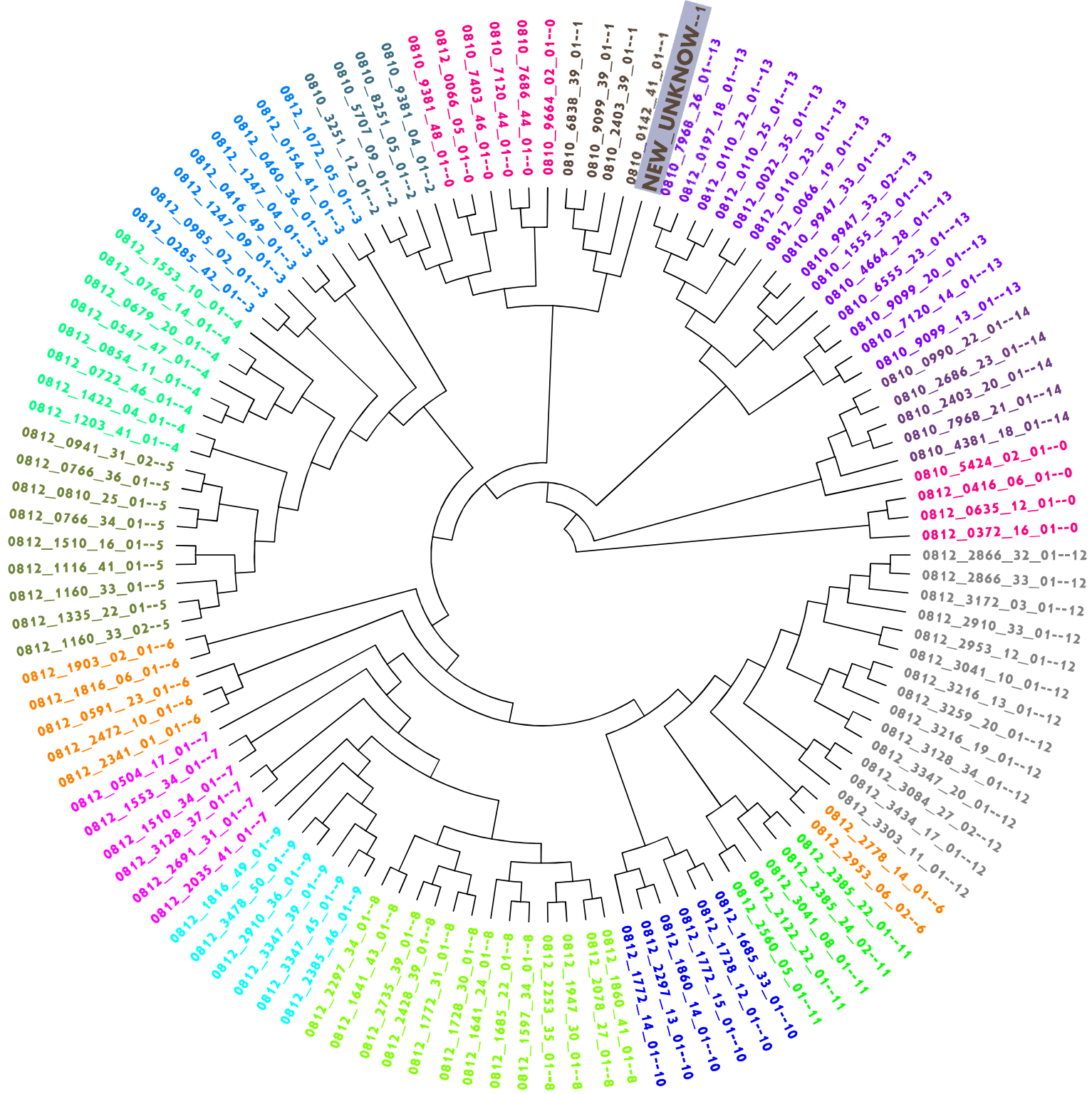

Fonte: Elaborada pelo autor. 
Essa falta foi agrupada no cluster 1. Seguindo a análise descrita na Seção 5.1, pelo fato desse cluster conter majoritariamente faltas no ramal lateral a equipe de campo deveria ser orientada erroneamente a procurar essa falta primeiro no ramal lateral.

Apesar desse erro na classificação, a capacidade da aplicação em reduzir a região de múltipla estimação é muito boa. Como descrito acima, essa falta está muito próxima à barra 808 (251 metros) e o ramal lateral em questão é muito pequeno em relação ao tamanho total do alimentador (1.769 metros). Quando olhamos para as outras faltas agrupadas no mesmo cluster (0810_0142_41_01, 0810_2403_39_01, 0810_6838_39_01, 0810_9099_39_01), as quais foram corretamente classificadas, percebemos que a distância de quase todas as faltas em relação à barra de derivação (808) é maior que a distância da falta classificada de maneira errada. Ou seja, analisando o R\% desse cluster em específico, dos 7.041 metros sujeitos a múltipla estimação (distância que as equipes de solo devem percorrer ao longo do ramal principal e lateral para cada falta no cluster) é reduzida para $502 \mathrm{~m}$ em torno do ramal 808, uma redução de $92,87 \%$.

\subsection{Considerações Finais Sobre o Capítulo}

A abordagem segmentada descrita neste capítulo, implementada na infraestrutura de computação em nuvem desenvolvida, apresentou bons resultados em relação à redução na distância percorrida em caso de múltipla estimação. Foi possível identificar que as medições feitas na subestação não contribuíram para melhorar o resultado da ferramenta, no entanto foi possível perceber que o aumento na quantidade de pontos de medição em uma dada região de múltipla estimação tende a melhorar os resultados, melhorando os agrupamentos obtidos pela mineração de dados em relação ao ramal faltoso.

A aplicação foi experimentada por meio de casos de uso, os quais foram realizados utilizando um localizador de faltas baseado em impedância, considerando o erro de localização foram feitos, os quais demonstram o funcionamento completo da ferramenta e sua a potencialidade para uso em sistemas reais. 


\section{Capítulo 6}

\section{Conclusões}

A modernização do sistema elétrico em direção às Smart Grids, em especial os sistemas de distribuição necessitam de ferramentas capazes de integrar e manipular uma grande quantidade de dados. Logo, o desenvolvimento de uma infraestrutura capaz de manipular de forma eficaz estes dados é fundamental.

A computação em nuvem tem sido vislumbrada como uma tecnologia capaz de lidar com esses dados, possibilitando o desenvolvimento de inúmeras novas aplicações. Nesse sentido, os estudos realizados neste trabalho visam contribuir para a difusão da computação em nuvem aplicada aos sistemas de distribuição, permitindo o desenvolvimento de novas aplicações. Para tanto, a partir de uma extensa revisão bibliográfica, foi proposta uma arquitetura de computação em nuvem genérica e modular com serviços essenciais, que pode ser estendida para abrigar novos serviços. Com base na arquitetura proposta foi desenvolvida uma plataforma de computação em nuvem, a qual foi utilizada para implementar uma nova aplicação de auxílio à localização de faltas para reduzir o problema da múltipla estimação nos sistemas de distribuição.

A plataforma desenvolvida utilizou ferramentas open source para implementar sobre uma nuvem IaaS as funcionalidades básicas de armazenamento de dados arbitrários e de séries temporais, permitindo o gerenciamento das aplicações e instanciação de serviços de maneira dinâmica.

Sobre essa infraestrutura foi implementado um serviço de mineração de dados que poderá ser utilizado por novas aplicações. Esse serviço de mineração de dados é baseado na técnica DAMICORE, e foi totalmente adaptado para ser executado sob demanda, em um ambiente de nuvem. Além disso, o serviço de mineração de dados também foi otimizado para trabalhar com dados incrementais de maneira a reduzir o tempo total de execução do serviço. 
Confirmando a viabilidade da arquitetura proposta, mesmo que em pequena escala, a infraestrutura desenvolvida permitiu o desenvolvimento de uma nova aplicação para auxílio à localização de faltas, que utilizando os dados provenientes dos smart meters, foi capaz de reduzir o problema da múltipla estimação nos sistemas de distribuição radial, auxiliando na definição do ramal em falta.

A ferramenta desenvolvida utiliza a mineração de dados para correlacionar os sinais pré-processados dos smart meters e assim definir uma proximidade entre o perfil de uma falta desconhecida e o de uma falta conhecida indicando um possível ramal faltoso. A partir da segmentação do alimentador em regiões de múltipla estimação, foram obtidos resultados expressivos na redução da múltipla estimação. Para essa ferramenta foi proposto um algoritmo de análise automática dos resultados tomando por base apenas informações topológicas do sistema sem a necessidade de um especialista.

Essa ferramenta foi testada com um extenso conjunto de faltas, utilizando diferentes configurações de pontos de medição de onde se concluiu que a melhor disposição é aquela que possui mais pontos de medição por região de múltipla estimação e que as medições da subestação não influenciam significativamente na melhora dos resultados. Como parte das análises, foi ainda avaliada a variação das respostas com relação à quantidade de dados de falta utilizados, tendo a aplicação apresentado pouca variação nos resultados a partir de 100 amostras, com uma taxa de redução da múltipla estimação acima de $80 \%$ para a maioria das regiões. Também foi possível observar que a região em que houve menor taxa de redução foi a região que possuía apenas um ponto de medição, onde os agrupamentos feitos pela mineração de dados consideraram a resistência da falta e não o ramal faltoso. Essa degradação no desempenho não aconteceu em outras regiões com características semelhantes utilizando mais de um medidor.

Para avaliar o comportamento da aplicação em relação a um estimador de distância não ideal foi implementado um método de localização de faltas baseado em impedância, o qual foi utilizado para estimar a distância da falta de maneira similar a um sistema real. Nesse sentido foram feitos três estudos de caso onde foi apresentado o funcionamento completo do sistema e sua utilização, demonstrando sua potencialidade para uso em sistemas reais. 
Cabe ressaltar ainda que a ferramenta desenvolvida tem o potencial de melhorar o desempenho de um estimador não ideal a medida que as faltas conhecidas agrupadas no mesmo cluster da falta desconhecida podem ser utilizadas para fornecer indícios da real posição da falta aproveitando para isso o potencial analítico da árvore filogenética gerada pelo DAMICORE.

\subsection{Continuidade da pesquisa}

As sugestões propostas para continuidade da pesquisa são:

口 Implementação dos mecanismos de segurança da informação para todo o sistema;

口 Desenvolvimento de novas aplicações utilizando a infraestrutura desenvolvida, como por exemplo, aplicações em antecipação de faltas ou detecção de perdas não técnicas;

口 Implantação da arquitetura em um ambiente de nuvem com mais recursos empregando gerenciamento de elasticidade;

口 Mensurar o consumo de recursos da aplicação considerando o espaço de armazenamento utilizado pela quantidade de dados de falta armazenados;

- Avaliação do comportamento da aplicação em um ambiente hostil, sujeito a erro de medição, erro de sincronismo e latência de comunicação;

口 Análise da aplicação perante um sistema de distribuição real;

- Testar o comportamento da aplicação em um sistema com geração distribuída;

口 Utilização de outros parâmetros provenientes dos smart meters, não somente o valor RMS e ângulo das componentes superpostas, buscando melhorar o resultado obtido. 



\section{Referências Bibliográficas}

[1] M. E. El-hawary, "The Smart Grid-State-of-the-art and Future Trends," Electr. Power Components Syst., vol. 42, no. 3-4, pp. 239-250, Mar. 2014.

[2] I. Colak, S. Sagiroglu, G. Fulli, M. Yesilbudak, and C.-F. F. Covrig, "A survey on the critical issues in smart grid technologies," Renew. Sustain. Energy Rev., vol. 54, pp. 396-405, Feb. 2016.

[3] M. L. Tuballa and M. L. Abundo, "A review of the development of Smart Grid technologies," Renew. Sustain. Energy Rev., vol. 59, pp. 710-725, Jun. 2016.

[4] H. Farhangi, "The path of the smart grid," IEEE Power Energy Mag., vol. 8, no. 1, pp. 18-28, 2010.

[5] X. Fang, S. Misra, G. Xue, and D. Yang, "Smart Grid - The New and Improved Power Grid: A Survey," IEEE Commun. Surv. Tutorials, vol. 14, no. 4, pp. 944-980, 2012.

[6] S. R. Thilaga, C. Sivapragash, and S. S. Kumar, "Advanced Cloud Computing in Smart Power Grid," in IET Chennai 3rd International Conference on Sustainable Energy and Intelligent Systems (SEISCON 2012), 2012, pp. 356-361.

[7] Yufeng Xin, I. Baldine, J. Chase, T. Beyene, B. Parkhurst, and A. Chakrabortty, "Virtual smart grid architecture and control framework," in 2011 IEEE International Conference on Smart Grid Communications (SmartGridComm), 2011, no. 1, pp. 1-6.

[8] S. Goose, J. Kirsch, and D. Wei, "SKYDA: cloud-based, secure SCADA-as-aservice," Int. Trans. Electr. Energy Syst., vol. 25, no. 11, pp. 3004-3016, Nov. 2015 .

[9] Z. Liang and L. Xiuqing, "The core of constructing the future power systems computation platform is cloud computing," in 2011 International Conference on Mechatronic Science, Electric Engineering and Computer (MEC), 2011, pp. 933937.

[10] M. Greer and M. Rodriguez-Martinez, "Autonomic Computing Drives Innovation of Energy Smart Grids," Procedia Comput. Sci., vol. 12, pp. 314-319, 2012. 
[11] F. C. L. Trindade, W. Freitas, and J. C. M. Vieira, "Fault Location in Distribution Systems Based on Smart Feeder Meters," IEEE Trans. Power Deliv., vol. 29, no. 1, pp. 251-260, Feb. 2014.

[12] CGEE, "Redes Elétricas Inteligentes : contexto nacional," Brasília, DF, 2012.

[13] C. Greer et al., "NIST Framework and Roadmap for Smart Grid Interoperability Standards, Release 3.0," Gaithersburg, MD, Oct. 2014.

[14] "EU Commission Task Force for Smart Grids Expert Group 1 : Functionalities of smart grids and smart meters Final Deliverable," Group, no. December, pp. 1-69, 2010 .

[15] EPRI, "SmartGrid Resource Center," 2016. [Online]. Available: http://smartgrid.epri.com/. [Accessed: 12-Feb-2016].

[16] D. S. Markovic, D. Zivkovic, I. Branovic, R. Popovic, and D. Cvetkovic, "Smart power grid and cloud computing," Renew. Sustain. Energy Rev., vol. 24, pp. 566-577, Aug. 2013.

[17] C. Gellings, "Estimating the costs and benefits of the smart grid," Palo Alto, CA, 2011.

[18] Federal Energy Regulatory Commission, "Smart Grid Policy," [Docket No. PL09-4-000], 2009. [Online]. Available: http://www.ferc.gov/whats-new/commmeet/2009/071609/E-3.pdf.

[19] M. M. Selvam, R. Gnanadass, and N. P. Padhy, "Initiatives and technical challenges in smart distribution grid," Renew. Sustain. Energy Rev., vol. 58, pp. 911-917, 2016.

[20] D. G. Hart, "Using AMI to realize the Smart Grid," IEEE Power Energy Soc. 2008 Gen. Meet. Convers. Deliv. Electr. Energy 21st Century, PES, pp. 1-2, 2008.

[21] R. Rashed Mohassel, A. Fung, F. Mohammadi, and K. Raahemifar, "A survey on Advanced Metering Infrastructure," Int. J. Electr. Power Energy Syst., vol. 63, pp. 473-484, 2014.

[22] H. E. Brown, S. Suryanarayanan, and G. T. Heydt, "Some characteristics of emerging distribution systems considering the smart grid initiative," Electr. J., vol. 23, no. 5, pp. 64-75, 2010. 
[23] H. E. Brown, S. Suryanarayanan, S. Member, and S. Suryanarayanan, "A survey seeking a definition of a smart distribution system," 41st North Am. Power Symp. NAPS 2009, vol. 80401, pp. 1-7, 2009.

[24] S. Kazemi, Reliability Evaluation os Smart Distribution Grids. 2011.

[25] R. E. Brown, "Impact of Smart Grid on Distribution System design," IEEE Power Energy Soc. 2008 Gen. Meet. Convers. Deliv. Electr. Energy 21st Century, PES, 2008.

[26] J. Ekanayake, N. Jenkins, and K. Liyanage, Smart grid: technology and applications. 2012.

[27] A. Bari, J. Jiang, W. Saad, and A. Jaekel, "Challenges in the Smart Grid Applications: An Overview," Int. J. Distrib. Sens. Networks, vol. 2014, pp. 1-11, 2014.

[28] P. Murphy, D. McFadden, M. Angemeer, and K. Major, "Enabling Tomorrow's Electricity System: Report of the Ontario Smart Grid Forum," 2010.

[29] H. Liang, B. J. Choi, W. Zhuang, and X. Shen, "Towards optimal energy storecarry-and-deliver for PHEVs via V2G system," in 2012 Proceedings IEEE INFOCOM, 2012, pp. 1674-1682.

[30] EDSO/ European Distribution System Operators for Smart Grids and D. Management, "Data Management: The role of Distribution System Operators in managing data," 2014.

[31] B. K. Fan, G. J. Ding, T. Long, H. B. Lan, and J. Wang, "Study on the cloud computing architecture for smart grid application," 2013 International Conference on Advances in Energy and Environmental Science, ICAEES 2013, vol. 805-806. pp. 1073-1077, 2013.

[32] N. Kayastha, D. Niyato, E. Hossain, and Z. Han, "Smart grid sensor data collection, communication, and networking: a tutorial," Wirel. Commun. Mob. Comput., vol. 14, no. 11, pp. 1055-1087, Aug. 2014.

[33] Z. Fan et al., "Smart Grid Communications: Overview of Research Challenges, Solutions, and Standardization Activities," IEEE Commun. Surv. Tutorials, vol. 15, no. 1, pp. 21-38, Jan. 2013.

[34] J. F. Martínez, J. Rodríguez-Molina, P. Castillejo, and R. De Diego, "Middleware architectures for the smart grid: Survey and challenges in the foreseeable future," Energies, vol. 6, no. 7, pp. 3593-3621, Jul. 2013. 
[35] M. Albano, L. L. Ferreira, and L. M. Pinho, "Convergence of Smart Grid ICT Architectures for the Last Mile," IEEE Trans. Ind. Informatics, vol. 11, no. 1, pp. 187-197, 2015.

[36] Y. Kabalci, "A survey on smart metering and smart grid communication," Renew. Sustain. Energy Rev., vol. 57, pp. 302-318, 2016.

[37] S. S. S. R. Depuru, L. Wang, and V. Devabhaktuni, "Smart meters for power grid: Challenges, issues, advantages and status," Renew. Sustain. Energy Rev., vol. 15, no. 6, pp. 2736-2742, 2011.

[38] N. Hargreaves, G. Taylor, and A. Carter, "Information standards to support application and enterprise interoperability for the smart grid," in 2012 IEEE Power and Energy Society General Meeting, 2012, pp. 1-6.

[39] Y. K. Penya, A. Pena, and Oihane Kamara Esteban, "Semantic integration of IEC 60870 into CIM," in 2011 IEEE International Conference on Smart Grid Communications (SmartGridComm), 2011, pp. 428-433.

[40] Y. Simmhan, Q. Zhou, and V. Prasanna, "Semantic Information Integration for Smart Grid Applications," in Green IT: Technologies and Applications, Berlin, Heidelberg: Springer Berlin Heidelberg, 2011, pp. 361-380.

[41] Zhihui Yang, Qin Zhou, Andy Guo Ma, Peter Xiaopei Cheng, and Yan Gao, "The design and implementation of smart grid high volume data management platform architecture," in ISGT 2014, 2014, vol. d, pp. 1-5.

[42] M. M. Albu, R. Neurohr, D. Apetrei, I. Silvas, and D. Federenciuc, "Monitoring voltage and frequency in smart distribution grids. A case study on data compression and accessibility.," IEEE PES Gen. Meet., pp. 1-6, 2010.

[43] C.-C. Chuang et al., "A Compression Algorithm for Fluctuant Data in Smart Grid Database Systems," 2013 Data Compression Conf., pp. 485-485, 2013.

[44] J. Yin, I. Gorton, and S. Poorva, "Toward Real Time Data Analysis for Smart Grids," Int. Conf. High Perform. Comput. Networking, Storage, Anal., pp. 827$832,2012$.

[45] H. Liang, A. K. Tamang, W. Zhuang, and X. S. Shen, "Stochastic Information Management in Smart Grid," IEEE Commun. Surv. Tutorials, vol. 16, no. 3, pp. 1746-1770, Jan. 2014. 
[46] G. Chicco, "Challenges for smart distribution systems: Data representation and optimization objectives," 12th Int. Conf. Optim. Electr. Electron. Equip., pp. 1236-1244, 2010.

[47] H. Maaß et al., "Data processing of high-rate low-voltage distribution grid recordings for smart grid monitoring and analysis," EURASIP J. Adv. Signal Process., vol. 2015, no. 1, p. 14, 2015.

[48] B. Taube, R. Bienert, T. Avenue, and M. Hill, "Advanced Data Management and Analytics for Automated Demand Response ( ADR ) based on NoSQL," GridWise Archit. Counc. - Grid-Interop 2012, pp. 1-10, 2012.

[49] P. D. Diamantoulakis, V. M. Kapinas, and G. K. Karagiannidis, "Big Data Analytics for Dynamic Energy Management in Smart Grids," Big Data Res., vol. 2, no. 3, pp. 94-101, 2015.

[50] F. Luo, Z. Y. Dong, J. Zhao, X. Zhang, W. Kong, and Y. Chen, "Enabling the big data analysis in the smart grid," in 2015 IEEE Power \&6 Energy Society General Meeting, 2015, pp. 1-5.

[51] N. Yu et al., "Big Data Analytics in Power Distribution Systems," 2015 IEEE Power Energy Soc. Innov. Smart Grid Technol. Conf., pp. 1-5, Feb. 2015.

[52] B. Yang, J. Yamazaki, N. Saito, Y. Kokai, and D. Xie, "Big data analytic empowered grid applications. Is PMU a big data issue?," in 2015 12th International Conference on the European Energy Market (EEM), 2015, vol. 2015-Augus, pp. 1-4.

[53] M. Arenas-Martinez et al., "A Comparative Study of Data Storage and Processing Architectures for the Smart Grid," in 2010 First IEEE International Conference on Smart Grid Communications, 2010, pp. 285-290.

[54] J. S. van der Veen, B. van der Waaij, and R. J. Meijer, "Sensor Data Storage Performance: SQL or NoSQL, Physical or Virtual," 2012 IEEE Fifth Int. Conf. Cloud Comput., pp. 431-438, 2012.

[55] Z. Aung, "Database Systems for the Smart Grid," in Smart Grid: Opportunities, Developments and Trends, A.B.M. Shawkat Ali, Ed. Springer Press, 2013, pp. 151-168.

[56] K. Zhou and S. Yang, "A framework of service-oriented operation model of China's power system," Renew. Sustain. Energy Rev., vol. 50, pp. 719-725, Oct. 2015 . 
[57] Z. Q. Bo et al., "Substation cloud computing for secondary auxiliary equipment," 2014 Int. Conf. Power Syst. Technol., no. Powercon, pp. 1853-1858, Oct. 2014.

[58] Fengji Luo, Zhao Yang Dong, Yingying Chen, Yan Xu, Ke Meng, and Kit Po Wong, "Hybrid cloud computing platform: The next generation IT backbone for smart grid," in 2012 IEEE Power and Energy Society General Meeting, 2012, pp. $1-7$.

[59] K. Zhou, C. Fu, and S. Yang, "Big data driven smart energy management: From big data to big insights," Renew. Sustain. Energy Rev., vol. 56, pp. 215-225, Apr. 2016.

[60] S. Rusitschka, K. Eger, C. Gerdes, and Ieee, "Smart Grid Data Cloud: A Model for Utilizing Cloud Computing in the Smart Grid Domain," Smart Grid Commun. (SmartGridComm), 2010 First IEEE Int. Conf., pp. 483-488, 2010.

[61] J. Baek, Q. H. Vu, J. K. Liu, X. Huang, and Y. Xiang, "A Secure Cloud Computing Based Framework for Big Data Information Management of Smart Grid," IEEE Trans. Cloud Comput., vol. 3, no. 2, pp. 233-244, Apr. 2015.

[62] X. Fang, S. Misra, G. Xue, and D. Yang, "Managing smart grid information in the cloud: opportunities, model, and applications," IEEE Netw., vol. 26, no. 4, pp. 32-38, 2012.

[63] N. Chaichi, J. Lavoie, S. Zarrin, R. Khalifa, and F. Sie, "A comprehensive assessment of cloud computing for smart grid applications: A multi-perspectives framework," in 2015 Portland International Conference on Management of Engineering and Technology (PICMET), 2015, pp. 2541-2547.

[64] J. Popeanga, "Cloud computing and smart grids," ERP E-bus. Appl. Deploy. Open Source Distrib. Cloud Syst., vol. III, no. 3, pp. 57-66, 2012.

[65] B. Fang et al., "The contributions of cloud technologies to smart grid," Renew. Sustain. Energy Rev., vol. 59, pp. 1326-1331, Jun. 2016.

[66] Y. Wang, X. Lin, and M. Pedram, "A Stackelberg Game-Based Optimization Framework of the Smart Grid With Distributed PV Power Generations and Data Centers," IEEE Trans. Energy Convers., vol. 29, no. 4, pp. 978-987, Dec. 2014.

[67] B. Lohrmann and O. Kao, "Processing smart meter data streams in the cloud," IEEE PES Innov. Smart Grid Technol. Conf. Eur., pp. 1-8, 2011. 
[68] X. Li and J. C. Lo, "Pricing and peak aware scheduling algorithm for cloud computing," in 2012 IEEE PES Innovative Smart Grid Technologies (ISGT), 2012, pp. 1-7.

[69] T. Rajeev and S. Ashok, "Dynamic load-shifting program based on a cloud computing framework to support the integration of renewable energy sources," Appl. Energy, vol. 146, pp. 141-149, May 2015.

[70] A.-H. Mohsenian-Rad and A. Leon-Garcia, "Coordination of Cloud Computing and Smart Power Grids," in 2010 First IEEE International Conference on Smart Grid Communications, 2010, pp. 368-372.

[71] H. Kim, Y.-J. Kim, K. Yang, and M. Thottan, "Cloud-based demand response for smart grid: Architecture and distributed algorithms," in 2011 IEEE International Conference on Smart Grid Communications (SmartGridComm), 2011, pp. 398-403.

[72] Y. Simmhan et al., "An Informatics Approach to Demand Response Optimization in Smart Grids," 2011.

[73] Y. Simmhan et al., "Cloud-based software platform for data-driven smart grid management," EEE/AIP Comput. Sci. Eng., pp. 1-6, 2013.

[74] Y. Simmhan et al., "Cloud-Based Software Platform for Big Data Analytics in Smart Grids," Comput. Sci. Eng., vol. 15, no. 4, pp. 38-47, 2013.

[75] A. Sheikhi, M. Rayati, S. Bahrami, and A. M. Ranjbar, "Integrated demand side management game in smart energy hubs," IEEE Trans. Smart Grid, vol. 6, no. 2, pp. 675-683, 2015.

[76] C.-T. Yang, W.-S. Chen, K.-L. Huang, J.-C. Liu, W.-H. Hsu, and C.-H. Hsu, "Implementation of Smart Power Management and Service System on Cloud Computing," Ubiquitous Intell. Comput. 9th Int. Conf. Auton. Trust. Comput. (UIC/ATC), 2012 9th Int. Conf., pp. 924-929, Sep. 2012.

[77] C.-T. Yang, C.-C. Lai, W.-S. Chen, J.-C. Liu, and W. C. Chu, "Implementation of a Smart Grid System with SOA-based Service on Cloud," in Communications in Computer and Information Science, vol. 223 CCIS, R. S. Chang, T. H. Kim, and S. L. Peng, Eds. 2011, pp. 159-168.

[78] X. Jin, Z. He, and Z. Liu, "Multi-agent-based cloud architecture of smart grid," Energy Procedia, vol. 12, pp. 60-66, 2011. 
[79] S. Bertagna De Marchi, F. Ponci, A. Monti, S. B. De Marchi, F. Ponci, and A. Monti, "Design of a MAS as Cloud Computing Service to control Smart Micro Grid," in IEEE PES ISGT Europe 2013, 2013, pp. 1-5.

[80] T. Rajeev and S. Ashok, "A cloud computing approach for power management of microgrids," in ISGT2011-India, 2011, pp. 49-52.

[81] C. Alcaraz, I. Agudo, D. Nunez, and J. Lopez, "Managing Incidents in Smart Grids à la Cloud," in 2011 IEEE Third International Conference on Cloud Computing Technology and Science, 2011, pp. 527-531.

[82] M. Fazio and A. Puliafito, "Cloud4sens: a cloud-based architecture for sensor controlling and monitoring," IEEE Commun. Mag., vol. 53, no. 3, pp. 41-47, Mar. 2015.

[83] H. Bai, Z. Ma, and Y. Zhu, "The Application of Cloud Computing in Smart Grid Status Monitoring," in Communications in Computer and Information Science, vol. 312 CCIS, Y. H. Wang and X. M. Zhang, Eds. 2012, pp. 460-465.

[84] C. Alcaraz and J. Lopez, "Addressing Situational Awareness in Critical Domains of a Smart Grid," in Lecture Notes in Computer Science (including subseries Lecture Notes in Artificial Intelligence and Lecture Notes in Bioinformatics), vol. 7645 LNCS, 2012, pp. 58-71.

[85] F. J. Gomez, J. Melendez, S. Herraiz, E. Gonzalez, M. Lopez-Perea, and C. Murphy Oconnor, "Web Services Framework for Power Quality Monitoring," in Smart Objects, Systems and Technologies (SmartSysTech), Proceedings of 2013 European Conference on, 2013, pp. 1-7.

[86] D. Wang and L. Xiao, "Storage and Query of Condition Monitoring Data in Smart Grid Based on Hadoop," in 2012 Fourth International Conference on Computational and Information Sciences, 2012, pp. 377-380.

[87] B. Bitzer and E. S. Gebretsadik, "Cloud computing for monitoring and controlling of distributed energy generations," in 2014 49 th International Universities Power Engineering Conference (UPEC), 2014, pp. 1-5.

[88] B. Bitzer and E. S. Gebretsadik, "Cloud computing framework for smart grid applications," in 2013 48th International Universities' Power Engineering Conference (UPEC), 2013, pp. 1-5.

[89] Jinsung Byun, Youngil Kim, Zion Hwang, and Sehyun Park, "An intelligent cloud-based energy management system using machine to machine 
communications in future energy environments," in 2012 IEEE International Conference on Consumer Electronics (ICCE), 2012, pp. 664-665.

[90] S. M. Hasan, A. Reid, M. Nielsen, and K. Dodrill, "Cloud connected smart grid enabled EVSE," in 2013 International Conference on Connected Vehicles and Expo (ICCVE), 2013, pp. 824-825.

[91] Q. Huang, M. Zhou, Y. Zhang, and Z. Wu, "Exploiting cloud computing for power system analysis," in 2010 International Conference on Power System Technology, 2010, pp. 1-6.

[92] P. M. Devie and S. Kalyani, "an Optimization Framework for Cloud-Based Data Management Model in Smart Grid," Int. J. Res. Eng. Technol., vol. 04, no. 02, pp. 751-758, Feb. 2015.

[93] X. Fang, D. Yang, and G. Xue, "Evolving Smart Grid Information Management Cloudward: A Cloud Optimization Perspective," IEEE Trans. Smart Grid, vol. 4, no. 1, pp. 111-119, Mar. 2013.

[94] K. Anderson, J. Du, A. Narayan, and A. El Gamal, "GridSpice: A Distributed Simulation Platform for the Smart Grid," IEEE Trans. Ind. Informatics, vol. 10, no. 4, pp. 2354-2363, Nov. 2014.

[95] G. Leijiao, W. Shouxiang, and G. Xianjun, "Framework Design of Cloud Computing Technology Application in Power System Transient Simulation," in Power and Energy Engineering Conference (APPEEC), 2014 IEEE PES AsiaPacific, 2014, pp. 1-6.

[96] K. Maheshwari, K. Birman, J. Wozniak, and D. Van Zandt, "Evaluating Cloud Computing Techniques for Smart Power Grid Design Using Parallel Scripting," in 2013 13th IEEE/ACM International Symposium on Cluster, Cloud, and Grid Computing, 2013, pp. 319-326.

[97] K. Maheshwari, M. Lim, L. Wang, K. Birman, and R. van Renesse, "Toward a reliable, secure and fault tolerant smart grid state estimation in the cloud," in 2013 IEEE PES Innovative Smart Grid Technologies Conference (ISGT), 2013, pp. 1-6.

[98] M. Mayilvaganan and M. Sabitha, "A cloud-based architecture for Big-Data analytics in smart grid: A proposal," in 2013 IEEE International Conference on Computational Intelligence and Computing Research, 2013, pp. 1-4. 
[99] A. Martin, R. Silva, A. Brito, and C. Fetzer, "Low Cost Energy Forecasting for Smart Grids Using Stream Mine 3G and Amazon EC2," in 2014 IEEE/ACM 7th International Conference on Utility and Cloud Computing, 2014, pp. 523-528.

[100] V. Nikolopoulos, G. Mpardis, I. Giannoukos, I. Lykourentzou, and V. Loumos, "Web-based decision-support system methodology for smart provision of adaptive digital energy services over cloud technologies," IET Softw., vol. 5, no. 5, p. 454, 2011.

[101] E. V. M. Papadopoulou, "Energy Management," in Energy Management in Buildings Using Photovoltaics, London: Springer London, 2012, pp. 1-9.

[102] "Energy management system," Wikipedia, the free encyclopedia, 2016. [Online]. Available: https://en.wikipedia.org/wiki/Energy_management_system. [Accessed: 15-Apr-2016].

[103] "What is data analytics (DA)? - Definition from WhatIs.com," 2016. [Online]. Available: http://searchdatamanagement.techtarget.com/definition/dataanalytics. [Accessed: 20-Apr-2016].

[104] "What is data mining? - Definition from WhatIs.com," 2016. [Online]. Available: http://searchsqlserver.techtarget.com/definition/data-mining. [Accessed: 20-Apr2016].

[105] A. C. da Rocha, "Computação em nuvem: uma nova abordagem em ambientes de rede," Centro Universitário da Cidade do Rio de Janeiro, 2009.

[106] B. J. S. Chee and C. F. Jr., Cloud Computing Technologies and Strategies. Boca Raton, FL: Taylor and Francis Group, 2010.

[107] E. Schmidt, "Search Engine Strategies Conference - Conversation with Eric Schmidt hosted by Danny Sullivan," The Google Podium Archive, 2006. [Online]. Available: http://www.google.com/press/podium/ses2006.html. [Accessed: 24Aug-2015].

[108] R. Chellappa, "Intermediaries in Cloud-Computing: A New Computing Paradigm," INFORMS, 1997.

[109] S. L. Garfinkel, Architects of the information society: thirty-five years of the Laboratory for Computer Science at MIT. Cambridge, Mass. [u.a.]: MIT Press, 1999. 
[110] E. Alecrim, "O que é cloud computing (computação nas nuvens)?," http://www.infowester.com/, 2008. [Online]. Available: http://www.infowester.com/cloudcomputing.php. [Accessed: 30-Jan-2016].

[111] L. M. Vaquero, L. Rodero-Merino, J. Caceres, and M. Lindner, "A break in the clouds," ACM SIGCOMM Comput. Commun. Rev., vol. 39, no. 1, p. 50, 2008.

[112] D. Mishra, "Cloud Computing: The era of Virtual world Opportunities and Risks involved," Int. J. Comput. Sci. Eng., vol. 3, no. 04, pp. 204-209, 2014.

[113] L. M. Vaquero, L. Rodero-merino, J. Caceres, and M. Lindner, "A Break in the Clouds: Towards a Cloud Definition," ACM SIGCOMM Comput. Commun. Rev., vol. 39, no. 1, p. 50, 2009.

[114] S. Zhang, S. Zhang, X. Chen, and X. Huo, "Cloud Computing Research and Development Trend," 2010 Second Int. Conf. Futur. Networks, pp. 93-97, 2010.

[115] Google Trends, "Pesquisa na web do Google interesse: cloud computing, grid computing, distributed computing - Todo o mundo, 2004 - presente," 2015. [Online]. Available: https://www.google.com/trends/explore\#q=Cloud computing $\% 2 \mathrm{C}$ grid computing $\% 2 \mathrm{C}$ distributed computing\&cmpt=q\&tz=Etc\%2FGMT\%2B3. [Accessed: 27-Aug-2015].

[116] I. Foster, Y. Zhao, I. Raicu, and S. Lu, "Cloud Computing and Grid Computing 360-Degree Compared," Proc. Grid Comput. Environ. Work., pp. 1-10, 2008.

[117] IBM, "IBM Knowledge Center - What is distributed computing." 01-Jan-2013.

[118] R. Giordanelli and C. Mastroianni, "The Cloud Computing Paradigm: Characteristics, Opportunities and Research Issues," Tech. Rep. RT-ICAR-CS10-01, 2010.

[119] NIST - National Institute of Standards and Technology, "NIST TWiki CloudComputing," 2015. [Online]. Available: http://collaborate.nist.gov/twikicloud-computing/bin/view/CloudComputing/WebHome. [Accessed: 25-Aug2015].

[120] NIST - National Institute of Standards and Technology, "Cloud Computing," 2015. [Online]. Available: http://www.nist.gov/itl/cloud/. [Accessed: 25-Aug2015].

[121] P. Mell and T. Grance, "The NIST Definition of Cloud Computing Recommendations of the National Institute of Standards and Technology," Nist Spec. Publ., vol. 145, p. 7, 2011. 
[122] Cloud Security Alliance, "Security Guidance for Critical Areas of Focus in Cloud Computing V3," Netw. Secur., vol. 3, no. 2, p. 176, Feb. 2011.

[123] F. Lui, "NIST Cloud Computing Reference Architecture Recommendations of the National Institute of Standards and," 2011.

[124] H. P. Borges, J. N. De Souza, B. Schulze, and A. R. Mury, "Computação em nuvem," p. 48, 2011.

[125] G. Haynes, "IaaS, PaaS, SaaS, \& the Cloud 101," 2014. [Online]. Available: https://www.linkedin.com/pulse/20140907071547-305726885-iaas-pass-saas-thecloud-101. [Accessed: 30-May-2016].

[126] D. C. Chou, "Rise of the Cloud Ecosystems," MSDN Architecture + Strategy, 2011. [Online]. Available:

https://blogs.msdn.microsoft.com/dachou/2011/03/16/rise-of-the-cloudecosystems/. [Accessed: 30-May-2016].

[127] Selvaratnam Uthaiyashankar, "Roadmap to the Clouds." 2012.

[128] N. Antonopoulos and L. Gillam, Cloud Computing: Principles, Systems and Applications, vol. 54. 2010.

[129] O. Achahbar, "The Impact of Virtualization on High Performance Computing Clustering in the Cloud," Al Akhawayn University, 2014.

[130] Google Cloud, "What are Containers and their benefits | Google Cloud." [Online]. Available: https://cloud.google.com/containers/. [Accessed: 28-Mar2018].

[131] Kubernetes, "Kubernetes | Production-Grade Container Orchestration." [Online]. Available: https://kubernetes.io/. [Accessed: 28-Mar-2018].

[132] Docker, "Docker - Build, Ship, and Run Any App, Anywhere." [Online]. Available: https://www.docker.com/. [Accessed: 28-Mar-2018].

[133] LXD Canonical, "The LXD pure-container hypervisor | Containers | Ubuntu." [Online]. Available: https://www.ubuntu.com/containers/lxd. [Accessed: 29-Mar2018].

[134] OpenStack project, "Software - OpenStack is open source software for creating private and public clouds." [Online]. Available:

https://www.openstack.org/software/. [Accessed: 29-Mar-2018]. 
[135] OpenNebula Project, "OpenNebula - Flexible Enterprise Cloud Made Simple." [Online]. Available: https://opennebula.org/. [Accessed: 29-Mar-2018].

[136] OpenStack project, "Logical architecture - OpenStack Networking Guide current." [Online]. Available: http://docs.ocselected.org/openstackmanuals/kilo/networking-guide/content/logical-architecture.html. [Accessed: 29Mar-2018].

[137] OpenNebula Project, "About the Project - OpenNebula." [Online]. Available: https://opennebula.org/about/project/. [Accessed: 30-Mar-2018].

[138] R. Moreno-Vozmediano, Montero, and I. M. Llorente, "IaaS Cloud Architecture: From Virtualized Datacenters to Federated Cloud Infrastructures," Computer (Long. Beach. Calif)., vol. 45, no. 12, pp. 65-72, Dec. 2012.

[139] "OpenNebula on CentOS." [Online]. Available: https://www.infoq.com/fr/presentations/opennebula-centos. [Accessed: 26-May2018].

[140] E. F. Codd, "A relational model of data for large shared data banks," Commun. $A C M$, vol. 13, no. 6, pp. 377-387, Jun. 1970.

[141] S. Prasad and S. B. Avinash, "Smart meter data analytics using OpenTSDB and Hadoop," in 2013 IEEE Innovative Smart Grid Technologies-Asia (ISGT Asia), 2013, pp. 1-6.

[142] "NOSQL Databases," 2016. [Online]. Available: http://nosql-database.org/. [Accessed: 31-May-2016].

[143] "NoSQL," Wikipedia, the free encyclopedia, 2016. [Online]. Available: https://en.wikipedia.org/wiki/NoSQL. [Accessed: 01-Jun-2016].

[144] Amazon Web Services (AWS), "O que é NoSQL?," Amazon Web Services (AWS), 2016. [Online]. Available: https://aws.amazon.com/pt/nosql/. [Accessed: 01-Jun-2016].

[145] A. Lith and J. Mattsson, "Investigating storage solutions for large data A comparison of well performing and scalable data storage solutions for real time extraction and batch insertion of data," Master Thesis, Chalmers University of Technology, 2011.

[146] R. Burtica, E. M. Mocanu, M. I. Andreica, and N. Tapus, "Practical application and evaluation of no-SQL databases in Cloud Computing," SysCon 2012 - 2012 IEEE Int. Syst. Conf. Proc., pp. 79-84, 2012. 
[147] V. Abramova and J. Bernardino, "NoSQL databases: MongoDB vs cassandra," Proc. Int. C* Conf. Comput. Sci. Softw. Eng. ACM 2013, pp. 14-22, 2013.

[148] T. W. Wlodarczyk, "Overview of Time Series Storage and Processing in a Cloud Environment," in 4th IEEE International Conference on Cloud Computing Technology and Science Proceedings, 2012, pp. 625-628.

[149] A. Bader, O. Kopp, and M. Falkenthal, "Survey and Comparison of Open Source Time Series Databases," in Datenbanksysteme für Business, Technologie und Web (BTW2017) -- Workshopband, 2017, pp. 249-268.

[150] E. Brewer, "CAP twelve years later: How the 'rules' have changed," Computer (Long. Beach. Calif)., vol. 45, no. 2, pp. 23-29, Feb. 2012.

[151] S. Joseph and S. Chandran, "Stream Computing: Opportunities and Challenges in Smart Grid," Procedia Technol., vol. 21, pp. 49-53, 2015.

[152] J. Dean and S. Ghemawat, "MapReduce: Simplified Data Processing on Large Clusters," Proc. 6th Symp. Oper. Syst. Des. Implement., pp. 137-149, 2004.

[153] T. Aarnio, "Parallel data processing with MapReduce," TKK T-110.5190 Semin. Internetworking, 2009.

[154] I. Foster and D. B. Gannon, "Data Analytics in the Cloud with Apache Hadoop," in Cloud Computing for Science and Engineering, London, England: Massachusetts Institute of Technology, 2017.

[155] Apache Spark, "Apache Spark ${ }^{\mathrm{TM}}$ - Lightning-Fast Cluster Computing." [Online]. Available: http://spark.apache.org/. [Accessed: 31-Mar-2018].

[156] "Apache Flink: Scalable Stream and Batch Data Processing." [Online]. Available: https://flink.apache.org/. [Accessed: 11-Apr-2018].

[157] “Apache Storm." [Online]. Available: http://storm.apache.org/. [Accessed: 11Apr-2018].

[158] "Samza." [Online]. Available: http://samza.apache.org/. [Accessed: 11-Apr-2018].

[159] "Spark Streaming | Apache Spark." [Online]. Available: https://spark.apache.org/streaming/. [Accessed: 11-Apr-2018].

[160] A. Bereş, B. Genge, and I. Kiss, "A Brief Survey on Smart Grid Data Analysis in the Cloud," Procedia Technol., vol. 19, pp. 858-865, 2015. 
[161] I. Foster and D. B. Gannon, "Streaming Data to the Cloud," in Cloud Computing for Science and Engineering, London, England: Massachusetts Institute of Technology, 2017.

[162] F. Zhou, X. Song, Y. Han, and J. Gao, "A Data Streams Analysis Strategy Based on Hadoop Scheduling Optimization for Smart Grid Application," in Frontiers in Algorithmics, vol. 9130, J. Wang and C. Yap, Eds. 2015, pp. 326333.

[163] "Hadoop, Storm, Samza, Spark, and Flink: Big Data Frameworks Compared | DigitalOcean." [Online]. Available: https://www.digitalocean.com/community/tutorials/hadoop-storm-samza-sparkand-flink-big-data-frameworks-compared\#apache-samza. [Accessed: 11-Apr-2018].

[164] "Web Services Glossary." [Online]. Available: https://www.w3.org/TR/wsgloss/. [Accessed: 24-May-2018].

[165] "JSON." [Online]. Available: http://json.org/. [Accessed: 24-May-2018].

[166] "XML-RPC Specification." [Online]. Available: http://xmlrpc.scripting.com/spec.html. [Accessed: 25-May-2018].

[167] "SOAP Specifications." [Online]. Available: https://www.w3.org/TR/soap/. [Accessed: 25-May-2018].

[168] R. T. Fielding, "Architectural Styles and the Design of Network-based Software Architectures," University of California, 2000.

[169] M. Yigit, V. C. Gungor, and S. Baktir, "Cloud Computing for Smart Grid applications," Comput. Networks, vol. 70, pp. 312-329, Sep. 2014.

[170] Y. Simmhan, A. G. Kumbhare, B. Cao, and V. Prasanna, "An Analysis of Security and Privacy Issues in Smart Grid Software Architectures on Clouds," in 2011 IEEE 4th International Conference on Cloud Computing, 2011, pp. 582589.

[171] C. Rong, S. T. Nguyen, and M. G. Jaatun, "Beyond lightning: A survey on security challenges in cloud computing," Comput. Electr. Eng., vol. 39, no. 1, pp. 47-54, Jan. 2013.

[172] L. Zheng, Y. Hu, and C. Yang, "Design and Research on Private Cloud Computing Architecture to Support Smart Grid," in 2011 Third International Conference on Intelligent Human-Machine Systems and Cybernetics, 2011, vol. 2, pp. 159-161. 
[173] E. Sisley, "Cloud Computing Considerations in the Smart Grid: Assessing and Implementing Cloud Computing Initiatives that Potentially Impact the Smart Grid," Smart Grid Interoperability Panel, no. November, 2014.

[174] B. Taube, "Data Management and Smart Grids," Alternative Energy eMagazine, 2012. [Online]. Available:

http://www.altenergymag.com/emagazine/2012/08/data-management-andsmart-grids-/1942. [Accessed: 24-Feb-2016].

[175] J. Baek, Q. H. Vu, A. Jones, S. Al Mulla, and C. Y. Yeun, Smart-Frame: a Flexible, Scalable, and Secure Information Management Framework for Smart Grids. 2012.

[176] D. Benhaddou, M. R. Abid, and O. Achahbar, "Big data processing for smart grids," IADIS Int. J. Comput. Sci. Inf. Syst., vol. 10, no. 1, pp. 32-46, 2015.

[177] R. S. Brewer and P. M. Johnson, "WattDepot: An Open Source Software Ecosystem for Enterprise-Scale Energy Data Collection, Storage, Analysis, and Visualization," in 2010 First IEEE International Conference on Smart Grid Communications, 2010, pp. 91-95.

[178] T. Mikkola et al., "Near real time energy monitoring for end users: Requirements and sample applications," in 2011 IEEE International Conference on Smart Grid Communications (SmartGridComm), 2011, pp. 451-456.

[179] L. Tang, J. Li, and R. Wu, "Synergistic model of power system cloud computing based on Mobile-agent," in 2012 3rd IEEE International Conference on Network Infrastructure and Digital Content, 2012, pp. 222-226.

[180] A. M. Van, H. L. Lv, V. L. Cheng, and F. V. Wang, "Design of cloud data warehouse and its application in smart grid," in International Conference on Automatic Control and Artificial Intelligence (ACAI 2012), 2012, pp. 849-852.

[181] G. Xiong, T. R. Nyberg, P. Hamalainen, X. Dong, Y. Liu, and J. Hou, "To enhance power distribution network management of local power service enterprise by using cloud platform," in 2015 5th International Conference on Information Science and Technology (ICIST), 2015, pp. 487-491.

[182] B. Yu, A. Cuzzocrea, D. Jeong, and S. Maydebura, "On managing very large sensor-network data using bigtable," in 2012 12th IEEE/ACM International Symposium on Cluster, Cloud and Grid Computing (ccgrid 2012), 2012, pp. 918922. 
[183] T. Rajeev and S. Ashok, "Operational Flexibility in Smart Grid through Cloud Computing," in 2012 International Symposium on Cloud and Services Computing, 2012, pp. 21-24.

[184] M. Fazio, A. Celesti, A. Puliafito, and M. Villari, "Big Data Storage in the Cloud for Smart Environment Monitoring," Procedia Comput. Sci., vol. 52, no. Ant, pp. 500-506, 2015.

[185] D. Xu, M. Lei, F. Zhou, and W. Luan, "Study on hybrid storage method of AMI mass data," China Int. Conf. Electr. Distrib. CICED, vol. 2014-Decem, no. Ciced, pp. 1288-1293, 2014.

[186] S. Prasad and S. B. Avinash, "Application of polyglot persistence to enhance performance of the energy data management systems," in 2014 International Conference on Advances in Electronics Computers and Communications, 2014, pp. 1-6.

[187] J. Yin, A. Kulkarni, S. Purohit, I. Gorton, and B. Akyol, "Scalable real time data management for smart grid," in Proceedings of the Middleware 2011 Industry Track Workshop on - Middleware '11, 2011, vol. 1, no. 509, pp. 1-6.

[188] J. Yin, P. Sharma, I. Gorton, and B. Akyoli, "Large-Scale Data Challenges in Future Power Grids," in 2013 IEEE Seventh International Symposium on Service-Oriented System Engineering, 2013, pp. 324-328.

[189] Y. Song, M. Wu, and L. Ma, "Design and Realization of the Smart Grid Marketing System Architecture Based on Hadoop," in Proceedings - 2012 International Conference on Control Engineering and Communication Technology, ICCECT 2012, 2012, pp. 500-503.

[190] "Birman, Ganesh, Renesse, 2011, Running smart grid control software on cloud computing architectures., „| Work.pdf.” .

[191] M. O. Areias, "Scada in a cloud-based architecture," Universidade de Lisboa, 2013.

[192] K. P. Birman, L. Ganesh, and R. Van Renesse, "Running smart grid control software on cloud computing architectures.," in Computational Needs for the Next Generation Electric Grid, 2011, pp. 1-28.

[193] Hewlett Packard Enterprise, "HPE Helion Eucalyptus Open Source Hybrid and Private Cloud Software for AWS Users," Hewlett Packard Enterprise, 2016. [Online]. Available: http://www8.hp.com/us/en/cloud/helion-eucalyptusoverview.html. [Accessed: 02-Jun-2016]. 
[194] D. Alahakoon and X. Yu, "Smart Electricity Meter Data Intelligence for Future Energy Systems: A Survey," IEEE Trans. Ind. Informatics, vol. PP, no. 99, pp. $1-1,2015$.

[195] R. H. Khan and J. Y. Khan, "A comprehensive review of the application characteristics and traffic requirements of a smart grid communications network," Comput. Networks, vol. 57, no. 3, pp. 825-845, Feb. 2013.

[196] S. Dawson-Haggerty, X. Jiang, G. Tolle, J. Ortiz, and D. Culler, "sMAP - a Simple Measurement and Actuation Profile for Physical Information Stephen," in Proceedings of the 8th ACM Conference on Embedded Networked Sensor Systems - SenSys '10, 2010, no. November, p. 197.

[197] S. Dawson-haggerty, A. Krioukov, D. E. Culler, A. Krioukov, and D. E. Culler, "Experiences Integrating Building Data with sMAP," 2012.

[198] S. Dawson-haggerty, "Building Operating Systems Services: An Architecture for Programmable Buildings," University of California at Berkeley Technical, 2014.

[199] S. Dawson-haggerty et al., "BOSS: building operating system services," Proc. 10th USENIX Conf. Networked Syst. Des. Implement., pp. 1-15, 2013.

[200] "PostgreSQL," 2016. [Online]. Available: https://www.postgresql.org/. [Accessed: 15-Jun-2016].

[201] "Readingdb," 2016. [Online]. Available: https://github.com/stevedh/readingdb. [Accessed: 15-Jun-2016].

[202] Grid Protection Alliance, "Grid Protection Alliance - Products." [Online]. Available: http://www.gridprotectionalliance.org/products.asp\#Historian. [Accessed: 06-Apr-2018].

[203] Smart Grid Store, "Introduction · SmartGridStore." [Online]. Available: https://docs.smartgrid.store/. [Accessed: 06-Apr-2018].

[204] Berkeley Tree Database, "BTrDB | Homepage." [Online]. Available: http://btrdb.io/. [Accessed: 06-Apr-2018].

[205] "MongoDB," 2016. [Online]. Available: https://docs.mongodb.com/. [Accessed: 15-Jun-2017].

[206] "Introduction to MongoDB - MongoDB Manual 3.6." [Online]. Available: https://docs.mongodb.com/manual/introduction/. [Accessed: 10-Apr-2018]. 
[207] "Python REST API Framework: Eve, the Simple Way to REST. — Eve 0.8-dev documentation." [Online]. Available: http://python-eve.org/. [Accessed: 19-Apr2018].

[208] "RESTHeart." [Online]. Available: http://restheart.org/. [Accessed: 19-Apr2018].

[209] "DreamFactory | API automation." [Online]. Available: https://www.dreamfactory.com/. [Accessed: 19-Apr-2018].

[210] "IEEE 1703-2012 - IEEE Standard for Local Area Network/Wide Area Network (LAN/WAN) Node Communication Protocol to Complement the Utility Industry End Device Data Tables." [Online]. Available: https://standards.ieee.org/findstds/standard/1703-2012.html. [Accessed: 16-Apr2018].

[211] "IEC 62056-6-2:2017 | IEC Webstore." [Online]. Available: https://webstore.iec.ch/publication/34317. [Accessed: 16-Apr-2018].

[212] "IEEE 2030.5-2013 - IEEE Adoption of Smart Energy Profile 2.0 Application Protocol Standard." [Online]. Available: https://standards.ieee.org/findstds/standard/2030.5-2013.html. [Accessed: 06Dec-2017].

[213] ETSI TS 104001 V2.1.1, "Open Smart Grid Protocol (OSGP); Smart Metering/Smart Grid Communication Protocol," 2016.

[214] S. F. Bush, "Standards Overview," in Smart Grid: Communication-Enabled Intelligence for the Electric Power Grid, Chichester, UK: John Wiley \& Sons, Ltd, 2014, pp. 333-355.

[215] A. Yousefi and S. M. Jameii, "Improving the security of internet of things using encryption algorithms," in 2017 International Conference on Io T and Application (ICIOT), 2017, vol. 11, no. 5, pp. 1-5.

[216] S.-H. Seo, X. Ding, and E. Bertino, "Encryption key management for secure communication in smart advanced metering infrastructures," in 2013 IEEE International Conference on Smart Grid Communications (SmartGridComm), 2013, pp. 498-503.

[217] R. Cilibrasi and P. M. B. Vitányi, "Clustering by compression," IEEE Trans. Inf. Theory, vol. 51, no. 4, pp. 1523-1545, 2005. 
[218] A. Sanches, J. M. P. Cardoso, and A. C. B. Delbem, "Identifying MergeBeneficial Software Kernels for Hardware Implementation," in 2011 International Conference on Reconfigurable Computing and FPGAs, 2011, pp. 74-79.

[219] M. Alfonseca, M. Cebrián, and A. Ortega, "Common Pitfalls Using the Normalized Compression Distance: What to Watch Out for in a Compressor," Commun. Inf. Syst., vol. 5, no. 4, pp. 367-384, 2005.

[220] P. Ferragina, R. Giancarlo, V. Greco, G. Manzini, and G. Valiente, "Compression-based classification of biological sequences and structures via the Universal Similarity Metric: experimental assessment," BMC Bioinformatics, vol. 8, no. 1, p. 252, 2007.

[221] R. Cilibrasi, "Statistical inference through data compression," University of Amsterdam, 2007.

[222] O. Gascuel, "Neighbor-Joining Revealed," Mol. Biol. Evol., vol. 23, no. 11, pp. 1997-2000, Aug. 2006.

[223] A. H. M. Soares, "Algoritmos de estimação de distribuição baseados em árvores filogenéticas," Universidade de São Paulo, São Carlos, 2014.

[224] M. E. J. Newman, "Fast algorithm for detecting community structure in networks," Phys. Rev. E - Stat. Nonlinear, Soft Matter Phys., vol. 69, no. 6 2, pp. 1-5, 2004.

[225] M. E. J. Newman, "Analysis of weighted networks," Phys. Rev. E, vol. 70, no. 5, p. 056131, Nov. 2004.

[226] A. Clauset, M. E. J. Newman, and C. Moore, "Finding community structure in very large networks," Phys. Rev. E, vol. 70, no. 6, p. 066111, Aug. 2004.

[227] B. K. M. Cesar, "Estudo e extensão da metodologia DAMICORE para tarefas de classificação," Universidade de São Paulo, São Carlos, 2016.

[228] "FAQ: Concurrency — MongoDB Manual 3.6." [Online]. Available: https://docs.mongodb.com/manual/faq/concurrency/\#which-operations-lockthe-database. [Accessed: 24-Apr-2018].

[229] M. J. Sullivan, T. Vardell, and M. Johnson, "Power interruption costs to industrial and commercial consumers of electricity," IEEE Trans. Ind. Appl., vol. 33, no. 6, pp. 1448-1458, 1997. 
[230] Y. Gong and A. Guzman, "Integrated Fault Location System for Power Distribution Feeders," IEEE Trans. Ind. Appl., vol. 49, no. 3, pp. 1071-1078, May 2013.

[231] J. Mora-Flòrez, J. Meléndez, and G. Carrillo-Caicedo, "Comparison of impedance based fault location methods for power distribution systems," Electr. Power Syst. Res., vol. 78, no. 4, pp. 657-666, Apr. 2008.

[232] W. F. Usida, D. V Coury, R. A. Flauzino, and I. N. Silva, "Alocação eficiente de indicadores de faltas em um sistema de distribuição real usando computação evolutiva," Sba Control. Automação Soc. Bras. Autom., vol. 23, no. 3, pp. 306320, Jun. 2012.

[233] E. C. Senger, G. Manassero, C. Goldemberg, and E. L. Pellini, "Automated Fault Location System for Primary Distribution Networks," IEEE Trans. Power Deliv., vol. 20, no. 2, pp. 1332-1340, Apr. 2005.

[234] J. Mora-Florez, N. Estrada-Cardona, and S. Perez-Londono, "Fault location in radial power systems based on statistical analysis," Proc. 10th Int. Conf. Probabilistic Methods Appl. to Power Syst. PMAPS 2008, 2008.

[235] G. Morales-Espana, J. Mora-Florez, and H. Vargas-Torres, "Elimination of Multiple Estimation for Fault Location in Radial Power Systems by Using Fundamental Single-End Measurements," IEEE Trans. Power Deliv., vol. 24, no. 3, pp. 1382-1389, Jul. 2009.

[236] J. Mora-Flórez, G. Morales-España, and S. Pérez-Londoño, "Learning-based strategy for reducing the multiple estimation problem of fault zone location in radial power systems," IET Gener. Transm. Distrib., vol. 3, no. 4, p. 346, 2009.

[237] K. Ramar and E. E. Ngu, "A new impedance-based fault location method for radial distribution systems," in IEEE PES General Meeting, 2010, pp. 1-9.

[238] G. Morales-Espana, J. Mora-Florez, and G. Carrillo-Caicedo, "A complete fault location formulation for distribution systems using the k-Nearest Neighbors for regression and classification," in 2010 IEEE/PES Transmission and Distribution Conference and Exposition: Latin America (TED-LA), 2010, pp. 810-815.

[239] R. Krishnathevar and E. E. Ngu, "Generalized Impedance-Based Fault Location for Distribution Systems," IEEE Trans. Power Deliv., vol. 27, no. 1, pp. 449451, Jan. 2012. 
[240] A. Pratul and P. M. R., "A wavelet packet transform approach for locating faults in distribution system," in 2012 IEEE Symposium on Computers 6 Informatics (ISCI), 2012, pp. 113-118.

[241] J. Ramirez-Ramirez, J. Arrieta-Giraldo, and J. Mora-Florez, "Elimination of multiple estimation for single phase fault location in power distribution systems considering the load current," in 2014 IEEE PES Transmission \& Distribution Conference and Exposition - Latin America (PES TESD-LA), 2014, vol. 2014Octob, pp. 1-6.

[242] J. P. Rossini, P. E. Farias, A. P. de Morais, G. Cardoso, and G. B. da Costa, "An alternative solution for the multiple estimation problem using fuzzy sets," in 2017 IEEE International Conference on Environment and Electrical Engineering and 2017 IEEE Industrial and Commercial Power Systems Europe (EEEIC / IECPS Europe), 2017, pp. 1-5.

[243] M. Tremblay, R. Pater, F. Zavoda, and G. Simard, "Accurate fault-location technique based on distributed power-quality measurements," in Conf. on Electricity Distribution, 2007, no. 0615, pp. 21-24.

[244] T. Short, Jinsang Kim, and C. Melhorn, "Update on distribution system fault location technologies and effectiveness," in IET Conference Publications, 2009, no. 0973, pp. 973-973.

[245] D. D. Sabin and A. R. Dettloff, "Overview of an automatic subtransmission fault location system at DTE energy," in 2012 IEEE Power and Energy Society General Meeting, 2012, pp. 1-6.

[246] D. D. Sabin, A. R. Dettloff, and P. Golden, "Automatic Subtransmission Fault Location System using Power Quality Monitors," in 2016 IEEE/PES Transmission and Distribution Conference and Exposition (TED), 2016, pp. 1-5.

[247] F. C. L. Trindade and W. Freitas, "Low Voltage Zones to Support Fault Location in Distribution Systems With Smart Meters," IEEE Trans. Smart Grid, vol. 8, no. 6, pp. 2765-2774, Nov. 2017.

[248] E. A. Reche, "Metodologia Baseada em Mineração de Dados para Redução de Múltipla Estimação na Localização de Faltas em Alimentadores de Distribuição Radiais," Dissertação (Mestrado), Escola de Engenharia de São Carlos da Universidade de São Paulo, 2018. 
[249] E. A. Reche, J. V. de Sousa, D. V. Coury, and R. A. S. Fernandes, "Data Mining-Based Method to Reduce Multiple Estimation for Fault Location in Radial Distribution Systems," IEEE Trans. Smart Grid, pp. 1-1, 2018.

[250] SIEMENS, "SIPROTEC 5 Distance and Line Differ- ential Protection, Breaker Management for 1-Pole and 3-Pole Tripping 7SA87, 7SD87, 7SL87, 7VK87," 2017.

[251] Schweitzer Engineering Laboratories, "SEL-351A Protection System." [Online]. Available: https://selinc.com/products/351A/. [Accessed: 08-May-2018].

[252] Alstom Grid, "Reason RPV311 Digital Fault Recorder with PMU and TWFL Technical Manual," 2014.

[253] W. H. Kersting, "Radial distribution test feeders," in 2001 IEEE Power Engineering Society Winter Meeting. Conference Proceedings (Cat. No.01CH37194), 2001, vol. 2, pp. 908-912.

[254] K. P. Schneider et al., "Analytic Considerations and Design Basis for the IEEE Distribution Test Feeders," IEEE Trans. Power Syst., vol. 33, no. 3, pp. 31813188, May 2018.

[255] A. A. Girgis, C. M. Fallon, and D. L. Lubkeman, "A fault location technique for rural distribution feeders," IEEE Trans. Ind. Appl., vol. 29, no. 6, pp. 1170-1175, 1993.

[256] "Virtualização," Wikipédia, 2016. [Online]. Available: https://pt.wikipedia.org/wiki/Virtualização. [Accessed: 08-Feb-2016].

[257] T. O'Reilly, "What Is Web 2.0?," O'Reilly Media, 2005. [Online]. Available: http://www.oreilly.com/pub/a/web2/archive/what-is-web-20.html. [Accessed: 31-Aug-2015].

[258] "Random Numbers in MATLAB." [Online]. Available: https://www.mathworks.com/help/matlab/math/random-numbers-inmatlab.html. [Accessed: 16-Jul-2018]. 